RAFAEL HORSCHUTZ NEMOTO

MODELAGEM E SIMULAÇÃO DE INTERMITÊNCIA SEVERA COM EFEITOS DE TRANSFERÊNCIA DE MASSA 



\section{MODELAGEM E SIMULAÇÃO DE INTERMITÊNCIA SEVERA COM EFEITOS DE TRANSFERÊNCIA DE MASSA}

Tese apresentada à Escola Politécnica da Universidade de São Paulo para obtenção do título de Doutor em Ciências. 



\section{RAFAEL HORSCHUTZ NEMOTO}

\section{MODELAGEM E SIMULAÇÃO DE INTERMITÊNCIA SEVERA COM EFEITOS DE TRANSFERÊNCIA DE MASSA}

Tese apresentada à Escola Politécnica da Universidade de São Paulo para obtenção do título de Doutor em Ciências.

Área de Concentração:

Engenharia Mecânica de Energia e Fluidos

Orientador:

Prof. Dr. Jorge Luis Baliño 
Este exemplar foi revisado e alterado em relação à versão original, sob responsabilidade única do autor e com a anuência de seu orientador.

São Paulo, de janeiro de 2013.

Assinatura do autor

Assinatura do orientador

FICHA CATALOGRÁFICA

Nemoto, Rafael Horschutz

Modelagem e simulação de intermitência severa com efeitos de transferência de massa / R.H. Nemoto. -- ed.rev. -- São Paulo, 2013.

$193 \mathrm{p}$.

Tese (Doutorado) - Escola Politécnica da Universidade de São Paulo. Departamento de Engenharia Mecânica.

1. Escoamento multifásico 2. Estabilidade 3. Sistemas de produção 4. Petróleo 5. Tubos flexíveis I. Universidade de São Paulo. Escola Politécnica. Departamento de Engenharia Mecânica II. t. 
Dedico esta tese à minha família. 



\section{AGRADECIMENTOS}

Agradeço ao Prof. Dr. Jorge Luis Baliño pela orientação em meus trabalhos de pesquisa e pelo tempo dispendido em aconselhamentos profissionais e pessoais.

Agradeço aos amigos queridos, professores e funcionários do Núcleo de Dinâmica e Fluidos (NDF) que tornaram o dia-a-dia de trabalho muito mais agradável e produtivo.

Agradeço à Escola Politécnica da Universidade de São Paulo e à Petrobras pela possibilidade em trabalhar no desenvolvimento de tecnologia atrelada à exploração de petróleo offshore.

Agradeço à Fundação de Apoio à Pesquisa do Estado de São Paulo (FAPESP) pelo apoio financeiro por meio da bolsa de doutorado fornecida. 



\section{RESUMO}

Um modelo matemático e simulações numéricas são apresentados para investigação da dinâmica do escoamento de gás, óleo e água em sistemas pipeline-riser. O pipeline é modelado como um sistema de parâmetros concentrados e considera dois estados comutáveis: um em que o gás é capaz de penetrar no riser e outro no qual há uma frente de acúmulo de líquido, prevenindo a penetração do gás. O modelo do riser considera um sistema de parâmetros distribuídos, no qual nós móveis são usados para avaliar as condições locais ao longo do subsistema. Efeitos de transferência de massa são modelados utilizando a aproximação de black-oil. O modelo prediz a localização da frente de acúmulo de líquido no pipeline e do nível de líquido no riser, de maneira que é possível determinar qual tipo de intermitência severa ocorre no sistema. O método das características é usado para simplificar a diferenciação no sistema de equações mistas hiperbólicas-parabólicas resultante. As equações são discretizadas e integradas usando um método implícito com um esquema preditor-corretor para o tratamento das não-linearidades. Simulações correspondentes às condições de intermitência severa são apresentadas e comparadas aos resultados obtidos com o código computacional OLGA, resultando em uma boa concordância. Apresenta-se uma descrição dos tipos de intermitência severa para o escoamento trifásico de gás, óleo e água em um sistema pipeline-riser com efeitos de transferência de massa, assim como um estudo da influência de parâmetros geométricos e de caracterização dos fluidos sobre os mapas de estabilidade.

Palavras-chave: Escoamento multifásico, Intermitência severa, Sistemas de produção de petróleo, Aproximação de black-oil, Mapas de estabilidade. 



\section{ABSTRACT}

A mathematical model and numerical simulations are presented to investigate the dynamics of gas, oil and water flow in a pipeline-riser system. The pipeline is modeled as a lumped parameter system and considers two switchable states: one in which the gas is able to penetrate into the riser and another in which there is a liquid accumulation front, preventing the gas from penetrating the riser. The riser model considers a distributed parameter system, in which movable nodes are used to evaluate local conditions along the subsystem. Mass transfer effects are modeled by using a black oil approximation. The model predicts the location of the liquid accumulation front in the pipeline and the liquid level in the riser, so it is possible to determine which type of severe slugging occurs in the system. The method of characteristics is used to simplify the differentiation of the resulting mixed hyperbolic-parabolic system of equations. The equations are discretized and integrated using an implicit method with a predictor-corrector scheme for the treatment of the nonlinearities. Simulations corresponding to severe slugging conditions are presented and compared to results obtained with OLGA computer code, showing a very good agreement. A description of the types of severe slugging for the three-phase flow of gas, oil and water in a pipeline-riser system with mass transfer effects is presented, as well as a study of the influence of geometric and fluid characterization parameters on the stability maps.

Keywords: Multiphase flow, Severe slugging, Petroleum production systems, Black oil approximation, Stability maps. 



\section{LISTA DE FIGURAS}

Figura - 1.1 Típicos sistemas de produção de petróleo offshore (fonte: Petrobras). $\ldots . .36$

Figura - 1.2 Estágios do ciclo de intermitência severa. Reproduzido de Taitel (1986). . 37

Figura - 2.1 Histórico de pressão para sistemas água-ar. Reproduzido de Schmidt, Doty e

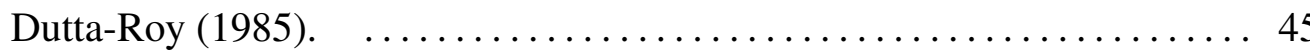

Figura - 2.2 Transiente de pressão na base do riser. Reproduzido de Baliño, Burr e Nemoto (2010).

Figura - 2.3 Mapa de estabilidade para $P_{s e p}=2$ bar. Reproduzido de Baliño, Burr e Nemoto (2010).

Figura - 2.4 Mapa de tipos de intermitência severa para $P_{s e p}=2$ bar. Reproduzido de Baliño, Burr e Nemoto (2010). .................... 57

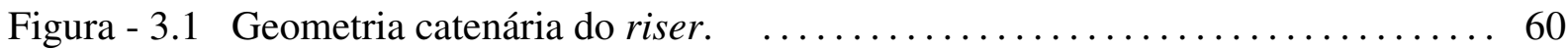

Figura - 3.2 Volumes de controle para o modelo do pipeline. $\quad \ldots \ldots \ldots \ldots \ldots \ldots \ldots \ldots$

Figura - 4.1 Direções características do gás (linhas vermelhas) e líquido (linhas azuis) no

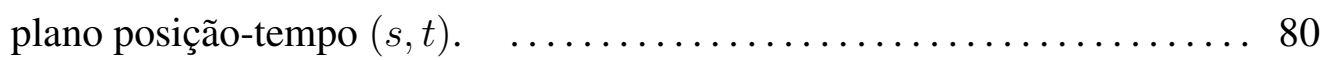

Figura -4.2 Direções características do gás. $\quad \ldots \ldots \ldots \ldots \ldots \ldots \ldots \ldots \ldots \ldots \ldots \ldots \ldots \ldots \ldots \ldots \ldots$

Figura - 4.3 Direções características do líquido. $\ldots \ldots \ldots \ldots \ldots \ldots \ldots \ldots \ldots \ldots \ldots \ldots \ldots \ldots \ldots \ldots$

Figura - 5.1 Fração de vazio na base do riser calculada com o modelo proposto. $\quad \ldots . .93$

Figura - 5.2 Fração volumétrica de óleo na base do riser calculada com o modelo pro-

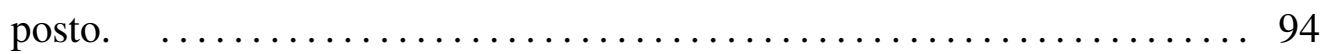

Figura - 5.3 Fração volumétrica de água na base do riser calculada com o modelo pro-

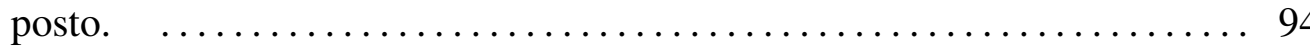

Figura - 5.4 Velocidade superficial de gás (vermelho), óleo (preto) e água (azul) na base do riser calculada com o modelo proposto.

Figura - 5.5 Velocidade superficial de gás (vermelho), óleo (preto) e água (azul) no topo do riser calculada com o modelo proposto.

Figura - 5.6 Pressão na base do riser calculada com o modelo proposto. 
Figura - 5.7 Comprimento de penetração de líquido no pipeline calculado com o modelo

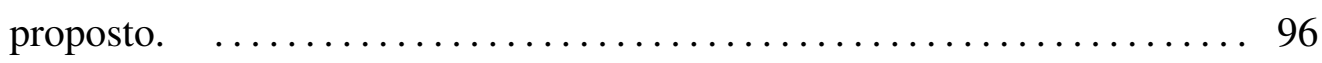

Figura - 5.8 Altura da coluna de líquido no riser calculada com o modelo proposto. . . 97

Figura - 5.9 Fração de vazio na base do riser calculada com o código OLGA. . ..... 98

Figura - 5.10 Fração volumétrica de óleo na base do riser calculada com o código OLGA. 98

Figura - 5.11 Fração volumétrica de água na base do riser calculada com o código OLGA. 99

Figura - 5.12 Velocidade superficial de gás (vermelho), óleo (preto) e água (azul) na base do riser calculada com o código OLGA. . ................ 99

Figura - 5.13 Pressão na base do riser calculada com o código OLGA. $\quad \ldots \ldots \ldots \ldots \ldots . \ldots 0$

Figura - 5.14 Histórico de pressão na base do riser para intermitência severa com efeitos de transferência de massa (as letras representam os diferentes estágios apre-

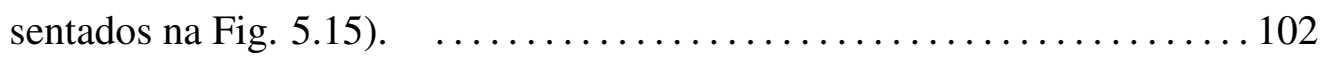

Figura - 5.15 Estágios da intermitência severa considerando efeitos de transferência de

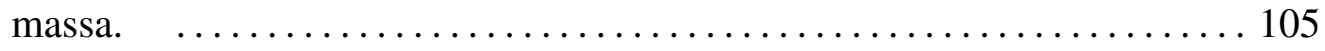

Figura - 5.16 Comportamento de diferentes variáveis observado por uma partícula de líquido ao evoluir desde a base do riser até a superfície de líquido. . . ... 106

Figura - 5.17 Pressão na base do riser para intermitência severa do tipo 1 (preto), 2 (azul) e 3 (vermelho). ........................................ 110

Figura - 5.18 Mapa de estabilidade.

Figura - 5.19 Mapa de estabilidade em função das velocidades superficiais de gás, óleo e

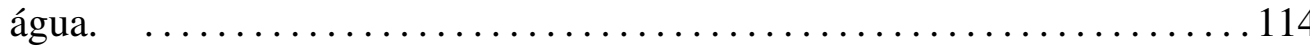

Figura - 5.20 Mapa de tipos de instabilidade.

Figura - 5.21 Mapa de estabilidade, segundo o critério de Pots, considerando razão de solubilidade nula $\left(R_{s}=0\right)$ e razão de solubilidade calculada segundo a aproximação de black-oil $\left(R_{s}>0\right)$.

Figura - 5.22 Mapa de tipos de instabilidade e fronteira de estabilidade segundo o critério de Pots.

Figura - 5.23 Regiões de GOR baixo, intermediário e elevado.

Figura - 5.24 Estudo paramétrico para a densidade API $\gamma_{A P I}$ utilizando o modelo pro-

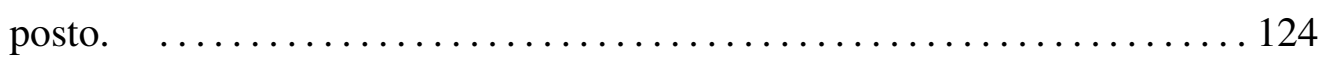

Figura - 5.25 Estudo paramétrico para a densidade API $\gamma_{A P I}$ utilizando o critério de Pots. 124 
Figura - 5.26 Estudo paramétrico para a densidade relativa do gás $\gamma_{g}$ utilizando o modelo proposto.

Figura - 5.27 Estudo paramétrico para a densidade relativa do gás $\gamma_{g}$ utilizando o critério de Pots.

Figura - 5.28 Estudo paramétrico para a razão água-óleo WOR utilizando o modelo proposto.

Figura - 5.29 Estudo paramétrico para a razão água-óleo $W O R$ utilizando o critério de Pots.

Figura - 5.30 Estudo paramétrico para a temperatura $T$ utilizando o modelo proposto. . . 127

Figura - 5.31 Estudo paramétrico para a temperatura $T$ utilizando o critério de Pots. $\ldots 127$

Figura - 5.32 Estudo paramétrico para o diâmetro interno $D$ utilizando o modelo pro-

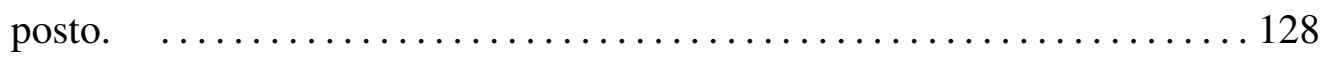

Figura - 5.33 Estudo paramétrico para o diâmetro interno $D$ utilizando o critério de Pots. 128

Figura - 5.34 Estudo paramétrico para a pressão no separador $P_{\text {sep }}$ utilizando o modelo proposto.

Figura - 5.35 Estudo paramétrico para a pressão no separador $P_{\text {sep }}$ utilizando o critério de Pots.

Figura - 5.36 Estudo paramétrico para a altura do topo do riser $Z_{r}$ utilizando o modelo proposto.

Figura - 5.37 Estudo paramétrico para a altura do topo do riser $Z_{r}$ utilizando o critério de Pots.

Figura - 5.38 Estudo paramétrico para a coordenada horizontal do topo do riser $W_{r}$ utilizando o modelo proposto.

Figura - 5.39 Estudo paramétrico para a coordenada horizontal do topo do riser $W_{r}$ utilizando o critério de Pots.

Figura - 5.40 Estudo paramétrico para o comprimento do pipeline $L$ utilizando o modelo proposto.

Figura - 5.41 Estudo paramétrico para o comprimento do pipeline $L$ utilizando o critério de Pots.

Figura - 5.42 Estudo paramétrico para o ângulo de inclinação do pipeline $\beta$ utilizando o modelo proposto. 
Figura - 5.43 Estudo paramétrico para o ângulo de inclinação do pipeline $\beta$ utilizando o critério de Pots.

Figura - A.1 Esboços dos padrões de escoamento para misturas água-ar em um tubo horizontal de diâmetro 5,1 cm. Adaptado de Weisman (1983).

Figura - A.2 Esboços dos padrões de escoamento para escoamento bifásico em um tubo vertical. Adaptado de Weisman (1983).

Figura - A.3 Mapa de padrão de escoamento para o escoamento de misturas água-ar em um tubo horizontal de $2,5 \mathrm{~cm}$ à temperatura de $25^{\circ} \mathrm{C}$ e pressão de $1 \mathrm{bar}$. Reproduzido de Mandhane, Gregory e Aziz (1974).

Figura - A.4 Mapa de padrão de escoamento para o escoamento de misturas água-ar em um tubo vertical de diâmetro 2, 5 cm. Adaptado de Weisman (1983). .. 149 


\section{LISTA DE TABELAS}

Tabela 5.1 Dados de entrada para as simulações.

Tabela 5.2 Estudo de convergência para diferentes números de nós.

Tabela 5.3 Comparação entre os resultados obtidos com o modelo proposto e com o código OLGA.

Tabela 5.4 Modificações nos parâmetros para eliminação da intermitência severa: ( $\uparrow$ ) indica aumento do parâmetro, $(\downarrow)$ indica diminuição do parâmetro e (-) indica pouca influência ou região de transição.

Tabela E.1 Parâmetros para uso na correlação de Dranchuk e Abou-Kassem (1975) (ver Seções E.2.1 e E.13.3). 179

Tabela E.2 Faixas de validade da correlação de Lee, Gonzalez e Eakin (1966). 184 



\section{LISTA DE SIGLAS}

API Instituto de Petróleo Americano (American Petroleum Institute)

BSW Razão de água mais sedimentos a líquido mais sedimentos (Basic Sediment and Water)

CFL Critério de estabilidade de Courant-Friedrich-Lewis

GOR Razão gás-óleo (Gas-Oil Ratio)

MC Método das Características

MVF Método dos Volumes Finitos

NPW Modelo sem ondas de pressão (No-Pressure-Wave)

SS1 Intermitência severa do tipo 1 (Severe Slugging 1)

SS2 Intermitência severa do tipo 2 (Severe Slugging 2)

SS3 Intermitência severa do tipo 3 (Severe Slugging 3)

WOR Razão água-óleo (Water-Oil Ratio) 



\section{LISTA DE SÍMBOLOS}

$a_{i} \quad$ Coeficientes para o cálculo da razão de solubilidade gás-óleo [-]

A Área de passagem do fluxo $\left[\mathrm{m}^{2}\right]$

$A_{i} \quad$ Coeficientes para o cálculo do fator de compressibilidade do gás [-]

$b_{i j} \quad$ Coeficiente das equações de estado para o riser [-]

$B_{g} \quad$ Fator volume de formação de gás [-]

$B_{o} \quad$ Fator volume de formação de óleo [-]

$B_{o b} \quad$ Fator volume de formação de óleo com relação às condições na base do riser [-]

$B_{w} \quad$ Fator volume de formação de água [-]

$C_{d} \quad$ Parâmetro do modelo de drift-flux [-]

$C_{i} \quad$ Coeficientes para o cálculo do fator de compressibilidade do gás [-]

$d_{1} \quad$ Coeficiente da equação de estado para o riser $[1 / s]$

$D \quad$ Diâmetro [m]

$e_{i} \quad$ Autovalor ou velocidade característica $[\mathrm{m} / \mathrm{s}]$

F $\quad$ Fator de atrito de Fanning [-]

$f_{i} \quad$ Coeficientes da equação de estado complementar para o riser $[1 / P a]$

$F_{i} \quad$ Coeficientes para o cálculo da viscosidade do gás [-]

$F r_{j} \quad$ Número de Froude [-]

$g \quad$ Aceleração da gravidade $\left[\mathrm{m} / \mathrm{s}^{2}\right]$

$g_{s} \quad$ Componente da aceleração da gravidade na direção $s\left[\mathrm{~m} / \mathrm{s}^{2}\right]$

$G_{i} \quad$ Coeficientes para o cálculo da viscosidade do óleo saturado [-]

H Coeficiente para o cálculo da viscosidade do óleo subsaturado [-]

$I_{i} \quad$ Coeficientes para o cálculo da viscosidade da água na pressão padrão [-]

$j \quad$ Velocidade superficial total $[\mathrm{m} / \mathrm{s}]$

$j_{g} \quad$ Velocidade superficial de gás $[\mathrm{m} / \mathrm{s}]$ 
$j_{g b} \quad$ Velocidade superficial de gás na base do riser $[\mathrm{m} / \mathrm{s}]$

$j_{\text {gin }} \quad$ Velocidade superficial de gás na entrada do pipeline $[\mathrm{m} / \mathrm{s}]$

$j_{g s} \quad$ Velocidade superficial de gás na interface entre os volume de controle $[\mathrm{m} / \mathrm{s}]$

$j_{l} \quad$ Velocidade superficial da fase líquida $[\mathrm{m} / \mathrm{s}]$

$j_{o} \quad$ Velocidade superficial de óleo $[\mathrm{m} / \mathrm{s}]$

$j_{o b} \quad$ Velocidade superficial de óleo na base do riser $[\mathrm{m} / \mathrm{s}]$

$j_{\text {oin }} \quad$ Velocidade superficial de óleo na entrada do pipeline $[\mathrm{m} / \mathrm{s}]$

$j_{o s} \quad$ Velocidade superficial de óleo na interface entre os volume de controle $[\mathrm{m} / \mathrm{s}$ ]

$j_{w} \quad$ Velocidade superficial de água $[\mathrm{m} / \mathrm{s}]$

$j_{w b} \quad$ Velocidade superficial de água na base do riser $[\mathrm{m} / \mathrm{s}]$

$j_{w i n} \quad$ Velocidade superficial de água na entrada do pipeline $[\mathrm{m} / \mathrm{s}]$

$j_{w s} \quad$ Velocidade superficial de água na interface entre os volume de controle $[\mathrm{m} / \mathrm{s}]$

L Comprimento do pipeline $[\mathrm{m}]$

$m_{d g} \quad$ Massa de gás dissolvida na condição local de temperatura e pressão $[k g]$

$\dot{m}_{g 0} \quad$ Vazão mássica de gás na condição padrão $[\mathrm{kg} / \mathrm{s}]$

$M_{a} \quad$ Massa molar do ar $[\mathrm{g} / \mathrm{mol}]$

$M_{g} \quad$ Massa molar do gás $[\mathrm{g} / \mathrm{mol}]$

$M_{g 0} \quad$ Massa molar aparente da mistura de gás livre na condição padrão $[\mathrm{g} / \mathrm{mol}]$

$M_{i} \quad$ Massa molecular do componente livre $i$ da mistura [-]

N Número de nós [-]

P Pressão [Pa, bara, psia, atm]

$P_{0} \quad$ Pressão na condição padrão [Psia, atm]

$P_{b} \quad$ Pressão na base do riser [bara]

$P_{b o l h a} \quad$ Pressão no ponto de bolha [psig, psia]

$P_{m} \quad$ Pressão média no volume de controle $\forall_{2}[P a]$

$P_{p c} \quad$ Pressão pseudo-crítica [psia]

$P_{p r} \quad$ Pressão pseudo-reduzida [-] 


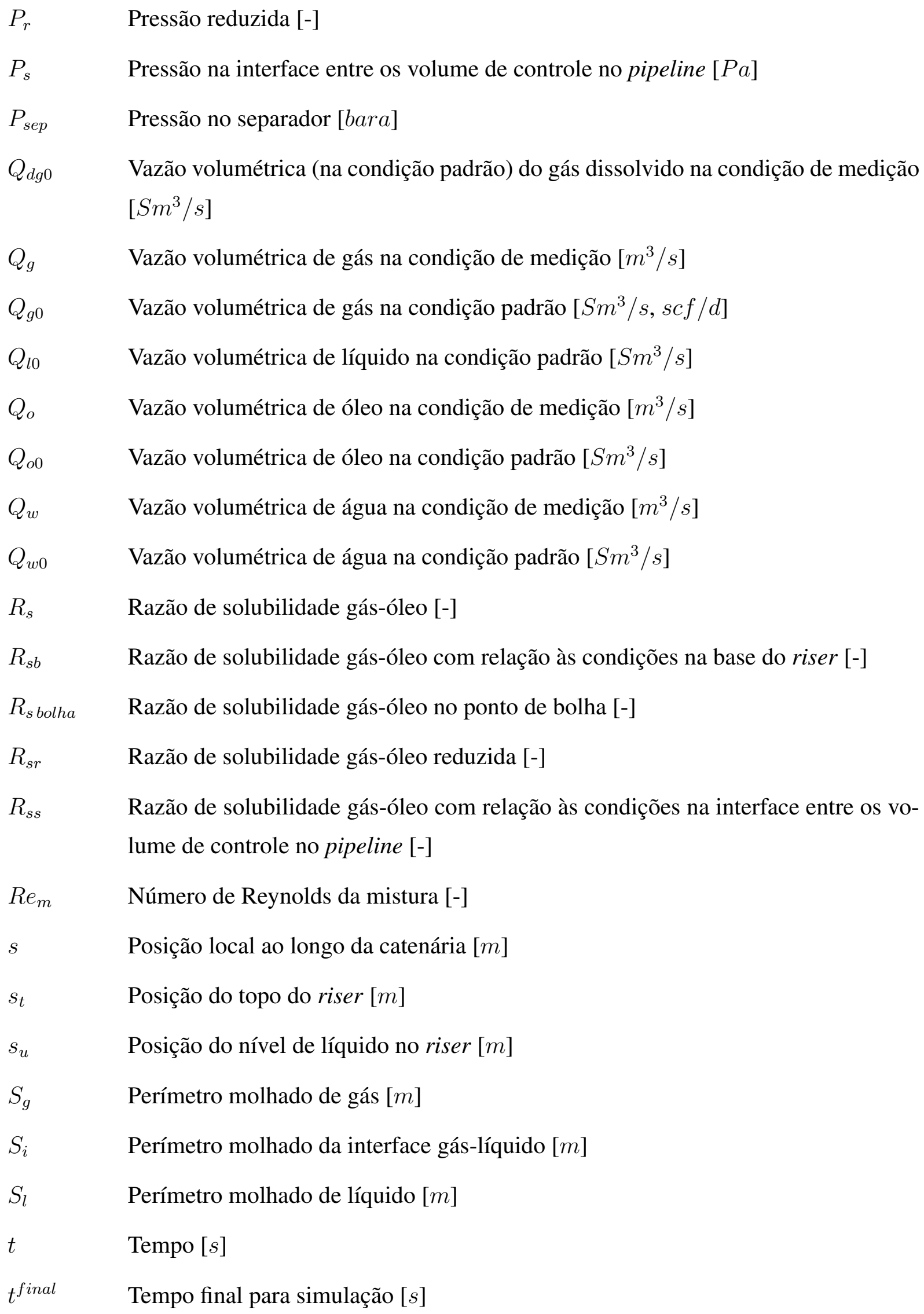




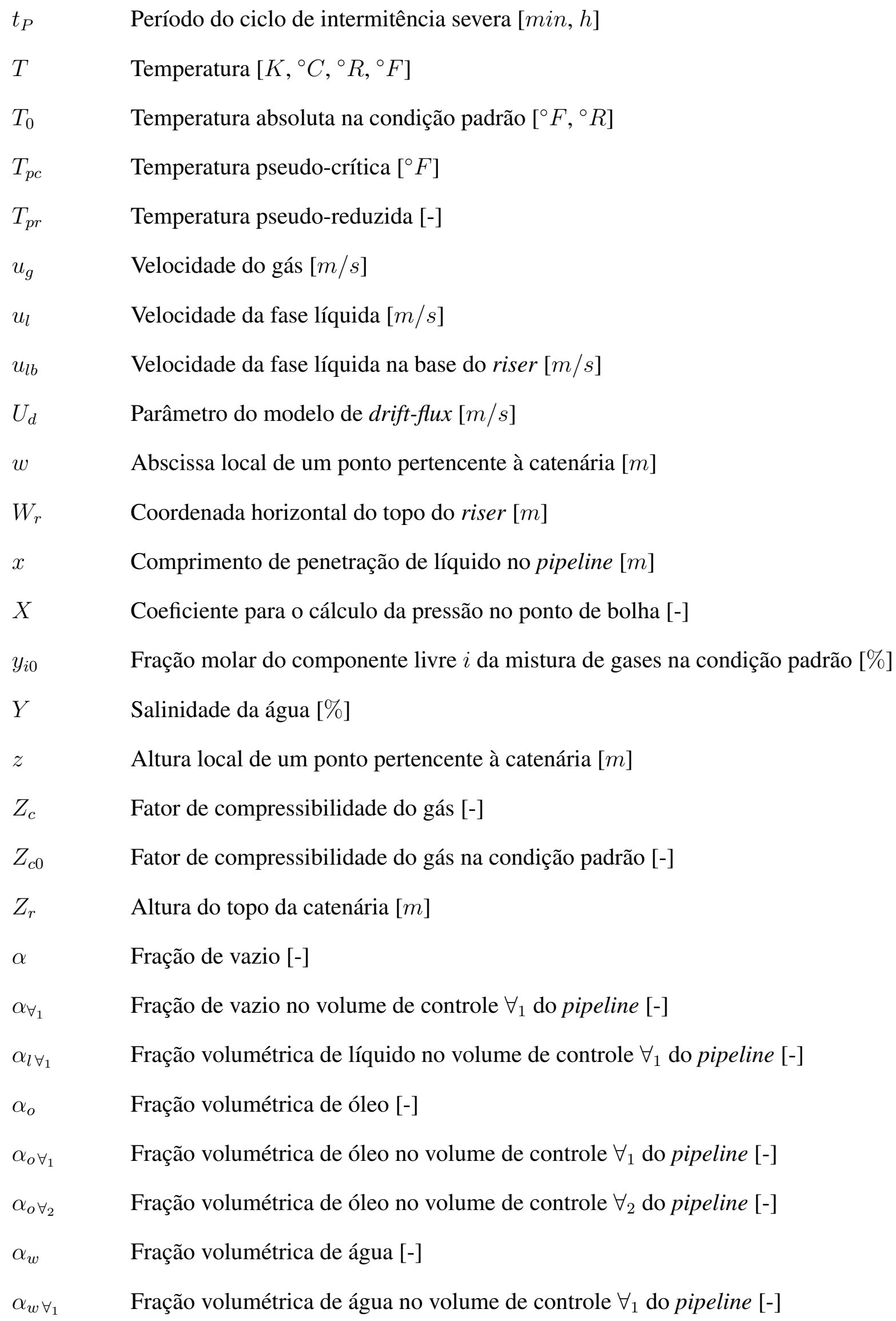


$\alpha_{w} \forall_{2} \quad$ Fração volumétrica de água no volume de controle $\forall_{2}$ do pipeline [-]

$\beta \quad$ Ângulo de inclinação do pipeline $\left[{ }^{\circ}\right]$

$\Delta t \quad$ Passo temporal $[s]$

$\Delta V_{w P} \quad$ Variação no volume devido à redução da pressão [-]

$\Delta V_{w T} \quad$ Variação no volume devido à redução da temperatura [-]

$\epsilon \quad$ Rugosidade do tubo $[m]$

$\varepsilon \quad$ Precisão para verificação da convergência [-]

$\gamma_{A P I} \quad$ Densidade API $\left[{ }^{\circ} A P I\right]$

$\gamma_{g} \quad$ Densidade relativa do gás [-]

$\gamma_{g 0} \quad$ Densidade relativa do gás na condição padrão [-]

$\gamma_{d g} \quad$ Densidade relativa do gás dissolvido [-]

$\gamma_{g s} \quad$ Densidade relativa do gás medida nas condições do separador [-]

$\gamma_{o 0} \quad$ Densidade relativa do óleo na condição padrão [-]

$\Gamma \quad$ Taxa temporal de massa de gás que deixa a solução e é adicionada ao gás livre por unidade de volume da mistura $\left[\mathrm{kg} / \mathrm{m}^{3} \mathrm{~s}\right]$

$\Lambda \quad$ Constante universal dos gases $\left[\mathrm{m}^{2} / \mathrm{s}^{2} \mathrm{~K}\right]$

$\mu_{g} \quad$ Viscosidade do gás $[c P]$

$\mu_{m} \quad$ Viscosidade da mistura $[c P]$

$\mu_{o} \quad$ Viscosidade do óleo $[c P]$

$\mu_{o d} \quad$ Viscosidade do óleo morto $[c P]$

$\mu_{w} \quad$ Viscosidade da água $[c P]$

$\mu_{w 0} \quad$ Viscosidade da água na pressão padrão $[c P]$

$\varphi \quad$ Comprimento suspenso $[m]$

$\Pi_{S S} \quad$ Parâmetro definido pelo critério de Pots, Bromilow e Konijn (1987) [-]

$\rho_{a} \quad$ Massa específica aparente do gás na superfície, se fosse um líquido $\left[\mathrm{lbm} / \mathrm{ft} \mathrm{f}^{3}\right]$

$\rho_{a r e f} 0 \quad$ Massa específica do ar de referência na condição padrão $\left[\mathrm{lbm} / \mathrm{ft} t^{3}\right]$ 
$\rho_{d g 0} \quad$ Massa específica (na condição padrão) do gás dissolvido na condição local de temperatura e pressão $\left[\mathrm{kg} / \mathrm{m}^{3}\right]$

$\rho_{g} \quad$ Massa específica do gás $\left[\mathrm{kg} / \mathrm{m}^{3}\right]$

$\rho_{g 0} \quad$ Massa específica do gás na condição padrão $\left[\mathrm{kg} / \mathrm{m}^{3}\right]$

$\rho_{g b} \quad$ Massa específica do gás com relação às condições na base do $\operatorname{riser}\left[\mathrm{kg} / \mathrm{m}^{3}\right]$

$\rho_{g s} \quad$ Massa específica do gás com relação às condições na interface entre os volumes de controle no pipeline $\left[\mathrm{kg} / \mathrm{m}^{3}\right]$

Massa específica da fase líquida $\left[\mathrm{kg} / \mathrm{m}^{3}\right]$

$\rho_{l b}$

Massa específica da fase líquida com relação às condições na base do riser $\left[\mathrm{kg} / \mathrm{m}^{3}\right]$

Massa específica da fase líquida com relação às condições médias no volume de controle $\forall_{2}\left[\mathrm{~kg} / \mathrm{m}^{3}\right]$

$\rho_{l s}$

Massa específica da fase líquida com relação às condições na interface entre os volumes de controle no pipeline $\left[\mathrm{kg} / \mathrm{m}^{3}\right]$

$\rho_{m} \quad$ Massa específica da mistura $\left[\mathrm{kg} / \mathrm{m}^{3}\right]$

$\rho_{o} \quad$ Massa específica do óleo $\left[\mathrm{lbm} / \mathrm{ft} \mathrm{t}^{3}, \mathrm{~kg} / \mathrm{m}^{3}\right]$

$\rho_{o 0} \quad$ Massa específica do óleo na condição padrão $\left[\mathrm{kg} / \mathrm{m}^{3}\right]$

$\rho_{o b} \quad$ Massa específica do óleo com relação às condições na base do riser $\left[\mathrm{kg} / \mathrm{m}^{3}\right]$

$\rho_{o m} \quad$ Massa específica do óleo com relação às condições médias no volume de controle $\forall_{2}\left[\mathrm{~kg} / \mathrm{m}^{3}\right]$

$\rho_{o s} \quad$ Massa específica do óleo com relação às condições na interface entre os volumes de controle no pipeline $\left[\mathrm{kg} / \mathrm{m}^{3}\right]$

$\rho_{p o} \quad$ Massa específica do pseudolíquido na condição padrão $\left[\mathrm{lbm} / \mathrm{ft} \mathrm{t}^{3}\right]$

$\rho_{p r} \quad$ Massa específica pseudo-reduzida [-]

$\rho_{w} \quad$ Massa específica da água $\left[\mathrm{kg} / \mathrm{m}^{3}\right]$

$\rho_{w 0} \quad$ Massa específica da água na condição padrão $\left[\mathrm{kg} / \mathrm{m}^{3}\right]$

$\rho_{w b} \quad$ Massa específica da água com relação às condições na base do riser $\left[\mathrm{kg} / \mathrm{m}^{3}\right]$

$\rho_{w m} \quad$ Massa específica da água com relação às condições médias no volume de controle $\forall_{2}\left[\mathrm{~kg} / \mathrm{m}^{3}\right]$ 
$\rho_{w r e f} 0 \quad$ Massa específica da água de referência na condição padrão $\left[\mathrm{lbm} / \mathrm{ft} \mathrm{t}^{3}, \mathrm{~kg} / \mathrm{m}^{3}\right]$

$\rho_{w s} \quad$ Massa específica da água com relação às condições na interface entre os volumes de controle no pipeline $\left[\mathrm{kg} / \mathrm{m}^{3}\right]$

$\tau_{i} \quad$ Tensão de cisalhamento na interface gás-líquido $[P a]$

$\tau_{w l} \quad$ Tensão de cisalhamento entre o líquido e a parede do tubo $[\mathrm{Pa}]$

$\tau_{w} \quad$ Tensão de cisalhamento média na parede do tubo $[P a]$

$\tau_{w g} \quad$ Tensão de cisalhamento entre o gás e a parede do tubo $[P a]$

$\theta \quad$ Ângulo de inclinação local da catenária $\left[{ }^{\circ}\right]$

$\forall \forall_{1} \quad$ Volume de controle $1[-]$

$\forall_{2} \quad$ Volume de controle $2[-]$

$v_{d g 0} \quad$ Volume (na condição padrão) do gás dissolvido na condição local de temperatura e pressão $\left[m^{3}\right]$

$v_{o} \quad$ Volume de óleo na condição local de temperatura e pressão $\left[\mathrm{m}^{3}\right]$

$v_{o 0} \quad$ Volume de óleo na condição padrão $\left[\mathrm{m}^{3}\right]$

$\zeta \quad$ Coeficiente de subrelaxação [-] 



\section{LISTA DE PUBLICAÇÕES}

Publicações do autor, entre 2009 e 2012, relacionadas à presente tese.

\section{Artigos publicados em revistas científicas}

NEMOTO, R.H.; BALIÑO, J.L. Modeling and simulation of severe slugging with mass transfer effects. International Journal of Multiphase Flow, v. 40, p. 144-157, 2012.

NEMOTO, R.H.; BALIÑO, J.L. Modeling and simulation of gas, oil and water flow in a catenary-shaped riser. Mecánica Computacional, v. 29, p. 8699-8715, 2010.

BALIÑO, J. L.; BURR, K. P.; NEMOTO, R.H. Modeling and simulation of severe slugging in air-water pipeline-riser systems. International Journal of Multiphase Flow, v. 36, p. 643-660, 2010.

\section{Artigos publicados em anais de congressos}

NEMOTO, R.H.; BALIÑO, J.L. Modeling and simulation of gas, oil and water flow in a pipeline-riser system. In: Proceedings of the 21th International Congress of Mechanical Engineering, Natal, RN, Brazil, October 2011.

NEMOTO, R.H.; BALIÑO, J.L. Modeling multiphase flow dynamics in offshore petroleum production systems. In: Proceedings of the 8th International Mediterranean and Latin American Modeling Multiconference, Rome, Italy, September 2011.

NEMOTO, R.H.; BALIÑO, J.L.; TANAKA, R. L.; GODINHO, C. A. A case study in flow assurance of a pipeline-riser system using OLGA. In: Proceedings of the 13th Brazilian Congress of Thermal Sciences and Engineering, Uberlândia, MG, Brazil, December 2010.

NEMOTO, R.H.; BALIÑO, J.L.; BURR, K. P. Characteristic values and compatibility conditions for the no-pressure-wave model applied to petroleum systems. In: Proceedings of the 20th International Congress of Mechanical Engineering, Gramado, RS, Brazil, November 2009. 



\section{SUMÁRIO}

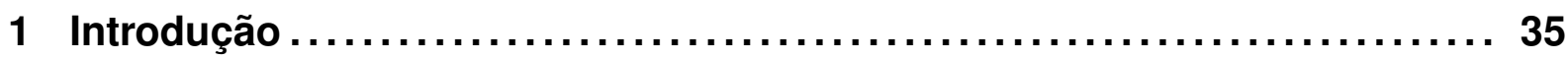

1.1 O fenômeno de intermitência severa $\ldots \ldots \ldots \ldots \ldots \ldots \ldots \ldots \ldots \ldots \ldots \ldots \ldots \ldots \ldots \ldots \ldots \ldots$

1.2 Sistemas água-ar e sistemas óleo-água-gás $\ldots \ldots \ldots \ldots \ldots \ldots \ldots \ldots \ldots \ldots \ldots$

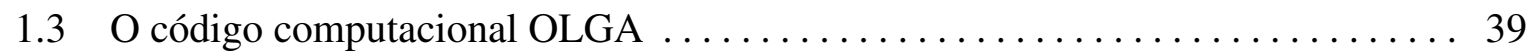

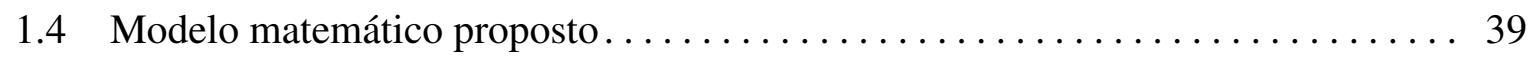

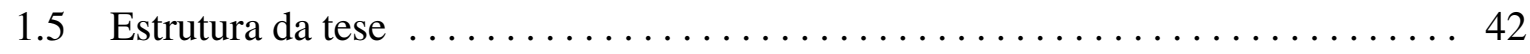

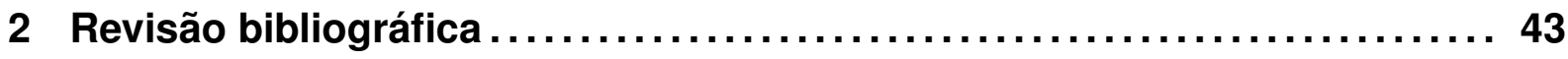

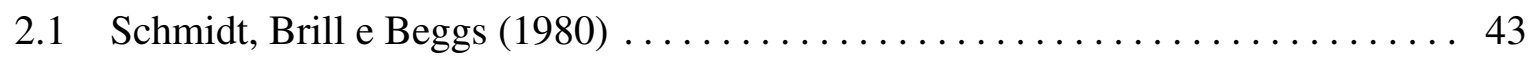

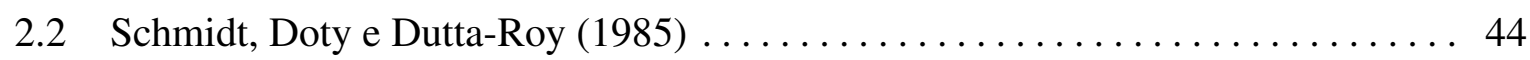

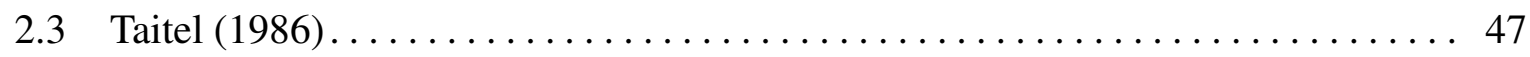

2.4 Pots, Bromilow e Konijn (1987) $\ldots \ldots \ldots \ldots \ldots \ldots \ldots \ldots \ldots \ldots \ldots \ldots \ldots \ldots \ldots \ldots \ldots \ldots \ldots \ldots$

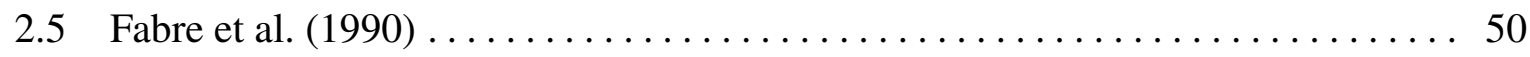

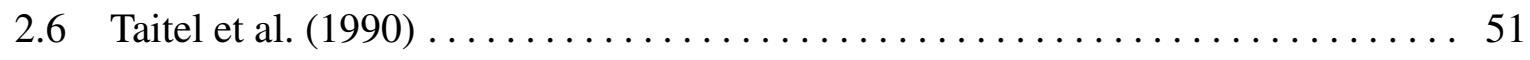

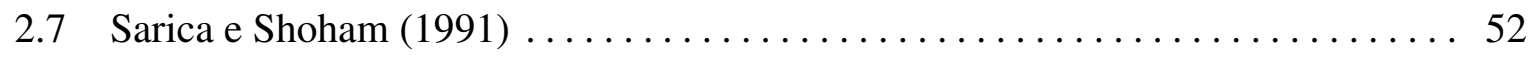

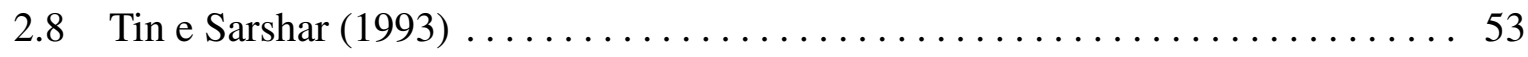

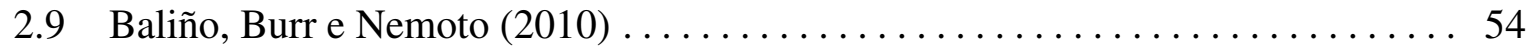

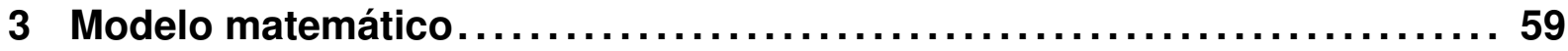

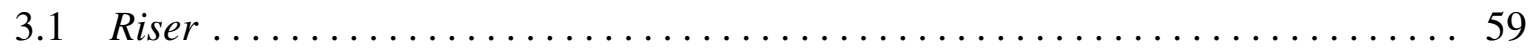

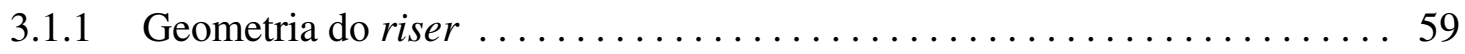

3.1.2 Equações de conservação $\ldots \ldots \ldots \ldots \ldots \ldots \ldots \ldots \ldots \ldots \ldots \ldots \ldots \ldots \ldots \ldots \ldots$

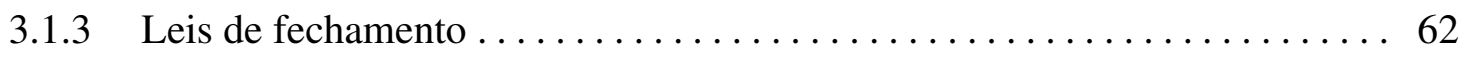


3.1.3.1 Homogeneização das fases líquidas $\ldots \ldots \ldots \ldots \ldots \ldots \ldots \ldots \ldots$

3.1.3.2 Tensão de cisalhamento na parede $\ldots \ldots \ldots \ldots \ldots \ldots \ldots \ldots \ldots \ldots \ldots$

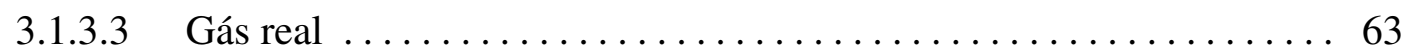

3.1.3.4 Escorregamento entre as fases líquida e gasosa . . . . . . . . . . 64

3.1.3.5 Aproximação de black-oil . ...................... 65

3.1.3.6 Termo de vaporização. ....................... 66

3.1.4 Método das características e condições de compatibilidade ........... 67

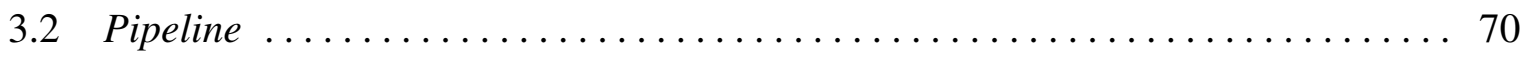

3.2.1 Modelo para comprimento de penetração de líquido nulo (estado $x=0$ ) . 71

3.2.2 Modelo para comprimento de penetração de líquido positivo (estado $x>0$ ) 71

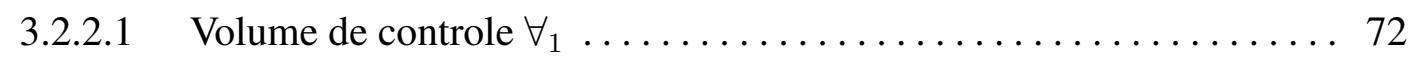

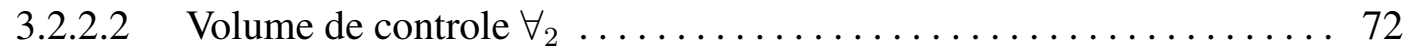

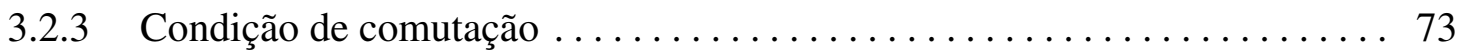

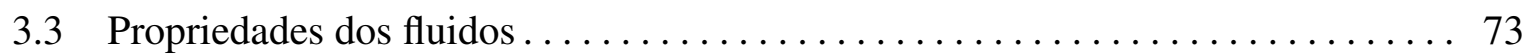

3.3.1 Fator volume de formação e massa específica do gás . . . . . . . . . 73

3.3.2 Fator volume de formação e massa específica da água . . . . . . . . . . 74

3.3.3 Solubilidade de gás em óleo e pressão de ponto de bolha $\ldots \ldots \ldots \ldots \ldots 74$

3.3.4 Fator volume de formação e massa específica de óleo . . . . . . . . . . 74

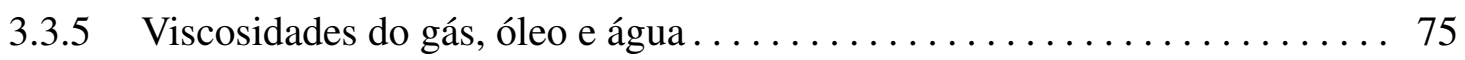

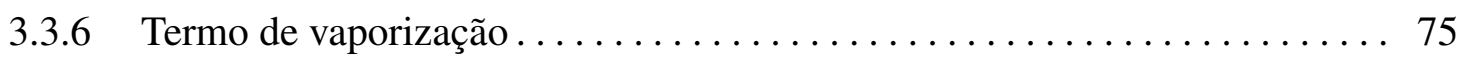

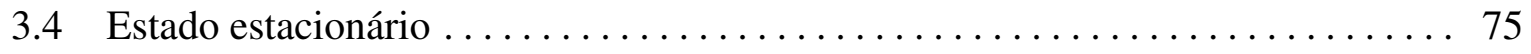

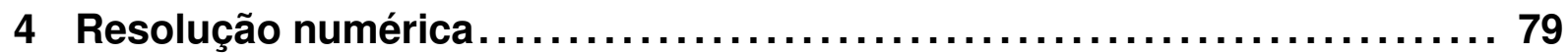

4.1 Discretização das equações de estado do riser . . . . . . . . . . . . . . 79

4.2 Discretização das equações de estado do pipeline $\ldots \ldots \ldots \ldots \ldots \ldots \ldots \ldots$

4.2.1 Equações discretizadas para comprimento de penetração de líquido nulo

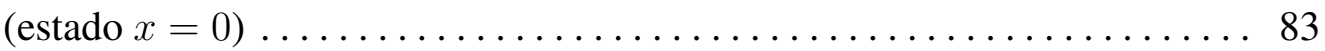


4.2.2 Equações discretizadas para comprimento de penetração de líquido posi-

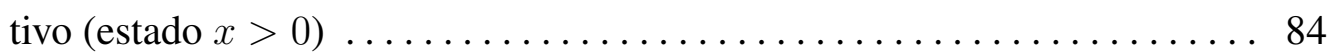

4.2.2.1 Volume de controle $\forall_{1} \ldots \ldots \ldots \ldots \ldots \ldots \ldots \ldots \ldots \ldots$

4.2.2.2 Volume de controle $\forall_{2} \ldots \ldots \ldots \ldots \ldots \ldots \ldots \ldots \ldots \ldots \ldots \ldots$

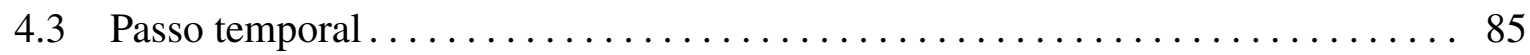

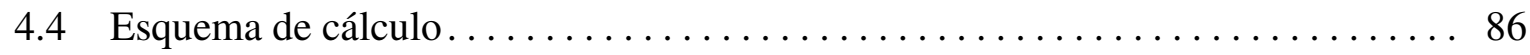

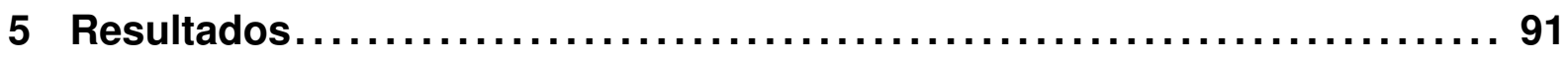

5.1 Estudo de convergência $\ldots \ldots \ldots \ldots \ldots \ldots \ldots \ldots \ldots \ldots \ldots \ldots \ldots \ldots \ldots \ldots \ldots \ldots \ldots \ldots \ldots$

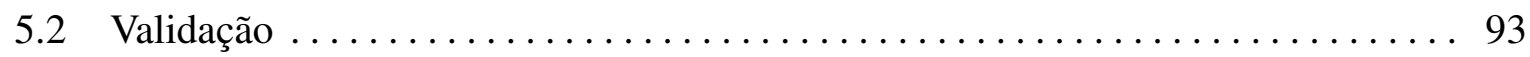

5.3 Descrição da intermitência severa utilizando o modelo proposto $\ldots \ldots \ldots \ldots \ldots$

5.4 Classificação da intermitência severa para sistemas com transferência de massa . 108

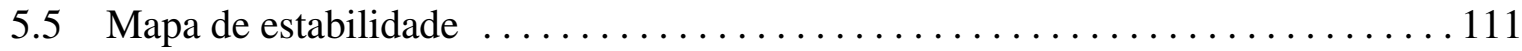

5.6 Mapa de tipos de instabilidade . . . . . . . . . . . . . . . . . . 114

5.7 Mapas de estabilidade utilizando o critério de Pots . . . . . . . . . . . 116

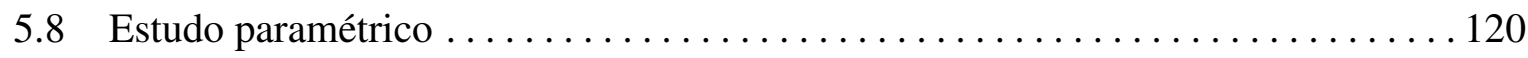

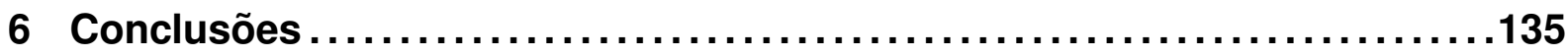

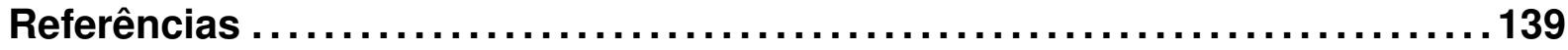

Apêndice A - Introdução ao escoamento multifásico gás-líquido . . . . . . . . . . 143

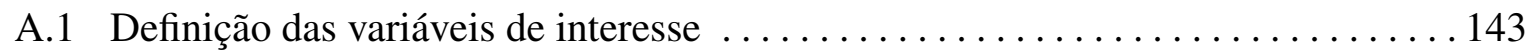

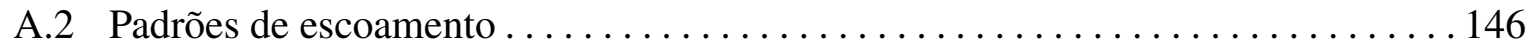

A.3 Dedução da equação da continuidade $\ldots \ldots \ldots \ldots \ldots \ldots \ldots \ldots \ldots \ldots \ldots \ldots \ldots \ldots \ldots \ldots \ldots$

Apêndice B - Dedução das equações de estado para o modelo do riser utilizando o método das características . . . . . . . . . . . . . . . . . . . . . . 151

B.1 Manipulação algébrica das equações de conservação $\ldots \ldots \ldots \ldots \ldots \ldots \ldots \ldots 1$ 
B.2 Procedimento para a obtenção do sistema de equações na forma normal . . . . . 156

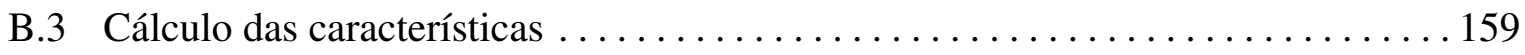

B.4 Determinação do sistema de equações na forma normal $\ldots \ldots \ldots \ldots \ldots \ldots \ldots 1$

\section{Apêndice C - Dedução da equação de estado complementar para o modelo} do riser .........................................................

Apêndice D - Dedução das equações de estado para o modelo do pipeline ..167

D.1 Equacionamento para comprimento de penetração de líquido nulo (estado $x=0) 168$

D.1.1 Equação da continuidade para o gás $\ldots \ldots \ldots \ldots \ldots \ldots \ldots \ldots \ldots \ldots \ldots \ldots \ldots \ldots \ldots$

D.1.2 Equação da continuidade para o óleo ...................... 169

D.1.3 Equação da continuidade para a água $\ldots \ldots \ldots \ldots \ldots \ldots \ldots \ldots \ldots \ldots \ldots \ldots \ldots$

D.2 Equacionamento para comprimento de penetração de líquido positivo (estado

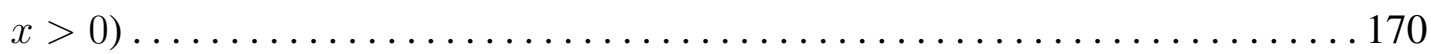

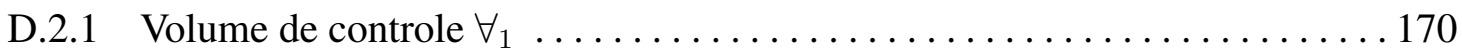

D.2.1.1 Equação da continuidade para o gás . ..................... 170

D.2.1.2 Equação da continuidade para o óleo ................... 171

D.2.1.3 Equação da continuidade para a água .................... 172

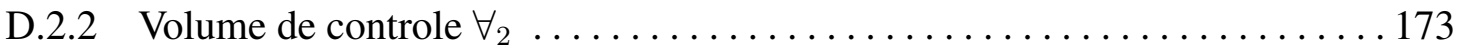

D.2.2.1 Equação da continuidade para o óleo $\ldots \ldots \ldots \ldots \ldots \ldots \ldots \ldots \ldots \ldots$

D.2.2.2 Equação da continuidade para água $\ldots \ldots \ldots \ldots \ldots \ldots \ldots \ldots \ldots \ldots$

D.2.2.3 Equação da continuidade para a fase líquida . . . . . . . . . . . . . . 174

Apêndice E - Correlações para as propriedades dos fluidos . . . . . . . . . . . 175

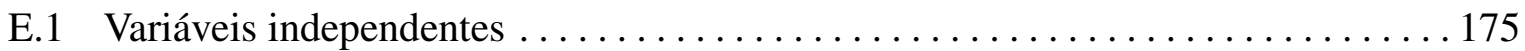

E.1.1 Densidade relativa do óleo na condição padrão e densidade API $\ldots . . . .175$

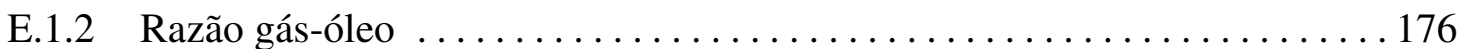

E.1.3 Razão água-óleo ou razão de água mais sedimentos a líquido mais sedimentos . . . . . . . . . . . . . . . . . . . . . . . . . . . . 176 


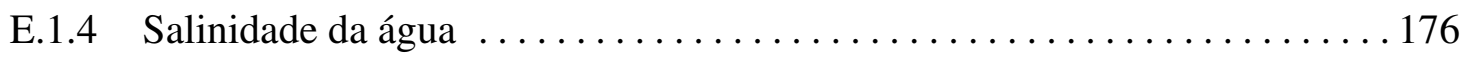

E.1.5 Densidade relativa do gás livre na condição padrão $\ldots \ldots \ldots \ldots \ldots \ldots \ldots$

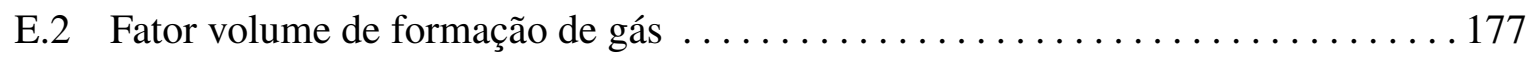

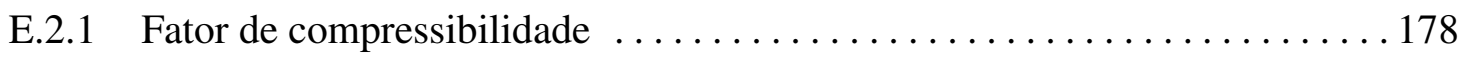

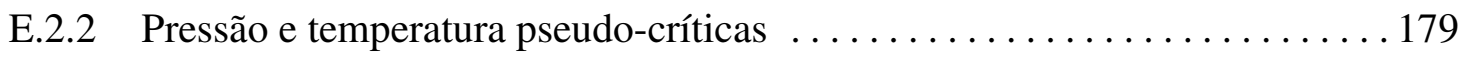

E.3 Massa específica do gás ...................................... 179

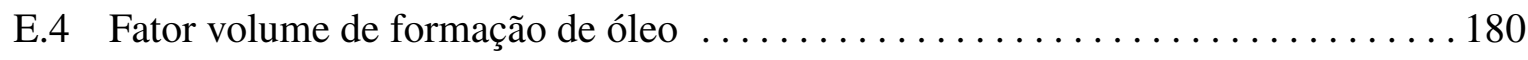

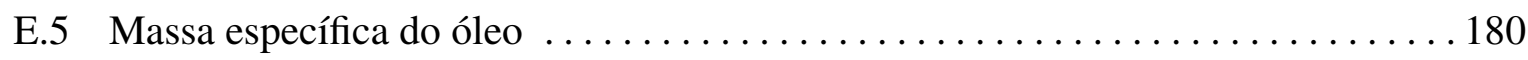

E.6 Fator volume de formação de água $\ldots \ldots \ldots \ldots \ldots \ldots \ldots \ldots \ldots \ldots \ldots \ldots \ldots \ldots \ldots \ldots$

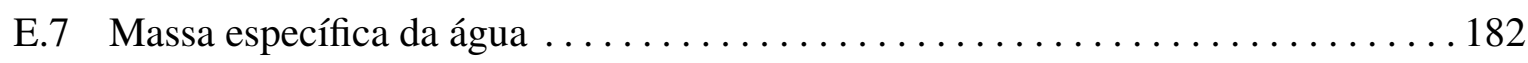

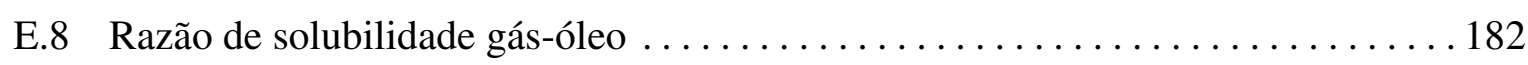

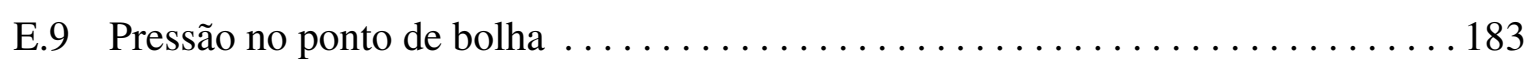

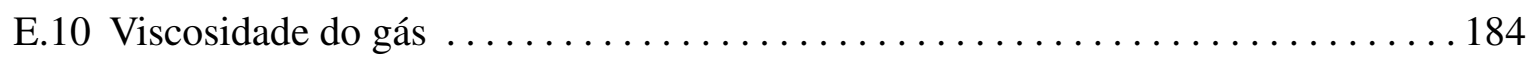

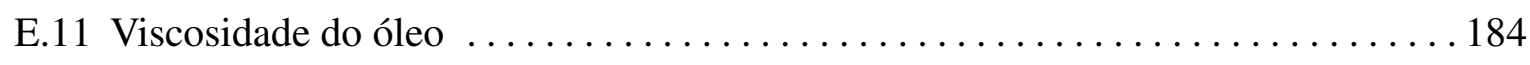

E.11.1 Viscosidade do óleo morto ............................. 184

E.11.2 Viscosidade do óleo saturado ........................... 185

E.11.3 Viscosidade do óleo subsaturado .......................... 185

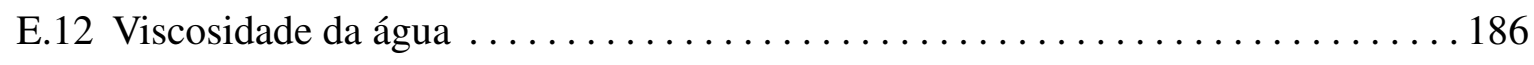

E.12.1 Viscosidade da água na pressão padrão $\ldots \ldots \ldots \ldots \ldots \ldots \ldots \ldots \ldots \ldots$

E.12.2 Viscosidade da água na condição de medição ................... 186

E.13 Derivadas das propriedades termodinâmicas ...................... 186

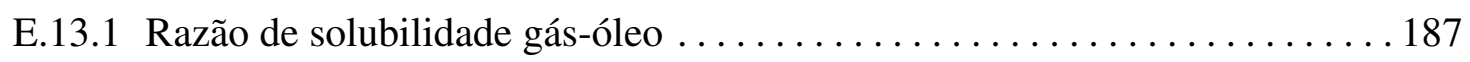

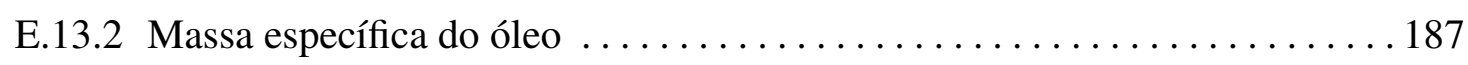

E.13.3 Massa específica do gás ............................... 188

E.13.4 Massa específica da água ................................. 189 



\section{INTRODUÇÃO}

Em sistemas de produção de petróleo, os fluidos que deixam a cabeça do poço são frequentemente transportados para plataformas por meio de tubos flexíveis. Os tubos são compostos de um pipeline (ou flowline), que conduz os fluidos acompanhando a topografia do solo oceânico, e um riser, que eleva os fluidos até o vaso separador localizado na plataforma, como pode ser visto na Fig. 1.1. Geralmente, os fluidos transportados são compostos de gás, óleo e água, mas devido às severas condições de pressão e temperatura, é possível a formação de emulsões, hidratos e cera. Estas características fazem da modelagem do escoamento multifásico envolvido uma complexa tarefa.

\subsection{O fenômeno de intermitência severa}

Intermitência severa (severe slugging, terrain induced slug flow ou terrain-dominated slug flow) é um fenômeno dominado pela topografia, caracterizado pela formação e produção cíclica de longas golfadas de líquido e rápida expulsão de gás. O fenômeno pode ocorrer para baixas vazões de gás e líquido quando uma seção com inclinação descendente (pipeline) é seguida por outra seção com inclinação ascendente (riser). A desestabilização do escoamento resulta de dois mecanismos que competem entre si: queda de pressão ao longo do riser (influenciada principalmente pela distribuição de fração de vazio) e compressibilidade do gás no pipeline.

A Fig. 1.2 mostra os quatro estágios do ciclo de intermitência severa: (a) formação da golfada, (b) produção da golfada, (c) penetração de gás e (d) expulsão de gás. Já a Fig. 1.2(e) apresenta o sistema pipeline-riser em uma situação em que a intermitência severa não ocorre e o estado permanente é alcançado.

No primeiro estágio, chamado de formação da golfada, o líquido proveniente do pipeline acumula-se na base do riser, bloqueando a passagem de gás e fazendo com que o gás seja comprimido. Quando a altura do líquido atinge o topo do riser, o segundo estágio tem início com a movimentação da golfada para dentro do separador. Após o gás que estava bloqueado no 


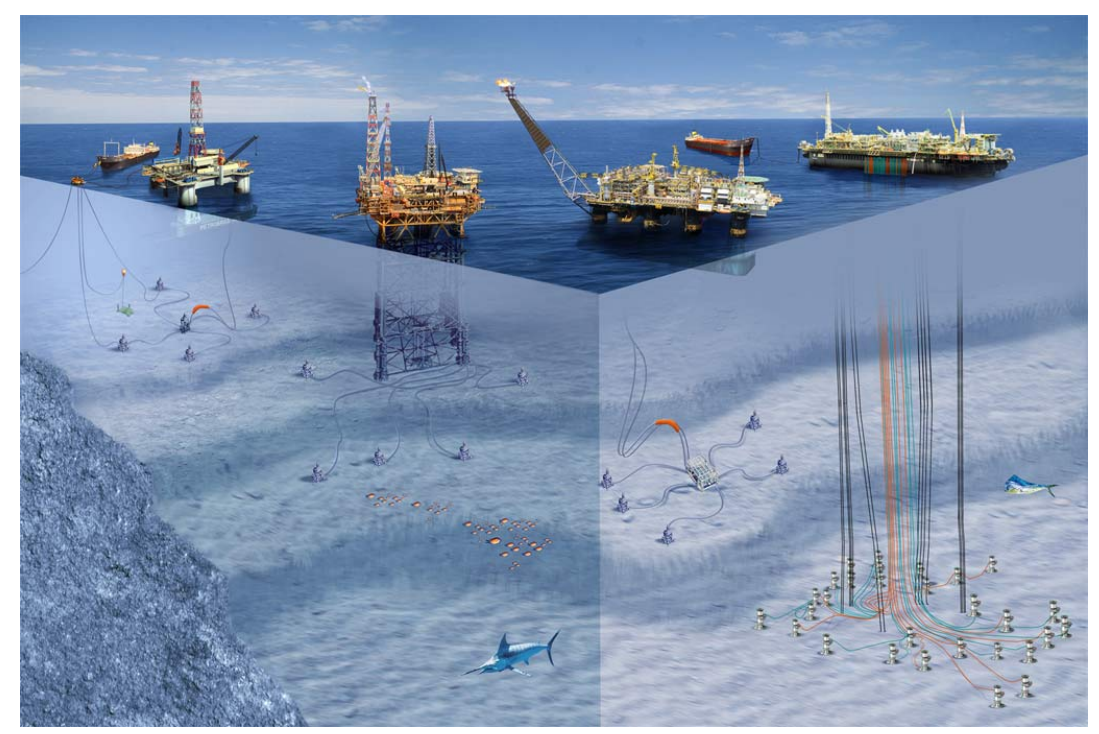

Figura 1.1: Típicos sistemas de produção de petróleo offshore (fonte: Petrobras).

pipeline alcançar a base do riser, a golfada de líquido continua a adentrar o separador, mas com uma velocidade maior, o que caracteriza o estágio de penetração de gás. No último estágio, a bolha de gás atinge o topo do riser, ocorrendo uma violenta expulsão de gás e rápida descompressão, fazendo com que o líquido restante no riser recue para a base do tubo e o processo de formação da golfada reinicie. Uma descrição mais detalhada do ciclo de intermitência severa, segundo diferentes autores, é apresentada no Capítulo 2.

Com base nas diferentes configurações do escoamento no sistema pipeline-riser após o ciclo limite ter sido alcançado, os seguintes tipos de intermitência severa foram definidos (TIN; SARSHAR, 1993; WORDSWORTH et al., 1998):

- Intermitência severa 1 (SS1): o comprimento da golfada de líquido é maior ou igual ao comprimento do riser e a máxima pressão no pipeline é aproximadamente igual à pressão hidrostática do riser (desconsiderando efeitos menores, como o atrito). Há penetração intermitente de gás na base do riser.

- Intermitência severa 2 (SS2): o comprimento da golfada de líquido é menor que o comprimento do riser. Há penetração intermitente de gás na base do riser.

- Intermitência severa 3 (SS3): há penetração contínua de gás na base do riser. Visualmente o escoamento assemelha-se ao escoamento em golfadas ( $\operatorname{lug}$ flow) e a pressão, comprimento e frequência das golfadas revelam variações cíclicas menores quando comparadas com a SS1.

- Oscilação (OSC): são observadas flutuações de pressão cíclicas com pequenas amplitu- 


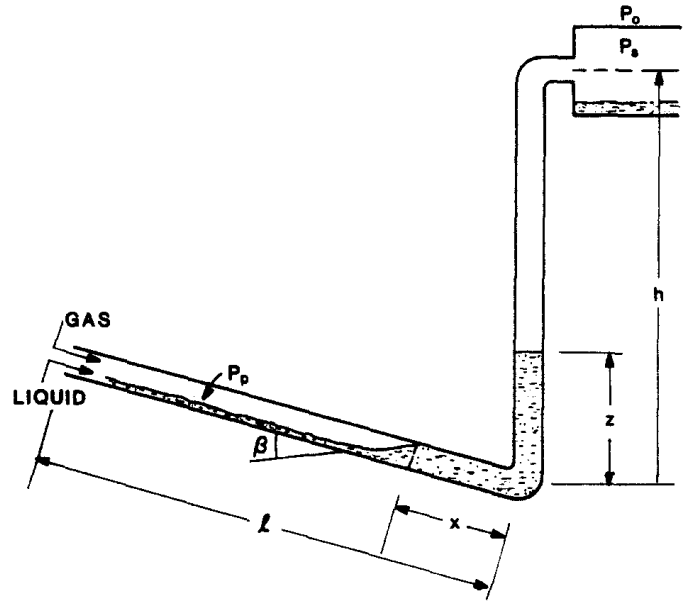

(a) Formação da golfada.

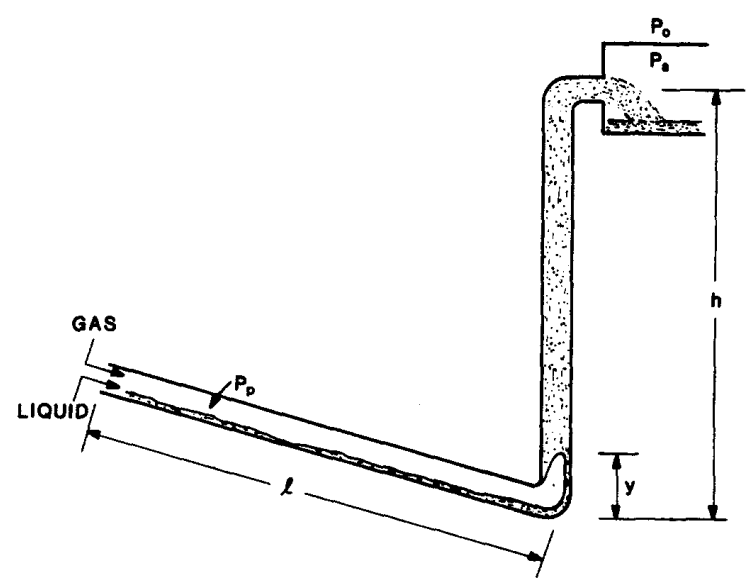

(c) Penetração de gás.

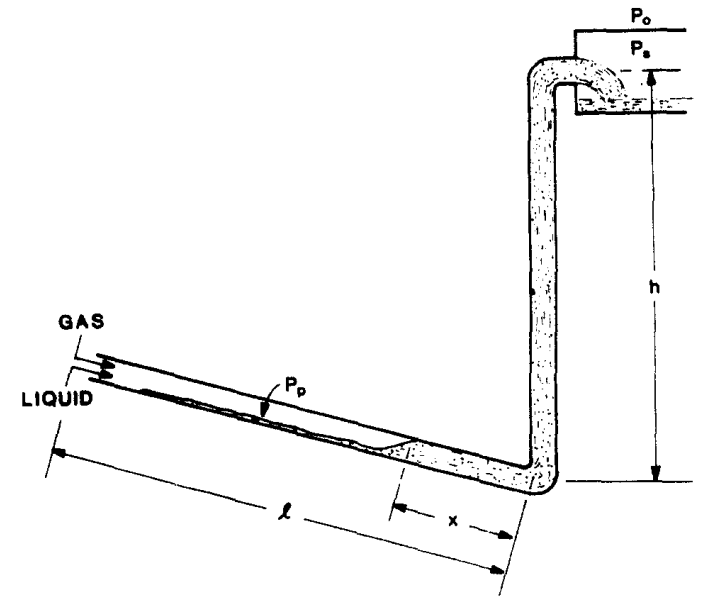

(b) Produção da golfada.

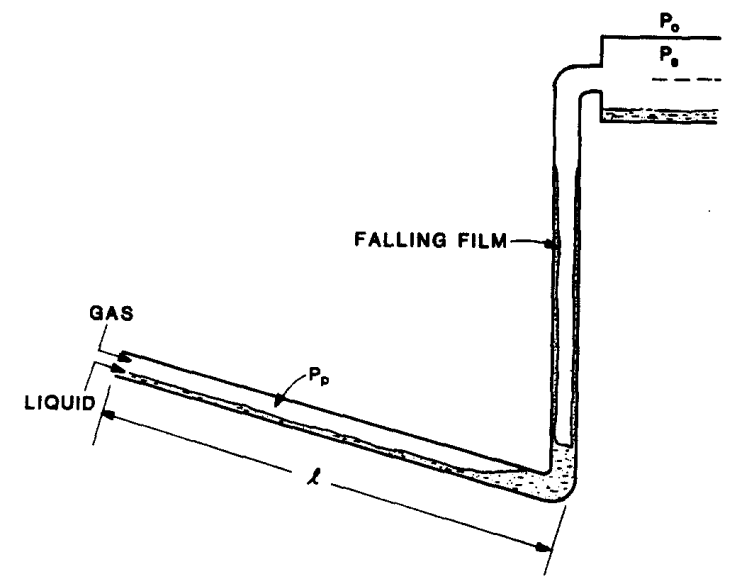

(d) Expulsão de gás.

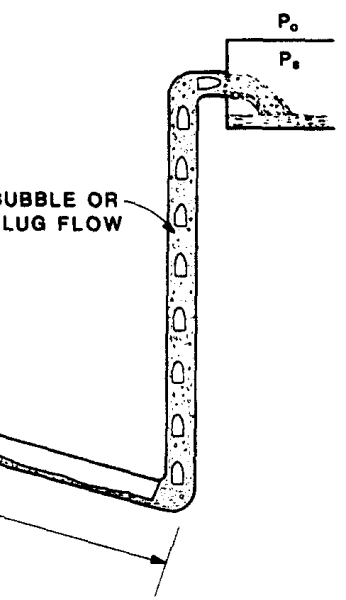

(e) Estado permanente.

Figura 1.2: Estágios do ciclo de intermitência severa. Reproduzido de Taitel (1986). 
des.

De acordo com Wordsworth et al. (1998), as consequências indesejáveis relacionadas com a intermitência severa são: (a) aumento da pressão na cabeça do poço, causando tremendas perdas de produção, (b) grandes vazões instantâneas, causando instabilidade no sistema de controle de líquido dos separadores e eventualmente paralisação da produção (shutdown), e (c) oscilações de vazão no reservatório.

Consequentemente, prever e evitar a ocorrência da intermitência severa durante o projeto das instalações de exploração tem se tornado uma atividade indispensável, de maneira a assegurar produção contínua em níveis desejáveis, visando a lucratividade do empreendimento (LORIMER; ELLISON, 2000).

A literatura reporta experimentos e estudos teóricos para sistemas água-ar (TAITEL, 1986; BALIÑO; BURR; NEMOTO, 2010) em que o aumento da pressão no separador, ou o aumento da pressão no topo do riser, tem efeito estabilizante; ou seja, aumentando-se a pressão no separador, observou-se a extinção da intermitência severa em casos nos quais o fenômeno ocorria. Há também relatos na literatura (JANSEN; SHOHAN; TAITEL, 1996; YOCUM, 1973; SCHMIDT; BRILL; BEGGS, 1980) em que o uso de uma válvula choke no topo do riser levou à estabilização do escoamento água-ar em sistemas pipeline-riser. Outra técnica que permite eliminar a intermitência severa é o gas-lift, que consiste na injeção contínua de gás na base do riser (JANSEN; SHOHAN; TAITEL, 1996; SCHMIDT; DOTY; DUTTA-ROY, 1985).

\subsection{Sistemas água-ar e sistemas óleo-água-gás}

Alguns modelos foram propostos para o estudo da intermitência severa em sistemas pipelineriser em que os fluidos escoantes são água e ar. Schmidt, Doty e Dutta-Roy (1985), Fabre et al. (1990), Taitel et al. (1990), Sarica e Shoham (1991) e Baliño, Burr e Nemoto (2010) são alguns dos autores que investigaram o comportamento deste escoamento bifásico e propuseram diferentes métodos para determinar a estabilidade do sistema. Uma recente monografia feita por Mokhatab (2010) revisa as principais questões relacionadas à intermitência severa para sistemas com água-ar.

As simulações numéricas e experimentos relatados na literatura utilizam água e ar como fluidos escoantes por questão de simplicidade. Embora os aspectos básicos da intermitência severa possam ser levados em consideração, existem muitas limitações ao se tentar extrapolar os resultados para sistemas de produção de petróleo. O comprimento do pipeline e 
a altura do riser em sistemas de produção de petróleo são muito maiores (ordem de quilômetros) que os valores observados nas instalações experimentais que se utilizam de ar e água. As grandes razões entre a pressão na base e no topo do riser dão origem a importantes efeitos de expansão na fase gasosa, invalidando modelos baseados na suposição de uma fração de vazio constante no riser.

O petróleo é composto de múltiplos hidrocarbonetos, sendo que as fases líquida e gasosa coexistem em condições de operação (MCCAIN, 1990). A transferência de massa entre as fases é dependente da pressão e temperatura locais, sendo, portanto, as vazões de gás e óleo dependentes do diagrama de fases ou diagrama pressão-volume-temperatura (PVT) do fluido em questão. Com as altas variações de pressão ao longo do riser, os efeitos da transferência de massa não podem ser ignorados. Além disso, os hidrocarbonetos provenientes do reservatório estão misturados à água, de maneira que três fases ocorrem em geral.

\subsection{O código computacional OLGA}

Os transientes em sistemas de produção de petróleo podem ser simulados usando códigos comerciais. Por exemplo, OLGA (SPT Group, 2012) é um programa computacional desenvolvido para simular o escoamento de gás, óleo e água em poços, tubos e instalações de recebimento dos fluidos. O programa resolve diferentes equações de continuidade para o gás, volume de líquido e gotas de líquido, duas equações de quantidade de movimento, uma para a fase líquida contínua e outra para a combinação de gás e possíveis gotas de líquido, e uma equação de energia para a mistura, considerando que as fases possuam a mesma temperatura. As equações são resolvidas utilizando o método dos volumes finitos e um esquema de integração semi-implícito.

\subsection{Modelo matemático proposto}

Embora códigos comerciais possam ser usados para a simulação do escoamento, é bem-vindo o desenvolvimento de modelos mais simples, que permitam uma maior compreensão da física básica envolvida no fenômeno.

Neste trabalho são apresentados um modelo matemático e simulações numéricas para o estudo da dinâmica do escoamento de gás, óleo e água em um sistema pipeline-riser. O modelo leva em conta a equação da continuidade para as fases gás, óleo e água. Considera-se que as fases óleo e água possuam a mesma velocidade e estão homogeneizadas. A transferência de massa entre o gás e o óleo é calculada usando a aproximação de black-oil (ver Seção 3.1.3.5). 
As propriedades dos fluidos são calculadas por meio de correlações analíticas baseada em resultados experimentais e dados de campo. Do mesmo modo que nos modelos anteriores para sistemas água-ar, é considerado escoamento isotérmico.

Algumas considerações devem ser feitas relacionadas à aproximação isotérmica para a modelagem de sistemas pipeline-riser com efeitos de transferência de massa. As diretrizes de projeto e operação de sistemas de produção submarinos, além de recomendar a prevenção da ocorrência de escoamentos instáveis, também recomendam a manutenção da temperatura em níveis suficientemente altos de maneira a evitar a formação de hidratos, ceras e asfaltenos. Como consequência, a queda de temperatura ao longo do pipeline e riser deve ser reduzida com isolamento térmico adequado, de maneira a manter a temperatura acima de valores críticos. A temperatura típica dos fluidos que deixam o poço é de aproximadamente $70^{\circ} \mathrm{C}$, enquanto a queda de temperatura ao longo dos tubos é de aproximadamente $40^{\circ} \mathrm{C}$.

Como afirmado anteriormente, a intermitência severa é um fenômeno controlado basicamente pela queda de pressão hidrostática no riser e compressibilidade do gás no pipeline, sendo outros efeitos físicos (atrito e forças inerciais, por exemplo) de menor importância; sendo assim, considera-se que a dependência do termo de atrito com relação à temperatura, devido principalmente à viscosidade do óleo, não seja significante. Já o efeito de expansão do gás, importante devido à sua influência na queda de pressão na coluna hidrostática, depende da temperatura absoluta; como mudanças fracionais na temperatura absoluta são pequenas, considera-se que a expansão do gás sofra pequena influência.

Finalmente, a temperatura também influencia moderadamente a solubilidade do gás e o fator volume de formação do óleo (ver Apêndice E). Como consequência, cálculos baseados em uma temperatura média são uma boa aproximação para estudos de intermitência severa.

Efeitos térmicos podem ser levados em conta no modelo adicionando a equação de energia para a mistura. É possível demonstrar que essa equação adicional não aumenta o número de valores característicos do sistema de equações resultante (ver Seção 3.1.4).

Diferentemente da temperatura, a pressão muda drasticamente em sistemas de produção submarinos, especialmente em águas ultra-profundas, onde a pressão pode variar de 20 a 300 bar. Como a pressão influencia todas as propriedades termodinâmicas, as grandes razões de pressão dão origem a importantes efeitos de expansão e transferência de massa.

O pipeline é modelado como um sistema de parâmetros concentrados e considera dois estados comutáveis, um em que o gás é capaz de penetrar no riser e outro no qual há uma frente de acúmulo de líquido, prevenindo a penetração do gás. Uma equação algébrica adicional que 
considera o balanço de quantidade de movimento para o padrão estratificado suave (smooth stratified) em estado estacionário é usada para relacionar as vazões e a fração de vazio no pipeline.

O modelo do riser considera um sistema de parâmetros distribuídos, no qual nós móveis são usados para avaliar as condições locais ao longo do subsistema. Uma equação de quantidade de movimento simplificada, sem os termos de inércia, é considerada para a mistura. O modelo de drift-flux (ZUBER; FINDLAY, 1965), avaliado para as condições locais no riser, é usado como lei de fechamento. Diferentes geometrias (vertical ou catenária) podem ser introduzidas para o riser. O método das características é usado para simplificar a diferenciação no sistema de equações mistas hiperbólicas-parabólicas resultante. As equações são discretizadas e integradas usando um método implícito com um esquema preditor-corretor para o tratamento das não-linearidades.

O modelo prediz a localização da frente de acúmulo de líquido no pipeline e do nível de líquido no riser, de maneira que é possível determinar qual tipo de intermitência severa ocorre no sistema. Como consequência, este trabalho pode ser considerado uma extensão do desenvolvido por Baliño, Burr e Nemoto (2010), tendo como novidades o escoamento trifásico, a transferência de massa entre gás e óleo, o comportamento de gás real, a compressibilidade dos fluidos e o cálculo das propriedades termodinâmicas locais baseando-se, para isso, na aproximação de black-oil.

A partir de simulações utilizando o modelo proposto foi possível descrever o ciclo de intermitência severa em sistemas com transferência de massa e compará-lo ao ciclo referente a sistemas água-ar. Também foi possível verificar a influência de diferentes parâmetros sobre os mapas de estabilidade. Esse estudo indica como os parâmetros geométricos devem ser modificados de maneira a tornar o sistema de transporte submarino e elevação de óleo menos suscetível à intermitência severa, além de indicar como os parâmetros relacionados à composição dos fluidos influenciam na iniciação da intermitência severa.

A fim de apresentar as variáveis fundamentais à modelagem em escoamentos multifásicos gás-líquido, assim como apresentar nomenclatura constantemente visitada ao longo do texto, o Apêndice A traz uma pequena introdução ao assunto.

No decorrer do texto, sempre que for citada a condição padrão de temperatura e pressão, serão consideradas a pressão de $1 \mathrm{~atm}$ e a temperatura de $60^{\circ} \mathrm{F}$, segundo a API (American Petroleum Institute). 


\subsection{Estrutura da tese}

Após esta introdução, o capítulo 2 apresenta uma breve revisão bibliográfica em que são apresentados os resultados dos autores que mais contribuíram para a descrição do fenômeno de intermitência severa por meio de investigações numéricas e experimentais. Em seguida, o capítulo 3 apresenta os modelos matemáticos do pipeline e riser e as correlações utilizadas para o cálculo das propriedades dos fluidos. As equações de estado para os subsistemas pipeline e riser devem ser discretizadas de modo a possibilitar a resolução numérica das mesmas, tal procedimento é apresentado no capítulo 4 . O capítulo 5 apresenta os resultados das simulações numéricas utilizando o modelo proposto, o que possibilitou verificar os efeitos da vaporização sobre o ciclo de intermitência severa e propor nova classificação para os tipos de intermitência severa. Ainda no capítulo 5, mapas de estabilidade são apresentados e um estudo paramétrico mostra a influência de diferentes variáveis geométricas e relacionadas à caracterização dos fluidos sobre a ocorrência da intermitência severa. Por fim, o capítulo 6 apresenta as conclusões e futuras atividades são propostas. 


\section{REVISÃo BIBLIOGRÁFICA}

Neste capítulo serão apresentados os artigos relacionados à intermitência severa que mais contribuíram para o entendimento e para o desenvolvimento da modelagem matemática desse fenômeno.

\subsection{Schmidt, Brill e Beggs (1980)}

Schmidt, Brill e Beggs (1980) construíram instalações experimentais a fim de estudar o escoamento em sistemas pipeline-riser. Os fluidos escoavam em um pipeline de 30, $48 \mathrm{~m}$ e seguiam por um riser vertical de $50 \mathrm{~m}$, ambos com diâmetro de 2". O pipeline foi posicionado em inclinações de $-5^{\circ},-2^{\circ}, 0^{\circ}$ e $+5^{\circ}$ a partir da horizontal e os fluidos usados no estudo foram ar e querosene.

Com base nos experimentos realizados foi possível uma descrição detalhada da intermitência severa. A descrição que segue tem início quando a pressão na base do riser apresenta seu menor nível e a cauda da golfada de líquido acaba de adentrar o separador (ver Fig. 1.2(d)).

Parte do líquido que deslocava-se junto à golfada retrocede no riser e inicia-se o acúmulo de líquido na base. Uma vez que o aumento de pressão no pipeline por unidade de tempo é menor que o aumento de pressão hidrostática por unidade de tempo no riser devido ao fluxo de entrada de líquido e a queda de líquido no riser, o líquido começa a acumular-se em ambos os tubos: pipeline e riser. Com isso, a passagem de ar para o riser fica bloqueada e a pressão no pipeline começa a aumentar. Quando a frente da golfada de líquido, ou a altura do líquido, atinge o topo do riser, a pressão no pipeline chega ao seu valor máximo. A pressão no pipeline começa a decrescer conforme o comprimento da golfada de líquido gradualmente diminui, visto que a golfada deixa o riser e adentra o separador. Quando a calda da golfada atinge o topo do riser, a pressão no pipeline atinge seu mínimo, igualando ou chegando próxima à pressão do separador.

Schmidt, Brill e Beggs (1980) observaram que ao mudar a vazão de líquido ou ao 
aumentar a vazão de gás, um novo padrão de escoamento é obtido, semelhante ao descrito anteriormente, porém as golfadas de líquido são ligeiramente aeradas e não excedem o comprimento do riser.

Aumentando ainda mais a vazão de gás, obtêm-se um outro padrão de escoamento, chamado pelos autores de "transição para intermitência severa". O novo padrão de escoamento se aproxima da intermitência severa. No entanto, o escoamento torna-se mais caótico. Regiões no riser continuamente são preenchidas por golfadas de líquido com alta concentração de bolhas e por partes em que ocorre apenas gás. Adicionalmente, as golfadas formadas na base do riser não mantém sua identidade conforme elas evoluem ao longo do riser. Um aumento adicional na vazão de gás resulta no padrão de escoamento em golfadas ou anular.

Vale ressaltar que a descrição da intermitência severa como apresentada é aplicável apenas para pipeline com inclinação negativa (escoamento descendente no pipeline e ascendente no riser). Não foi observada a ocorrência da intermitência severa em um pipeline com inclinação positiva (escoamento ascendente no pipeline) ou horizontal.

Um modelo matemático foi proposto, assumindo que a vazão mássica de gás e líquido na entrada do pipeline mantêm-se constantes; a pressão no separador é constante; não há bolhas de gás nas golfadas de líquido; a fração volumétrica de líquido é uniforme ao longo de todo o comprimento do pipeline; as interfaces de gás e líquido são horizontais; e o processo é isotérmico. A força predominante envolvida no fenômeno é a gravidade, e devido ao movimento lento do líquido durante a formação da golfada, consideram-se desprezíveis o atrito e a aceleração. As variáveis de interesse no modelo são a altura do líquido no pipeline e riser, a velocidade do gás, a pressão no pipeline e o tempo para formação da golfada de líquido no riser. Esse modelo está limitado ao estudo de como a golfada de líquido é gerada na base do riser.

Os autores reportam ainda que o uso de uma válvula reguladora (choke valve) no topo do riser tem efeito estabilizante, ou seja, evita a ocorrência da intermitência severa. Efeito semelhante foi observado por Yocum (1973), que foi capaz de estabilizar o escoamento no sistema pipeline-riser por meio do aumento da pressão no separador. As consequências do aumento da contrapressão (backpressure) são reduções de até $50 \%$ na vazão dos fluidos.

\subsection{Schmidt, Doty e Dutta-Roy (1985)}

Schmidt, Doty e Dutta-Roy (1985) afirmam que a ocorrência da intermitência severa depende da geometria do sistema pipeline-riser. O pipeline deve apresentar inclinação negativa para 


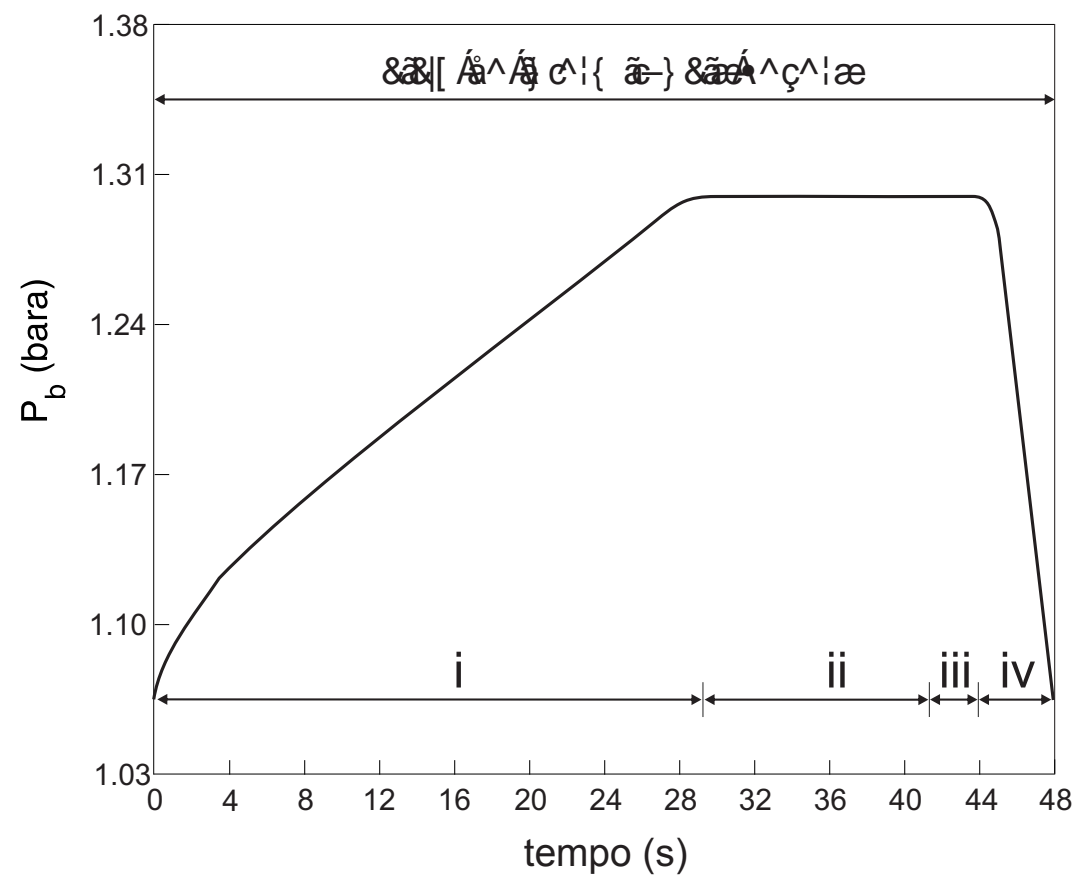

Figura 2.1: Histórico de pressão para sistemas água-ar. Reproduzido de Schmidt, Doty e DuttaRoy (1985).

que a golfada se forme na base do riser, assim como deve apresentar padrão de escoamento estratificado.

Um novo aparato experimental foi montado, com um pipeline de $9,14 \mathrm{~m}$ e inclinação de $-1^{\circ}$ e um riser vertical de $3,05 \mathrm{~m}$. Ambos tubos possuíam diâmetro de $1^{\prime \prime}$ e os fluidos usados foram água e ar.

Os autores propõem uma descrição mais detalhada para a intermitência severa, separando o ciclo em estágios, como pode ser visto na Fig. 2.1. A figura mostra o histórico de pressão no pipeline para um ciclo de intermitência severa, composto pelos estágios: (i) geração da golfada (slug-generation), (ii) produção da golfada (slug-production), (iii) penetração de gás (bubble-penetration) e (iv) expulsão de gás (gas blowdown).

A descrição inicia-se no momento em que a golfada de líquido acaba de deixar o riser e adentrar o separador (ver Fig. 1.2(d)). Devido ao fato de o pipeline possuir padrão de escoamento estratificado, o gás que flui em sequência à golfada de líquido inicia sua rápida expansão, levando consigo gotas de líquido que estavam suspensas no interior do riser.

Visto que a vazão mássica de gás que deixa o sistema durante este estágio, chamado de estágio de expulsão de gás, é muito maior do que a vazão mássica de gás injetada no sistema, o acúmulo de gás no pipeline é rapidamente eliminado com a consequente despressurização desse tubo. A partir do momento em que a velocidade do gás torna-se insuficiente para suportar 
o líquido nas paredes do riser, o líquido inicia sua queda, acumulando-se na base do riser. Esse processo é chamado de queda de líquido (liquid fallback).

Uma vez que o aumento de pressão do gás no pipeline por unidade de tempo é menor que o aumento de pressão hidrostática no riser por unidade de tempo, sendo o primeiro efeito resultante da baixa vazão mássica de gás injetada e grande volume a ser ocupado no pipeline e o segundo efeito causado pelo líquido que adentra o riser proveniente do pipeline e pela queda de líquido no riser, inicia-se o acúmulo de líquido na base do riser e na saída do pipeline. Com isso, a passagem de gás para o riser é bloqueada e a pressão no pipeline começa a aumentar. Ao mesmo tempo, o líquido continua a se acumular, o que o força a subir no riser e invadir o pipeline. Quando a golfada de líquido alcança o topo do riser, a pressão no pipeline atinge seu máximo valor. Esse ponto define o fim do estágio de geração da golfada e o início do estágio de produção da golfada.

Durante o estágio de produção da golfada, o gás acumulado no pipeline é submetido a um aumento de pressão devido à constante vazão mássica de gás injetada no sistema; com isso, a golfada de líquido é gradualmente empurrada para fora do pipeline, invadindo o riser. Esse estágio continua até que todo o conteúdo de líquido da golfada presente no pipeline adentre a base do riser, o que marca o fim do estágio de produção da golfada e o início do estágio de penetração de gás.

O estágio de penetração de gás é caracterizado pela rápida expansão do gás que continuamente invade o riser e deixa um fino filme de líquido ao longo de toda a parede interna do riser. Esse estágio continua até que o gás atinja o separador, momento a partir do qual o estágio de expulsão do gás se inicia. Desse modo, a intermitência severa é caracterizada por um ciclo repetitivo.

Os autores apresentam três condições segundo as quais a intermitência severa deixa de existir: (a) modificação do padrão de escoamento no pipeline de estratificado ondulado para o escoamento em golfadas ou disperso, (b) utilização de uma vazão mássica de gás na entrada do pipeline suficiente para superar a taxa de aumento de pressão hidrostática no riser, causada pela queda de líquido no riser e a entrada de líquido proveniente do pipeline e (c) obtenção de um escoamento estável no riser vertical, ou seja, que para um aumento na vazão volumétrica de gás seja obtida uma maior queda de pressão no riser.

No caso (a), sob um escoamento em golfadas ou disperso, as golfadas de líquido geradas no pipeline deslocam-se praticamente sem alterações ao longo do riser, o que previne a formação de uma golfada de líquido na base do mesmo. No caso (b), o maior volume de gás injetado no pipeline faz com que bolhas penetrem no riser antes do comprimento da golfada de 
líquido atingir o topo do riser. Já no caso (c), se o riser possuir o comportamento estável, ao se aumentar a vazão de gás no riser, haverá uma maior queda de pressão no mesmo, o que, por sua vez, requer uma maior pressão no pipeline. Esse aumento de pressão no pipeline é obtido por meio da diminuição da vazão de gás que o deixa; com isso, a fase de expulsão de gás será impossibilitada de ocorrer.

Um modelo matemático é apresentado para cada estágio da intermitência severa e os valores finais para um estágio são utilizados como valores de entrada para o estágio seguinte. Os quatro modelos ignoram queda de pressão no pipeline, assim como quaisquer variações na pressão, massa específica e vazões volumétricas ao longo do seu comprimento.

Os autores propõem ainda a injeção de gás no pipeline ou riser como um método para aliviar as grandes variações de pressão que ocorrem na intermitência severa.

\subsection{Taitel (1986)}

Taitel (1986) afirma que a intermitência severa é um padrão de escoamento instável por estar associada com grandes e abruptas flutuações de pressão e de vazão dos fluidos. Esse padrão de escoamento ocorre tipicamente quando são observadas baixas vazões de gás e líquido.

O autor descreve o fenômeno de maneira semelhante a Schmidt, Doty e Dutta-Roy (1985), fornecendo ilustrações para cada estágio da intermitência severa (ver Fig. 1.2). No entanto, usa terminologia própria para os estágios, chamados pelo autor de: (a) formação da golfada (slug formation), (b) movimentação da golfada para dentro do separador (slug movement into separator), (c) expulsão de gás (blowout) e (d) queda de líquido (liquid fallback). Já a Fig. 1.2(e) apresenta o sistema pipeline-riser em uma situação em que a intermitência severa não ocorre e o estado permanente é alcançado.

Taitel apresenta um critério de estabilidade para sistemas pipeline-riser que indica condições segundo as quais observa-se a ocorrência ou não do fenômeno de intermitência severa. O critério é obtido a partir de um balanço de forças que agem sobre o líquido contido no riser durante o início da fase de expulsão do gás. A compressibilidade do gás é responsável pela força que impulsiona o líquido para fora do pipeline e a pressão no separador (localizado no topo do riser) somada à pressão exercida pela coluna de líquido no riser age no sentido contrário a tal movimento. Se a força devido à compressão do gás for menor que a força devido à pressão no separador somada à pressão hidrostática no instante em que o gás penetra no riser, o sistema será estável. Logo, o aumento da pressão no separador tem efeito estabilizante. 
O critério de estabilidade é dado pela seguinte desigualdade:

$$
P_{\text {sep }}>\rho_{l} g(1-\alpha)\left[\left(\alpha_{p} / \alpha^{\prime}\right) L-H\right]
$$

onde $P_{\text {sep }}$ é a pressão no separador, $\rho_{l}$ é a massa específica do líquido, $g$ é a aceleração da gravidade, $\alpha$ é a fração de vazio média no riser, $\alpha_{p}$ é a fração de vazio na região estratificada do pipeline, $\alpha$ ' é a fração de vazio da frente de gás que penetra no líquido contido no riser, $L$ é o comprimento do pipeline e $H$ é a altura do riser vertical.

O critério sugere que ao se aumentar a pressão no separador até o nível em que a desigualdade dada pela Eq. (2.1) seja satisfeita, a intermitência severa será eliminada e o estado permanente será alcançado. Também a partir da Eq. (2.1) é possível concluir que o sistema se torna menos estável quanto maior o comprimento do pipeline e mais estável quanto maior a altura do riser.

Também é possível concluir que a operação em estado permanente é mais estável que o início da fase de expulsão de gás do ciclo de intermitência. No estado permanente há gás no riser, fazendo com que a fração de vazio média no riser $\alpha$ seja maior que zero, exigindo menores pressões no separador para que o critério seja satisfeito.

Taitel (1986) também procura explicar o efeito estabilizante observado por Schmidt, Brill e Beggs (1979) ao adicionar uma válvula reguladora (choke valve) no topo do riser, antes do separador. Para isso desenvolve novo critério de estabilidade que contempla a inserção da válvula reguladora no sistema.

Os resultados obtidos são comparados com os resultados experimentais obtidos por Schmidt, Brill e Beggs (1980). Apesar do separador não estar localizado no topo do riser nos experimentos de Schmidt, Brill e Beggs como considera o modelo de Taitel, a formulação obtida por Taitel permite obter com sucesso a região - em um gráfico que relaciona a velocidade superficial de líquido e a velocidade superficial de gás - em que se observa a ocorrência da intermitência severa do tipo 1 .

\subsection{Pots, Bromilow e Konijn (1987)}

Pots, Bromilow e Konijn (1987) afirmam que, para a ocorrência da intermitência severa, o fluxo de gás na base do riser deve ser completamente inibido durante o estágio de produção da golfada. Para isso, a taxa de aumento da pressão hidrostática no riser, resultante do crescimento da golfada de líquido, deve exceder a taxa de aumento da pressão do gás no pipeline. Sob tais 
condições, o riser preenche-se completamente de líquido antes que a pressão do gás seja capaz de expulsar a frente de acúmulo de líquido do pipeline. Desprezando a transferência de massa entre as fases, assumindo que a massa específica do gás é desprezível frente a massa específica do líquido, considerando um riser vertical e negligenciando a queda de líquido no riser (estágio do ciclo de intermitência severa determinado por Taitel (1986)), pode-se expressar a razão entre as taxas de aumento de pressão como segue:

$$
\Pi_{S S}=\frac{\Lambda Z_{c} T}{\alpha_{p} L \gamma_{g} M_{a} g} \frac{\dot{m}_{g}}{\dot{m}_{l}}
$$

onde $\gamma_{g}=M_{g} / M_{a}$ é a densidade relativa do gás, $M_{g}$ e $M_{a}=28,966 \mathrm{~g} / \mathrm{mol}$ são respectivamente as massas molares do gás e do ar, $Z_{c}$ é o fator de compressibilidade do gás, $\Lambda=$ $8314 \mathrm{~J} / \mathrm{K} \mathrm{kmol} \mathrm{é} \mathrm{a} \mathrm{constante} \mathrm{universal} \mathrm{dos} \mathrm{gases,} T$ é a temperatura, $\alpha_{p}$ é a fração de vazio no pipeline, $L$ é o comprimento do pipeline, $\dot{m}_{g}$ é a vazão mássica de gás e $\dot{m}_{l}$ é a vazão mássica de líquido.

Se $\Pi_{S S}<1$, então a intermitência severa pode ocorrer. O parâmetro $\Pi_{S S}$ é utilizado também para indicar a intensidade da intermitência severa, sendo que quanto menor o valor do parâmetro, maior será o comprimento da golfada de líquido.

De acordo com a Eq. (2.2), o parâmetro depende principalmente da razão de vazões mássicas gás-líquido, do comprimento do pipeline e da fração de vazio no tubo. Aumentando-se a contrapressão (backpressure), menores frações de vazio no pipeline seriam obtidas, fazendo com que a intermitência severa seja eliminada. No entanto, segundo Schmidt, Doty e DuttaRoy (1985), um aumento substancial na contrapressão é necessário para obter tal efeito, fazendo com que a produção decresça.

Os autores também investigam as afirmações de Schmidt, Doty e Dutta-Roy (1985) com relação à eliminação da intermitência severa, indicando que a mesma deixa de ocorrer antes que a estabilidade do riser torne-se importante. Sendo assim, para a eliminação da intermitência severa, basta que a padrão de escoamento no pipeline deixe de ser estratificado ou que se verifique $\Pi_{S S} \geq 1$.

Experimentos foram realizados utilizando um pipeline de $30 \mathrm{~m}$ conectado a um acumulador de gás (gas buffer) para simulação de maiores comprimentos. O riser possui comprimento de $15 \mathrm{~m}$ e ambos os tubos tem diâmetro de $50 \mathrm{~mm}$. Os fluidos utilizados são ar e água ou ar e uma mistura água-glicerina.

As diferentes viscosidades obtidas a partir de misturas água-glicerina não mostraram ter influência sobre a ocorrência da intermitência severa. No entanto, quanto maior a viscosi- 
dade do líquido, menor a velocidade de chegada no separador da golfada.

A influência da injeção de gás (gas-lift) sobre o fenômeno de intermitência severa foi investigada, concluindo-se que injetar gás ao longo do pipeline tem o mesmo efeito que a adição da injeção de gás na entrada. Já a injeção de gás na base do riser faz com que a golfada do líquido seja fragmentada, separando-a em pedaços que alcançam menores velocidades de chegada no separador. A completa eliminação da golfada severa exige injeções de gás em volumes não praticáveis em condições reais; para injeções de gás na base do riser de $300 \%$ da vazão de gás de entrada foi ainda observado o ciclo característico da intermitência severa, pois os mecanismos básicos da intermitência severa (bloqueio da vazão de gás livre e $\Pi_{S S}<1$ ) dependem mais das condições no pipeline do que no riser.

\subsection{Fabre et al. (1990)}

Fabre et al. (1990) apresentam investigações experimentais e simulações numéricas a fim de explicar a ocorrência de instabilidades no escoamento em sistemas pipeline-riser.

Os experimentos contemplam pipelines com geometria ascendente, descendente e horizontal. Devido ao fato da fração de vazio média no riser apresentar grandes variações causadas pelas mudanças no padrão de escoamento e pelas variações no nível de líquido, a pressão na base do riser, que é controlada principalmente pelo peso hidrostático da coluna de líquido, é muito sensível. Portanto, utiliza-se este último parâmetro para a apresentação dos resultados obtidos com os experimentos e simulações.

A partir dos experimentos foi observado, como comportamento universal, que o aumento da vazão de gás implica na diminuição do período das oscilações de pressão na base do riser, assim como na diminuição da amplitude das oscilações. Isso faz com que, para vazões de gás crescentes, o escoamento deixe de caracterizar a intermitência severa e possua um padrão de escoamento em golfadas ou anular.

Também foi observado a partir dos experimentos que não é necessária uma inclinação descendente do pipeline para que um ciclo instável seja verificado. Em um pipeline horizontal é possível a ocorrência da intermitência severa; entretanto, não se observa a fase de produção da golfada (fase $i i$ na Fig. 2.1). Já em um pipeline descendente, tem-se a ocorrência da intermitência severa na qual se observa a fase de produção da golfada, o que faz com que a pressão máxima seja alcançada. Para um sistema com pipeline ascendente, apenas o padrão de escoamento em golfadas é observado. 
Também foi observado que uma condição necessária para a ocorrência da intermitência severa é que o pipeline apresente padrão de escoamento estratificado.

Um modelo foi desenvolvido com as seguintes características: massa específica do gás calculada a partir de uma equação de estado assumindo um processo isotérmico; escoamento homogêneo no pipeline; variáveis dependentes do tempo e da posição ao longo do riser; forças de atrito e de inércia são desprezadas; não há transferência de massa entre as fases.

Da comparação entre os resultados experimentais e as simulações observou-se que o modelo não apresenta bons resultados para situações em que se verifica a ocorrência da intermitência severa. A explicação para a deficiência do modelo está no uso do modelo homogêneo para o pipeline. Isso implica na hipótese de contínua penetração de gás no riser, o que faz com que a frente de acúmulo de líquido no pipeline e, portanto, a existência de uma interface monofásica e bifásica, sejam desprezados.

\subsection{Taitel et al. (1990)}

Taitel (1986) ponderou que se a coluna de líquido no riser é instável, o que significa não obediência ao critério dado pela Eq. (2.1), haverá uma expulsão violenta de gás e um processo cíclico iniciar-se-á, chamado intermitência severa. Já se a coluna de líquido no riser é estável, o estado permanente resultará.

Em seu novo trabalho (TAITEL et al., 1990), resultados experimentais evidenciam que mesmo o sistema sendo estável, há a tendência de a fração de vazio oscilar durante a penetração de gás no riser. Este processo oscilatório pode ser amortecido e resultar no estado permanente, mas também pode continuar indefinidamente e resultar em um ciclo que se assemelha à intermitência severa; entretanto, a expulsão violenta de gás não é observada.

Portanto, três diferentes possibilidades podem ocorrer em decorrência da penetração de gás na coluna de líquido considerada estável pelo critério de Taitel (1986):

- Penetração de gás que leva à oscilação, resultando em um estado permanente estável. Nesse caso, a vazão de gás na entrada do riser é sempre positiva.

- Penetração de gás que leva à operação cíclica sem retorno de líquido. Nesse caso, o líquido acumula-se na base do riser e bloqueia a passagem de gás proveniente do pipeline. A pressão do gás no pipeline aumenta até que a interface de líquido que havia se acumulado no pipeline recue e alcance a base do riser, resultando na penetração do gás no 
riser e o reinício do ciclo. A vazão de líquido é grande o suficiente para manter o nível de líquido no topo do riser, evitando seu recuo.

- Penetração de gás que leva à operação cíclica com retorno de líquido. Nesse caso, após o acúmulo de líquido na base do riser e consequente bloqueio da passagem de gás, o gás que já estava no riser propaga-se para o topo. A baixa vazão de líquido favorece o acúmulo desse gás no topo do riser, resultando em um nível de líquido variável.

Um modelo matemático foi desenvolvido para a simulação da dinâmica descrita e tem as seguintes características: modelo dominado pela gravidade; modelo de drift-flux é usado para o cálculo da velocidade de ascensão das bolhas no riser; a fração de vazio no pipeline é considerada constante; uma massa específica média do gás é considerada para todo o riser (constante no espaço, mas variável no tempo); a fração de vazio é propagada segundo a velocidade do gás; não há transferência de massa entre as fases.

A programação relacionada ao modelo baseou-se em um esquema numérico lagrangeano explícito. Apesar da boa concordância entre os resultados experimentais e aqueles obtidos por meio das simulações, o modelo apresenta problemas de convergência nas proximidades da fronteira de estabilidade no espaço de parâmetros.

\subsection{Sarica e Shoham (1991)}

Sarica e Shoham (1991) apresentam um modelo simplificado para um sistema pipeline-riser vertical. Nesse trabalho, o modelo de Fabre et al. (1990) é modificado para incluir descontinuidades no escoamento durante a fase de formação da golfada.

O modelo possui as seguintes características: escoamento unidimensional dominado pela gravidade; variáveis no riser são função do espaço e do tempo, enquanto no pipeline são função apenas do tempo; modelo de drift-flux é usada para o escoamento no riser; o cálculo da fração de vazio no pipeline em regime estratificado é baseado no conceito de equilíbrio local; e não se considera a transferência de massa entre as fases.

A partir das equações da continuidade para o líquido e o gás e da equação da quantidade de movimento para a mistura no riser, é possível definir um sistema de equações diferenciais parciais. Esse sistema é representado na forma matricial, sendo as matrizes de coeficientes utilizadas para calcular os autovalores relacionados com o sistema de equações. Esses autovalores, chamados de características do sistema, resultam em números reais, o que assegura que o modelo é bem-posto. 
Os resultados obtidos com simulações usando o modelo desenvolvido são comparados aos resultados experimentais obtidos por Fabre et al. (1990), Vierkandt (1988) e Jansen (1990) e também são comparados com os resultados apresentados pelo modelo de Taitel (1986). O modelo de Sarica e Shoham apresentou resultados mais próximos dos obtidos por meio de experimentos que o modelo de Taitel. Entretanto, observou-se um erro sistemático nos períodos da intermitência severa.

A partir da comparação com os dados experimentais de Fabre et al., foi observado que os valores de velocidade superficial de gás e líquido de determinado experimento resultaram em um ponto que situava-se fora da região determinada pelo critério de Bøe (1981), que define a região em que ocorre a intermitência severa. O experimento mostrou a existência de um comportamento cíclico típico da intermitência severa. Isso evidencia que até para geometrias simples como as de risers verticais, não existe um critério de estabilidade satisfatório.

Também foi observado que o modelo apresenta não-convergência para pontos de operação abaixo da fronteira de estabilidade proposta por Taitel (1986), resultando em diferentes resultados para diferentes passos temporais assumidos. Os autores justificam a não-convergência pelo fato de, abaixo da fronteira de estabilidade, termos inerciais adquirirem maior importância frente a termos gravitacionais na equação de quantidade de movimento. No entanto, Baliño, Burr e Nemoto (2010) mostraram que a não-convergência não está relacionada ao modelo matemático proposto por Sarica e Shoham, mas sim ao esquema de solução numérica empregado.

\subsection{Tin e Sarshar (1993)}

Tin e Sarshar desenvolveram um modelo para a predição de flutuações de pressão e vazão de líquido durante o ciclo de intermitência severa para risers em geometria catenária e lazy-s.

Resultados experimentais foram obtidos utilizando um pipeline com comprimento de $60 \mathrm{~m}$ e um riser flexível com altura de $33 \mathrm{~m}$, ambos os tubos com diâmetro de 2". Os fluidos utilizados foram água e ar. Os valores preditos pelo modelo apresentaram boa concordância com os resultados experimentais para o riser em geometria catenária, mas para o riser em geometria lazy-s grandes erros foram observados.

Com base nas diferentes configurações do escoamento no sistema pipeline-riser após o ciclo limite ter sido alcançado, os seguintes tipos de intermitência severa foram definidos:

- Intermitência severa 1 (SS1): o comprimento da golfada de líquido é maior ou igual à altura do riser; a máxima pressão no pipeline é igual à pressão hidrostática da coluna de 
líquido no riser; o aumento da pressão no pipeline por unidade de tempo é menor que o aumento da pressão hidrostática no riser por unidade de tempo, no estágio de produção da golfada.

- Intermitência severa 2 (SS2): o comprimento da golfada é menor que a altura do riser; há penetração intermitente de bolhas durante o estágio de produção da golfada.

- Intermitência severa 3 (SS3): visualmente o escoamento no pipeline e no riser assemelhase ao escoamento em golfadas; a pressão, comprimento e frequência das golfadas revelam variações cíclicas.

- Oscilação (OSC): são observadas flutuações cíclicas de pressão, sem expulsão violenta de gás.

\subsection{Baliño, Burr e Nemoto (2010)}

Baliño, Burr e Nemoto (2010) desenvolveram um modelo de intermitência severa aplicável a sistemas pipeline-riser com inclinação variável. As características principais do modelos são: escoamento unidimensional dominado pela gravidade no pipeline; escoamento unidimensional dominado pela gravidade e, em menor medida, pelo atrito no riser; capacidade de descrever descontinuidades no escoamento (acúmulo de líquido no pipeline, nível de líquido no riser e ondas de fração de vazio no riser); modelo de drift-flux para levar em conta o escorregamento entre as fases; e despreza-se a transferência de massa entre as fases.

Wordsworth et al. (1998) apresenta os resultados de experimentos realizados com o intuito de investigar a iniciação da intermitência severa em sistemas pipeline-riser. O pipeline possui comprimento de $57,4 \mathrm{~m}$, diâmetro de 2 " e ângulo de inclinação de $-2^{\circ}$ a partir da horizontal. O riser tem formato de catenária com $9,9 \mathrm{~m}$ de altura e mesmo diâmetro que o pipeline. Ar e água foram utilizados, com pressões entre 1 e 15 barg, sendo que a intermitência severa foi observada experimentalmente para pressões de até 4 barg.

Utilizando os dados geométricos da bancada e os dados termodinâmicos correspondentes aos fluidos água e ar de Wordsworth et al. (1998), um conjunto de simulações foi realizado. A Fig. 2.2 mostra o resultado da simulação do transiente de pressão na base do riser para valores constantes de vazão de gás e líquido e de pressão no separador; neste caso a vazão volumétrica de líquido na condição padrão é dada por $Q_{l 0}=1,2984 \cdot 10^{-3} \mathrm{~m}^{3} / \mathrm{s}$, a vazão mássica de gás na condição padrão é dada por $\dot{m}_{g 0}=1,0 \cdot 10^{-4} \mathrm{~kg} / \mathrm{s}$ e a pressão no separador é dada por $P_{\text {sep }}=2$ bara . Como condição inicial para o programa computacional transiente foi 


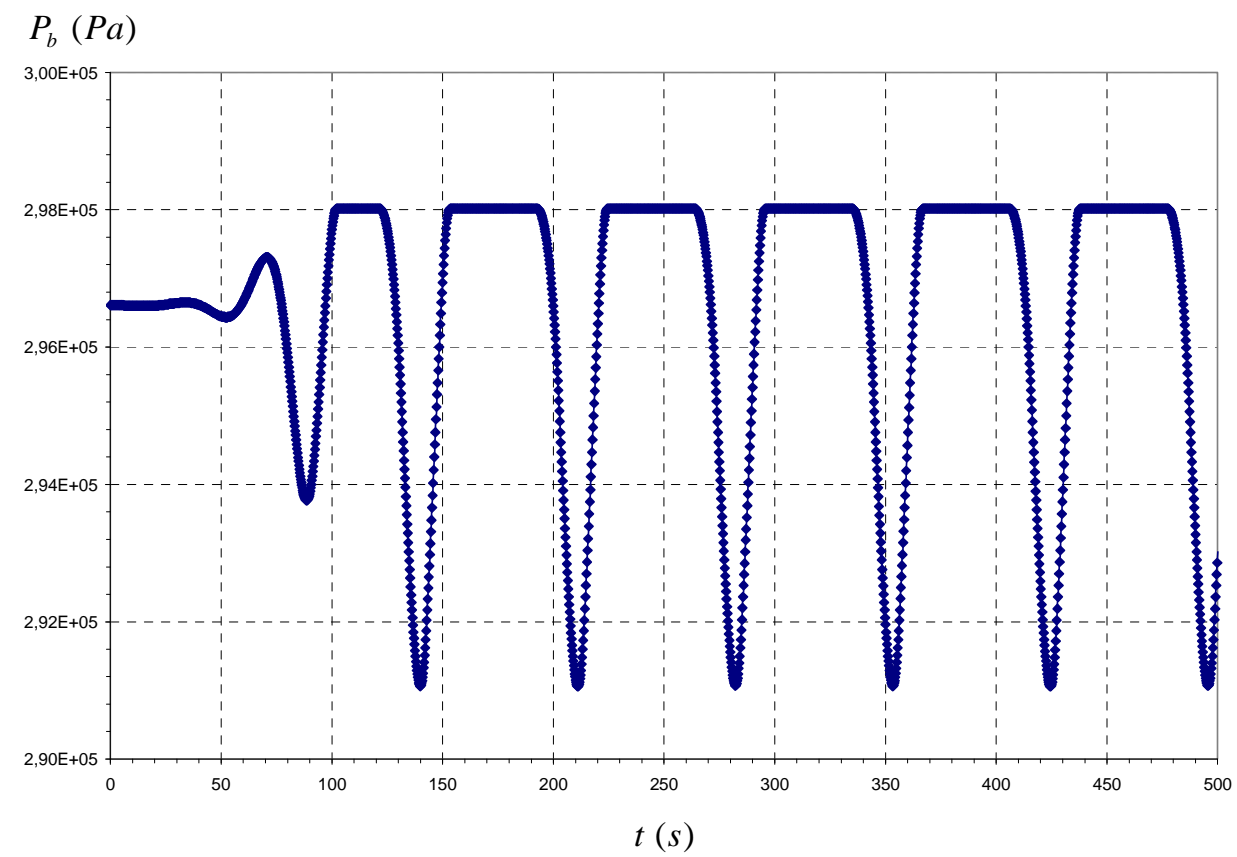

Figura 2.2: Transiente de pressão na base do riser. Reproduzido de Baliño, Burr e Nemoto (2010).

imposta a solução de estado estacionário. Observa-se que, para o caso apresentado, o sistema desestabiliza-se e atinge um ciclo limite.

A partir dos resultados das simulações é possível prever a ocorrência da intermitência severa, assim como é possível prever se o sistema atingirá o estado permanente, considerado como estável. Na Fig. 2.3 apresenta-se o mapa de estabilidade correspondente à pressão no separador $P_{s e p}=2$ bara. A abscissa é dada pela velocidade superficial de gás $j_{g 0}$ e a ordenada é dada pela velocidade superficial de líquido $j_{l 0}$, ambas na condição padrão. A fronteira de estabilidade, obtida por meio de simulações numéricas, divide o plano em duas regiões. A região interna à curva de fronteira é caracterizada como a região instável, na qual a intermitência severa do tipo 1 (SS1), do tipo 2 (SS2) e do tipo 3 (SS3) ou outros processos oscilatórios (OSC) ocorrem. Por sua vez, a região externa à curva de fronteira define a região estável, na qual padrões de escoamento como escoamento em golfadas (SF) e em bolhas (BF) são observados. Na mesma figura são mostrados os padrões de escoamento obtidos experimentalmente por Wordsworth et al. (1998), considerando os valores médios das vazões de líquido e de gás. Note que a curva numérica é capaz de predizer a região de estabilidade para os diferentes tipos de intermitência severa relatados experimentalmente.

Embora do ponto de vista prático seja importante a operação na região estável com uma boa margem de segurança, constatou-se que é importante estudar os diferentes tipos de instabilidades, já que sua periculosidade dependerá dos períodos e amplitudes das flutuações 


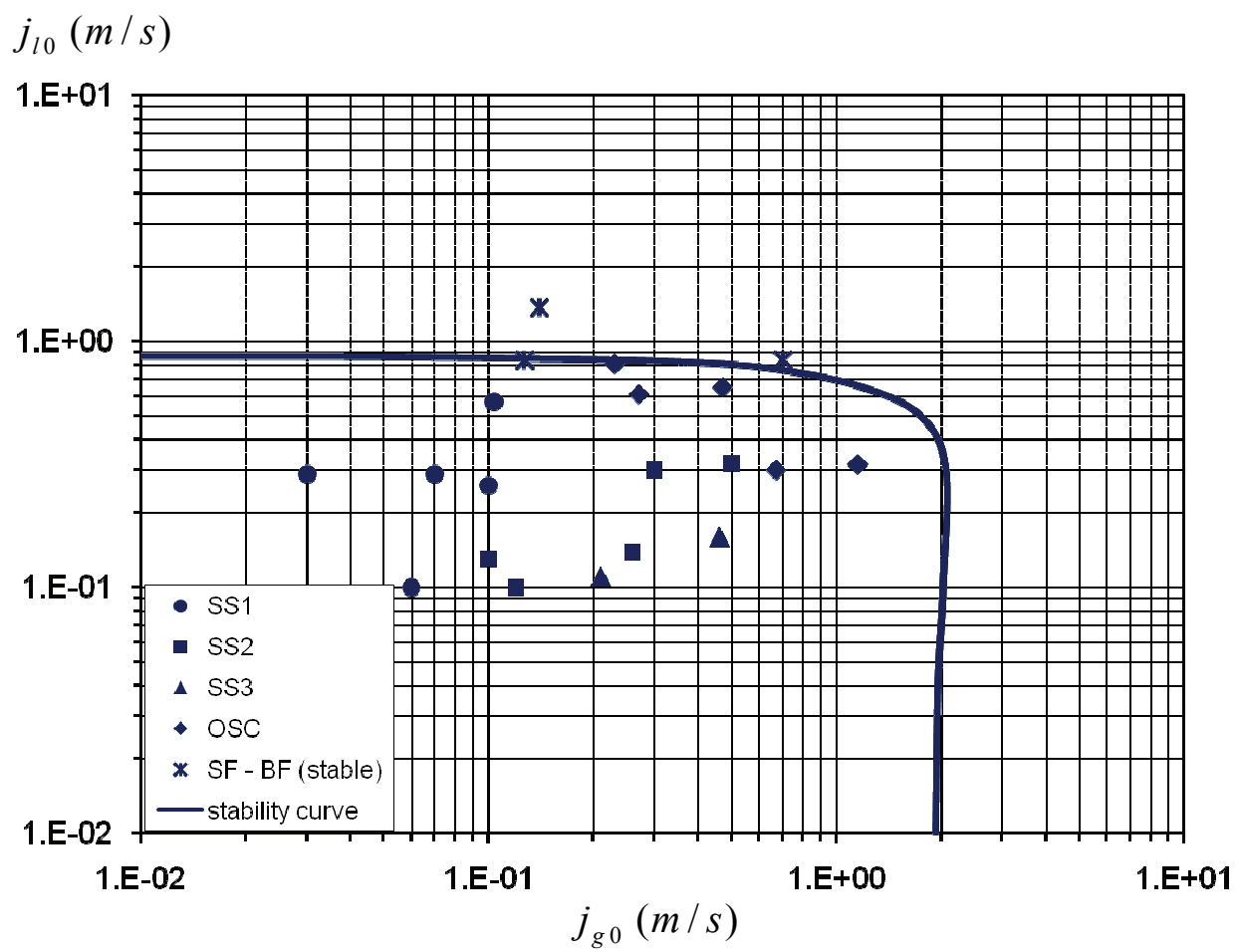

Figura 2.3: Mapa de estabilidade para $P_{\text {sep }}=2$ bar. Reproduzido de Baliño, Burr e Nemoto (2010).

das variáveis envolvidas.

Ainda com base nos resultados das simulações, foi construído o mapa de tipos de intermitência severa, apresentado na Fig. 2.4, para uma pressão de separação de $P_{\text {sep }}=2$ bara. A parte interior à curva de fronteira definida por SS1-SS2 define a região em que ocorre a intermitência severa do tipo 1. A região delimitada pelas curvas SS1-SS2 e SS2-SS3 define a região em que ocorre a intermitência severa do tipo 2. Por sua vez, a região delimitada pela curva SS2-SS3 e pela fronteira de estabilidade define a região em que ocorre a intermitência severa do tipo 3.

Pode-se depreender da Fig. 2.4 que a região em que ocorre a intermitência severa do tipo 3 se estende numa ampla faixa de vazões de gás (dentro da região instável), para pequenas vazões de líquido. Isto significa que um sistema real poderia eventualmente continuar operando na região instável, com flutuações aceitáveis de pressão e vazões, dependendo da geometria e das características do separador. 
$j_{l 0}(\mathrm{~m} / \mathrm{s})$

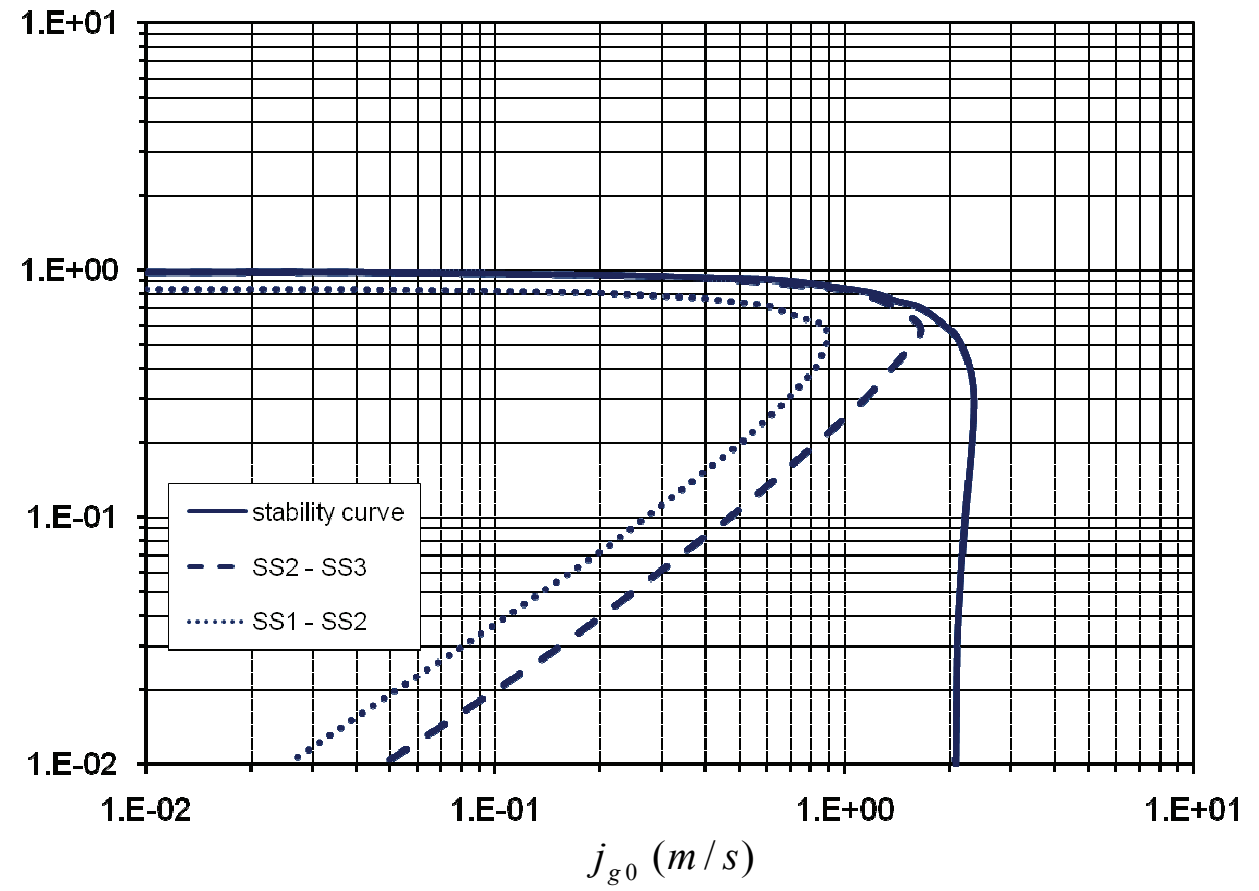

Figura 2.4: Mapa de tipos de intermitência severa para $P_{\text {sep }}=2$ bar. Reproduzido de Baliño, Burr e Nemoto (2010). 


\section{MODELO MATEMÁTICO}

Neste capítulo são apresentadas as equações de governo utilizadas para modelar os subsistemas riser e pipeline, assim como hipóteses e simplificações assumidas. As variáveis de estado são determinadas e as equações de estado são desenvolvidas. O estado estacionário, ou de equilíbrio, é calculado por meio do cancelamento das derivadas temporais nas equações de conservação e as equações que o determinam são apresentadas. Por fim, as propriedades termodinâmicas e a aproximação de black-oil são introduzidas de modo a tornar o modelo completo.

\subsection{Riser}

O modelo do riser considera escoamento unidimensional, trifásico e isotérmico. Equações da continuidade para o gás, óleo e água e uma equação de conservação da quantidade de movimento simplificada (sem os termos de inércia) para a mistura são as equações governantes. Considera-se que óleo e água possuam a mesma velocidade e estejam homogeneizados. A hipótese de fases homogeneizadas baseia-se no fato de que as massas específicas das fases possuem a mesma ordem de grandeza. O escorregamento entre a fase líquida e gasosa é levado em conta por meio do modelo de drift-flux. A transferência de massa entre o gás e o óleo é calculada por meio da aproximação de black-oil. Assume-se que as fases líquidas e gasosa sejam compressíveis e que o gás se comporte como um gás real. A solubilidade de gás e vaporização são desprezados para a água. As variáveis de estado para o modelo do riser são a fração de vazio $\alpha$, a fração volumétrica de óleo $\alpha_{o}$, a pressão $P$ e a velocidade superficial total $j$. A definição das variáveis de estado pode ser conferida no Apêndice A.1.

\subsubsection{Geometria do riser}

Posto que o escoamento será considerado unidimensional, é suficiente que a geometria seja caracterizada pela linha elástica do riser. Desconsidera-se a influência do escoamento externo e do escoamento interno sobre a geometria do tubo. 


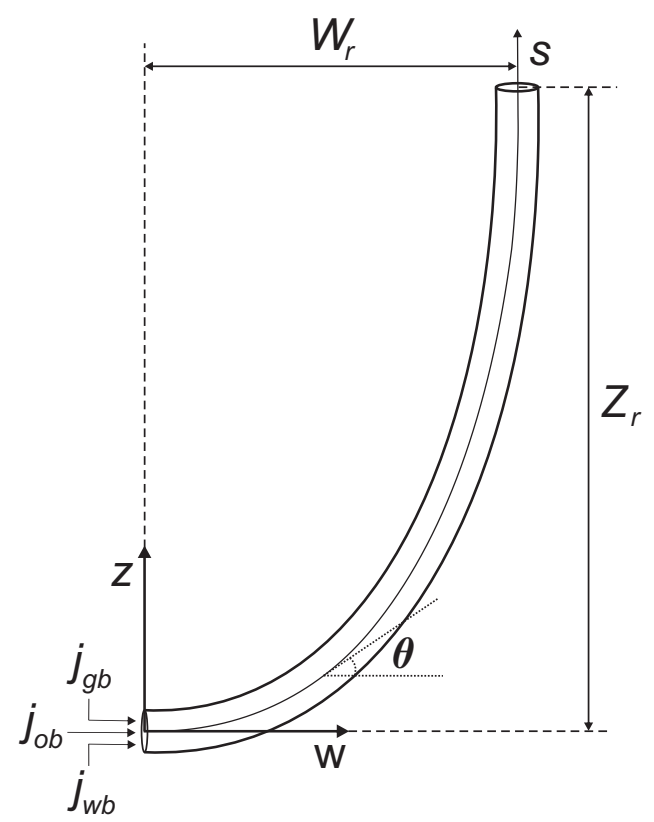

Figura 3.1: Geometria catenária do riser.

Para um riser em 'catenária', a geometria é completamente caracterizada conhecendose as coordenadas $W_{r}$ e $Z_{r}$, correspondentes à abscissa e à altura do topo do riser (ver Fig. 3.1). Assume-se que o ângulo de inclinação na base seja zero.

A altura local $z$ de um ponto pertencente à catenária é dada por:

$$
z=\varphi\left[\cosh \left(\frac{w}{\varphi}\right)-1\right]
$$

onde o comprimento suspenso $\varphi$ é calculado por meio da seguinte equação transcendental:

$$
Z_{r}=\varphi\left[\cosh \left(\frac{W_{r}}{\varphi}\right)-1\right]
$$

A posição local $s$ ao longo da catenária resulta:

$$
s=\varphi \sinh \left(\frac{w}{\varphi}\right)
$$

E o ângulo de inclinação local $\theta$ é dado por:

$$
\theta=\arctan \left[\sinh \left(\frac{w}{\varphi}\right)\right]
$$

Conhecendo a posição $s$, a abscissa local $w$ pode ser calculada a partir da Eq. (3.3):

$$
w=\varphi \operatorname{arcsinh}\left(\frac{s}{\varphi}\right)
$$




\subsubsection{Equações de conservação}

Como demonstrado no Apêndice A.3, as equações da continuidade para as fases gás, óleo e água são dadas por:

$$
\begin{gathered}
\frac{\partial}{\partial t}\left(\rho_{g} \alpha\right)+\frac{\partial}{\partial s}\left(\rho_{g} j_{g}\right)=\Gamma \\
\frac{\partial}{\partial t}\left(\rho_{o} \alpha_{o}\right)+\frac{\partial}{\partial s}\left(\rho_{o} j_{o}\right)=-\Gamma \\
\frac{\partial}{\partial t}\left(\rho_{w} \alpha_{w}\right)+\frac{\partial}{\partial s}\left(\rho_{w} j_{w}\right)=0
\end{gathered}
$$

onde $s$ é a coordenada ao longo da direção do fluxo (ver Fig. 3.1), $t$ é o tempo, $\rho_{g}, \rho_{o}$ e $\rho_{w}$ são as massas específicas das fases (correspondentemente gás, óleo e água), $j_{g}, j_{o}, j_{w}$ são as velocidades superficiais, $\alpha, \alpha_{o}$ e $\alpha_{w}$ são as frações volumétricas e $\Gamma$ é a taxa temporal de massa de gás, por unidade de volume da mistura, que deixa a solução e é adicionada ao gás livre (ver Seção 3.1.3.6).

Na maioria dos transientes que ocorrem no transporte de óleo e gás, por exemplo na intermitência severa, a resposta do sistema revela-se relativamente lenta, o que faz com que ondas de pressão não tenham um efeito determinante na iniciação e transporte de ondas de continuidade. Ondas de continuidade (continuity waves) ocorrem sempre que há relação entre vazão (ou velocidade superficial) e concentração (ou fração volumétrica): um valor em estado permanente propaga-se para outro valor sem que estejam presentes efeitos dinâmicos de inércia ou quantidade de movimento (WALLIS, 1969).

No modelo NPW, ou no-pressure-wave (MASELLA et al., 1998), ondas acústicas são desprezadas ao se descartar os termos de inércia na equação de quantidade de movimento, resultando na seguinte relação algébrica para o gradiente de pressão:

$$
\begin{gathered}
\frac{\partial P}{\partial s}=-\frac{4 \tau_{w}}{D}+\rho_{m} g_{s} \\
\rho_{m}=\rho_{g} \alpha+\rho_{o} \alpha_{o}+\rho_{w} \alpha_{w}
\end{gathered}
$$

onde $P$ é a pressão, $\rho_{m}$ é a massa específica da mistura, $D$ é o diâmetro do tubo, $g_{s}$ é a componente da gravidade na direção $s$ e $\tau_{w}$ é a tensão de cisalhamento média na parede do tubo. As frações volumétricas estão relacionadas de acordo com a seguinte expressão: 


$$
\alpha+\alpha_{o}+\alpha_{w}=1
$$

\subsubsection{Leis de fechamento}

De maneira a fechar matematicamente o problema, algumas simplificações devem ser realizadas.

\subsubsection{Homogeneização das fases líquidas}

A hipótese de escoamento homogêneo para as fases água e óleo faz com que a velocidade da água $u_{w}$ e a velocidade do óleo $u_{o}$ sejam idênticas e representadas pela velocidade da fase líquida, ou seja, $u_{l}=u_{w}=u_{o}$.

Assumindo escoamento homogêneo para as fases líquidas, obtemos:

$$
\begin{gathered}
j_{o}=j_{l} \frac{\alpha_{o}}{1-\alpha} \\
j_{w}=j_{l} \frac{\alpha_{w}}{1-\alpha} \\
j_{l}=j_{o}+j_{w}=u_{l}(1-\alpha)
\end{gathered}
$$

onde $j_{l}$ e $u_{l}$ são a velocidade superficial e a velocidade da fase líquida (mistura de óleo e água), respectivamente.

\subsubsection{Tensão de cisalhamento na parede}

Pots, Bromilow e Konijn (1987) mostraram que a viscosidade tem pouca influência sobre o fenômeno de intermitência severa. Portanto, as forças viscosas tem menor relevância frente à força gravitacional e de compressão do gás. Desse modo, a tensão de cisalhamento na parede é estimada usando o modelo homogêneo e a definição de fator de atrito de Fanning, resultando a seguinte relação:

$$
\tau_{w}=\frac{1}{2} f_{m} \rho_{m} j|j|
$$


onde $j$ é a velocidade superficial total e $f_{m}$ é o fator de atrito para a mistura, definido como:

$$
f_{m}=f\left(R e_{m}, \frac{\epsilon}{D}\right)
$$

onde $f$ é o fator de atrito de Fanning, $R e_{m}$ é o número de Reynolds para a mistura e $\epsilon$ é a rugosidade do tubo.

O número de Reynolds para a mistura é calculado como segue:

$$
R e_{m}=\frac{\rho_{m} D|j|}{\mu_{m}}
$$

onde $\mu_{m}$ é a viscosidade da mistura, definida como:

$$
\mu_{m}=\mu_{g} \alpha+\mu_{o} \alpha_{o}+\mu_{w} \alpha_{w}
$$

onde $\mu_{g}, \mu_{o}$ e $\mu_{w}$ são, respectivamente, as viscosidades do gás, óleo e água.

A velocidade superficial total é dada por (ver Apêndice A):

$$
j=j_{g}+j_{o}+j_{w}
$$

Com relação ao fator de atrito de Fanning $f$, a expressão analítica $\left(f=16 / \operatorname{Re}_{m}\right)$ é utilizada para escoamento laminar $\left(R e_{m}<2000\right)$, enquanto a correlação de Chen (1979) é usada para escoamento turbulento $\left(R e_{m}>2300\right)$; para números de Reynolds intermediários, é feita uma interpolação linear.

A correlação de Chen para o cálculo do fator de atrito de Fanning é apresentada abaixo:

$$
\begin{gathered}
f\left(R e, \frac{\epsilon}{D}\right)=\left\langle-4 \log _{10}\left\{\frac{1}{3,7065} \frac{\epsilon}{D}\right.\right. \\
\left.\left.-\frac{5,0452}{R e} \log _{10}\left[\frac{1}{2,8257}\left(\frac{\epsilon}{D}\right)^{1,1098}+\frac{5,8506}{R e^{0,8981}}\right]\right\}\right\rangle^{-2}
\end{gathered}
$$

\subsubsection{Gás real}

Devido às altas pressões envolvidas no fenômeno estudado, a relação constitutiva para o gás é dada por:

$$
\rho_{g}=\frac{\gamma_{g} M_{a}}{\Lambda T} \frac{P}{Z_{c}}
$$


onde $\gamma_{g}=M_{g} / M_{a}$ é a densidade relativa do gás, $M_{g}$ e $M_{a}=28,966 \mathrm{~g} / \mathrm{mol}$ são respectivamente as massas molares do gás e do ar, $Z_{c}$ é o fator de compressibilidade do gás (dependente da pressão, temperatura e composição do gás), $\Lambda=8,314 \mathrm{~m}^{2} \mathrm{~s}^{-2} K^{-1}$ é a constante universal dos gases e $T$ é a temperatura.

\subsubsection{Escorregamento entre as fases líquida e gasosa}

As velocidades superficiais para as fases líquida e gasosa são determinadas pelo modelo de drift-flux, proposto por Zuber e Findlay (1965):

$$
\begin{gathered}
\frac{j_{g}}{\alpha}=C_{d} j+U_{d} \\
j_{l}=\left(1-\alpha C_{d}\right) j-\alpha U_{d}
\end{gathered}
$$

De uma forma geral, os parâmetros $C_{d}$ e $U_{d}$ podem depender da geometria local e das condições do escoamento (BENDIKSEN, 1984; CHEXAL et al., 1992), ou seja, $C_{d}=C_{d}(\alpha, P, j, \theta)$ e $U_{d}=U_{d}(\alpha, P, j, \theta)$.

A correlação de Bendiksen (1984), permite o cálculo dos parâmetros $C_{d}$ e $U_{d}$ como uma função da velocidade superficial total $j$ e da inclinação local $\theta$. Inicialmente deve-se calcular o número de Froude $\mathrm{Fr}_{j}$ como segue:

$$
F r_{j}=\frac{|j|}{\sqrt{g D}}
$$

E os parâmetros $C_{d}$ e $U_{d}$ são calculados da seguinte maneira:

- Para $F r_{j}<3,5$ :

$$
\begin{gathered}
C_{d}=1,05+0,15 \operatorname{sen} \theta \\
U_{d}=\sqrt{g D}(0,35 \operatorname{sen} \theta+0,54 \cos \theta)
\end{gathered}
$$

- $\operatorname{Para} F r_{j} \geq 3,5$ :

$$
C_{d}=1,2
$$




$$
U_{d}=0,35 \sqrt{g D} \operatorname{sen} \theta
$$

\subsubsection{Aproximação de black-oil}

Ao deixar o reservatório e avançar até a superfície, os fluidos experimentam um decréscimo na pressão e temperatura. Com isso, o equilíbrio entre as fases e suas propriedades são afetadas. Idealmente as propriedades deveriam ser medidas por meio de análises laboratoriais do tipo pressão-volume-temperatura (PVT) de uma amostra do fluido proveniente de um reservatório específico. Entretanto, na falta de propriedades medidas experimentalmente, pode-se estimá-las utilizando correlações.

A aproximação de black-oil permite estimar as propriedades termofísicas dos fluidos em função da pressão e temperatura a partir de uma quantia mínima de dados de entrada medidos na condição padrão $\left(1 \mathrm{~atm}\right.$ e $\left.60^{\circ} \mathrm{F}\right)$ : densidade relativa do gás $\gamma_{g 0}$, densidade API do óleo $\gamma_{A P I}$, massa específica da água $\rho_{w 0}$, razão gás-óleo $G O R$ e razão água-óleo $W O R$.

De acordo com a aproximação de black-oil (MCCAIN, 1990), a densidade relativa do gás não muda com variações de pressão e temperatura:

$$
\begin{gathered}
\gamma_{g} \cong \gamma_{g 0} \\
\gamma_{d g} \cong \gamma_{g 0}
\end{gathered}
$$

onde $\gamma_{g}$ é a densidade relativa do gás nas condições locais e $\gamma_{d g}$ é a densidade relativa do gás dissolvido no óleo.

A hipótese de densidade relativa constante significa que as concentrações (números moleculares) de diferentes hidrocarbonetos são constantes nas fases gasosa e líquida, de maneira que a mistura gás-óleo possa ser considerada como um pseudo-fluido ao invés de uma solução multicomponente. Essa aproximação é valida para fluidos com baixas razões gás-óleo $(G O R<$ $2000 s c f / S T B)$ e baixas densidades API $\left(\gamma_{A P I}<45\right)$. Em uma situação real, componentes mais leves vaporizam em maiores pressões e uma melhor representação do fenômeno poderia ser obtida com o modelo composicional.

Assim, as propriedades correspondentes às fases em condições locais podem ser estimadas com base em parâmetros na condição padrão e em um conjunto de correlações dependentes da pressão, temperatura e composição. As correlações serão consideradas como localmente 
e instantaneamente válidas.

\subsubsection{Termo de vaporização}

Da definição de fator de solubilidade de gás em óleo $R_{s}$, resulta:

$$
R_{s}=\frac{v_{d g 0}}{v_{o 0}}=\frac{m_{d g}}{\rho_{d g 0} v_{o 0}}
$$

onde $v_{d g 0}$ e $\rho_{d g 0}$ são, correspondentemente, o volume e a massa específica (na condição padrão) do gás dissolvido na condição local de temperatura e pressão, $m_{d g}$ é a massa de gás dissolvida na condição local de temperatura e pressão e $v_{o 0}$ é o volume de óleo na condição padrão. Não são consideradas a solubilidade do gás na água e a vaporização da água.

Como $v_{d g 0}$ e $\rho_{d g 0}$ são constantes e considerando que o processo de solubilização do gás no óleo seja independente da quantidade da fase gasosa, assim como que o óleo se desloque com a velocidade do líquido (ver Seção 3.1.3.1), a taxa temporal de absorção de massa de gás pela partícula de óleo é calculada pela expressão que segue:

$$
\frac{D_{l} m_{d g}}{D t}=\rho_{d g 0} v_{o 0} \frac{D_{l} R_{s}}{D t}=\rho_{d g 0} v_{o 0}\left(\frac{\partial R_{s}}{\partial t}+u_{l} \frac{\partial R_{s}}{\partial s}\right)
$$

onde o operador de derivada direcional é dado por:

$$
\frac{D_{l}}{D t}=\frac{\partial}{\partial t}+u_{l} \frac{\partial}{\partial s}
$$

O fator volume de formação de óleo $B_{o}$ é definido como:

$$
B_{o}=\frac{v_{o}}{v_{o 0}}
$$

onde $v_{o}$ é o volume de óleo na condição local de temperatura e pressão. Assim, a taxa temporal de massa de gás que deixa a solução e é adicionada ao gás livre por unidade de volume da mistura, chamada de $\Gamma$, é dada por:

$$
\Gamma=-\frac{1}{v_{o}} \frac{v_{o}}{v} \frac{D_{l} m_{d g}}{D t}=-\frac{\rho_{d g 0} \alpha_{o}}{B_{o}} \frac{D_{l} R_{s}}{D t}
$$

Vale observar que para $\Gamma>0$ devemos ter $\alpha_{o}>0$ (deve haver óleo para ocorrer vaporização), enquanto para $\Gamma<0$ devemos ter $\alpha>0$ (deve haver gás para ocorrer condensação). 


\subsubsection{Método das características e condições de compatibilidade}

Para um modelo descrever um fenômeno físico corretamente, ele deve ser matematicamente bem-posto (well-posed), ou seja, a solução deve existir, deve ser determinada de maneira única e deve depender de uma forma contínua das condições iniciais e de contorno (DREW; PASSMAN, 1999). Essa propriedade é particularmente importante em escoamentos multifásicos, para os quais equações diferenciais parciais de natureza hiperbólica podem ser obtidas; neste caso, para o sistema ser bem-posto, os valores característicos (autovalores ou velocidades de onda característica) devem ser reais. Nemoto, Baliño e Burr (2009) mostraram que os valores característicos do sistema de equações apresentado são dados por (ver Apêndice B.3):

$$
e_{1}=\frac{\partial j_{g}}{\partial \alpha} ; \quad e_{2}=\frac{j_{o}}{\alpha_{o}}=u_{l} ; e_{3}=\infty ; e_{4}=\infty
$$

Observe que quatro autovalores foram obtidos, dos quais dois são reais e outros dois resultam em $\infty$. Com base nisso, o modelo é qualificado como misto hiperbólico-parabólico.

Se os parâmetros $C_{d}$ e $U_{d}$ são independentes de $\alpha$, como na correlação desenvolvida por Bendiksen (1984), obtemos:

$$
\frac{\partial j_{g}}{\partial \alpha}=\frac{j_{g}}{\alpha}=u_{g}
$$

onde $u_{g}$ é a velocidade do gás.

Existem dois autovalores iguais a $\infty$, os quais estão relacionados à velocidade das ondas de pressão e à velocidade superficial total $j$. Essas variáveis são propagadas com uma velocidade infinita, o que significa que qualquer mudança em seus valores são sentidos pelo sistema todo instantaneamente.

Dois métodos são elegíveis para resolver numericamente o sistema de equações diferenciais parciais: o método das características (MC) e o método dos volume finitos (MVF).

Historicamente, o MC é utilizado para a investigação numérica da intermitência severa por se tratar de uma abordagem unidimensional (FABRE et al., 1990; SARICA; SHOHAM, 1991). Algumas vantagens do MC sobre o MVF para essa aplicação são: (a) o MC satisfaz naturalmente o critério de estabilidade de Courant, Friedrichs e Levy, critério CFL (TANNEHILL; ANDERSON; PLETCHER, 1997), já o MVF, quando resolvido de maneira explícita, deve passar por verificações para garantir a obediência ao critério CFL; (b) o uso do MC faz com que o sistema de equações diferenciais parciais no espaço e no tempo seja reduzido a um sistema de 
equações diferenciais direcionais, resolvido como um sistema de equações diferenciais ordinárias, diminuindo assim o número de derivadas a serem discretizadas, o que leva à diminuição do erro de truncamento associado. Já o uso do MVF exigiria a discretização das derivadas parciais espaciais e temporais separadamente, resultando num maior erro de truncamento; (c) o uso do MVF exige a discretização do domínio computacional em volumes de controle, procedimento complexo quando comparado ao MC, que necessita apenas da determinação do número de nós móveis, que acompanham a velocidade do gás e do líquido.

O MC torna-se de difícil aplicação quando a expressão analítica dos autovalores relacionados ao sistema de equações diferenciais parciais apresenta múltiplos termos e envolve grande número de variáveis. Isso ocorre, por exemplo, ao se considerar os termos inerciais na equação de conservação da quantidade de movimento, ou ao se considerar modelos de drift-flux para os quais os parâmetros $C_{d}$ e $U_{d}$ sejam dependentes da fração de vazio $\alpha$, como no modelo de Chexal et al. (1992). Nesse caso, a dificuldade matemática para a obtenção do sistema de equações diferenciais direcionais justificaria o uso do MVF.

Assim, o método das características foi aplicado ao sistema de equações; esse método é o procedimento numérico comumente utilizado para sistemas hiperbólicos. Sabe-se que, por meio da escolha adequada de coordenadas, o sistema original de equações hiperbólicas de primeira ordem pode ser substituído pelo sistema expresso nas coordenadas características. As coordenadas características são as coordenadas naturais do sistema, no sentido de que, em função dessas coordenadas, a diferenciação torna-se bastante simplificada (AMES, 1992). Como já citado, a simplificação dá-se ao ser obtido um sistema de equações em derivadas direcionais, as quais podem ser resolvidas como equações diferenciais ordinárias. Matematicamente, o método das características envolve um procedimento algébrico em que uma transformação linear é aplicada ao sistema de equações em sua base original a fim de representá-lo segundo sua base natural. O Apêndice B apresenta em detalhes o procedimento matemático utilizado.

As equações resultantes nas coordenadas características, ou as condições de compatibilidade, são dadas por (ver Apêndice B.4):

$$
\begin{gathered}
\frac{D_{g} \alpha}{D t}+b_{13} \frac{D_{g} P}{D t}+d_{1}=0 \\
b_{21} \frac{D_{l} \alpha}{D t}+b_{22} \frac{D_{l} \alpha_{o}}{D t}+b_{23} \frac{D_{l} P}{D t}=0
\end{gathered}
$$

onde as derivadas direcionais são definidas por: 


$$
\begin{aligned}
& \frac{D_{g}}{D t}=\frac{\partial}{\partial t}+u_{g} \frac{\partial}{\partial s} \\
& \frac{D_{l}}{D t}=\frac{\partial}{\partial t}+u_{l} \frac{\partial}{\partial s}
\end{aligned}
$$

As equações de estado complementares são dadas pela Eq. (3.9) e pela expressão que segue (ver Apêndice C):

$$
\frac{\partial j}{\partial s}=f_{1} \frac{D_{g} P}{D t}+f_{2} \frac{D_{l} P}{D t}
$$

Os coeficientes $b_{13}, b_{21}, b_{22}, b_{23}, d_{1}, f_{1}$ e $f_{2}$ são função das variáveis de estado e das variáveis dependentes:

$$
\begin{aligned}
& b_{13}=\frac{\left(1-\alpha C_{d}\right)}{\rho_{g}}\left(\alpha \frac{\partial \rho_{g}}{\partial P}+\frac{\rho_{d g 0} \alpha_{o}}{B_{o}} \frac{\partial R_{s}}{\partial P}\right)-\frac{\alpha_{o}}{\rho_{o}} \frac{\partial \rho_{o}}{\partial P} \alpha C_{d} \\
& +\frac{\rho_{d g 0} \alpha_{o}}{\rho_{o} B_{o}} \frac{\partial R_{s}}{\partial P} \alpha C_{d}-\frac{\alpha_{w}}{\rho_{w}} \frac{\partial \rho_{w}}{\partial P} \alpha C_{d} \\
& b_{21}=\alpha_{o} \\
& b_{22}=\alpha_{o}+\alpha_{w} \\
& b_{23}=\alpha_{o} \alpha_{w}\left(\frac{1}{\rho_{o}} \frac{\partial \rho_{o}}{\partial P}-\frac{\rho_{d g} 0}{\rho_{o} B_{o}} \frac{\partial R_{s}}{\partial P}-\frac{1}{\rho_{w}} \frac{\partial \rho_{w}}{\partial P}\right) \\
& d_{1}=\alpha\left(j \frac{\partial C_{d}}{\partial s}+\frac{\partial U_{d}}{\partial s}\right)+\left(u_{l}-u_{g}\right)\left(\frac{4 \tau_{w}}{D}-\rho_{m} g_{s}\right) \\
& \times\left\{\frac{-\rho_{d g} 0 \alpha_{o}}{\rho_{o} B_{o}} \frac{\partial R_{s}}{\partial P}\left[\frac{\rho_{o}}{\rho_{g}}\left(1-\alpha C_{d}\right)+\alpha C_{d}\right]+\frac{\alpha_{o}}{\rho_{o}} \frac{\partial \rho_{o}}{\partial P} \alpha C_{d}\right. \\
& \left.+\frac{\alpha_{w}}{\rho_{w}} \frac{\partial \rho_{w}}{\partial P} \alpha C_{d}\right\} \\
& f_{1}=-\frac{\alpha}{\rho_{g}} \frac{\partial \rho_{g}}{\partial P}
\end{aligned}
$$




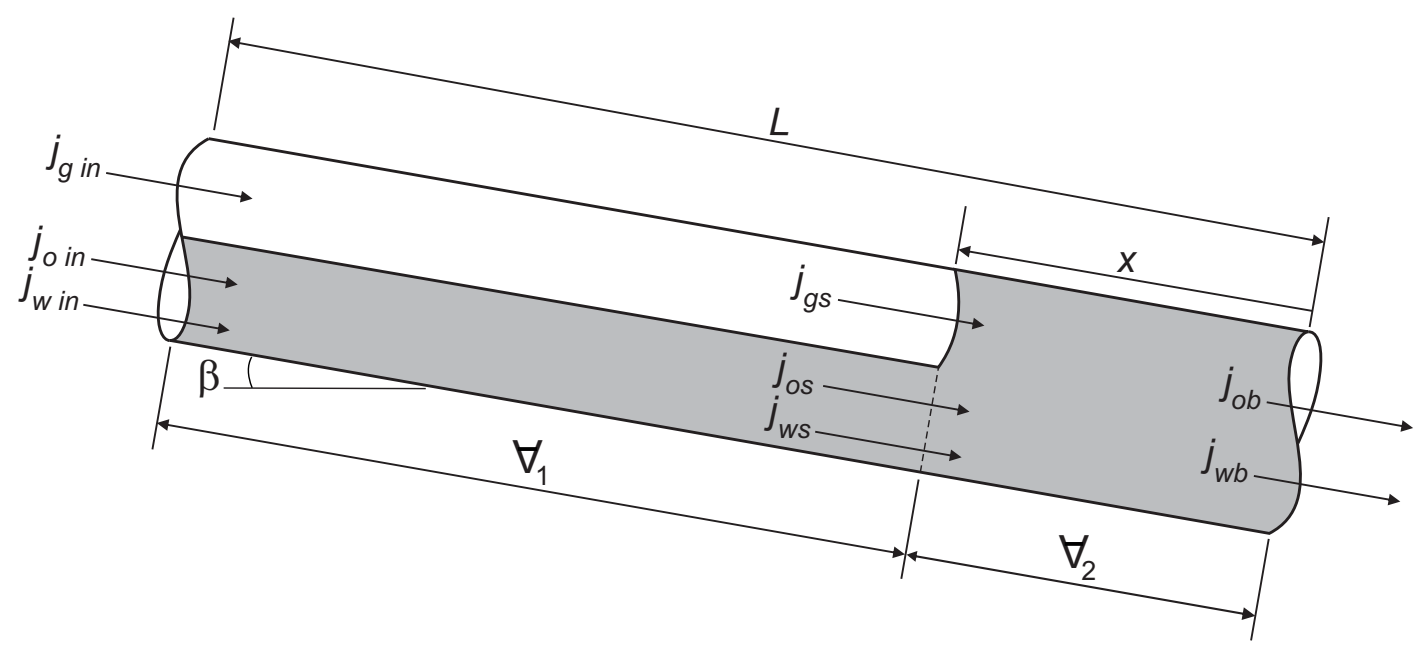

Figura 3.2: Volumes de controle para o modelo do pipeline.

$$
f_{2}=\frac{\rho_{d g 0 \alpha_{o}}}{B_{o}} \frac{\partial R_{s}}{\partial P}\left(\frac{1}{\rho_{o}}-\frac{1}{\rho_{g}}\right)-\frac{\alpha_{o}}{\rho_{o}} \frac{\partial \rho_{o}}{\partial P}-\frac{\alpha_{w}}{\rho_{w}} \frac{\partial \rho_{w}}{\partial P}
$$

\subsection{Pipeline}

Igualmente, o modelo do pipeline considera um escoamento unidimensional, trifásico e isotérmico. As equações de conservação são as equações de continuidade para as fases gás, óleo e água e uma equação de balanço de quantidade de movimento avaliada no estado estacionário, a qual é usada para calcular a fração de vazio no pipeline (ver Seção 3.4).

Assume-se que as fases óleo e água possuem a mesma velocidade e são homogeneizadas, o padrão de escoamento é estratificado, a pressão é constante na cavidade de gás, a transferência de massa entre o óleo e o gás é calculada por meio da aproximação de black-oil e as variações na fração de vazio $\alpha_{\forall_{1}}$ são negligenciadas durante o transiente.

O modelo do pipeline é composto de dois volumes de controle (ver Fig. 3.2). O volume de controle $\forall_{1}$ compreende o gás e líquido na região estratificada, enquanto o volume de controle $\forall_{2}$ compreende a região de penetração de líquido. Na Fig. 3.2, o gás está presente na região estratificada e é representado pela bolha na cor branca; já o líquido é representado na cor cinza. Observe que o sentido positivo da variável $x$, o comprimento de penetração de líquido no pipeline, é contrário ao sentido do fluxo dos fluidos.

Assumindo que a composição dos fluidos que deixam o poço e escoam para o interior do pipeline não muda ao longo do tempo, as vazões volumétricas de gás, óleo e água na entrada dependem das condições de pressão e temperatura no pipeline. É possível a ocorrência de um 
fluxo de gás nulo no pipeline quando a pressão na entrada do mesmo for maior que a pressão de ponto de bolha, ou pressão de saturação. As velocidades superficiais de gás $j_{\text {gin }}$, óleo $j_{\text {oin }} \mathrm{e}$ água $j_{w i n}$ na entrada do pipeline são calculadas usando as Eqs. (3.70), (3.71) e (3.72).

As variáveis de estado para o modelo do pipeline são o comprimento de penetração de líquido $x$ e a pressão na base do riser $P_{b}$.

O modelo do pipeline contempla dois estados: um estado em que o comprimento de penetração de líquido é nulo (estado $x=0$ ); e outro estado em que o comprimento de penetração de líquido é maior que zero (estado $x>0$ ).

\subsubsection{Modelo para comprimento de penetração de líquido nulo (estado $x=0$ )}

O estado $x=0$ é observado quando não há penetração de líquido no pipeline. Nesse caso, existe apenas um volume de controle $\left(\forall_{1}\right)$ e a pressão na cavidade de gás é constante e igual à pressão na base do riser.

As equações de estado são obtidas por meio da aplicação das equações de continuidade para o gás, óleo e água, resultando em expressões finais que permitem o cálculo das velocidades superficiais de gás $j_{g b}$, óleo $j_{o b}$ e água $j_{w b}$ na base do riser (ver Apêndice D.1):

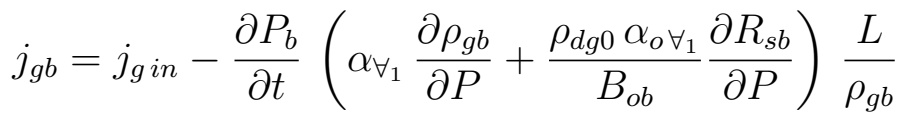

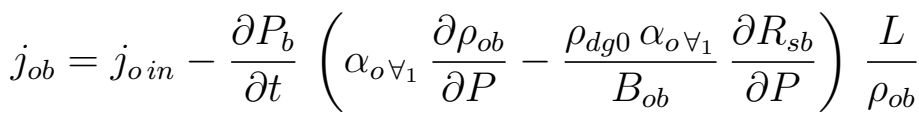

$$
\begin{aligned}
& j_{w b}=j_{w i n}-\alpha_{w \forall_{1}} \frac{\partial \rho_{w b}}{\partial P} \frac{\partial P_{b}}{\partial t} \frac{L}{\rho_{w b}}
\end{aligned}
$$

onde $L$ é o comprimento do pipeline e o índice $b$ indica que a variável está relacionada à base do riser.

\subsubsection{Modelo para comprimento de penetração de líquido positivo (estado $x>0$ )}

Nesse estado, a frente de líquido penetra no pipeline e dois volumes de controle são levados em conta. A pressão no volume de controle $\forall_{1}, P_{s}$, é constante ao longo de seu comprimento e a 
pressão no volume de controle $\forall_{2}$ depende da posição. De maneira a estimar as propriedades dos fluidos e suas derivadas, uma pressão representativa $P_{m}$ para o volume de controle $\forall_{2}$ é usada:

$$
\begin{gathered}
P_{s}=P_{b}-\rho_{l} g x \sin \beta \\
P_{m}=\frac{P_{b}+P_{s}}{2}
\end{gathered}
$$

onde $\rho_{l}$ é a massa específica média da fase líquida no volume de controle $\forall_{2}, g$ é a gravidade, $\beta$ é a inclinação do pipeline, $x$ é o comprimento de penetração de líquido, o índice $s$ refere-se à interface entre os volumes de controle e o índice $m$ refere-se ao valor médio no volume de controle $\forall_{2}$.

\subsubsection{Volume de controle $\forall_{1}$}

A partir das equações da continuidade para o gás, óleo e água, é possível obter expressões para a velocidade da frente de acúmulo de líquido $d x / d t$ e a velocidade superficial de óleo $j_{o s}$ e água $j_{w s}$ na interface entre os volumes de controle (ver Apêndice D.2.1):

$$
\begin{aligned}
& \frac{d x}{d t}=-\frac{j_{g i n}}{\alpha_{\forall_{1}}}+\frac{\partial P_{s}}{\partial t}\left(\alpha_{\forall_{1}} \frac{\partial \rho_{g s}}{\partial P}+\frac{\rho_{d g 0} \alpha_{o \forall_{1}}}{B_{o s}} \frac{\partial R_{s s}}{\partial P}\right) \frac{(L-x)}{\rho_{g s} \alpha_{\forall_{1}}} \\
& j_{o s}=j_{o i n}-\frac{\partial P_{s}}{\partial t}\left(\alpha_{o \forall} \frac{\partial \rho_{o s}}{\partial P}-\frac{\rho_{d g 0} \alpha_{o \forall}}{B_{o s}} \frac{\partial R_{s s}}{\partial P}\right) \frac{(L-x)}{\rho_{o s}}-\alpha_{o \forall} \frac{d x}{d t} \\
& j_{w s}=j_{w i n}-\alpha_{w \forall} \frac{\partial \rho_{w s}}{\partial P} \frac{\partial P_{s}}{\partial t} \frac{(L-x)}{\rho_{w s}}-\alpha_{w \forall} \frac{d x}{d t}
\end{aligned}
$$

\subsubsection{Volume de controle $\forall_{2}$}

A partir das equações de continuidade para o óleo e a água, obtemos as velocidade superficiais de óleo $j_{o b}$ e água $j_{w b}$ na base do riser (ver Apêndice D.2.2):

$$
j_{o b}=\frac{1}{\rho_{o b}}\left(\rho_{o s} j_{o s}+\rho_{o s} \alpha_{o \forall} \frac{d x}{d t}-x \alpha_{o \forall 2} \frac{\partial \rho_{o m}}{\partial P} \frac{\partial P_{m}}{\partial t}\right)
$$




$$
j_{w b}=\frac{1}{\rho_{w b}}\left(\rho_{w s} j_{w s}+\rho_{w s} \alpha_{w \forall} \frac{d x}{d t}-x \alpha_{w \forall 2} \frac{\partial \rho_{w m}}{\partial P} \frac{\partial P_{m}}{\partial t}\right)
$$

A velocidade do líquido na base do riser $u_{l b}$ é calculada como segue:

$$
u_{l b}=\frac{1}{\rho_{l b}}\left[\rho_{l s}\left(j_{o s}+j_{w s}+\alpha_{l \forall_{1}} \frac{d x}{d t}\right)-x \frac{\partial \rho_{l m}}{\partial P} \frac{\partial P_{m}}{\partial t}\right]
$$

onde $\alpha_{l}$ é a fração volumétrica do líquido.

Baseada nas variáveis definidas acima, as frações volumétricas de óleo e água no volume de controle $\forall_{2}$ são dadas por:

$$
\begin{gathered}
\alpha_{o \forall}=\frac{j_{o b}}{u_{l b}} \\
\alpha_{w \forall_{2}}=1-\alpha_{o \forall_{2}}
\end{gathered}
$$

\subsubsection{Condição de comutação}

Sempre que a velocidade superficial do gás na base do riser torna-se zero, existe a comutação entre o conjunto de equações determinado pelo estado $x=0$ para o conjunto de equações determinado pelo estado $x>0$. A comutação do estado $x>0$ para o estado $x=0$ acontece quando o comprimento de penetração de líquido torna-se zero.

\subsection{Propriedades dos fluidos}

As propriedades dos fluidos são calculadas por meio de correlações baseadas em resultados experimentais e dados de campo. As expressões analíticas utilizadas para o cálculo das propriedades, assim como a base teórica para compreensão das mesmas, são apresentadas no Apêndice E.

\subsubsection{Fator volume de formação e massa específica do gás}

O fator volume de formação do gás $B_{g}$ é calculado como segue:

$$
B_{g}=\frac{P_{0}}{T_{0}} \frac{Z_{c} T}{P}
$$


onde $P_{0}$ é a pressão na condição padrão, $T_{0}$ é a temperatura absoluta na condição padrão, $Z_{c}$ é o fator de compressibilidade e $P$ e $T$ são a pressão e temperatura absoluta na condição local de temperatura e pressão.

O fator de compressibilidade é determinado usando a correlação de Dranchuk e AbouKassem (1975). Para calcular o fator de compressibilidade também é necessário avaliar a temperatura e pressão pseudo-críticas, as quais podem ser determinadas usando a correlação de Standing (1981).

Considerando a aproximação de black-oil, a qual assume que a densidade relativa do gás seja aproximadamente constante, pode ser provado que a Eq. (3.21) reduz-se a:

$$
\rho_{g} \cong \frac{\rho_{g 0}}{B_{g}}
$$

\subsubsection{Fator volume de formação e massa específica da água}

A correlação para o fator volume de formação de água $B_{w}$ é apresentada em McCain (1990). A massa específica da água na condição local de temperatura e pressão é determinada por meio da seguinte expressão:

$$
\rho_{w}=\frac{\rho_{w 0}}{B_{w}}
$$

\subsubsection{Solubilidade de gás em óleo e pressão de ponto de bolha}

Se a pressão local é maior que a pressão de ponto de bolha, a solubilidade de gás em óleo $R_{s}$ é igual à razão gás-óleo $G O R$, caso contrário a solubilidade de gás em óleo é calculada de acordo com a correlação de Velarde, Blasingame e McCain (1999). A pressão de ponto de bolha é determinada por meio do trabalho do mesmo autor.

\subsubsection{Fator volume de formação e massa específica de óleo}

Define-se o fator volume de formação de óleo da maneira que segue:

$$
B_{o}=\frac{v_{o}}{v_{o 0}}
$$


onde $v_{o}$ e $v_{o 0}$ são, respectivamente, o volume de óleo na condição local de temperatura e pressão e na condição padrão.

Do balanço material resulta (MCCAIN, 1990):

$$
B_{o}=\frac{\rho_{o 0}+\frac{P_{0} M_{a}}{\Lambda T_{0}} R_{s} \gamma_{d g}}{\rho_{o}}
$$

Assumindo que a aproximação de black-oil seja valida e substituindo a Eq. (3.30) na Eq. (3.67), obtêm-se:

$$
B_{o} \cong \frac{\rho_{o 0}+\rho_{g 0} R_{s}}{\rho_{o}}
$$

A massa específica do óleo é calculada pela correlação de Velarde, Blasingame e McCain (1999).

\subsubsection{Viscosidades do gás, óleo e água}

A viscosidade do gás é calculada usando a correlação de Lee, Gonzalez e Eakin (1966). A viscosidade do óleo morto na condição padrão de pressão é calculada usando a correlação de Egbogah e Ng (1990). A viscosidade do óleo morto é necessária para se calcular a viscosidade do óleo saturado e subsaturado. A primeira é calculada usando a correlação de Beggs e Robinson (1975), enquanto a última é calculada usando a correlação de Vasquez e Beggs (1980).

A viscosidade da água é calculada usando os resultados de Collins (1987). O primeiro passo consiste na determinação da viscosidade da água na pressão padrão, em seguida deve-se avaliar a viscosidade na condição local de temperatura e pressão.

\subsubsection{Termo de vaporização}

Considerando o escoamento como isotérmico, $R_{s}$ depende somente da pressão. Portanto, a Eq. (3.35) reduz-se a:

$$
\Gamma=-\frac{\rho_{g 0} \alpha_{o}}{B_{o}} \frac{\partial R_{s}}{\partial P} \frac{D_{l} P}{D t}
$$

\subsection{Estado estacionário}

O estado de escoamento estacionário para o riser, usado como condição inicial para as simulações transientes, pode ser obtido tornando nulas as derivadas temporais nas equações dinâmicas 
(OLIVEIRA, 2009). Aplicando esse procedimento para as Eqs. (3.6), (3.7) e (3.8) (ver Apêndice F), obtemos respectivamente:

$$
\begin{gathered}
j_{g}=\frac{Q_{o 0}\left(G O R-R_{s}\right) B_{g}}{A} \\
j_{o}=\frac{Q_{o 0} B_{o}}{A} \\
j_{w}=\frac{Q_{o 0} W O R B_{w}}{A}
\end{gathered}
$$

onde $Q_{o 0}$ é a vazão de óleo na condição padrão, $A$ é a área de passagem do fluxo, $G O R$ é a razão gás-óleo e $W O R$ é a razão água-óleo.

A fração de vazio $\alpha$ ao longo do riser é calculada usando a Eq. (3.22). A fração volumétrica de óleo é calculada usando a seguinte expressão, obtida a partir das Eqs. (3.11), (3.12) e (3.13):

$$
\alpha_{o}=j_{o} \frac{1-\alpha}{j_{w}+j_{o}}
$$

A fração volumétrica de água $\alpha_{w}$ é calculada a partir da Eq. (3.11):

$$
\alpha_{w}=1-\alpha-\alpha_{o}
$$

A distribuição de pressão ao longo do riser pode ser calculada por meio da integração numérica da Eq. (3.9), dado que todos os termos são funções da pressão e o ângulo de inclinação é função da posição.

Assumindo a mesma área de passagem do fluxo para o pipeline e o riser, pressão e velocidades superficiais são contínuas na base do riser, de maneira que é possível o acoplamento entre os modelos dos subsistemas. Assim, a velocidade superficial das fases no pipeline é a mesma que a velocidade superficial das fases no primeiro nó do riser, localizado na base do mesmo.

De modo a avaliar a fração de vazio no pipeline, uma equação de balanço da quantidade de movimento para o escoamento estratificado, avaliada no estado estacionário (TAITEL; DUKLER, 1976), é usada: 


$$
\tau_{w g} \frac{S_{g}}{\alpha_{\forall_{1}}}-\tau_{w l} \frac{S_{l}}{1-\alpha_{\forall_{1}}}+\tau_{i} S_{i}\left(\frac{1}{1-\alpha_{\forall_{1}}}+\frac{1}{\alpha_{\forall_{1}}}\right)+\left(\rho_{l}-\rho_{g}\right) A g \sin \beta=0
$$

onde $\tau_{w l}, \tau_{w g}$ e $\tau_{i}$ são as tensões de cisalhamento entre o líquido e a parede, entre o gás e a parede e na interface gás-líquido, respectivamente e $S_{l}, S_{g}$ e $S_{i}$ são correspondentemente os perímetros molhados de líquido, gás e interface gás-líquido. O procedimento de cálculo pode ser visto em Kokal e Stanislav (1989).

As frações volumétrica de óleo e água no pipeline são calculadas usando as Eqs. (3.73) e (3.74). 


\section{RESOLUÇÃO NUMÉRICA}

Neste capítulo será apresentada a discretização das equações de estado dos modelos do riser e pipeline, assim como o esquema numérico para resolução das equações discretizadas.

As equações de estado serão integradas segundo um esquema implícito, com um método preditor-corretor para o tratamento das não-linearidades. Nas equações discretizadas que seguem, o sobrescrito $P C$ indica que serão utilizados valores preditores para os cálculos, segundo o esquema iterativo preditor-corretor.

\subsection{Discretização das equações de estado do riser}

Para o instante de tempo $t^{k}$, são conhecidas as variáveis de estado para cada nó $i$ do riser, localizados nas posições $s_{i}, \operatorname{com} 1 \leq i \leq N: \alpha_{i}^{k}, \alpha_{o i}^{k}, P_{i}^{k}, j_{i}^{k}$.

A posição $s_{N}^{k}$ corresponde à posição da superfície de líquido $s_{u}\left(t^{k}\right)$ e a posição $s_{1}$ é zero para todo tempo, referindo-se à base do riser.

Os valores característicos, ou autovalores, calculados na Seção 3.1.4, dados pela velocidade do gás $u_{g}$ e pela velocidade do líquido $u_{l}$, definem retas no plano posição-tempo $(s, t)$, chamadas linhas características (ver Fig. 4.1). A integração da Eq. (3.38), projetada na direção do gás, é realizada sobre as linhas características do gás, assim como a integração da Eq. (3.39), projetada na direção do líquido, é realizada sobre as linhas características do líquido.

Os nós que acompanham as linhas características do gás movimentam-se com a velocidade do gás. Esses nós são criados na base do riser em $s_{1}=0$ e desaparecem ao cruzar a superfície de líquido $s_{u}$. A Fig. 4.2 apresenta um gráfico com quatro passos temporais consecutivos no eixo das ordenadas (de $t^{k}$ a $t^{k+3}$ ) e no eixo das abscissas a posição dos nós $s_{i}$ é apresentada. A origem da abscissa representa a base do riser e a cada novo instante de tempo um novo nó é criado nessa posição. Para compensar o novo nó criado, um nó desaparece ao cruzar o nível de líquido $s_{u}$. Tal mecanismo mantém o número de nós $N$ constante. Dado que $u_{g}>u_{l}$ para todo nó $i$, não é possível o acúmulo de um número de nós maior que $N$. 


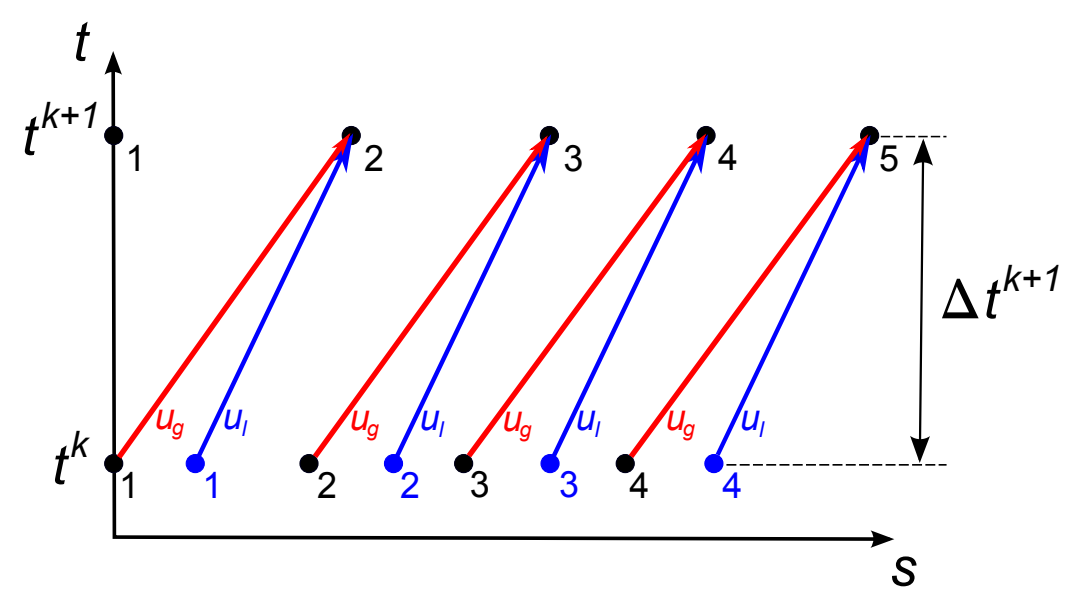

Figura 4.1: Direções características do gás (linhas vermelhas) e líquido (linhas azuis) no plano posição-tempo $(s, t)$.

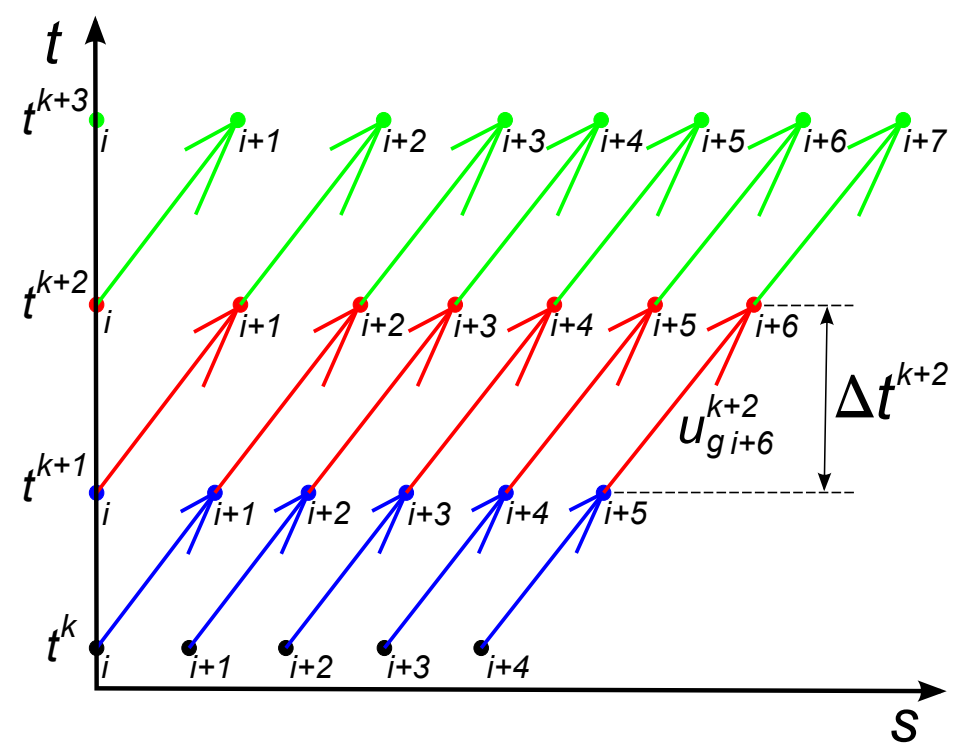

Figura 4.2: Direções características do gás.

Devido ao fato de ser utilizado um método implícito de integração, a posição dos nós no tempo $t^{k+1}$ deve ser determinada utilizando a posição dos nós no tempo $t^{k}$, a velocidade dos nós determinada no instante de tempo $t^{k+1}$ e o passo temporal $\Delta t^{k+1}$, cujo cálculo é apresentado na Seção 4.3. Portanto, a posição $s_{i+1}^{k+1}$ é dada por:

$$
s_{i+1}^{k+1}=s_{i}^{k}+u_{g i+1}^{k+1} \Delta t^{k+1}
$$

Por exemplo, para determinar a posição do nó $i+6$ no tempo $t^{k+2}$, devemos conhecer a posição desse nó no momento $t^{k+1}$, dada por $s_{i+5}^{k+1}$, a velocidade do gás no nó $i+6$ no tempo $t^{k+2}$, dada por $u_{g i+6}^{k+2}$, e o passo temporal $\Delta t^{k+2}$ (ver Fig. 4.2).

Considera-se que, para determinado instante de tempo $t^{k+1}$, a posição dos nós que 


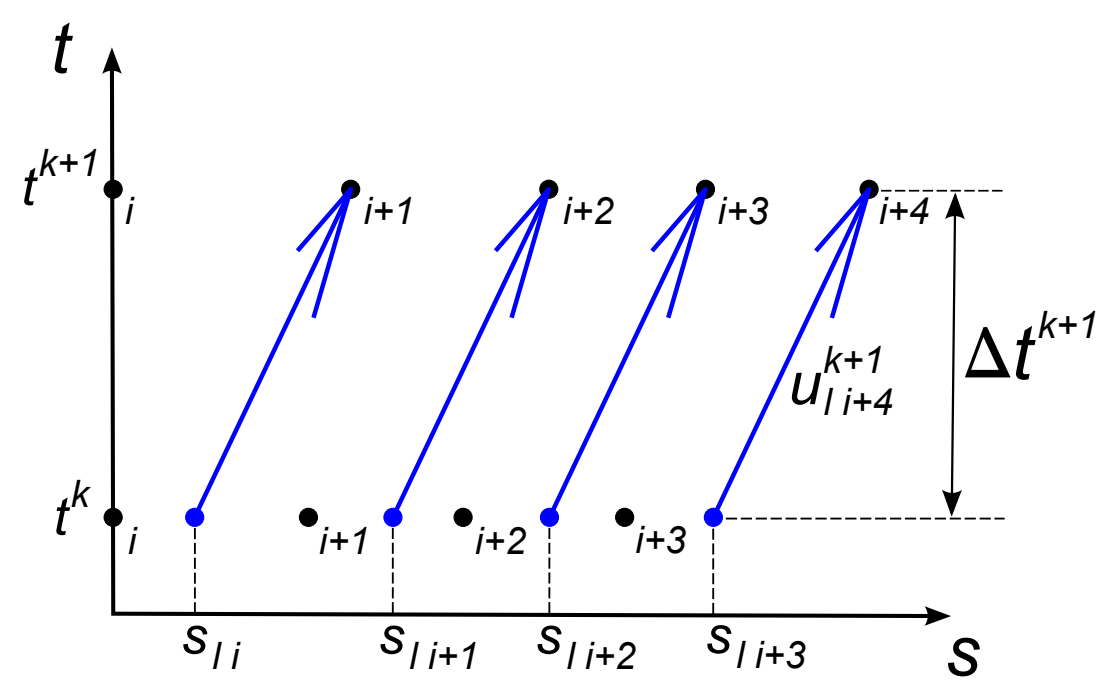

Figura 4.3: Direções características do líquido.

acompanham a linha característica do líquido (e que portanto movem-se com a velocidade do líquido) encontram-se na mesma posição dos nós que acompanham a linha característica do gás. Entretanto, para resolução numérica das equações discretizadas, faz-se necessário o conhecimento da posição dos nós que acompanham a linha característica do líquido no instante de tempo anterior $t^{k}$. A Fig. 4.3 apresenta as linhas características do líquido e posição dos nós para a fase líquida (pontos em azul) no instante de tempo $t^{k}$, assim como a posição dos nós para a fase gasosa (pontos em negro) para os instantes de tempo $t^{k}$ e $t^{k+1}$. A posição dos nós que acompanham a linha característica do líquido no instante de tempo $t^{k}$ é calculada como segue:

$$
s_{l i}^{k}=s_{i+1}^{k+1}-u_{l i+1}^{k+1} \Delta t^{k+1}
$$

onde $s_{i}$ indica a posição do nó $i$ considerando a linha característica do gás e $s_{l i}$ indica a posição do nó $i$ considerando a linha característica do líquido.

Por exemplo, para determinar a posição do nó $i+3$ no tempo $t^{k}$ com relação à direção característica do líquido, dada por $s_{l i+3}^{k}$, é necessário conhecer a posição desse nó no instante de tempo $t^{k+1}$, dada por $s_{i+4}^{k+1}$, a velocidade do líquido nesse mesmo nó para o instante de tempo $t^{k+1}$, dada por $u_{l i+4}^{k+1}$, e o passo temporal $\Delta t^{k+1}$ (ver Fig. 4.3).

Os valores das variáveis de estado e das variáveis dependentes são conhecidos para os nós que seguem a direção característica do gás. Uma vez que a posição dos nós que se movem na direção do líquido é conhecida para o tempo $t^{k}$, o valor das variáveis de estado nesses nós deve ser interpolado a partir do conhecimento do valor das variáveis de estado nos nós que se movem na direção do gás no tempo $t^{k}$. 
É possível que haja momentos em que se verifica a condição $\alpha_{i}^{k}=0$, ou ausência de gás em determinado instante de tempo para determinada posição. Nesse caso, a velocidade do gás $u_{g i}^{k}$ está definida e deve ser interpretada como o valor limite para $\alpha_{i}^{k} \rightarrow 0$.

Os cálculos em regime transiente iniciam-se tomando como condição inicial aquela determinada pelas variáveis de estado calculadas utilizando-se o modelo de estado estacionário, apresentado na Seção 3.4. Para os demais passos temporais, a condição inicial será tomada pela condição determinada pelas variáveis de estado no instante de tempo anterior.

Para resolução das equações de estado do riser devem ser conhecidas as velocidades superficiais do gás, do óleo e da água na base do riser, dadas respectivamente por $j_{g b}, j_{o b}$ e $j_{w b}$. Esses valores são calculados por meio das equações de estado do pipeline, apresentadas em sua forma discretizada na Seção 4.2. Também deve ser conhecida a pressão no separador $P_{s e p}$, uma das condições de contorno do problema.

A primeira equação a ser integrada é a equação de conservação de quantidade de movimento para a mistura, dada pela Eq. (3.9). A pressão no separador $P_{\text {sep }}$ é associada à pressão no último nó do riser $N$, de maneira que caso a superfície de líquido se encontre em uma posição abaixo do topo do riser, ou seja $s_{u}^{k}<s_{t}$, será considerada pressão constante e igual a $P_{\text {sep }}$ no intervalo $s_{u} \leq s \leq s_{t}$, em que existe apenas gás.

Assim, a integração é realizada a partir do último nó $(i=N)$ até a base do riser $(i=1)$, segundo a expressão que segue:

$$
P_{i-1}^{k+1}=P_{i}^{k+1}-\left(s_{i}^{k+1}-s_{i-1}^{k+1}\right)\left(-\frac{4 \tau_{w}}{D}+\rho_{m} g_{s}\right)_{i-1}^{k+1 P C}
$$

A segunda equação a ser integrada é a equação da continuidade para o gás, dada pela Eq. (3.38). A fração de vazio no primeiro nó do riser é conhecida e a integração ocorre na direção de deslocamento do gás, partindo do início do riser $(i=2)$ até o topo $(i=N)$ :

$$
\alpha_{i}^{k+1}=\alpha_{i-1}^{k}-\Delta t^{k+1}\left(\left(b_{13}^{*}\right)_{i}^{k+1 P C} \frac{P_{i}^{k+1}-P_{i-1}^{k}}{\Delta t^{k+1}}+\left(d_{1}^{*}\right)_{i}^{k+1 P C}\right)
$$

A terceira equação a ser integrada é a equação da continuidade para o óleo, dada pela Eq. (3.39). A fração volumétrica de óleo no primeiro nó do riser é conhecida e a integração ocorre na direção de deslocamento do líquido, partindo do início do riser $(i=2)$ até o topo $(i=N)$ :

$$
\alpha_{o i}^{k+1}=\alpha_{o l i-1}^{k}-\frac{\Delta t^{k+1}}{\left(b_{22}^{*}\right)_{i}^{k+1 P C}}\left(\frac{\alpha_{i}^{k+1}-\alpha_{l i-1}^{k}}{\Delta t^{k+1}}+\left(b_{23}^{*}\right)_{i}^{k+1 P C} \frac{P_{i}^{k+1}-P_{l i-1}^{k}}{\Delta t^{k+1}}\right)
$$


onde o subscrito $l$ nas variáveis $\alpha_{o l}, \alpha_{l}$ e $P_{l}$, relaciona tais variáveis à linha característica do líquido.

A quarta equação refere-se à equação de estado para a velocidade superficial total, dada pela Eq. (3.42). Considera-se conhecida a velocidade superficial total no primeiro nó do riser e calcula-se a variável ao longo do riser a partir do nó $i=2$ até o nó $i=N$, como segue:

$$
\begin{gathered}
j_{i}^{k+1}=j_{i-1}^{k+1}+\left(s_{i}^{k+1}-s_{i-1}^{k+1}\right)\left\{-\left(\frac{\alpha}{\rho_{g}} \frac{\partial \rho_{g}}{\partial P}\right)_{i}^{k+1 P C} \frac{P_{i}^{k+1}-P_{i-1}^{k}}{\Delta t^{k+1}}\right. \\
\left.+\frac{P_{l i}^{k+1}-P_{l i-1}^{k}}{\Delta t^{k+1}}\left[\frac{\rho_{d g 0 \alpha_{o}}}{B_{o}} \frac{\partial R_{s}}{\partial P}\left(\frac{1}{\rho_{o}}-\frac{1}{\rho_{g}}\right)-\frac{\alpha_{o}}{\rho_{o}} \frac{\partial \rho_{o}}{\partial P}-\frac{\alpha_{w}}{\rho_{w}} \frac{\partial \rho_{w}}{\partial P}\right]_{i}^{k+1 P C}\right\}
\end{gathered}
$$

\subsection{Discretização das equações de estado do pipeline}

Nesta seção serão apresentadas as equações de estado do pipeline discretizadas para os dois estados em que pode se encontrar o sistema, quais sejam, estado em que não há penetração de líquido no pipeline $(x=0)$ e estado em que há penetração de líquido no pipeline $(x>0)$.

Para resolução das equações que seguem, devem ser conhecidas as velocidades superficiais de gás $j_{g i n}$, óleo $j_{o i n}$ e água $j_{w i n}$ na entrada do pipeline, que são condições de contorno do problema, assim como a pressão na base do riser $P_{b}$, determinada a partir da integração da Eq. (4.3).

\subsubsection{Equações discretizadas para comprimento de penetração de líquido nulo (estado $x=0$ )}

Discretizando a Eq. (3.50), obtemos:

$$
j_{g b}^{k+1}=j_{g i n}^{k+1}-\frac{P_{b}^{k+1}-P_{b}^{k}}{\Delta t^{k+1}}\left(\alpha_{\forall_{1}} \frac{\partial \rho_{g b}}{\partial P}+\frac{\rho_{d g 0} \alpha_{o \forall_{1}}}{B_{o b}} \frac{\partial R_{s b}}{\partial P}\right)^{k+1} \frac{L}{\rho_{g b}^{k+1}}
$$

Discretizando a Eq. (3.51), chegamos a:

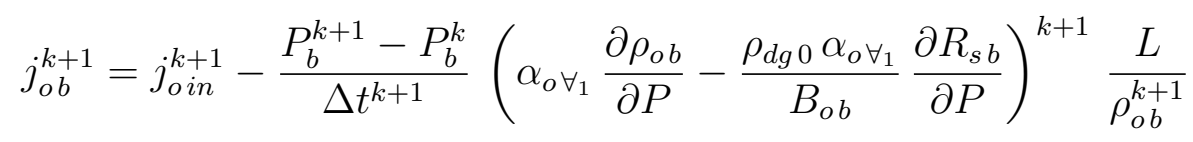

Discretizando a Eq. (3.52), temos:

$$
j_{w b}^{k+1}=j_{w i n}^{k+1}-\frac{P_{b}^{k+1}-P_{b}^{k}}{\Delta t^{k+1}}\left(\alpha_{w \forall_{1}} \frac{\partial \rho_{w b}}{\partial P}\right)^{k+1} \frac{L}{\rho_{w b}^{k+1}}
$$




\subsubsection{Equações discretizadas para comprimento de penetração de líquido positivo (estado $x>0$ )}

Nessa condição deve-se determinar as equações de estado segundo dois volumes de controle.

\subsubsection{Volume de controle $\forall_{1}$}

As equações de estado para o volume de controle $\forall_{1}$, dadas pelas Eqs. (3.55), (3.56) e (3.57), ao serem discretizadas, assumem a forma que segue:

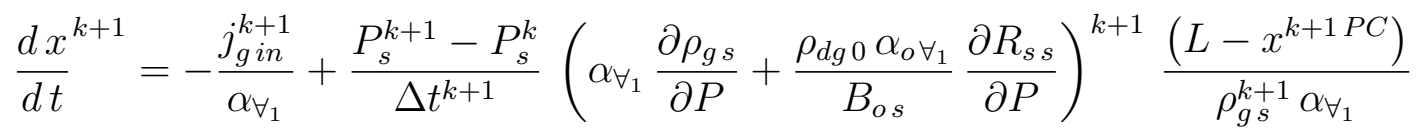

$$
\begin{aligned}
& j_{o s}^{k+1}=j_{o i n}^{k+1}-\frac{P_{s}^{k+1}-P_{s}^{k}}{\Delta t^{k+1}}\left(\alpha_{o \forall} \frac{\partial \rho_{o s}}{\partial P}-\frac{\rho_{d g 0} \alpha_{o \forall}}{B_{o s}} \frac{\partial R_{s s}}{\partial P}\right)^{k+1} \\
& \times \frac{\left(L-x^{k+1}\right)}{\rho_{o s}^{k+1}}-\alpha_{o \forall} \frac{d x^{k+1}}{d t} \\
& j_{w s}^{k+1}=j_{w i n}^{k+1}-\frac{P_{s}^{k+1}-P_{s}^{k}}{\Delta t^{k+1}}\left(\alpha_{w \forall_{1}} \frac{\partial \rho_{w s}}{\partial P}\right)^{k+1} \frac{\left(L-x^{k+1}\right)}{\rho_{w s}^{k+1}}-\alpha_{w \forall_{1}} \frac{d x^{k+1}}{d t}
\end{aligned}
$$

A posição da interface gás-liquido no pipeline é calculada por:

$$
x^{k+1}=x^{k}+{\frac{d x^{k+1}}{d t}}^{k+1}
$$

\subsubsection{Volume de controle $\forall_{2}$}

As equações de estado para o volume de controle $\forall_{2}$, dadas pelas Eqs. (3.58), (3.59) e (3.60), ao serem discretizadas, assumem a forma:

$$
j_{o b}^{k+1}=\frac{1}{\rho_{o b}^{k+1}}\left[\rho_{o s}^{k+1} j_{o s}^{k+1}+\alpha_{o \forall} \rho_{o s}^{k+1} \frac{d x^{k+1}}{d t}-x^{k+1} \alpha_{o \forall 2}^{k+1} P C \frac{\partial \rho_{o m}^{k+1}}{\partial P} \frac{P_{m}^{k+1}-P_{m}^{k}}{\Delta t^{k+1}}\right]
$$




$$
\begin{aligned}
& j_{w b}^{k+1}=\frac{1}{\rho_{w b}^{k+1}}\left[\rho_{w s}^{k+1} j_{w s}^{k+1}+\alpha_{w \forall} \rho_{w s}^{k+1} \frac{d x^{k+1}}{d t}-x^{k+1} \alpha_{w \forall 2}^{k+1 P C} \frac{\partial \rho_{w m}^{k+1}}{\partial P} \frac{P_{m}^{k+1}-P_{m}^{k}}{\Delta t^{k+1}}\right] \\
& u_{l b}^{k+1}=\frac{1}{\rho_{l b}^{k+1}}\left[\rho_{l s}^{k+1}\left(j_{o s}^{k+1}+j_{w s}^{k+1}+\alpha_{l \forall_{1}} \frac{d x^{k+1}}{d t}\right)\right. \\
& \left.-x^{k+1} \alpha_{l \forall 2}^{k+1 P C} \frac{\partial \rho_{l m}^{k+1}}{\partial P} \frac{P_{m}^{k+1}-P_{m}^{k}}{\Delta t^{k+1}}\right]
\end{aligned}
$$

As Eqs. (3.61) e (3.62), são calculadas como segue:

$$
\begin{gathered}
\alpha_{o \forall_{2}}^{k+1}=\frac{j_{o b}^{k+1}}{u_{l b}^{k+1}} \\
\alpha_{w \forall_{2}}^{k+1}=1-\alpha_{o \forall_{2}^{k+1}}^{k+1}
\end{gathered}
$$

\subsection{Passo temporal}

O passo temporal $\Delta t^{k+1}$ é usado para o cálculo do novo instante de tempo $t^{k+1}$, segundo a expressão que segue:

$$
t^{k+1}=t^{k}+\Delta t^{k+1}
$$

Devido ao fato de um esquema implícito ser utilizado, o passo temporal também faz parte do esquema iterativo, assumindo diferentes valores até a convergência.

Seu cálculo ocorre com base no intervalo de tempo necessário para que o penúltimo nó $N-1$ desloque-se até a posição do último nó $N$, o qual está localizado no menisco, ou nível de líquido no riser $s_{u}$, ocupando sua posição e fazendo com que este último nó desapareça.

Se a velocidade do nível de líquido no riser for positiva $\left(u_{l u}^{k+1}>0\right)$ e o último nó localizar-se no topo do riser $\left(s_{N}^{k}=s_{t}\right)$, o passo temporal será determinado da maneira que segue:

$$
\Delta t^{k+1}=\frac{s_{t}-s_{N-1}^{k}}{u_{g N}^{k+1}}
$$

Se a velocidade do nível de líquido no riser for positiva $\left(u_{l u}^{k+1}>0\right)$ e o último nó localizar-se numa posição anterior ao topo do riser $\left(s_{N}^{k}<s_{t}\right)$, deve-se calcular duas possibilidades antes de determinar o passo temporal. Inicialmente calcula-se o tempo necessário para o 
último nó, localizado em $s_{N}^{k}$, encontrar o topo do riser, localizado em $s_{t}$ :

$$
\Delta t_{c a s o 1}^{k+1}=\frac{s_{t}-s_{N}^{k}}{u_{l u}^{k+1}}
$$

Calcula-se, então, o tempo necessário para o penúltimo nó, localizado em $s_{N-1}^{k}$, encontrar o último, localizado em $s_{N}^{k}$ :

$$
\Delta t_{c a s o 2}^{k+1}=\frac{s_{N}^{k}-s_{N-1}^{k}}{u_{g N}^{k+1}}
$$

Caso se tenha $\Delta t_{\text {caso } 1}^{k+1}<\Delta t_{c a s o 2}^{k+1}$, ou seja, caso o tempo necessário para o último nó chegar até o topo do riser seja menor que o tempo necessário para o penúltimo nó encontrarse com o último nó, o passo temporal será calculado segundo a Eq. (4.20). Caso se tenha $\Delta t_{\text {caso } 1}^{k+1} \geq \Delta t_{\text {caso } 2}^{k+1}$, o passo temporal será dado pelo tempo necessário para o penúltimo nó encontrar-se com o último, ou seja, será calculado pela Eq. (4.22).

Se a velocidade do nível de líquido é negativa ou nula $\left(u_{l u}^{k+1} \leq 0\right)$, o passo temporal será calculado segundo a expressão:

$$
\Delta t^{k+1}=\frac{s_{N}^{k}-s_{N-1}^{k}}{u_{g N}^{k+1}-u_{l u}^{k+1}}
$$

\subsection{Esquema de cálculo}

O esquema de cálculo pode ser resumido como segue:

1. Definição dos seguintes dados: número de nós $N$, subrelaxação $\zeta$, precisão para verificação da convergência $\varepsilon$, ângulo de inclinação do pipeline $\beta$, comprimento do pipeline $L$, altura do riser $Z_{r}$, coordenada horizontal do topo do riser $W_{r}$, rugosidade interna dos tubos $\epsilon$, diâmetro dos tubos $D$, salinidade $Y$, temperatura dos fluidos $T$, densidade relativa do gás na condição padrão $\gamma_{g 0}$, densidade API do óleo $\gamma_{A P I}$, razão água-óleo $W O R$, vazão volumétrica de gás na condição padrão $Q_{g}$, razão gás-óleo $G O R$, pressão no separador $P_{\text {sep }}$ e tempo final para simulação $t^{\text {final }}$.

2. Cálculo do estado estacionário segundo o procedimento que segue:

(a) Cálculo das posições dos nós utilizando as Eqs. (F.2) e (F.3).

(b) Atribuição do valor da pressão ao último nó: $P_{N}=P_{s e p}$. 
(c) Cálculo das propriedades apresentadas na Seção (3.3) para o nó $N$ e das variáveis $j_{g N}, j_{o N}$ e $j_{w N}$ segundo as Eqs. (3.70), (3.71) e (3.72).

(d) Assume-se como valores preditores das variáveis no nó $i-1$ os valores das variáveis obtidos no nó $i, \omega_{i-1}^{P C}=\omega_{i}$, sendo $\omega$ uma variável genérica.

(e) Cálculo das propriedades termodinâmicas para as condições no nó $i-1$ e cálculo das variáveis $j_{g i-1}, j_{o i-1}$ e $j_{w i-1}$ segundo as Eqs. (3.70), (3.71) e (3.72) e cálculo de $P_{i-1}$ utilizando a Eq. (4.3).

(f) Verificação da convergência das variáveis para o nó $i-1$. A convergência da variável genérica $\omega$ é atingida ao verificar-se $\left|\left(\omega_{i-1 \text { novo }}-\omega_{i-1 \text { velho }}\right) / \omega_{i-1 \text { novo }}\right|<\varepsilon$. E duas condições são possíveis:

i. Caso a convergência das variáveis não tenha sido atingida, deve-se subrelaxar as variáveis segundo a expressão $\omega_{i-1}^{P C}=\zeta \omega_{i-1 \text { novo }}+(1-\zeta) \omega_{i-1 \text { velho, }}$ e os cálculos prosseguem segundo o item $2 \mathrm{e}$.

ii. Caso a convergência das variáveis tenha sido atingida, duas condições são possíveis:

A. Caso $i>1$, deve-se decrementar o valor de $i$, de acordo com a expressão $i \leftarrow i-1$, e retorna-se ao item $2 \mathrm{~d}$.

B. Caso $i=1$, fim da simulação do estado estacionário.

3. Determinação das variáveis de estado preditoras para o estado transiente segundo os casos que seguem:

(a) Se $t=0$, os valores preditores são tomados do estado estacionário:

$$
\omega_{i}^{1 P C}=\omega_{i}^{0}
$$

(b) Se $t^{k}>0$, os valores preditores são tomados do instante de tempo anterior:

$$
\omega_{i}^{k+1 P C}=\omega_{i}^{k}
$$

4. Cálculo do passo temporal $\Delta t^{k+1}$ de acordo com as equações apresentadas na Seção 4.3. Definição das novas posições dos nós para o tempo $t^{k+1}$, de acordo com a Eq. (4.1).

5. Utilizando as variáveis preditoras $j_{g b}^{k+1 P C}, j_{o b}^{k+1 P C}, j_{w b}^{k+1 P C}$ e a condição de contorno $P_{s e p}$, as seguintes variáveis são calculadas para o riser:

(a) Cálculo das propriedades termodinâmicas apresentadas na Seção 3.3.

(b) Cálculo de $P_{i}^{k+1}$ para $1 \leq i \leq N-1$, utilizando a Eq. (4.3). 
(c) Cálculo de $\alpha_{i}^{k+1}$ para $2 \leq i \leq N$, utilizando a Eq. (4.4).

(d) Cálculo de $\alpha_{o i}^{k+1}$ para $2 \leq i \leq N$, utilizando a Eq. (4.5).

(e) Cálculo de $j_{i}^{k+1}$ para $2 \leq i \leq N$, utilizando a Eq. (4.6).

(f) Cálculo de $u_{g i}^{k+1}$ para $1 \leq i \leq N$, utilizando a Eq. (3.22).

(g) Cálculo de $u_{l i}^{k+1}$ para $1 \leq i \leq N$, utilizando a relação:

$$
u_{l i}^{k+1}=\left(j_{i}^{k+1}-j_{g i}^{k+1}\right) /\left(1-\alpha_{i}^{k+1}\right)
$$

6. Considerando a pressão na base do riser $P_{b}^{k+1}$, calculada no item $5 \mathrm{~b}$, e as condições de contorno $j_{\text {gin }}, j_{\text {oin }}$ e $j_{w i n}$, as seguintes variáveis são calculadas para o pipeline:

(a) Caso $x=0$ :

i. Cálculo de $j_{g b}^{k+1}$, utilizando Eq. (4.7).

ii. Cálculo de $j_{o b}^{k+1}$, utilizando Eq. (4.8).

iii. Cálculo de $j_{w b}^{k+1}$, utilizando Eq. (4.9).

iv. Ao se verificar $j_{g b}^{k+1}<0$, parte-se para os cálculos com $x>0$ (item 6b).

(b) Caso $x>0$ :

i. Cálculo das propriedades termodinâmicas para o volume de controle $\forall_{2}$ utilizando a pressão $P_{m}^{k+1 P C}$.

ii. Cálculo de $P_{s}^{k+1}$, utilizando a Eq. (3.53).

iii. Cálculo de $P_{m}^{k+1}$, utilizando a Eq. (3.54).

iv. Cálculo das propriedades termodinâmicas para o volume de controle $\forall_{1}$ utilizando a pressão $P_{s}^{k+1}$.

v. Cálculo de $d x / d t^{k+1}$, utilizando a Eq. (4.10).

vi. Cálculo de $x^{k+1}$, utilizando a Eq. (4.13).

vii. Cálculo de $j_{o s}^{k+1}$, utilizando a Eq. (4.11).

viii. Cálculo de $j_{w s}^{k+1}$, utilizando a Eq. (4.12).

ix. Cálculo de $j_{o b}^{k+1}$, utilizando a Eq. (4.14).

x. Cálculo de $j_{w b}^{k+1}$, utilizando a Eq. (4.15).

xi. Cálculo de $u_{l b}^{k+1}$, utilizando a Eq. (4.16).

xii. Cálculo de $\alpha_{o \forall_{2}}^{k+1}$, utilizando a Eq. (4.17).

xiii. Cálculo de $\alpha_{w \forall_{2}}^{k+1}$, utilizando a Eq. (4.18).

xiv. Ao se verificar $x^{k+1}<0$, parte-se para os cálculos com $x=0$ (item 6a). 
7. Verificação da convergência das variáveis de estado. A convergência é atingida ao obter $\left|\left(\omega_{i}^{k+1 P C}-\omega_{i}^{k+1}\right) / \omega_{i}^{k+1}\right|<\varepsilon$. E duas condições são possíveis:

(a) Caso a convergência das variáveis tenha sido atingida, outras duas condições são possíveis:

i. Caso $t^{k+1}<t^{f i n a l}$, um novo passo temporal será calculado, retornando ao item 3.

ii. Caso $t^{k+1} \geq t^{\text {final }}$, chega-se ao fim da simulação.

(b) Caso a convergência das variáveis não tenha sido atingida, as seguintes ações são necessárias:

i. Cálculo da velocidade superficial total na base do riser usando a expressão:

$$
j_{1}^{k+1}=j_{g b}^{k+1}+j_{o b}^{k+1}+j_{w b}^{k+1}
$$

ii. Cálculo da velocidade do gás na base do riser $u_{g 1}^{k+1}$, segundo a Eq. (3.22).

iii. Cálculo da fração de vazio na base do riser, por meio da equação:

$$
\alpha_{1}^{k+1}=j_{g b}^{k+1} / u_{g 1}^{k+1}
$$

iv. Cálculo da fração volumétrica de óleo na base do riser, usando a expressão:

$$
\alpha_{o 1}^{k+1}=\left(1-\alpha_{1}^{k+1}\right) /\left(j_{w b}^{k+1} / j_{o b}^{k+1}+1\right)
$$

v. Cálculo da fração volumétrica de água na base do riser, utilizando:

$$
\alpha_{w 1}^{k+1}=1-\alpha_{1}^{k+1}-\alpha_{o 1}^{k+1}
$$

vi. Cálculo da velocidade de líquido na base do riser, utilizando:

$$
u_{l 1}^{k+1}=\left(j_{1}^{k+1}-j_{g b}^{k+1}\right) /\left(1-\alpha_{1}^{k+1}\right)
$$

vii. Subrelaxa-se as variáveis de estado de maneira a obter novas variáveis preditoras por meio da expressão:

$$
\omega_{i \text { nova }}^{k+1 P C}=\zeta \omega_{i}^{k+1}+(1-\zeta) \omega_{i \text { velha }}^{k+1 P C}
$$

viii. Faz-se a verificação do andamento da simulação e dois casos são possíveis:

A. Caso a velocidade do gás no riser resulte negativa em algum dos nós, $u_{g i}^{k+1}<0$ (condição que não ocorre em sistemas reais), ou caso o número de iterações exceda 2000, o valor da subrelaxação é dividido por dois, $\zeta_{\text {nova }}=\zeta_{\text {velha }} / 2$. Com isso, o cálculo das variáveis para o passo temporal em questão é reiniciado, retornando-se ao item 3.

B. Caso nenhuma das condições acima ocorram, as iterações rumo à convergência continuam com a subrelaxação $\zeta$ inalterada; e retorna-se ao item 4. 


\section{RESULTADOS}

Neste capítulo serão apresentados o estudo de convergência e a validação do modelo proposto, assim como uma interpretação do fenômeno de intermitência severa considerando os efeitos de transferência de massa. Com isso, um mapa de estabilidade será apresentado e comparado com um mapa de estabilidade para sistemas água-ar, ambos obtidos de maneira numérica. Por fim serão discutidos os efeitos da variação de diferentes parâmetros sobre os mapas de estabilidade.

\subsection{Estudo de convergência}

Um estudo de convergência faz-se necessário para avaliar a influência do número de nós $N$ sobre o resultado das simulações. A Tabela 5.1 apresenta os dados de entrada utilizados nas simulações, as quais contemplaram um número de nós entre 75 e 601.

A Tabela 5.2 apresenta os resultados das simulações, considerando as seguintes variáveis para comparação: período do ciclo de intermitência severa $t_{P}$; amplitude da pressão na base do riser durante o ciclo $\Delta P_{b}$; máximo comprimento de penetração de líquido no pipeline $x_{\text {max }}$; mínima altura do nível de líquido no riser $z_{u \text { min }}$; máxima velocidade superficial de gás na base do riser $j_{g b \max }$; e máxima fração de vazio na base do riser $\alpha_{b \max }$. Também são apresentados o menor passo temporal $\Delta t_{\text {min }}$ e o maior passo temporal $\Delta t_{\text {max }}$ para cada caso.

O intervalo de tempo simulado é de 10 horas. O tempo necessário para simular um caso usando a menor discretização (75 nós) é de cerca de 15 minutos, enquanto que usando a maior discretização (601 nós) é de aproximadamente 48 horas. Cada caso foi simulado utilizando um núcleo de uma estação composta por dois processadores do modelo Quad-core Intel Xeon (total de oito núcleos) com frequência (clock rate) de 2,66 GHz e 8 GB de memória RAM. Devido ao fato de oito casos serem rodados em paralelo, sendo cada caso simulado em um núcleo, a memória RAM era compartilhada pelos oito casos.

Para a construção de um mapa de estabilidade (ver Seção 5.5) são necessárias centenas de simulações; sendo assim é importante que o tempo consumido em uma simulação seja o mais 
Tabela 5.1: Dados de entrada para as simulações.

\begin{tabular}{|c|c|c|}
\hline Símbolo & Variável & Valores \\
\hline$\gamma_{A P I}$ & Densidade API & 19 \\
\hline$\gamma_{g}$ & Densidade relativa do gás & 0,6602 \\
\hline$Q_{g 0}$ & Vazão volumétrica de gás na condição padrão & $0,2 \mathrm{Sm}^{3} / \mathrm{s}$ \\
& & $\left.1410,24 \times 10^{3} \mathrm{scf} / \mathrm{d}\right)$ \\
\hline$G O R$ & Razão gás-óleo & 145 \\
& & $(814,11 \mathrm{scf} / \mathrm{STB})$ \\
\hline$W O R$ & Razão água-óleo & 0,3 \\
\hline$T$ & Temperatura & $323 \mathrm{~K}$ \\
\hline$D$ & Diâmetro interno & $4 "$ \\
\hline$W_{r}$ & Coordenada horizontal do topo do riser & $845 \mathrm{~m}$ \\
\hline$Z_{r}$ & Altura do topo do riser & $1300 \mathrm{~m}$ \\
\hline$\epsilon$ & Rugosidade & $4,6 \times 10^{-5} \mathrm{~m}$ \\
\hline$P_{s e p}$ & Pressão no separador & $25 \mathrm{bara}$ \\
\hline$Y$ & Salinidade & 0 \\
\hline$N$ & Número de nós & 101 \\
\hline$L$ & Comprimento do pipeline & $2000 \mathrm{~m}$ \\
\hline$\beta$ & Ângulo de inclinação do pipeline & 2 \\
\hline
\end{tabular}

Tabela 5.2: Estudo de convergência para diferentes números de nós.

\begin{tabular}{|c|c|c|c|c|c|c|c|c|}
\hline$N$ & $\Delta t_{\min }(s)$ & $\Delta t_{\max }(s)$ & $t_{P}(\min )$ & $\Delta P_{b}($ bara $)$ & $x_{\max }(\operatorname{m})$ & $z_{u \min }(\operatorname{m})$ & $j_{g b \max }(\operatorname{m} / s)$ & $\alpha_{b \max }(-)$ \\
\hline 75 & 1,839 & 53,51 & 98,3 & 71,99 & 88,48 & 726,18 & 1,49 \\
\hline 85 & 1,943 & 50,35 & 98,4 & 72,10 & 88,41 & 722,20 & 1,51 \\
\hline 91 & 1,647 & 50,10 & 98,1 & 72,16 & 88,47 & 722,44 & 1,51 & 0,64 \\
\hline 101 & 1,400 & 48,62 & 98,5 & 72,15 & 88,43 & 722,00 & 1,52 & 0,64 \\
\hline 151 & 1,154 & 28,14 & 98,9 & 72,19 & 88,40 & 709,83 & 1,54 & 0,64 \\
\hline 201 & 0,642 & 22,21 & 99,0 & 72,31 & 88,69 & 699,87 & 1,56 \\
\hline 301 & 0,439 & 14,01 & 99,3 & 72,38 & 87,98 & 734,26 & 1,55 & 0,65 \\
\hline 401 & 0,321 & 19,04 & 99,4 & 72,40 & 87,97 & 733,69 & 1,52 & 0,65 \\
\hline 501 & 0,290 & 19,76 & 99,4 & 72,41 & 88,04 & 731,77 & 1,48 & 0,64 \\
\hline 601 & 0,229 & 19,43 & 99,4 & 72,41 & 88,06 & 731,11 & 1,48 & 0,64 \\
\hline
\end{tabular}

breve possível, o que remete ao uso de um pequeno número de nós. Concorrentemente, para se obter menores erros ao aproximar derivadas espaciais e temporais por sua forma discretizada (ver Seção 4.1), deve-se utilizar o maior número de nós possível.

Observa-se que a discretização de 101 nós permite obter uma boa convergência das variáveis em comparação com o caso de maior número de nós, com maior diferença observada de 2,6\% para a máxima velocidade superficial de gás na base do riser. O tempo consumido na simulação utilizando 101 nós é de 30 minutos. Portanto, essa discretização será utilizada para os casos apresentados a seguir, assim como para a construção dos mapas de estabilidade. 


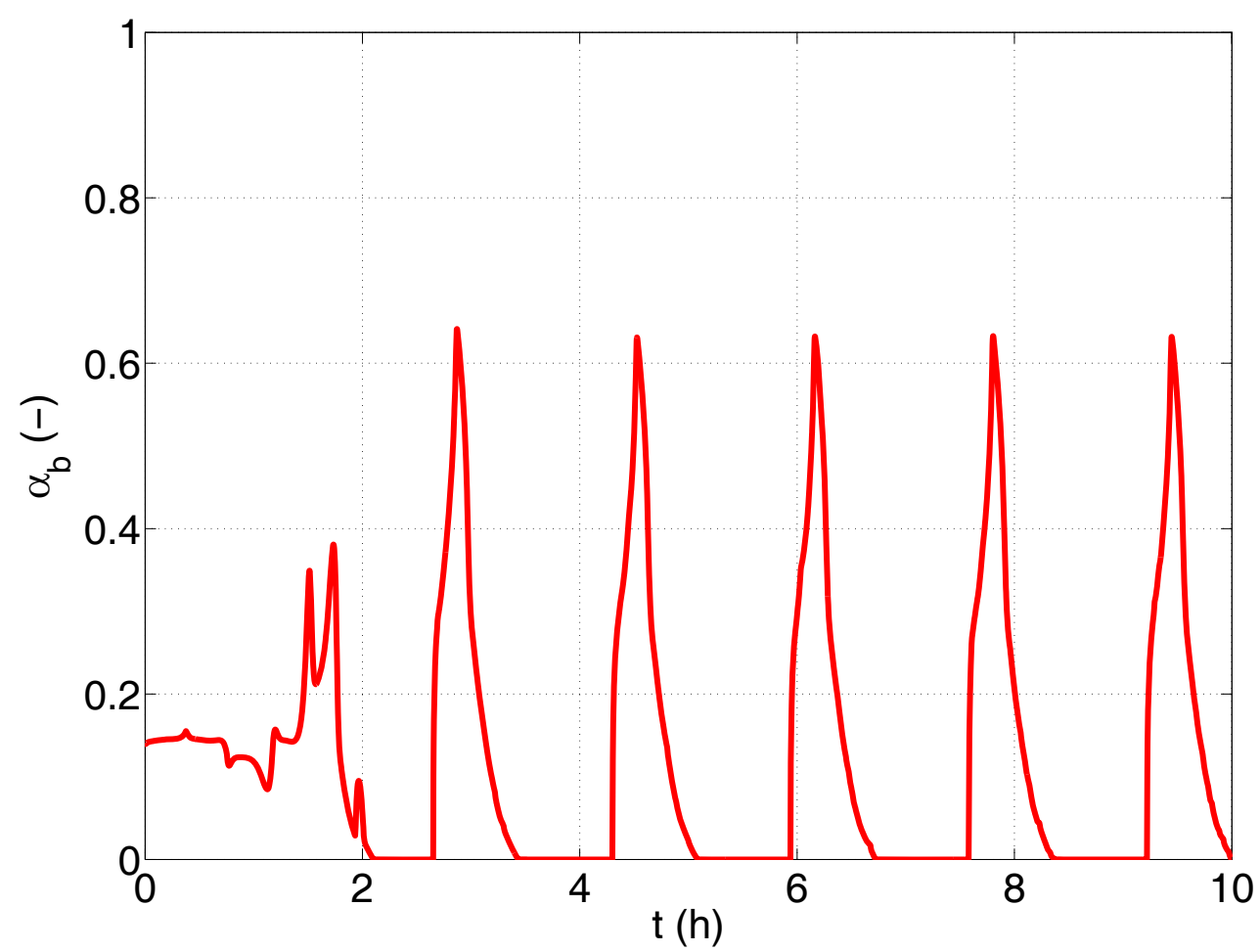

Figura 5.1: Fração de vazio na base do riser calculada com o modelo proposto.

\subsection{Validação}

A Tabela 5.1 apresenta os dados de entrada usados para realizar um estudo de caso. Por meio de simulações numéricas utilizando o modelo apresentado foi possível obter a resposta transiente de importantes variáveis, as quais são apresentadas a seguir: fração de vazio na base do riser (Fig. 5.1), fração volumétrica de óleo na base do riser (Fig. 5.2), fração volumétrica de água na base do riser (Fig. 5.3), velocidade superficial de gás (vermelho), óleo (preto) e água (azul) na base do riser (Fig. 5.4), velocidade superficial de gás (vermelho), óleo (preto) e água (azul) no nível de líquido no riser (Fig. 5.5), pressão na base do riser (Fig. 5.6), comprimento de penetração de líquido no pipeline (Fig. 5.7) e altura do nível de líquido no riser (Fig. 5.8).

Observe que o modelo exibe um comportamento transiente de aproximadamente três horas até que o ciclo limite seja alcançado, quando, então, fica evidente a ocorrência da intermitência severa.

Simulações com os mesmos dados de entrada também foram realizadas usando o software comercial OLGA (SPT Group, 2012), versão 6.2.4. O modelo desenvolvido usando OLGA considera 59 seções de aproximadamente 45 metros como discretização espacial e utiliza o módulo de black-oil para o cálculo das propriedades dos fluidos. 


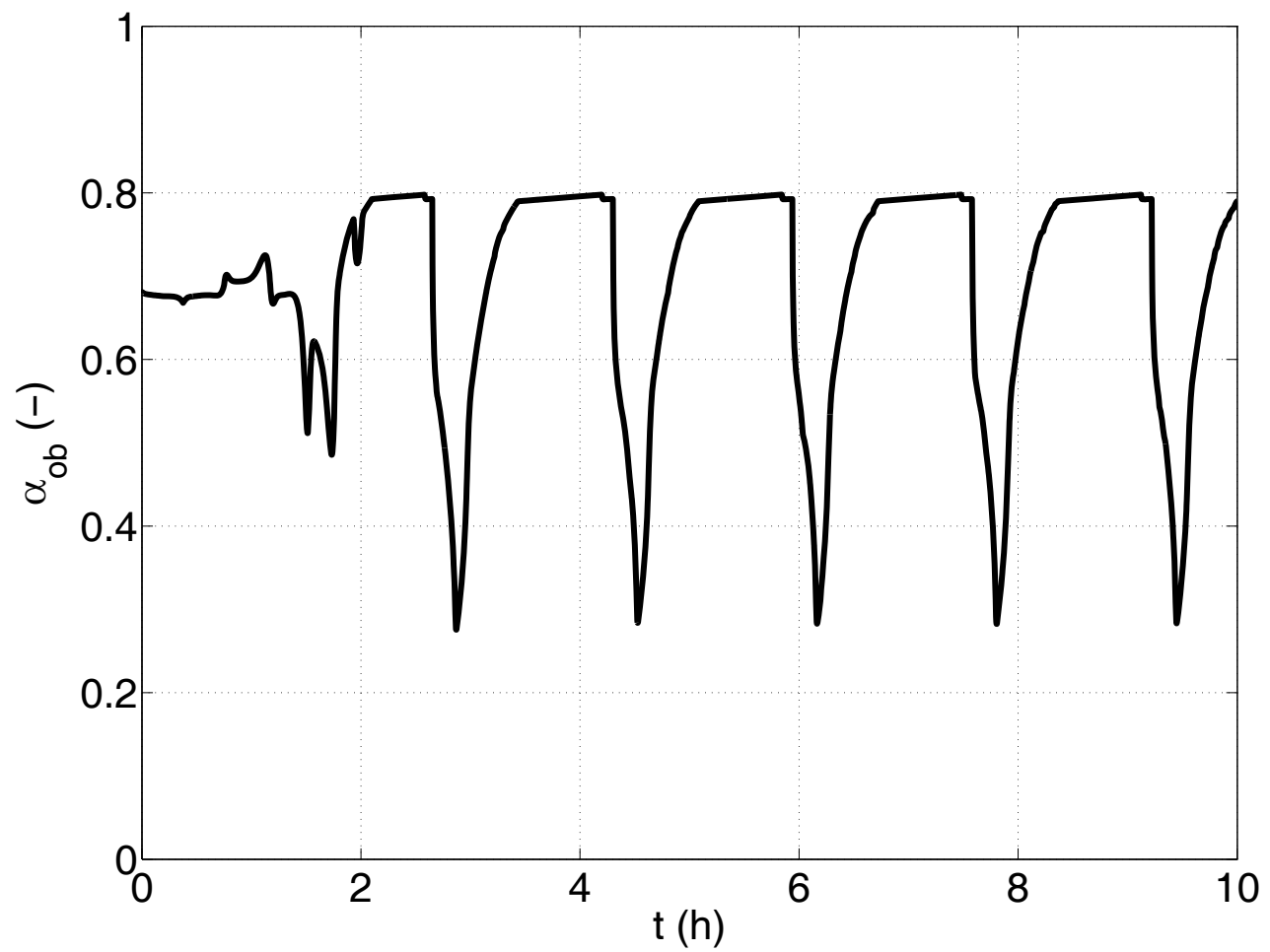

Figura 5.2: Fração volumétrica de óleo na base do riser calculada com o modelo proposto.

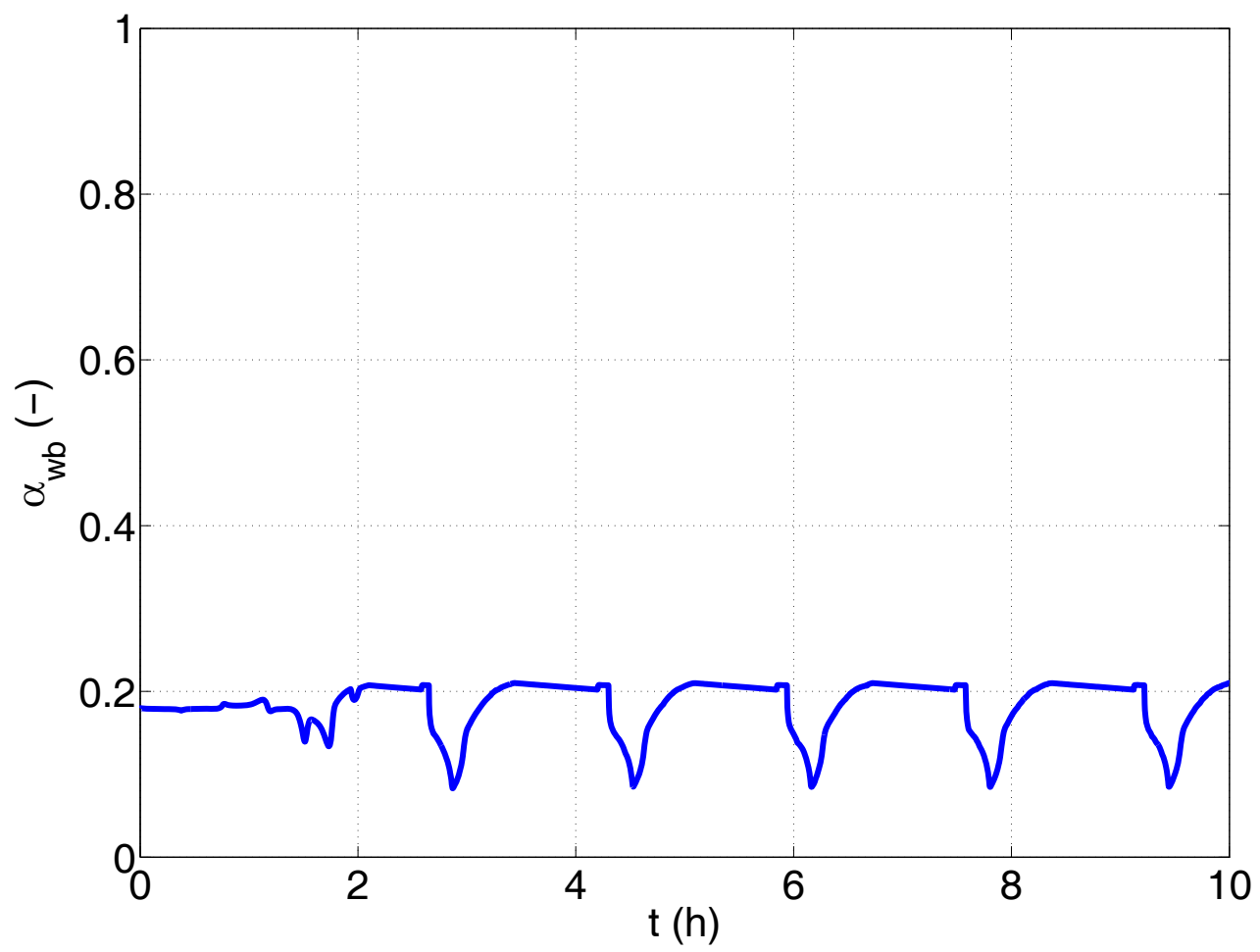

Figura 5.3: Fração volumétrica de água na base do riser calculada com o modelo proposto. 


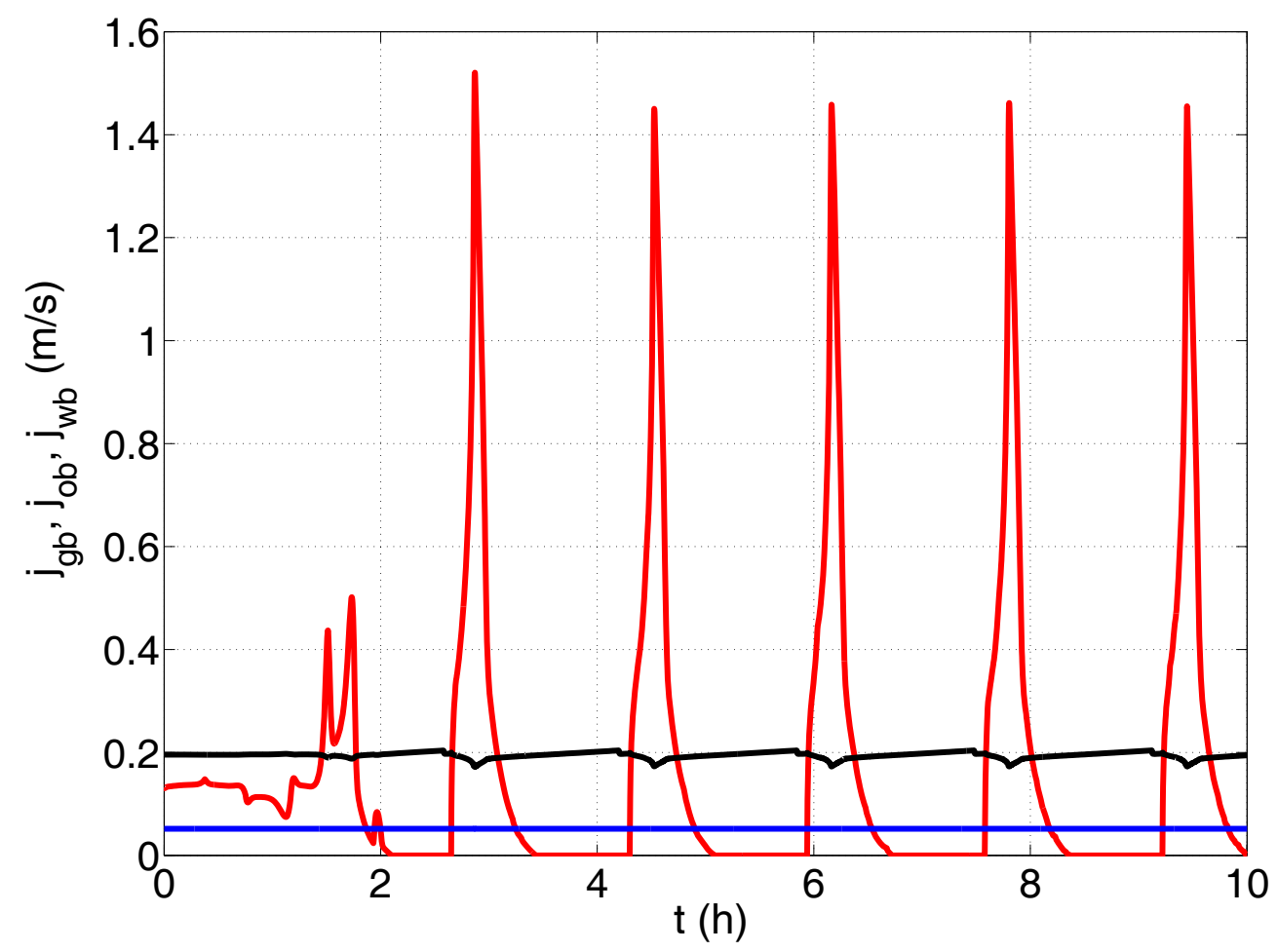

Figura 5.4: Velocidade superficial de gás (vermelho), óleo (preto) e água (azul) na base do riser calculada com o modelo proposto.

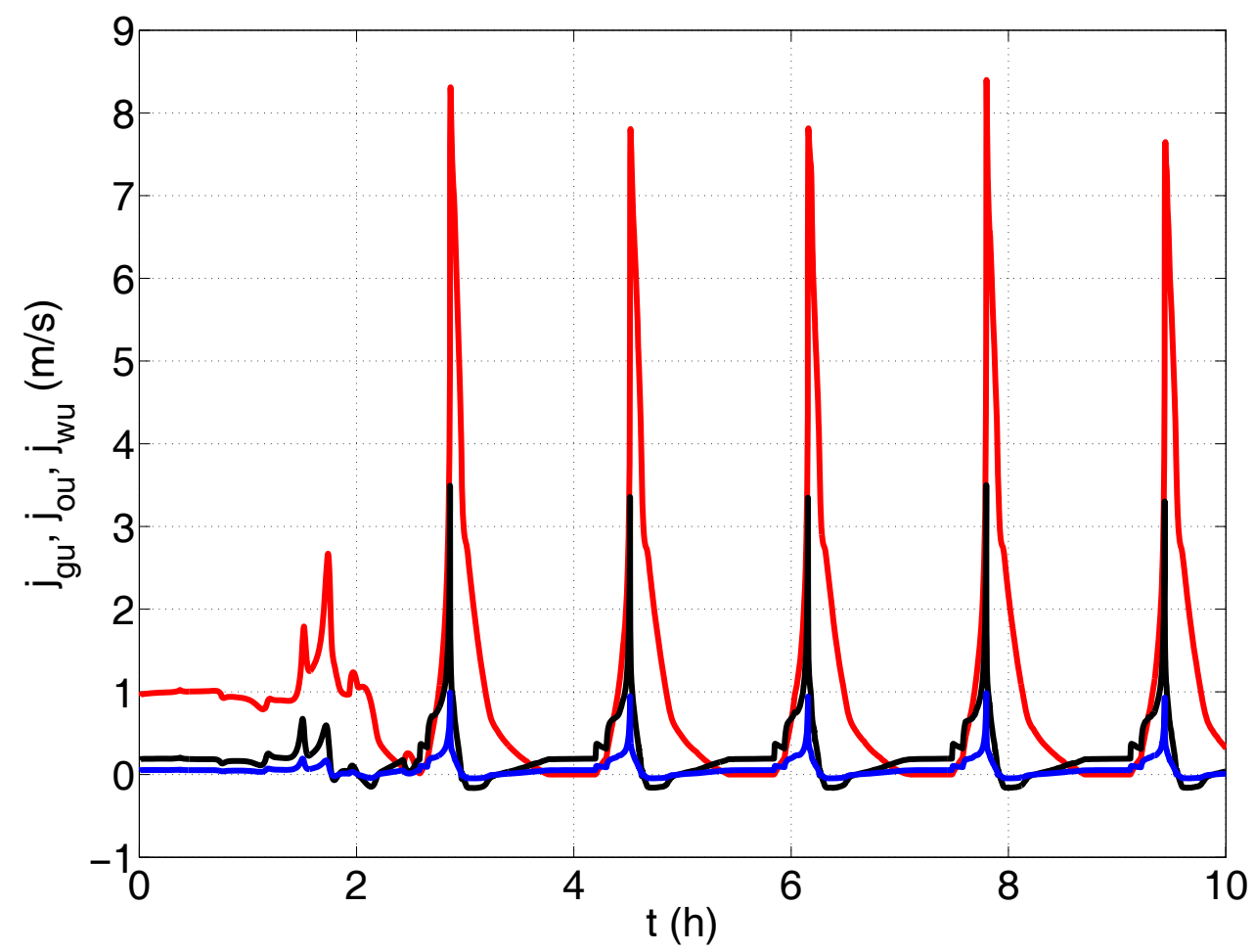

Figura 5.5: Velocidade superficial de gás (vermelho), óleo (preto) e água (azul) no topo do riser calculada com o modelo proposto. 


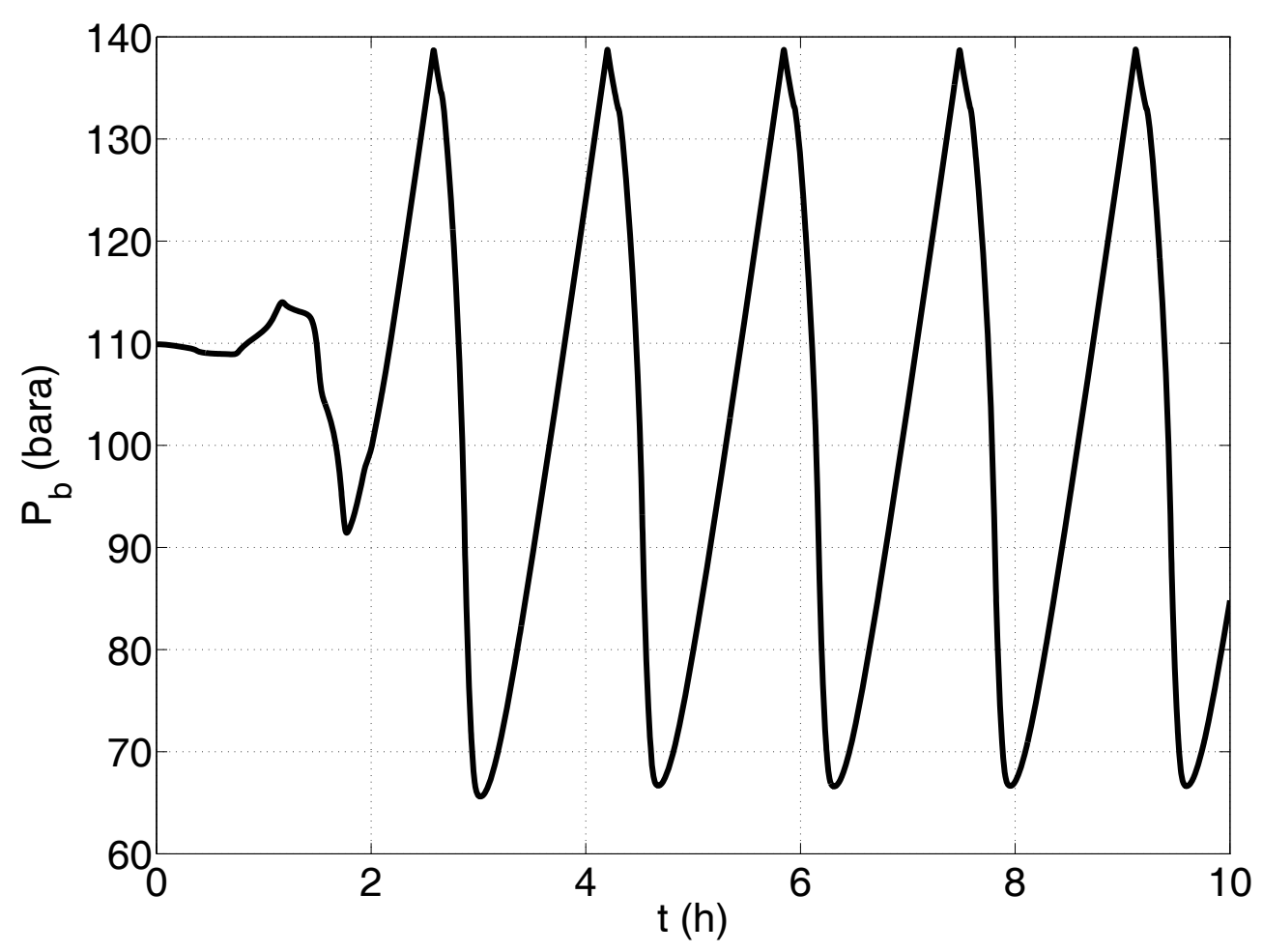

Figura 5.6: Pressão na base do riser calculada com o modelo proposto.

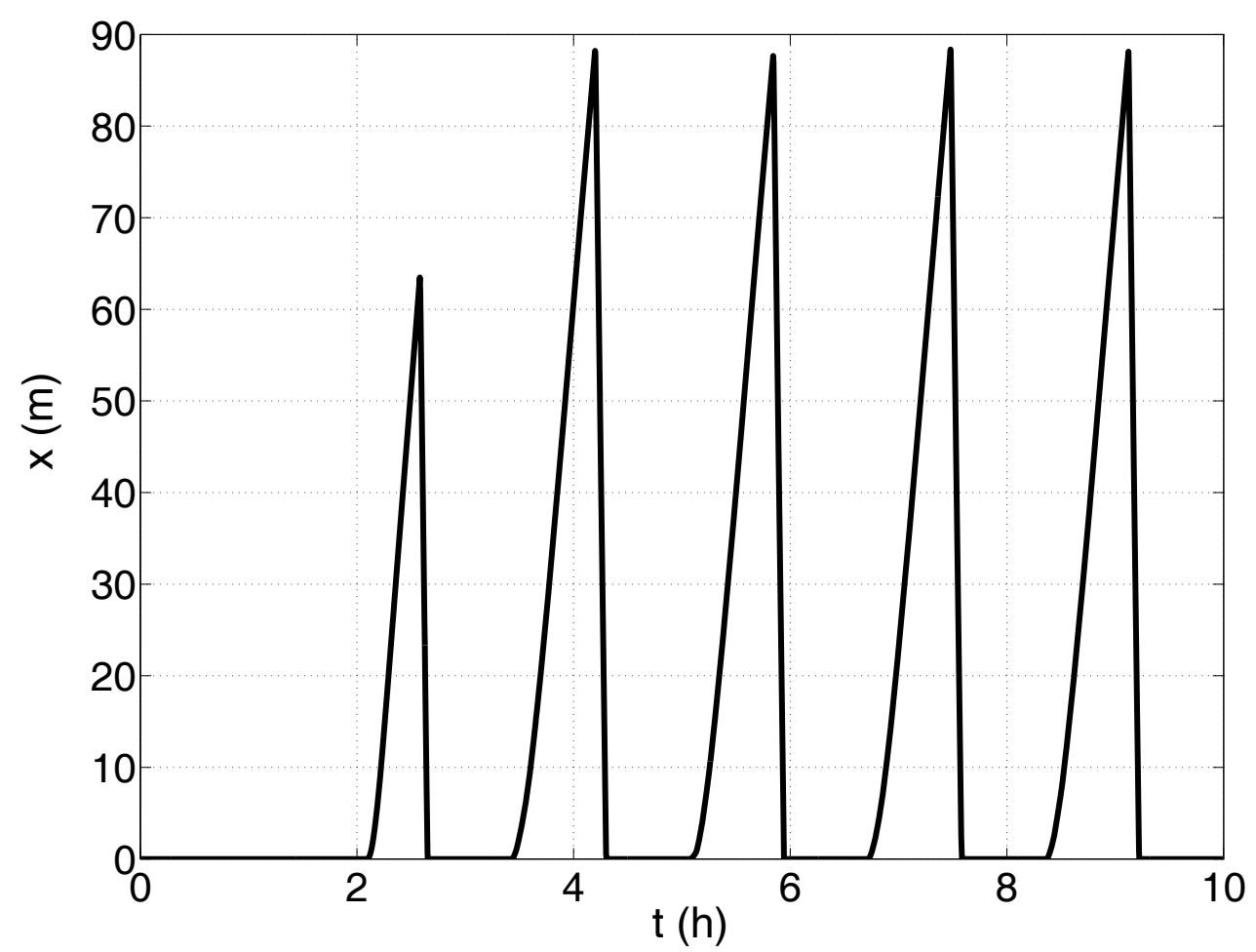

Figura 5.7: Comprimento de penetração de líquido no pipeline calculado com o modelo proposto. 


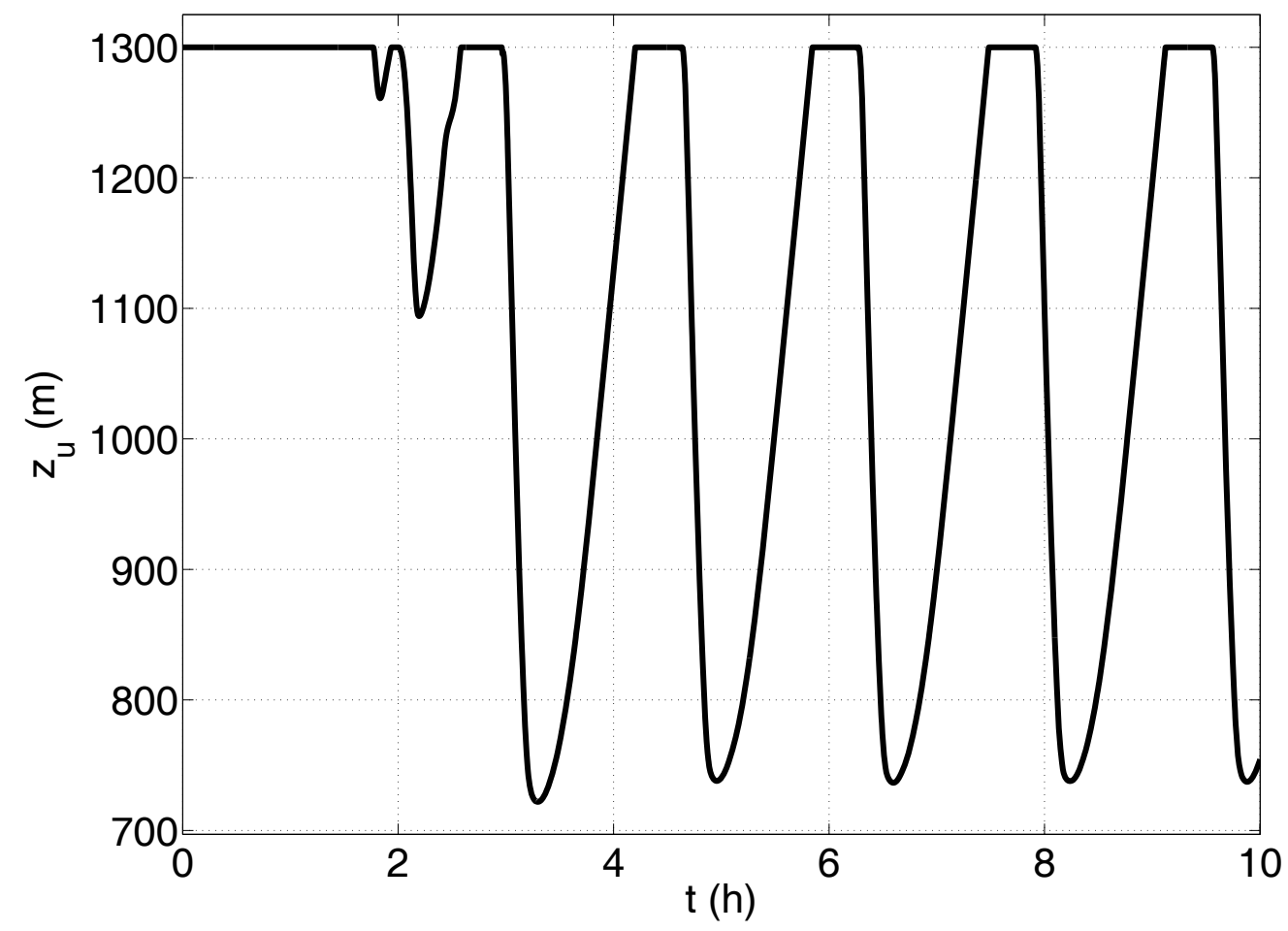

Figura 5.8: Altura da coluna de líquido no riser calculada com o modelo proposto.

As seguintes figuras mostram a resposta transiente de importantes variáveis usando o simulador OLGA: fração de vazio na base do riser (Fig. 5.9), fração volumétrica de óleo na base do riser (Fig. 5.10), fração volumétrica de água na base do riser (Fig. 5.11), velocidade superficial de gás (vermelho), óleo (preto) e água (azul) na base do riser (Fig. 5.12) e pressão na base do riser (Fig. 5.13).

Observa-se que as variáveis calculadas por meio do OLGA apresentam oscilações espúrias, ou seja, oscilações não-físicas, de alta frequência e ocorrem devido ao método numérico semi-implícito empregado. Essas oscilações fazem-se presentes nos resultados fornecidos pelo OLGA sempre que as vazões dos fluidos são de pequena magnitude. Como já mencionado, vazões com essa característica podem levar à ocorrência da intermitência severa, fazendo com que a simulação do fenômeno instável utilizando o OLGA apresente resultados afetados pelas oscilações indesejadas.

A Tabela 5.3 apresenta uma comparação entre os resultados obtidos com o modelo proposto e com o modelo desenvolvido usando o código OLGA. Os dados de entrada usados nas simulações são os mesmos apresentados na Tabela 5.1, exceto a vazão volumétrica de gás na condição padrão. Esse parâmetro define três diferentes casos: $Q_{g 0}=0,2 \mathrm{~m}^{3} / \mathrm{s}, Q_{g 0}=$ $0,4 \mathrm{~m}^{3} / \mathrm{s}$ e $Q_{g 0}=0,5 \mathrm{~m}^{3} / \mathrm{s}$. As pressões máxima e mínima na base do riser, $P_{b \max }$ and $P_{b \min }$ 


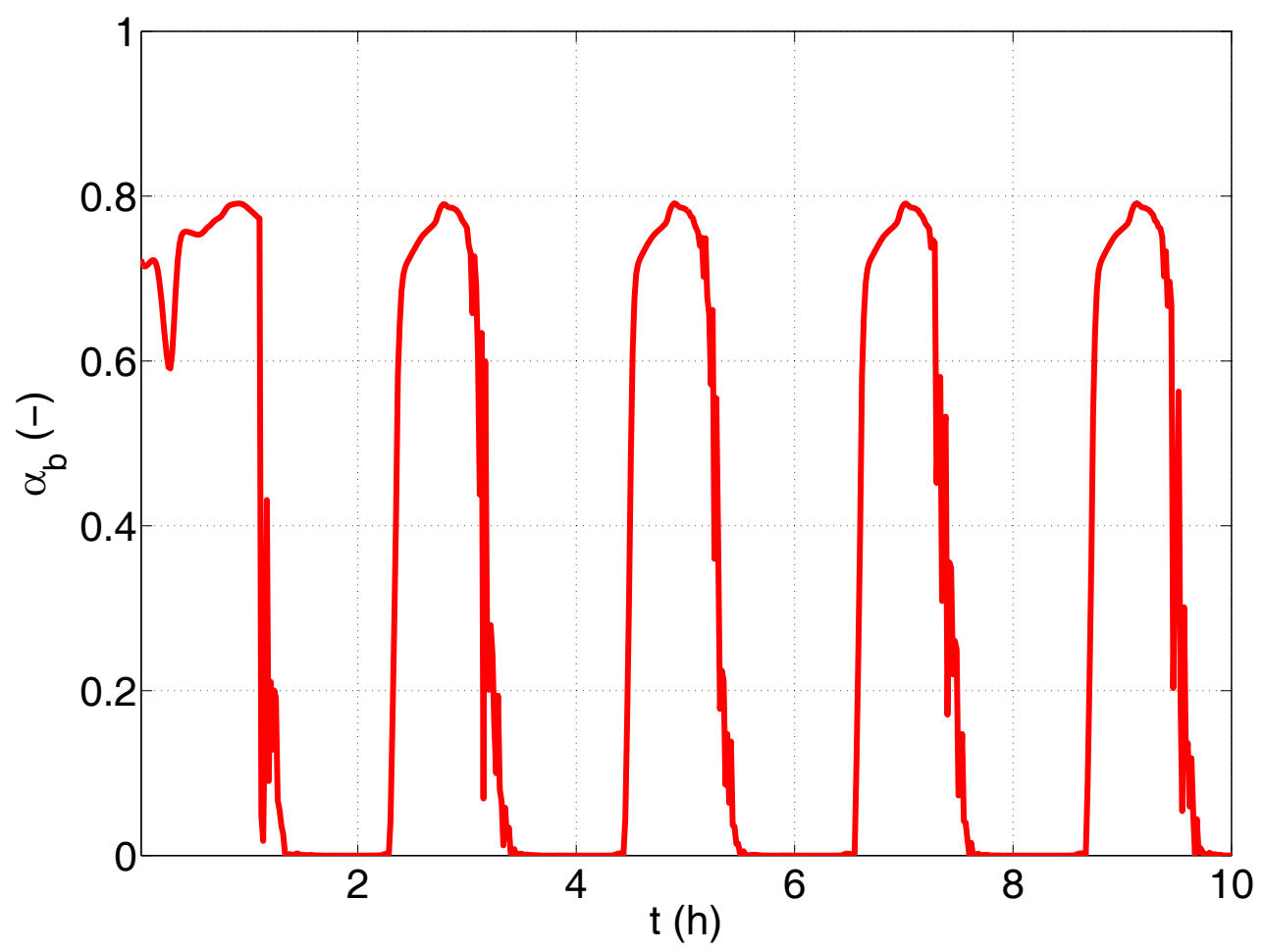

Figura 5.9: Fração de vazio na base do riser calculada com o código OLGA.

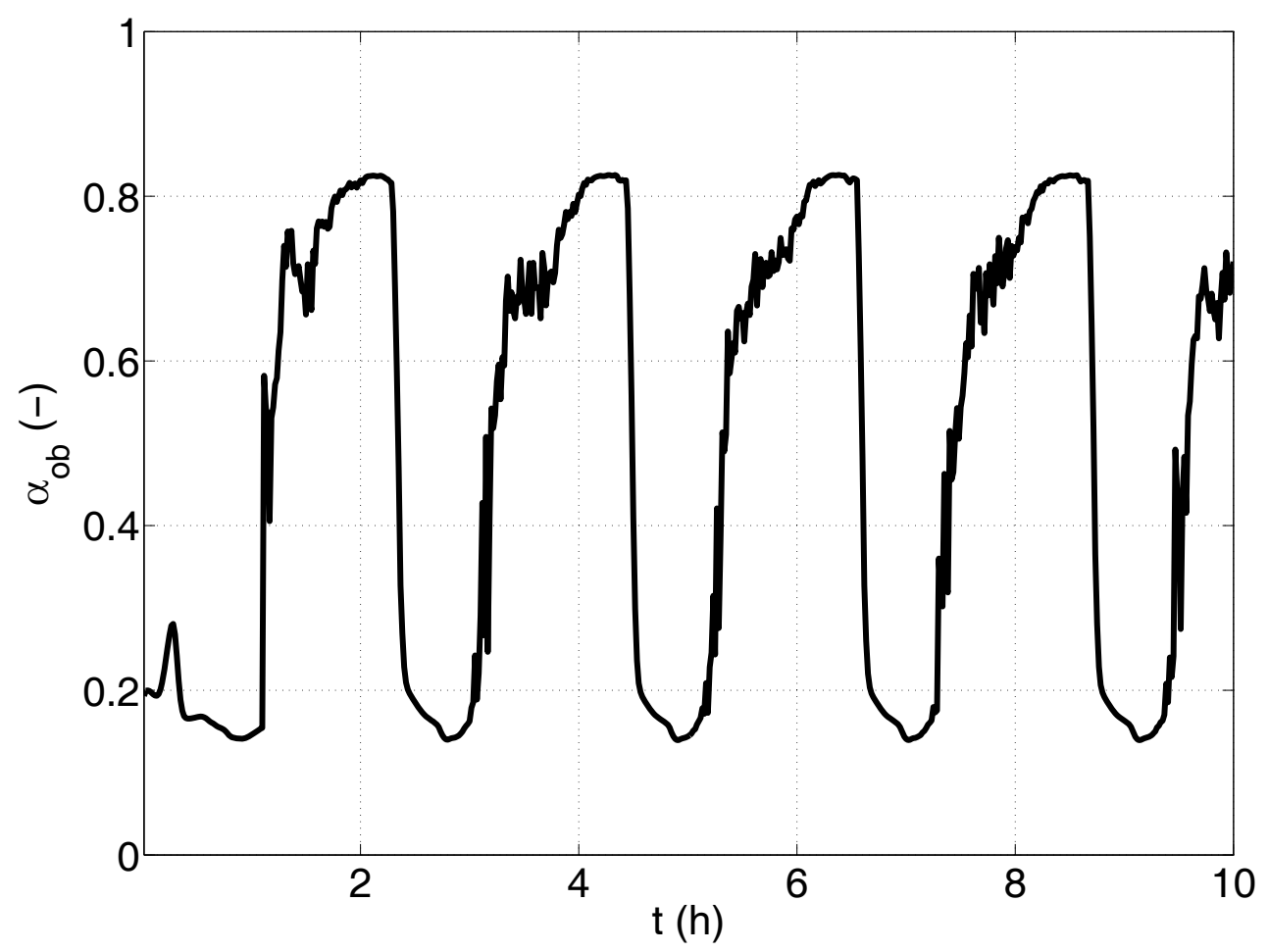

Figura 5.10: Fração volumétrica de óleo na base do riser calculada com o código OLGA. 


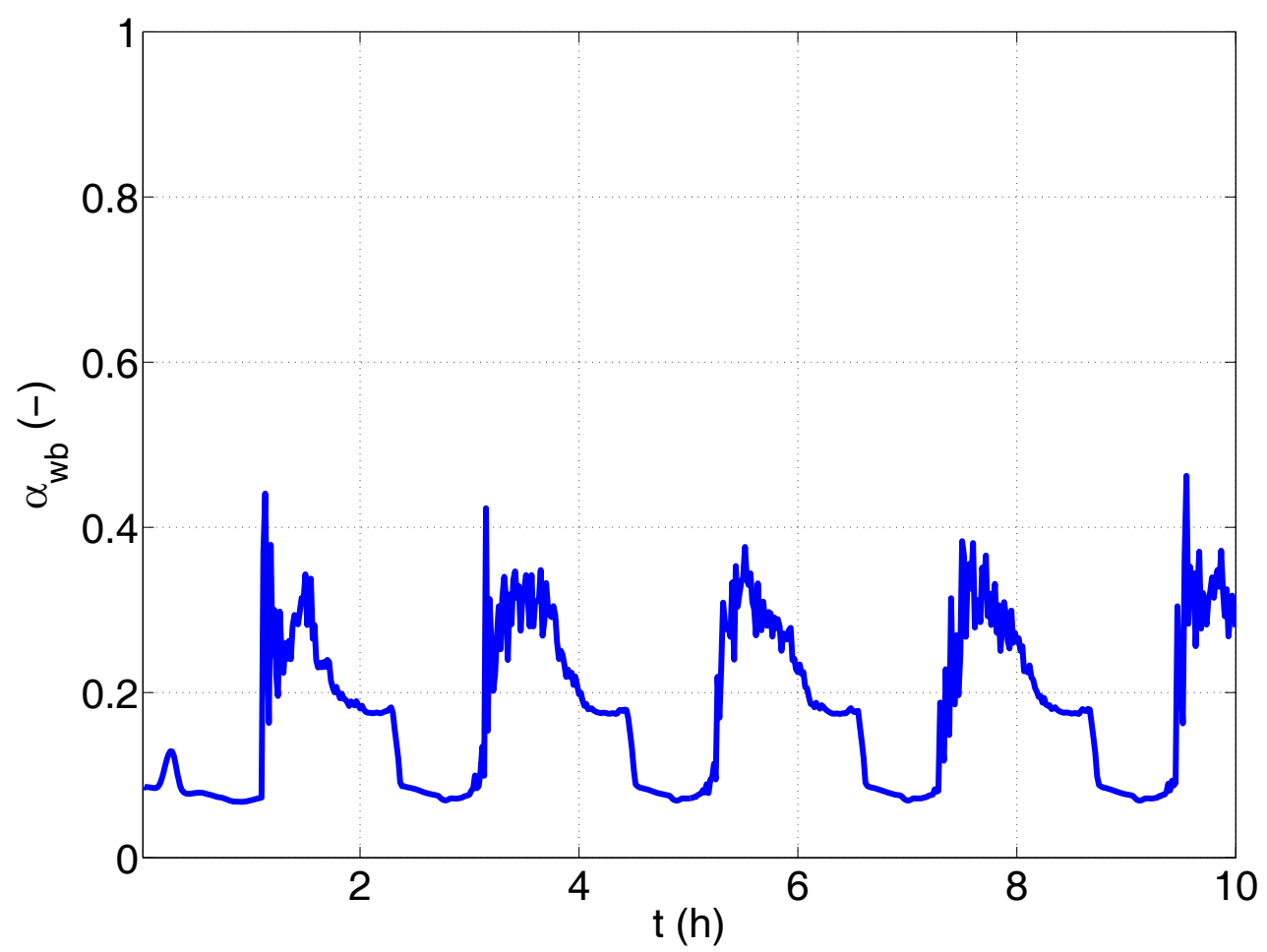

Figura 5.11: Fração volumétrica de água na base do riser calculada com o código OLGA.

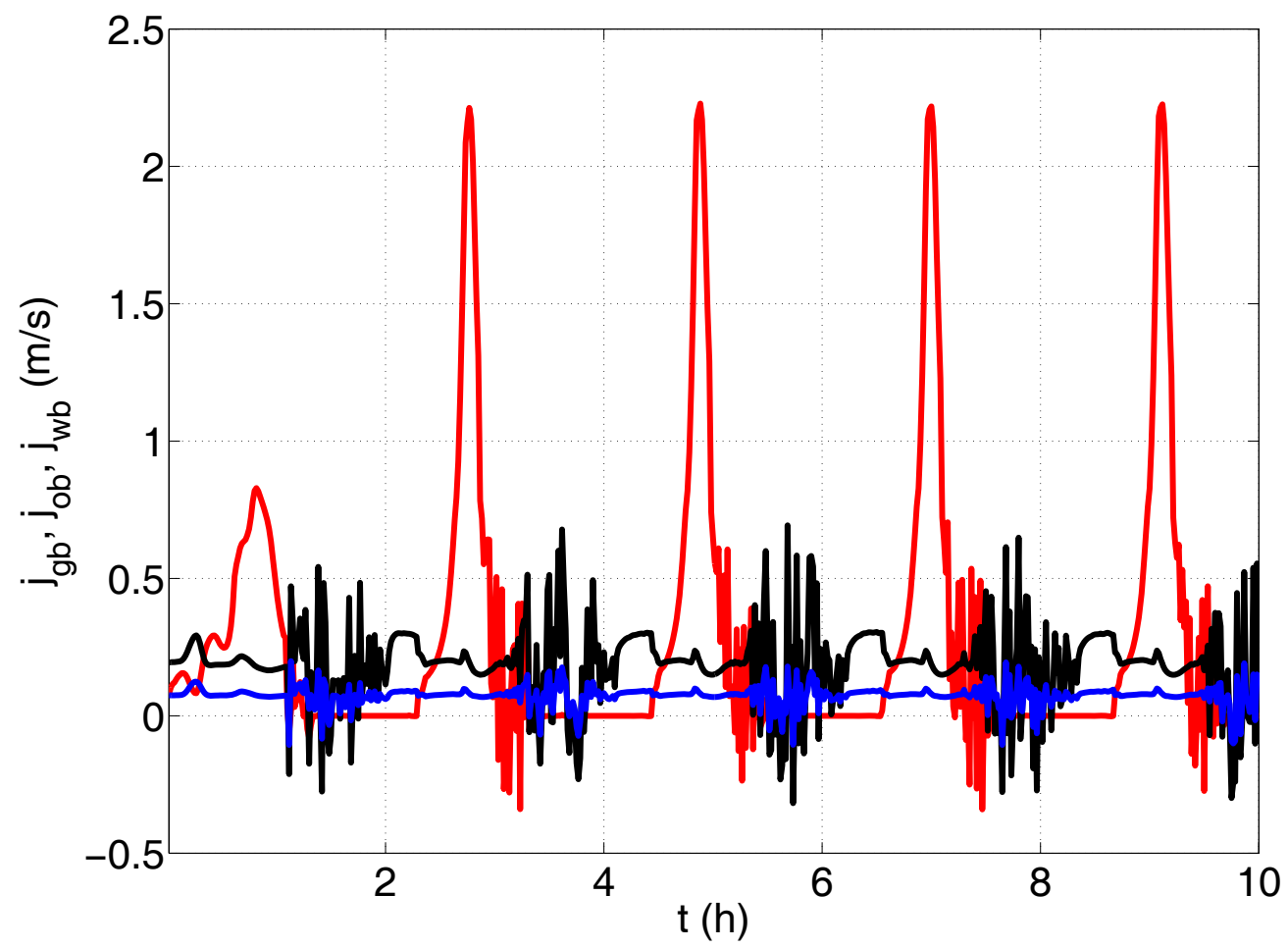

Figura 5.12: Velocidade superficial de gás (vermelho), óleo (preto) e água (azul) na base do riser calculada com o código OLGA. 


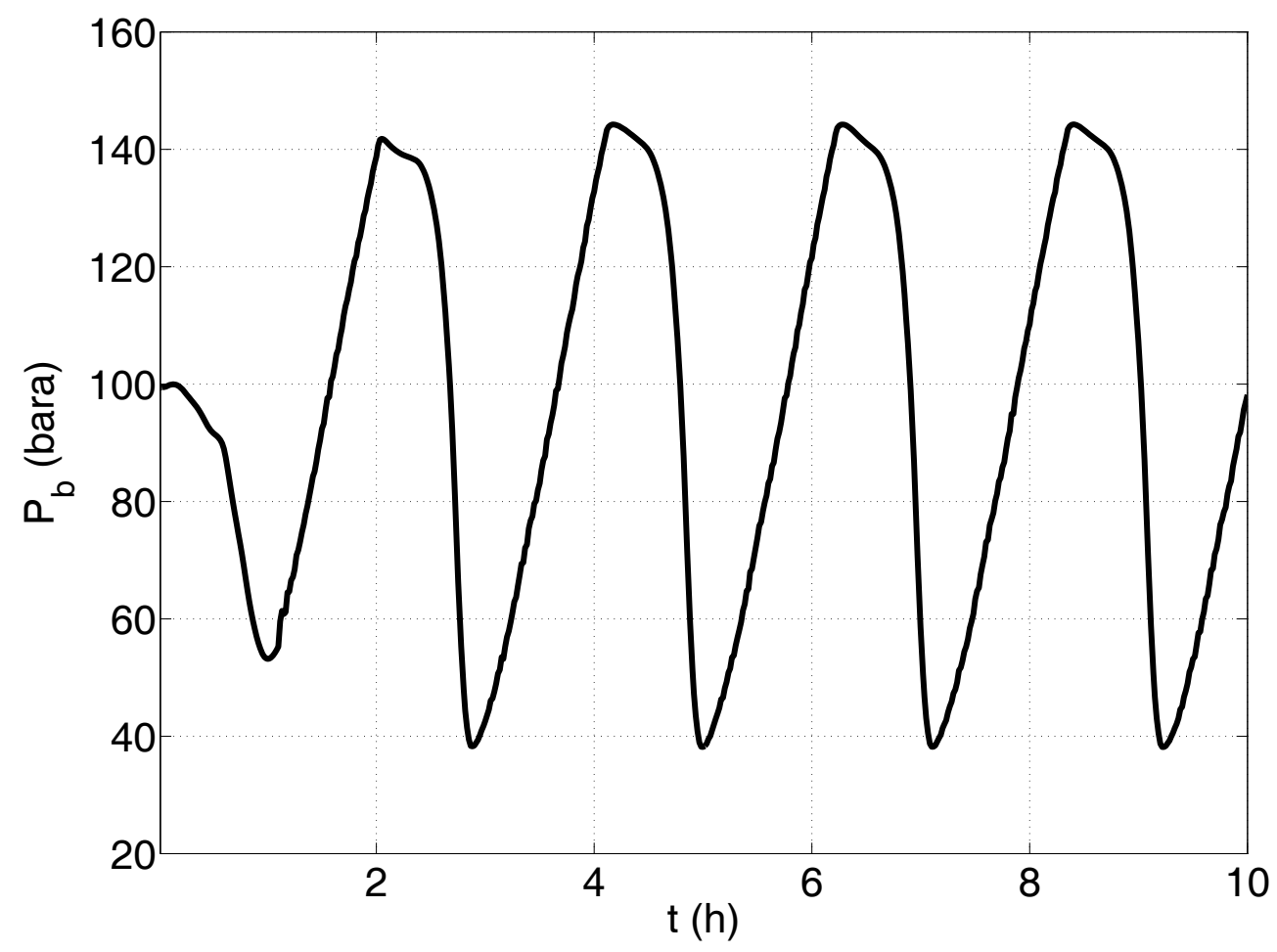

Figura 5.13: Pressão na base do riser calculada com o código OLGA.

respectivamente, a amplitude da pressão na base do riser $\Delta P$, o período do sinal de pressão na base do riser $t_{P}$ e a máxima velocidade superficial de gás na base do riser $j_{g b \max }$ são as variáveis usadas para comparar os resultados.

Vale ressaltar que os resultados deveriam ser comparados com dados experimentais ou de campo como referência. Entretanto, na ausência de tais dados, resultados provenientes do software OLGA - validado utilizando dados experimentais da SINTEF (SINTEF, 2012) - podem ser considerados como referência alternativa. Como o código OLGA possui diferentes modelos e procedimentos numéricos, não é esperado obter os mesmo resultados, mas as mesmas tendências devem ser observadas em ambos os casos. Observando os resultados contidos na Tabela 5.3 , pode-se afirmar que o modelo proposto apresenta resultados coerentes com os previstos pelo OLGA na predição da intermitência severa.

\subsection{Descrição da intermitência severa utilizando o modelo proposto}

De acordo com Schmidt, Doty e Dutta-Roy (1985) e Taitel (1986), um ciclo de intermitência severa para sistemas água-ar pode ser descrito de acordo com os seguintes estágios: (i) formação 
Tabela 5.3: Comparação entre os resultados obtidos com o modelo proposto e com o código OLGA.

\begin{tabular}{|c|c|c|c|c|c|c|c|c|c|}
\hline & \multicolumn{3}{|c|}{$Q_{g 0}=0,2 \mathrm{~m}^{3} / \mathrm{s}$} & \multicolumn{3}{c|}{$Q_{g 0}=0,4 \mathrm{~m}^{3} / \mathrm{s}$} & \multicolumn{3}{c|}{$Q_{g 0}=0,5 \mathrm{~m}^{3} / \mathrm{s}$} \\
\cline { 2 - 10 } & Modelo & OLGA & $\Delta(\%)$ & Modelo & OLGA & $\Delta(\%)$ & Modelo & OLGA & $\Delta(\%)$ \\
\hline$P_{\text {max }}$ (bar $)$ & 138,73 & 144,23 & $-3,81$ & 136,82 & 126,17 & 8,44 & 131,68 & 100,17 & 31,46 \\
\hline$P_{b \min }($ bar $)$ & 66,59 & 38,16 & 74,51 & 71,93 & 54,18 & 32,77 & 75,15 & 65,54 & 14,67 \\
\hline$\Delta P($ bar $)$ & 72,14 & 106,07 & $-31,98$ & 64,89 & 71,99 & $-9,87$ & 56,52 & 34,62 & 63,24 \\
\hline$t_{P}($ min $)$ & 98,52 & 127,01 & $-22,43$ & 50,53 & 59,00 & $-14,36$ & 40,81 & 51,00 & $-19,98$ \\
\hline$j_{g b \max }(\mathrm{m} / \mathrm{s})$ & 1,46 & 2,23 & $-34,34$ & 1,51 & 1,52 & $-0,27$ & 1,32 & 1,14 & 15,79 \\
\hline
\end{tabular}

da golfada (slug formation), (ii) produção da golfada (slug production), (iii) penetração de gás (blowout ou bubble penetration) e (iv) expulsão de gás (blowdown). A Fig. 2.1 mostra os diferentes estágios no histórico de pressão na base do riser correspondente a um experimento sob condições de laboratório desenvolvido por Schmidt, Doty e Dutta-Roy (1985).

A partir dos resultados das simulações, os mesmos estágios são observados no ciclo de intermitência severa incluindo efeitos de transferência de massa; entretanto, o histórico de pressão tem uma evolução ligeiramente diferente. A Fig. 5.14 mostra o histórico de pressão para o caso apresentado na Tabela 5.1, cujos resultados da simulação são apresentados nas Figs. $5.1-5.8$.

A análise dos resultados das simulações permite descrever o ciclo de intermitência severa com transferência de massa. Historicamente, o início do ciclo é caracterizado pela fase de formação da golfada, tendo como ponto de partida o momento em que a pressão na base do riser $P_{b}$ é mínima (ver Fig. 5.15(a)). Nessa condição, o comprimento de penetração de líquido $x$ é zero, isto é, o gás penetra livremente no riser. A distribuição da fração de vazio no riser é alta, sendo aproximadamente 0,2 na base e 0,75 no nível de líquido $z_{u}$, devido à expansão e aos efeitos de vaporização. O nível de líquido no riser está localizado em uma posição intermediária com relação aos valores máximo e mínimo que a variável pode assumir durante o ciclo todo.

O nível de líquido possui uma velocidade negativa, de modo que seu menor nível no ciclo é alcançado (ver Fig. 5.15(b)); neste momento o comprimento de penetração de líquido $x$ continua a ser zero; entretanto, a velocidade superficial de gás na base do riser $j_{g b}$ decresce rapidamente, causando uma redução na distribuição da fração de vazio ao longo do riser.

Alguns minutos depois, o comprimento de penetração de líquido $x$ torna-se positivo, bloqueando a passagem de gás para o riser (ver Fig. 5.15(c)). O nível de líquido tem agora uma velocidade positiva, estando localizado alguns metros acima de seu nível mínimo. 


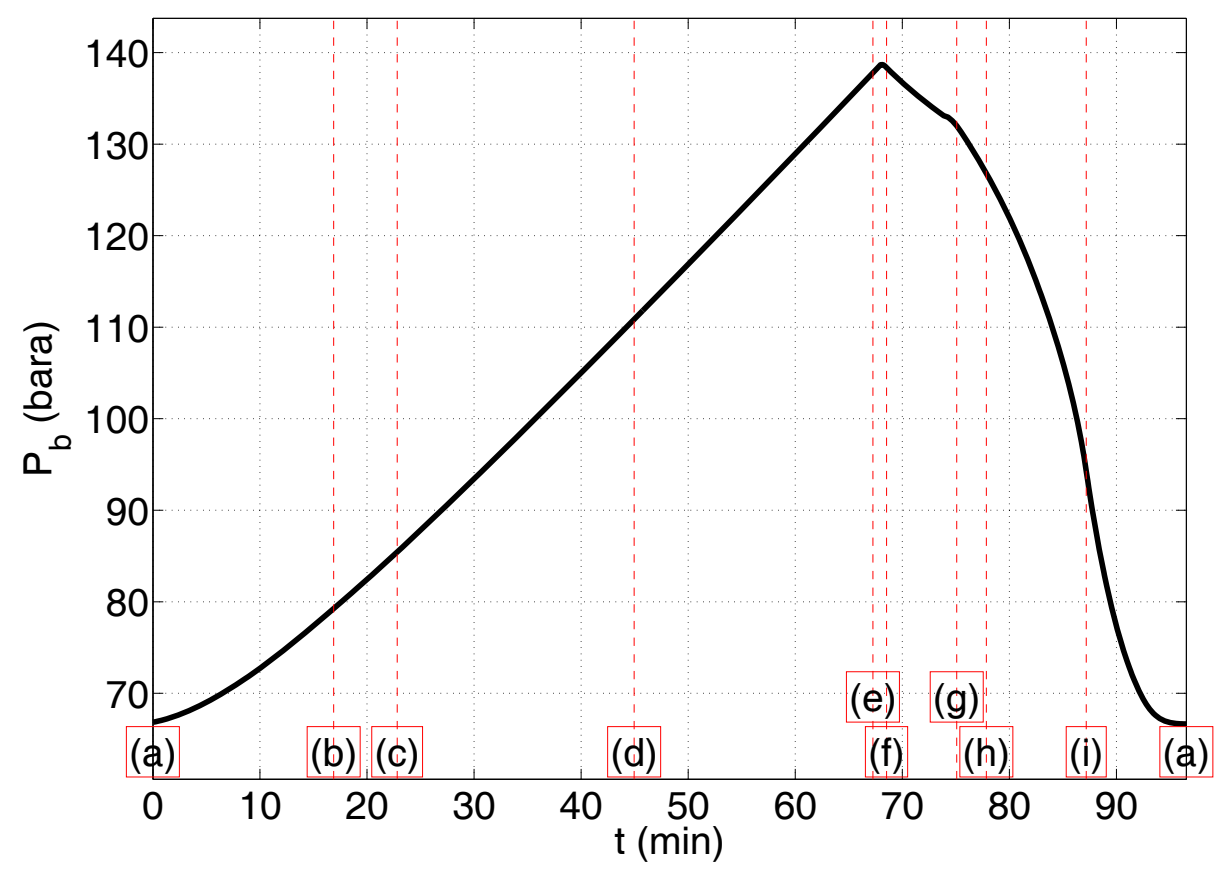

Figura 5.14: Histórico de pressão na base do riser para intermitência severa com efeitos de transferência de massa (as letras representam os diferentes estágios apresentados na Fig. 5.15).

Como o gás que ascendia na coluna de líquido avança para o topo do riser, acumulandose nessa posição, ou condensa, a coluna de líquido atinge um estado em que a presença de gás não mais é observada (ver Fig. 5.15(d)). Devido ao fato de o suprimento de líquido na base do riser continuar praticamente inalterado, o nível de líquido no riser aumenta e a coluna de líquido no riser se torna mais pesada. Com isso, a pressão na base do riser aumenta continuamente, levando ao aumento do comprimento de penetração de líquido, comprimindo o gás no pipeline.

A condição de ausência de gás no riser permanece até o momento em que o maior valor para o comprimento de penetração de líquido, assim como o máximo nível de líquido no riser, são alcançados. Neste instante, a pressão na base do riser é máxima (ver Fig. 5.15(e)).

Imediatamente após o nível de líquido alcançar seu nível máximo (o topo do riser), ocorre vaporização e a fase gasosa é novamente observada no riser (ver Fig. 5.15(f)). Como consequência, a mistura que deixa o topo do riser e adentra o separador apresenta algum teor de gás durante os quatro estágios do ciclo de intermitência severa, sendo esta uma importante diferença com relação aos sistemas água-ar.

Dado que o gás continua a adentrar o pipeline, a pressão da região estratificada de gás eventualmente iguala e supera a pressão imposta pelo riser, de modo que a frente de acúmulo 


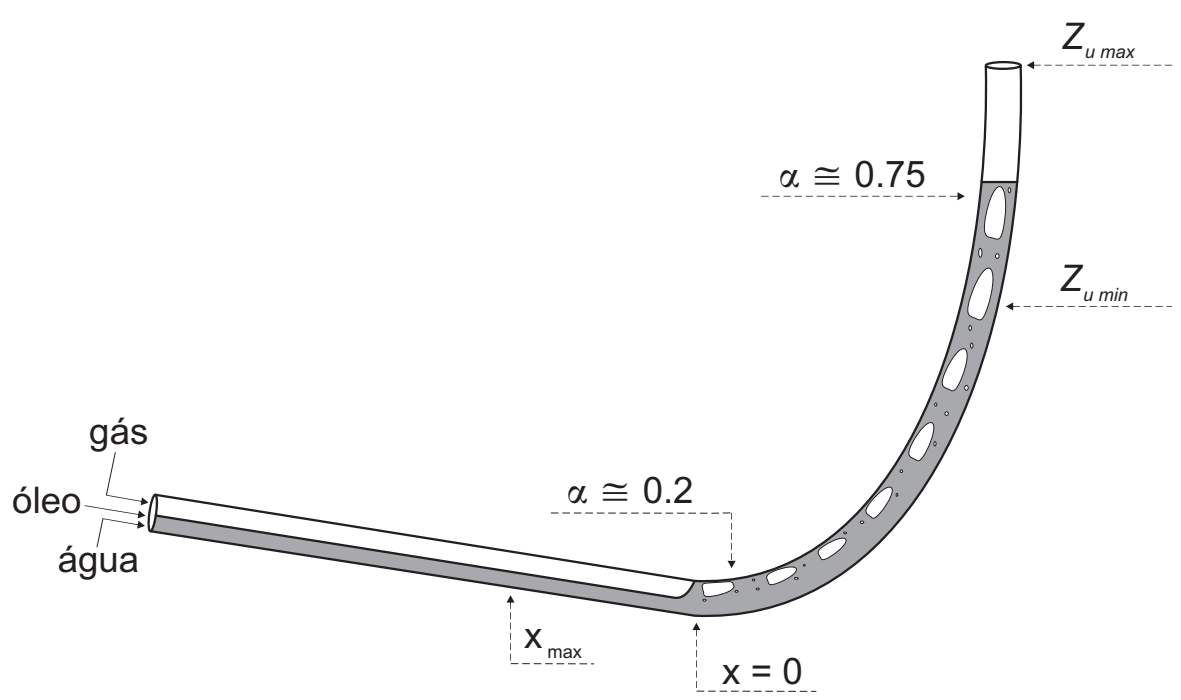

(a) $t=0 \mathrm{~min}$

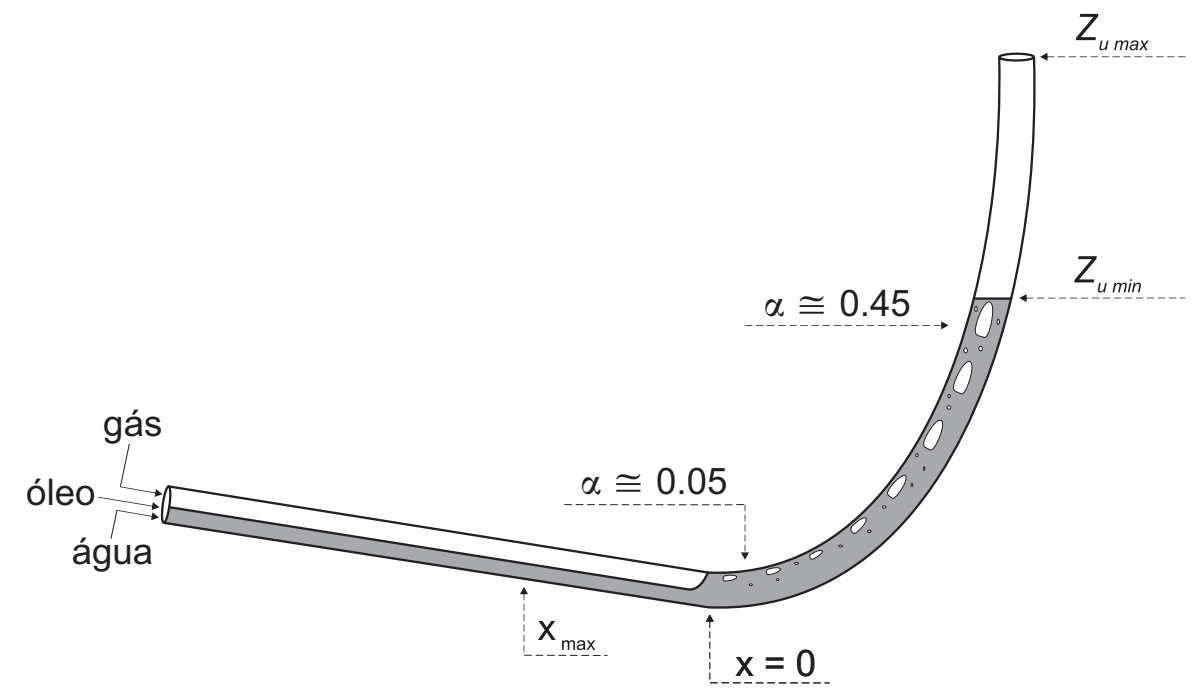

(b) $t \cong 17 \mathrm{~min}$

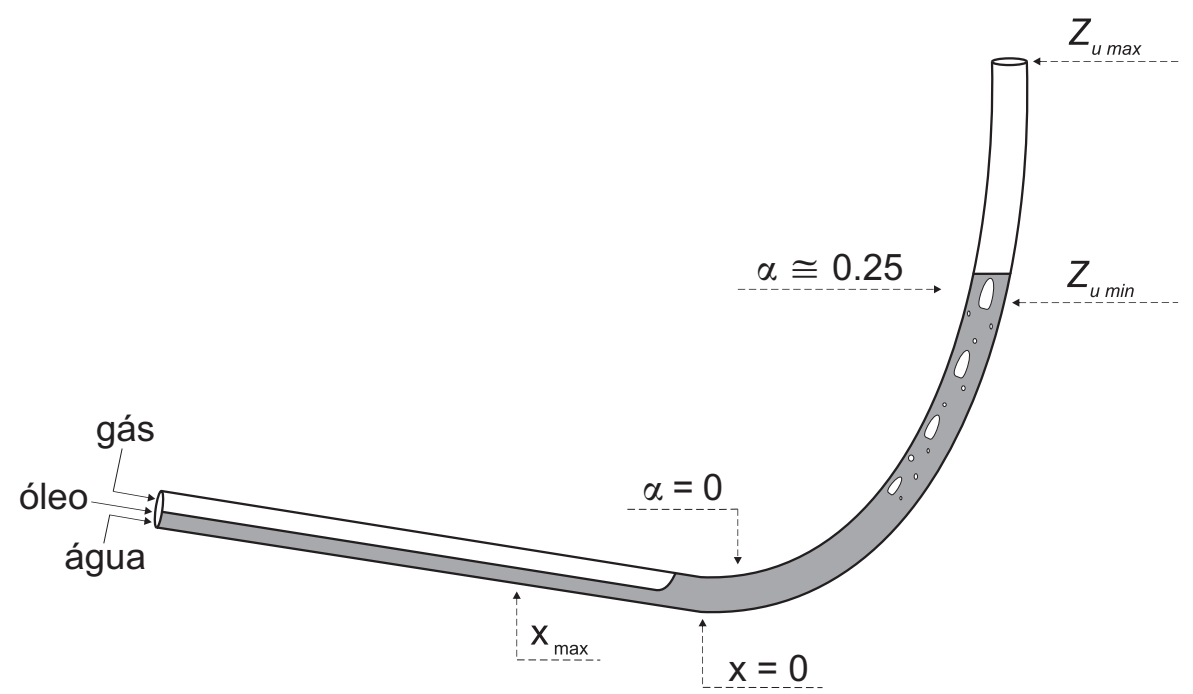

(c) $t \cong 23 \mathrm{~min}$ 


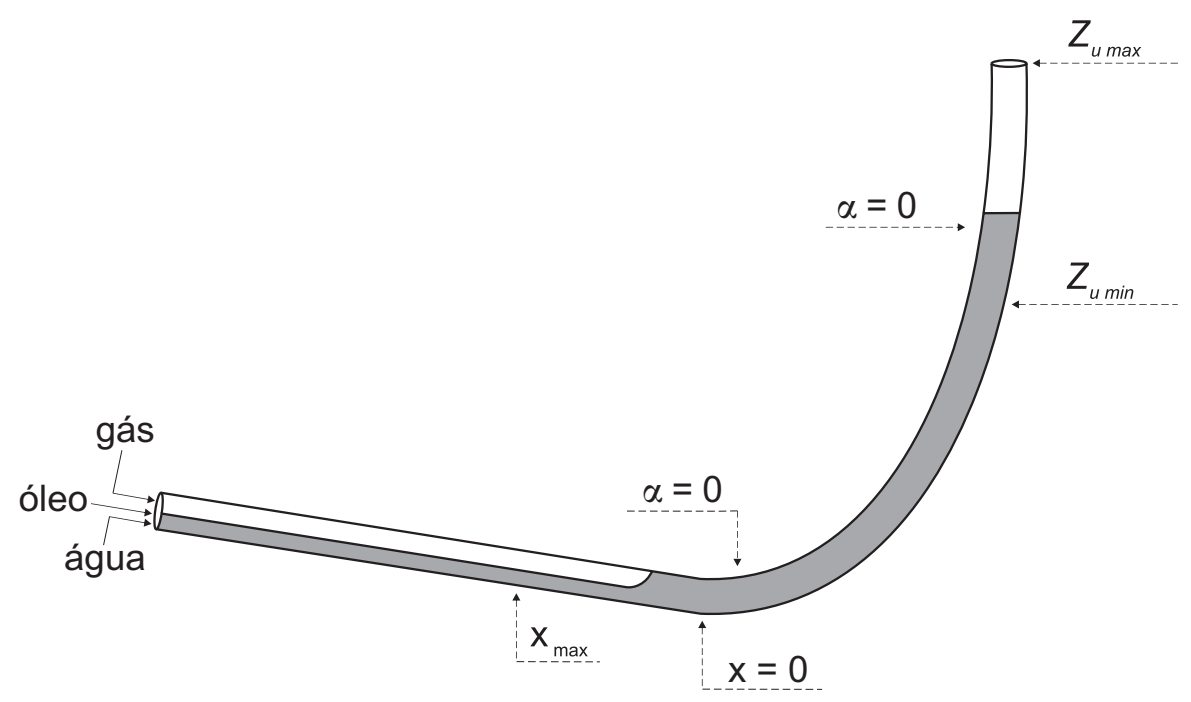

(d) $t \cong 45 \mathrm{~min}$

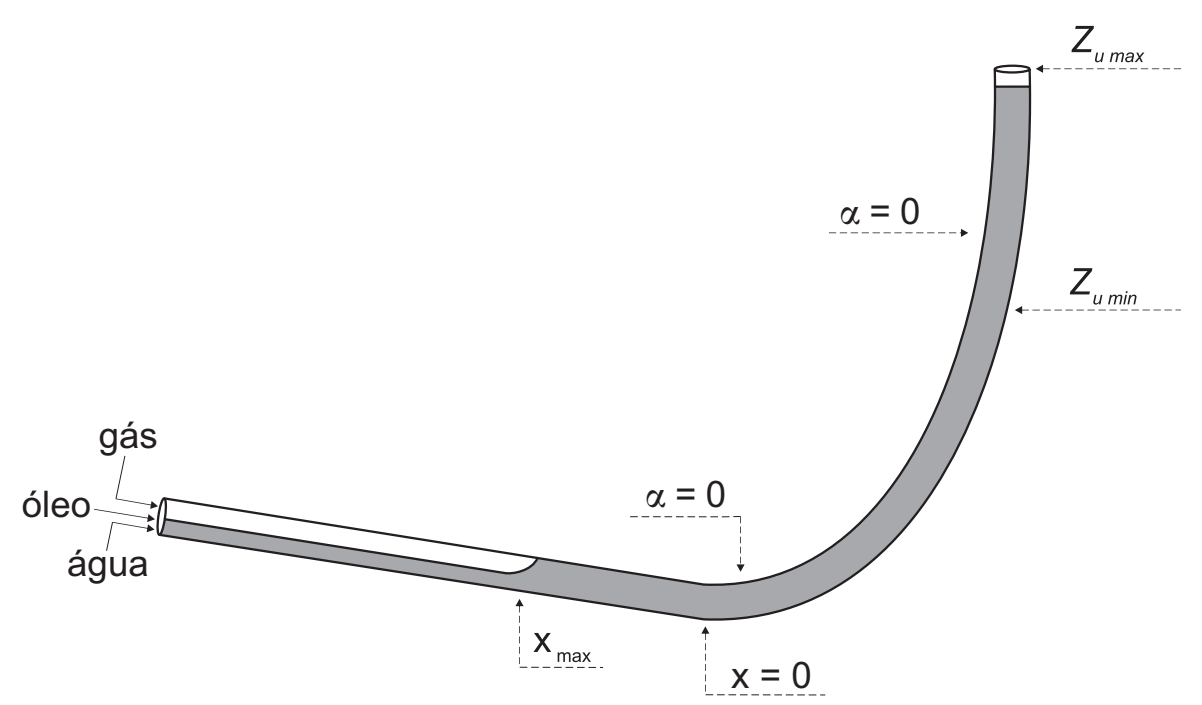

(e) $t \cong 67 \mathrm{~min}$

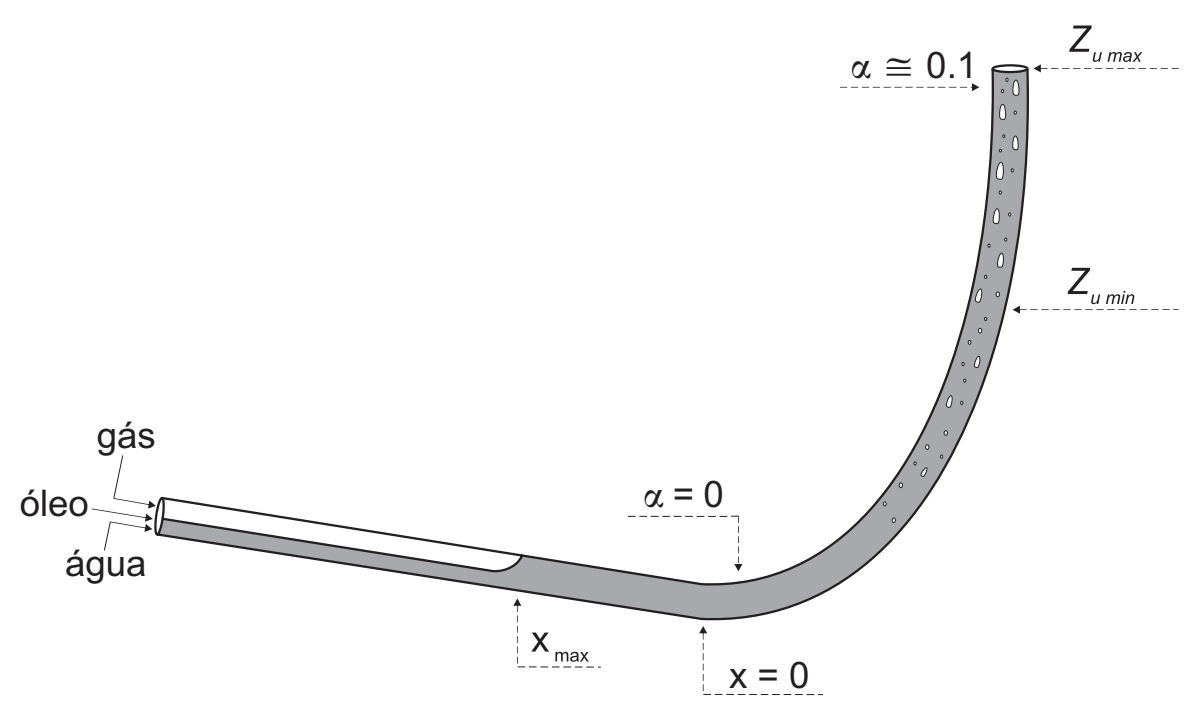

(f) $t \cong 69 \mathrm{~min}$ 


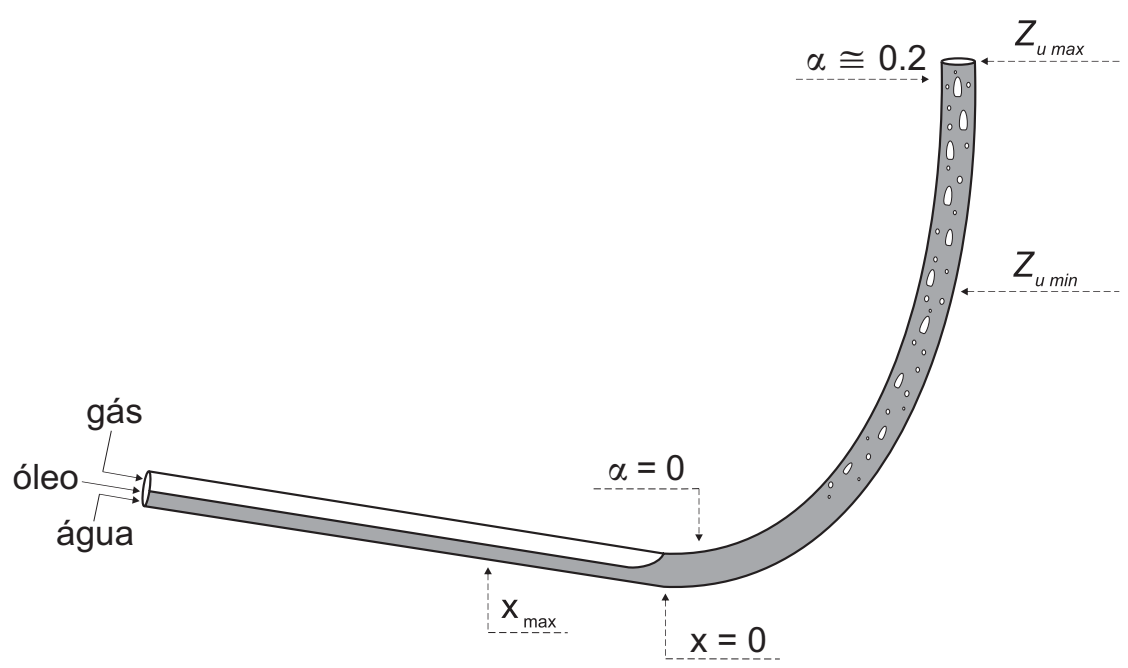

(g) $t \cong 75 \min$

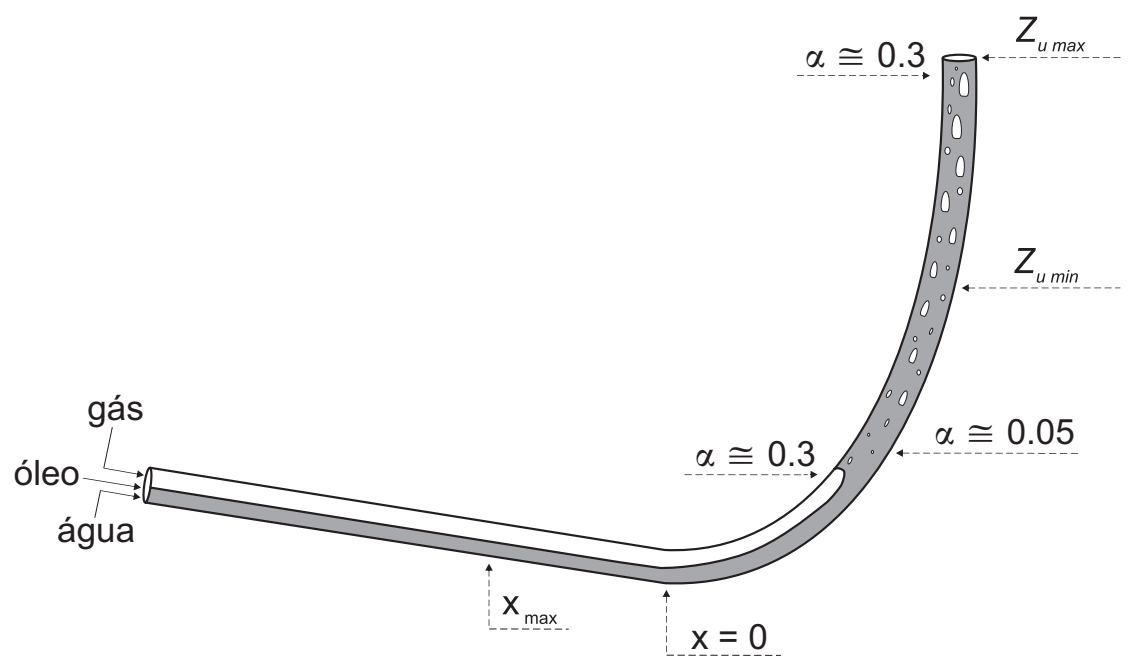

(h) $t \cong 78 \min$

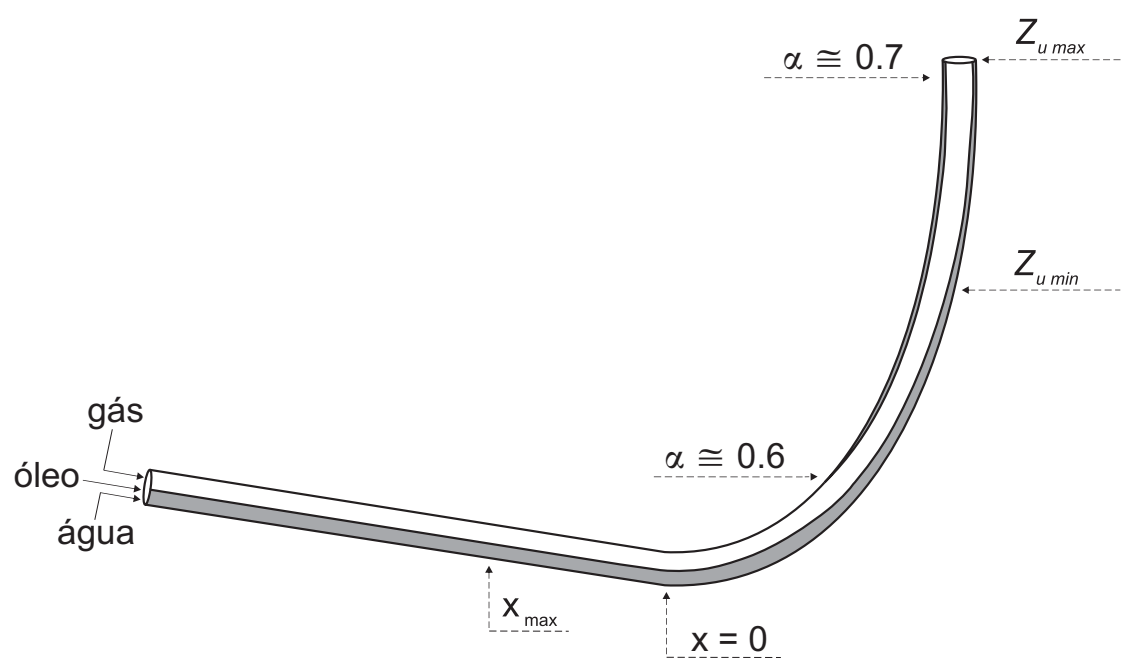

(i) $t \cong 87 \mathrm{~min}$

Figura 5.15: Estágios da intermitência severa considerando efeitos de transferência de massa. 


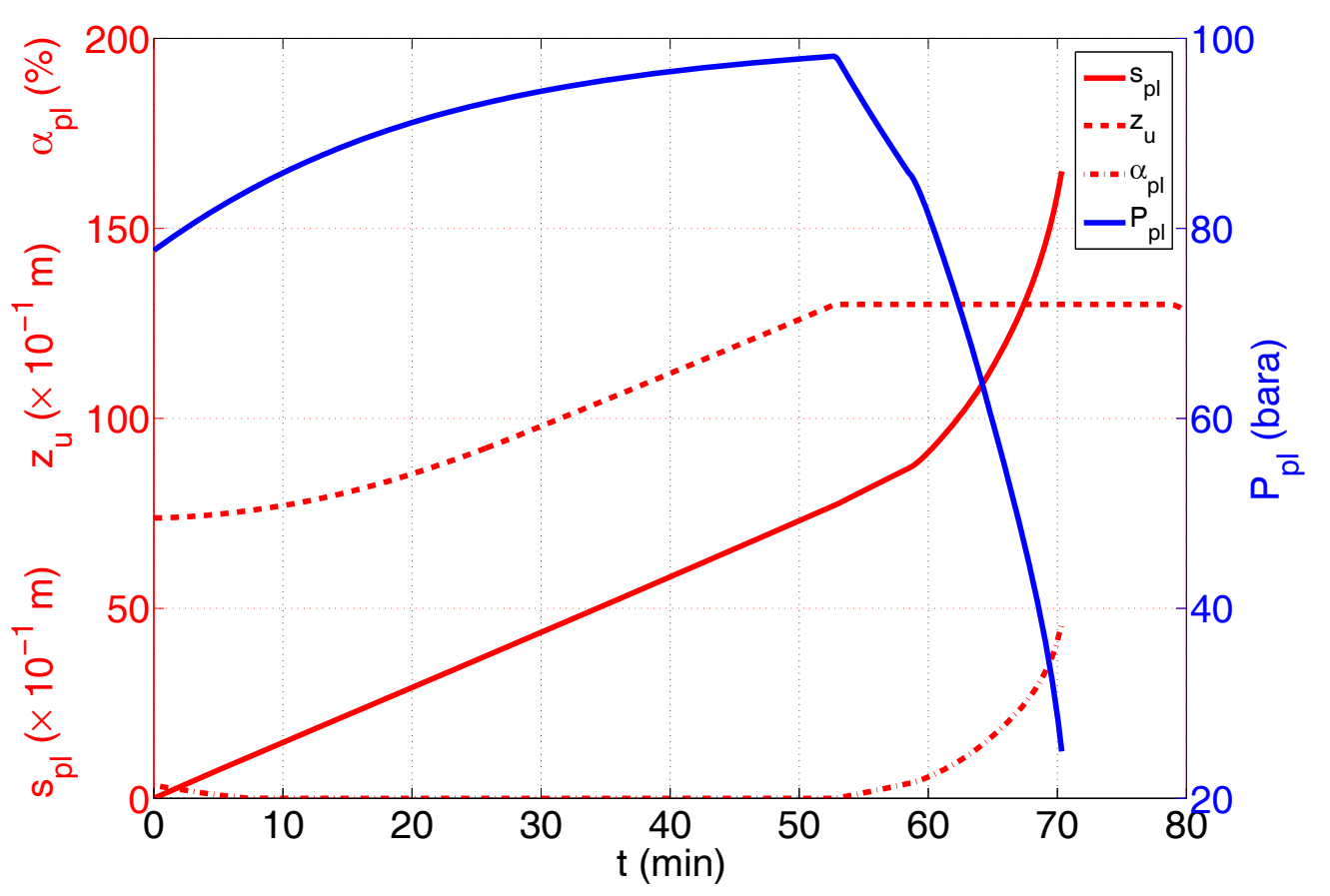

Figura 5.16: Comportamento de diferentes variáveis observado por uma partícula de líquido ao evoluir desde a base do riser até a superfície de líquido.

de líquido é empurrada até alcançar a base do riser (ver Fig. 5.15(g)), fazendo com que o comprimento de penetração de líquido torne-se nulo.

Observe que durante o período compreendido entre os estágios (b) e (e) da Fig. 5.15 a vaporização não ocorre até que o nível de líquido atinja o topo. A partir da Eq. (3.69), como $\partial R_{s} / \partial P>0$, a condição necessária para vaporização é $D_{l} P / D t<0$. Dado que o ângulo de inclinação no riser aumenta com a posição, a componente de velocidade vertical das partículas de líquido ao longo do riser é menor que a componente de velocidade vertical do nível de líquido. Como consequência, as partículas de líquido no riser experimentam elevação da pressão (principalmente hidrostática) ao moverem-se para cima, ou seja, experimentam a condição $D_{l} P / D t>0$, impedindo a vaporização.

Por outro lado, quando o nível de líquido alcança o topo do riser, as partículas de líquido experimentam quedas de pressão ao fluírem para cima e a vaporização ocorre no riser. A vaporização leva a uma redução de pressão na base devido à diminuição da queda de pressão hidrostática; logo, no estágio de produção da golfada, o vapor que deixa o riser é proveniente da vaporização que ocorre ao longo desse subsistema. Esse fenômeno previne a pressão na base de manter o valor máximo durante o estágio de produção, como é observado nos ciclos de intermitência severa para sistemas água-ar (estágio $i i$ na Fig. 2.1). 
Esse comportamento é evidenciado pela Fig. 5.16, que apresenta a evolução de diferentes variáveis avaliada por uma partícula de líquido que parte da base do riser $\left(s_{1}=0\right)$ até a superfície de líquido $\left(s_{N}=s_{u}\right)$. A partícula inicia seu deslocamento no momento em que o nível de líquido no riser registra seu menor valor $\left(z_{u \text { min }}\right)$. A variável $s_{p l}$ mostra a posição da partícula de líquido com relação à posição $s$ (ver Fig. 3.1); a variável $z_{u}$ mostra a posição do nível de líquido no riser; a variável $\alpha_{p l}$ mostra a fração de vazio avaliada pela partícula de líquido; e a variável $P_{p l}$ mostra a pressão avaliada pela partícula de líquido. As curvas na cor vermelha referem-se ao eixo da ordenada esquerda e a curva na cor azul refere-se ao eixo da ordenada direita.

Observe que a partícula de líquido parte da base do riser com velocidade aproximadamente constante devido à alimentação constante de líquido proveniente do pipeline. O nível de líquido possui a componente de velocidade vertical positiva e de maior magnitude que a da partícula de líquido, fazendo com que a pressão sentida pela partícula aumente ao deslocar-se no riser. A curva de pressão avaliada pela partícula $P_{p l}$ revela um gradiente de pressão positivo nessa etapa $\left(D_{l} P / D t>0\right)$, fazendo com que o gás livre existente solubilize-se no óleo, resultando em $\alpha_{p l}=0$. Quando o nível de líquido atinge o topo do riser, a partícula experimenta pressões menores ao deslocar-se, o que caracteriza um gradiente de pressão negativo $\left(D_{l} P / D t<0\right)$. Nesse momento, a fração de vazio avaliada pela partícula torna-se positiva, evidenciando a ocorrência da vaporização. O gás livre possui maior velocidade que a da partícula de líquido, fazendo com que a velocidade da partícula de líquido seja acelerada. A vaporização continua, aumentando o volume de gás livre, até que a partícula chega ao topo do riser e a pressão avaliada por ela seja a pressão no separador $P_{\text {sep }}=25$ bara.

Imediatamente após a frente de acúmulo de líquido alcançar a base do riser, resultando um comprimento de penetração de líquido nulo $(x=0)$, a bolha de gás penetra no mesmo (ver Fig. 5.15(h)). Ao ocorrer a penetração, a coluna torna-se mais leve, decrescendo a pressão e causando um aumento no fluxo de gás. Quando o gás atinge o topo, a passagem de gás fica livre através do padrão estratificado no pipeline e do padrão intermitente/anular no riser (ver Fig. 5.15(i)), causando uma expulsão violenta e rápida descompressão que traz o processo ao estágio de formação da golfada novamente. O estágio (i) na Fig. 5.15 representa o momento no qual as maiores velocidades superficial dos fluidos no topo do riser $j_{g u}, j_{o u}$ e $j_{w u}$ são observadas.

Como pode ser visto nas Figs. 5.1 - 5.8, os períodos associados à intermitência severa nas instalações offshore são da ordem de horas; além disso, os valores das variáveis apresentam grande flutuação quando comparados aos valores assumidos no estado estacionário. Esses longos períodos nos quais ocorre majoritariamente fase líquida escoando, seguidos por períodos 
relativamente menores nos quais há uma violenta expulsão de gás, causam instabilidades nos sistemas de controle de líquido dos separadores e eventualmente levam à paralisação da produção na plataforma (platform shutdown). Vale notar que o estado estacionário, usado como condição inicial, não existe; portanto um programa que considere apenas o estado estacionário, associando-o ao estado permanente, forneceria resultados errôneos.

Ainda com relação à Fig. 5.15 e fazendo uma comparação com sistemas água-ar, podese depreender que as condições de (a) até (e) caracterizam o estágio de formação da golfada. As condições de (e) até (g) caracterizam o estágio de produção da golfada, embora haja sempre algum gás deixando o topo do riser e a pressão na base do riser não mantenha seu valor máximo devido aos efeitos da vaporização. Finalmente as condições de (g) até (i) e de (i) até (a) caracterizam respectivamente o estágio de penetração de gás e o estágio de expulsão de gás, com gás adicional proveniente da vaporização.

\subsection{Classificação da intermitência severa para sistemas com transferência de massa}

De acordo com Tin e Sarshar (1993) e Wordsworth et al. (1998), um dos parâmetros para classificação do ciclo de intermitência severa para sistemas água-ar é o comprimento da golfada de líquido (ver Seção 1.1). Essa variável é calculada como a integral no tempo da velocidade do líquido no topo do riser durante o período em que há apenas líquido escoando.

A classificação de acordo com o comprimento da golfada de líquido não é apropriada para sistemas trifásicos com transferência de massa, devido ao fato de haver algum gás escoando para fora no topo do riser em todos os estágios.

Sendo assim, faz-se necessário definir uma nova classificação para sistemas óleo-águagás com transferência de massa, baseada na classificação prévia para sistemas água-ar. A classificação proposta é apresentada abaixo:

- Intermitência severa 1 (SS1): ocorre a obstrução da passagem de gás do pipeline para o riser, fazendo com que exista uma frente de acúmulo de líquido no pipeline. O riser, em algum momento, encontra-se completamente cheio de líquido, não sendo observada a presença de gás. Como consequência, as amplitudes de pressões na base do riser possuem as maiores magnitudes.

- Intermitência severa 2 (SS2): ocorre a obstrução da passagem de gás do pipeline para o riser, fazendo com que exista uma frente de acúmulo de líquido no pipeline. O riser 
em nenhum momento encontra-se completamente cheio de líquido, havendo sempre alguma quantidade de gás. Como consequência, as amplitudes de pressões na base do riser possuem magnitudes menores que as observadas na SS1.

- Intermitência severa 3 (SS3): há contínua penetração de gás na base do riser, ou seja, não existe a formação da frente de acúmulo de líquido no pipeline. As amplitudes de pressão e períodos do ciclo limite mostram-se menores que os observados na SS2.

Para sistemas água-ar, um comprimento de golfada de líquido maior ou igual ao comprimento do riser, como ocorre na SS1, faz com que o riser esteja completamente cheio de líquido durante determinado período de tempo. Como consequência, a pressão na base do riser atinge um patamar máximo e o mantém durante o mesmo período. Já no caso de haver trocas mássicas entre as fases, devido ao fato de imediatamente após o nível de líquido atingir o topo do riser ocorrer vaporização, o patamar máximo de pressão ocorre apenas momentaneamente. Logo, a nova classificação não leva em conta o comprimento da golfada de líquido, calculado ao longo do tempo, mas sim um estado momentâneo que o sistema pode alcançar.

A partir das considerações apresentadas acima, os resultados da simulação exibidos nas Figs. 5.1 - 5.8 e os estágios mostrados na Fig. 5.15, correspondentes ao caso $Q_{g 01}=0,2 \mathrm{~m}^{3} / \mathrm{s}$, são classificados como intermitência severa do tipo 1 (SS1).

Outras simulações com os mesmos dados de entrada apresentados na Tabela 5.1, mas com diferentes vazões de gás na condição padrão $\left(Q_{g 02}=0,4 \mathrm{~m}^{3} / \mathrm{s}\right.$ e $\left.Q_{g 03}=0,6 \mathrm{~m}^{3} / \mathrm{s}\right)$, foram realizadas e as diferenças no comportamento do sistema são avaliadas abaixo.

Na simulação com $Q_{g 02}=0,4 \mathrm{~m}^{3} / \mathrm{s}$, os estágios (a), (b) e (c) também são observados como na Fig. 5.15; entretanto, a partir do estágio (c), quando o comprimento de penetração de líquido torna-se positivo $(x>0)$, o nível de líquido atinge o topo enquanto ainda há gás na porção superior do riser. Logo, o riser não se encontra completamente cheio de líquido em nenhum momento e, como consequência, a máxima pressão na base é menor que a observada na SS1. Esse comportamento caracteriza a intermitência severa do tipo 2 (SS2).

Na simulação com $Q_{g 03}=0,6 \mathrm{~m}^{3} / \mathrm{s}$ o comprimento de penetração de líquido é sempre zero, permitindo que o gás penetre no riser durante o ciclo inteiro; nesse caso, o nível de líquido não muda e está localizado no topo do riser. A pressão máxima na base do riser é menor que a observada na SS2. Esse comportamento caracteriza a intermitência severa do tipo 3 (SS3).

A Fig. 5.17 mostra a evolução da pressão na base do riser para os três casos simulados (linha preta contínua para $Q_{g 01}=0,2 \mathrm{~m}^{3} / \mathrm{s}$, linha azul tracejada para $Q_{g 02}=0,4 \mathrm{~m}^{3} / \mathrm{s}$ e linha vermelha traço-pontilhada para $Q_{g 03}=0,6 \mathrm{~m}^{3} / \mathrm{s}$ ). O intervalo de tempo considerado 


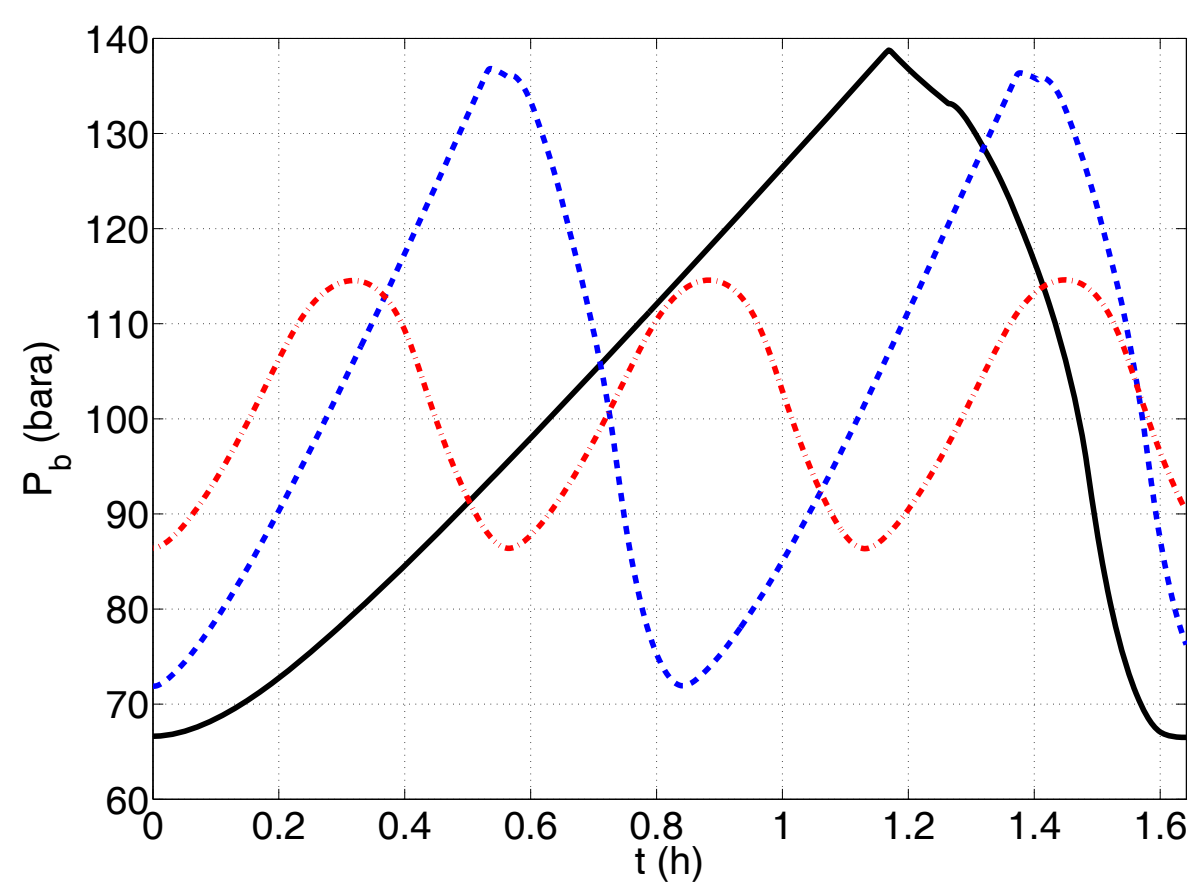

Figura 5.17: Pressão na base do riser para intermitência severa do tipo 1 (preto), 2 (azul) e 3 (vermelho).

na abscissa do gráfico é exatamente o período do ciclo de intermitência severa para o caso $Q_{g 01}=0,2 \mathrm{~m}^{3} / \mathrm{s}(\mathrm{SS} 1)$ e vale $t_{P 1}=1,64 h$. Para esse caso, a máxima pressão observada é 138,7 bar e a mínima é 66, 6 bar, resultando uma amplitude de pressão de $\Delta P_{1}=72,1$ bar .

Para o caso $Q_{g 02}=0,4 \mathrm{~m}^{3} / \mathrm{s}(\mathrm{SS} 2)$, o período do ciclo de intermitência severa é $t_{P 2}=0,84 h$, aproximadamente metade do período obtido no caso SS1. A máxima pressão no ciclo é 136, 8 bar e a mínima é 71, 9 bar, resultando uma amplitude de pressão de $\Delta P_{2}=$ 64, 9 bar. Essa amplitude de pressão representa $90 \%$ do valor obtido na SS1.

Para o caso $Q_{g 03}=0,6 \mathrm{~m}^{3} / \mathrm{s}$ (SS3), o período do ciclo de intermitência severa é $t_{P 3}=0,57 h$, aproximadamente um terço do período obtido no caso SS1. A máxima pressão no ciclo é 114,6 bar e a mínima é 86,3 bar, resultando uma amplitude de pressão de $\Delta P_{3}=$ 28, 3 bar. Essa amplitude de pressão representa aproximadamente $40 \%$ do valor obtido na SS1.

Observe que o período do ciclo de intermitência severa está relacionado com o tempo de escoamento do gás no sistema pipeline-riser, de modo que um aumento na vazão de gás resulta em uma diminuição proporcional no tempo necessário para o transporte dos fluidos ao longo dos subsistemas, dado o comprimento constante dos tubos. Por esse motivo, observa-se que $t_{P 1} \cong 2 t_{P 2} \cong 3 t_{P 3}$ e $Q_{g 01}=Q_{g 02} / 2=Q_{g 03} / 3$.

A existência dos tipos SS1, SS2 e SS3 revela grande riqueza em termos de configu- 
rações que podem ser alcançadas por um sistema pipeline-riser, assim como representa um desafio para as capacidades de simulação do modelo proposto.

\subsection{Mapa de estabilidade}

Um mapa de estabilidade mostra a região de determinado espaço de parâmetros na qual instabilidades, como a intermitência severa, ocorrem. Para o seu cálculo é considerada uma geometria fixa para o sistema pipeline-riser e um conjunto fixo de variáveis, com a vazão volumétrica de líquido e gás sendo variada de maneira a determinar as regiões estáveis e instáveis.

Para sistemas água-ar, Baliño, Burr e Nemoto (2010) obtiveram mapas de estabilidade com propriedades termofísicas constantes, considerando o ar como um gás ideal. Essa aproximação é aceitável dado que o escoamento é considerado isotérmico e as variações de pressão não são grandes. Nas simulações e na construção do mapa de estabilidade foi possível variar de maneira independente as vazões de ar e água.

No caso de sistemas de produção de petróleo, os fluidos produzidos podem ser classificados em água e hidrocarbonetos. Os hidrocarbonetos assumem a forma de gás e óleo se estão sujeitos a uma pressão abaixo da pressão de ponto de bolha ou somente óleo caso contrário. De acordo com o modelo, se a pressão está abaixo da pressão de ponto de bolha, haverá transferência de massa para $D_{l} P / D t \neq 0$ (ver Seção 3.3.6). Portanto, as vazões locais de gás e óleo dependem das condições de pressão e temperatura locais, diferentemente dos sistemas água-ar, nos quais as vazões de gás e líquido podiam variar de maneira independente.

A caracterização dos fluidos produzidos dá-se por meio do conhecimento da razão gás-óleo GOR (ou solubilidade de gás em óleo no ponto de bolha), da densidade API $\gamma_{A P I}$, da densidade relativa do gás $\gamma_{g}$, da massa específica da água $\rho_{w 0}$ e da razão água-óleo $W O R$. Uma vez que estes parâmetros sejam conhecidos, as vazões de gás, óleo e água podem ser calculadas a partir da definição da pressão, temperatura e da vazão volumétrica média de óleo $Q_{o 0}$ (ou vazão volumétrica média de gás $Q_{g 0}$ ) na condição padrão.

Para a construção do mapa de estabilidade foram utilizados os dados apresentados na Tabela 5.1, exceto que os parâmetros $Q_{g 0}$ e $Q_{o 0}$ (e portanto $G O R$ ) variam; consequentemente, a vazão de água $Q_{w 0}$ varia de maneira a manter a razão água-óleo $W O R$ constante. A fronteira de estabilidade numérica foi obtida mantendo constante o valor da vazão volumétrica de gás ou óleo e variando a outra em incrementos fixos até ser observada a passagem de uma condição (estável ou instável) para outra; quando isso ocorre, o procedimento é repetido com metade do incremento, até que a convergência seja alcançada. Assume-se condição estável quando a 


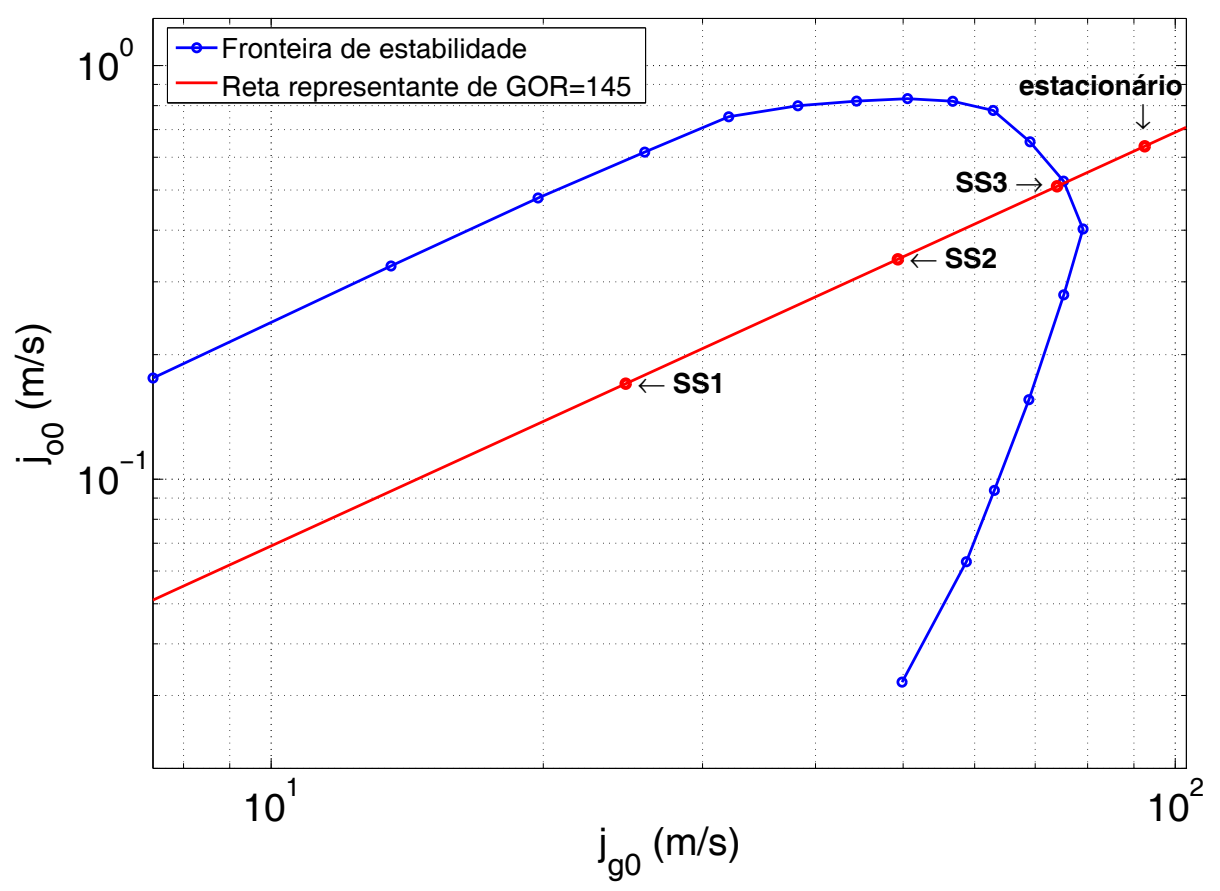

Figura 5.18: Mapa de estabilidade.

amplitude das flutuações de pressão na base do riser é menor que $0,25 \%$ da média da pressão e considera-se que a convergência seja atingida quando o incremento da vazão volumétrica for menor que $0,5 \%$ do valor médio. Esse procedimento é computacionalmente custoso e foi executado por meio de um algoritmo numérico.

Em um mapa construído com base em um plano cartesiano, sendo o eixo das abscissas dado por $Q_{g 0}$ e o eixo das ordenadas dado por $Q_{o 0}$, cada reta que cruza a origem dos eixos define uma mistura de hidrocarbonetos específica, dado que a inclinação da reta é definida pelo inverso de GOR. Desse modo, o mapa apresenta as regiões estáveis e instáveis para uma geometria fixa para o pipeline e riser e um WOR fixo e contempla todos os GOR possíveis.

Ao utilizar as velocidades superficiais de gás e óleo na condição padrão, ao invés das vazões volumétricas de gás e óleo na condição padrão, para definir os eixos do plano cartesiano, é possível representar os mapas de estabilidade em função de variáveis intensivas do escoamento (ver Apêndice A.1). Fazendo isso, as retas que cruzam a origem dos eixos continuam a definir diferentes misturas de hidrocarbonetos, pois a inclinação de cada reta ainda vale $G O R^{-1}$.

De maneira a permitir uma visualização mais detalhada para baixos valores de velocidades superficiais, é comum o uso do plano log-log para apresentação dos mapas de estabilidade. A Fig. 5.18 mostra o mapa de estabilidade considerando o plano log-log, sendo o eixo das abscissas determinado por $j_{g 0}$ e o eixo das ordenadas por $j_{00}$. 
Utilizando o plano log-log, diferentes valores de GOR (diferentes misturas de hidrocarbonetos) são representados por retas de inclinação fixa de $45^{\circ}$ com ponto de cruzamento com o eixo das ordenadas determinado por $G O R^{-1}$ (considerando que o eixo das ordenadas está posicionado em $j_{g 0}=1 \mathrm{~m} / \mathrm{s}$ ). Ou seja, no plano log-log, diferentes misturas de hidrocarbonetos são representadas por retas paralelas com diferentes pontos de cruzamento com o eixo das ordenadas.

Na Fig. 5.18, a reta vermelha representa a mistura de hidrocarbonetos usada para simular os casos discutidos na seção 5.3, nos quais foi utilizado $G O R=145$. O ponto vermelho classificado como SS1, refere-se ao caso $Q_{g 0}=0,2 \mathrm{~m}^{3} / \mathrm{s}$, o próximo ponto, classificado como $\mathrm{SS} 2$, refere-se ao caso $Q_{g 0}=0,4 \mathrm{~m}^{3} / \mathrm{s}$ e o último ponto dentro da região instável, classificado como SS3, refere-se ao caso $Q_{g 0}=0,6 \mathrm{~m}^{3} / \mathrm{s}$. O ponto fora da região instável corresponde à simulação realizada com $Q_{g 0}=0,75 \mathrm{~m}^{3} / \mathrm{s}$; para esse caso, não foram observadas flutuações nos valores das variáveis e o estado permanente foi atingido. O estado permanente pode corresponder a um escoamento em golfadas ou em bolhas no qual as pequenas oscilações das variáveis não estão associadas à intermitência severa. Simulações realizadas com o software OLGA usando $G O R=145$ também mostraram uma boa concordância com relação à posição do ponto correspondente à fronteira de estabilidade.

Observa-se que, para um GOR fixo e aumentando-se a vazão volumétrica de gás, o sistema passa de SS1 para SS2 e, posteriormente, para SS3. Como consequência, quanto mais o ponto de operação $\left(j_{g 0}, j_{o 0}\right)$ se aproxima da fronteira de estabilidade, menores amplitudes de pressão são observadas; esse comportamento também foi verificado em sistemas água-ar (BALIÑO; BURR; NEMOTO, 2010).

Observa-se também que o patamar da fronteira de estabilidade decresce para baixas vazões volumétricas de gás, diferentemente do que ocorre com sistemas água-ar, nos quais o patamar da fronteira de estabilidade mantém seu valor máximo. A região de baixas vazões volumétricas de gás corresponde a misturas com baixos GOR; nessas condições, o volume de gás que condensa é significante quando comparado ao volume de gás livre, dando origem a um efeito estabilizante.

Dado que o escoamento envolve três fases, uma representação mais detalhada do mapa de estabilidade deve levar em conta a velocidade superficial de água. A Fig. 5.19 mostra o mapa de estabilidade tridimensional referente aos dados geométricos apresentados na Tabela 5.1. Para a construção do mapa, além da variação da velocidade superficial de gás $j_{g 0}$ e da razão gás-óleo GOR (com a consequente variação da velocidade superficial de óleo $j_{o 0}$ ), varia-se também a razão água-óleo $W O R$, fazendo com que diferentes velocidades superficiais de água 


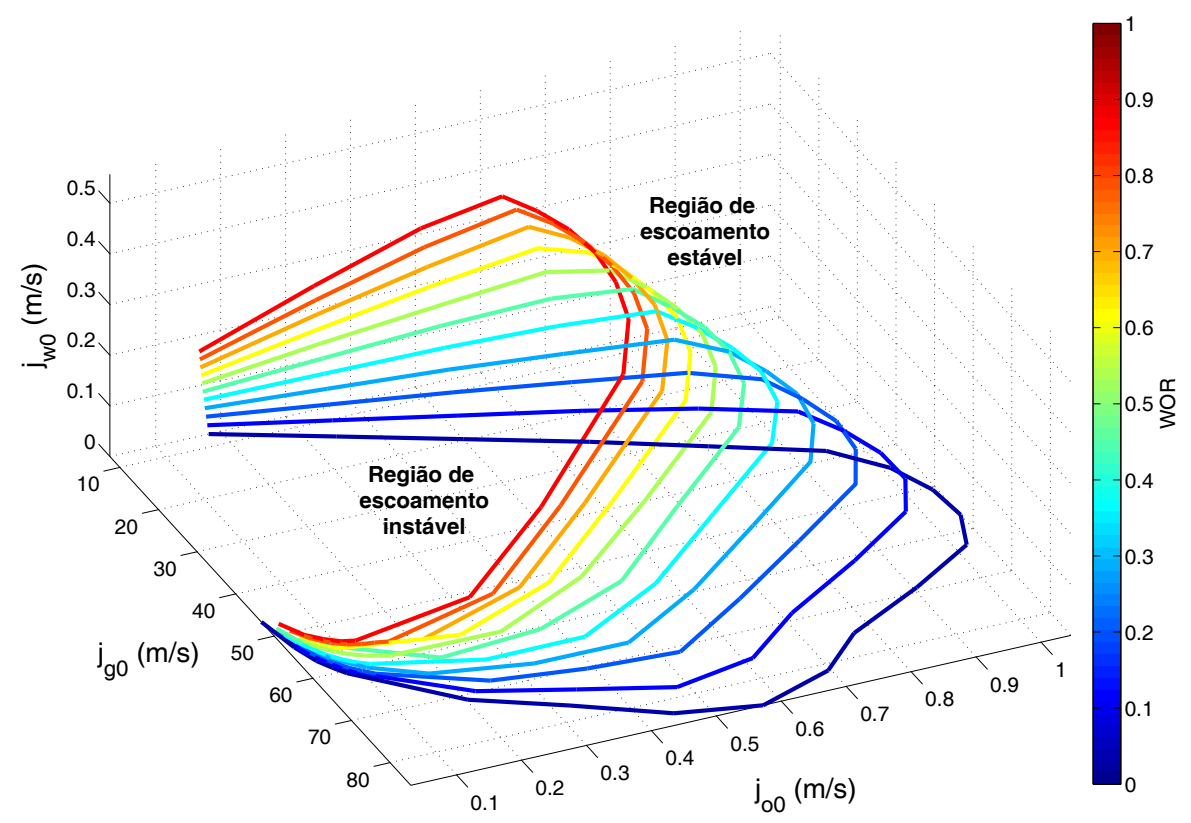

Figura 5.19: Mapa de estabilidade em função das velocidades superficiais de gás, óleo e água.

sejam levadas em conta. Em um mapa de estabilidade tridimensional, a fronteira curvilínea de estabilidade dá lugar a uma fronteira superficial de estabilidade, no interior da qual localizam-se os pontos de escoamento instáveis (SS1, SS2 e SS3).

Na Fig. 5.19, a fronteira superficial de estabilidade foi construída de forma paramétrica e é composta por fronteiras curvilíneas para as quais a razão $W O R$ foi mantida constante, de maneira que a fronteira de estabilidade apresentada na Fig. 5.18 resulta da projeção da curva correspondente da fronteira superficial de estabilidade no plano $j_{g 0} \times j_{o 0}$. Observe que a região instável do mapa torna-se menor conforme a razão água-óleo, e consequentemente a velocidade superficial de água, aumenta.

\subsection{Mapa de tipos de instabilidade}

A Fig. 5.20 apresenta o mapa de tipos de instabilidade. Por meio de simulações numéricas na região instável do mapa de estabilidade, e utilizando a nova classificação para a intermitência severa apresentada na Seção 5.4, é possível verificar em que região se concentram os diferentes tipos de instabilidade.

A região em que se localiza a intermitência severa do tipo 3 no mapa de estabilidade para sistemas com transferência de massa corresponde à região próxima da fronteira de esta- 


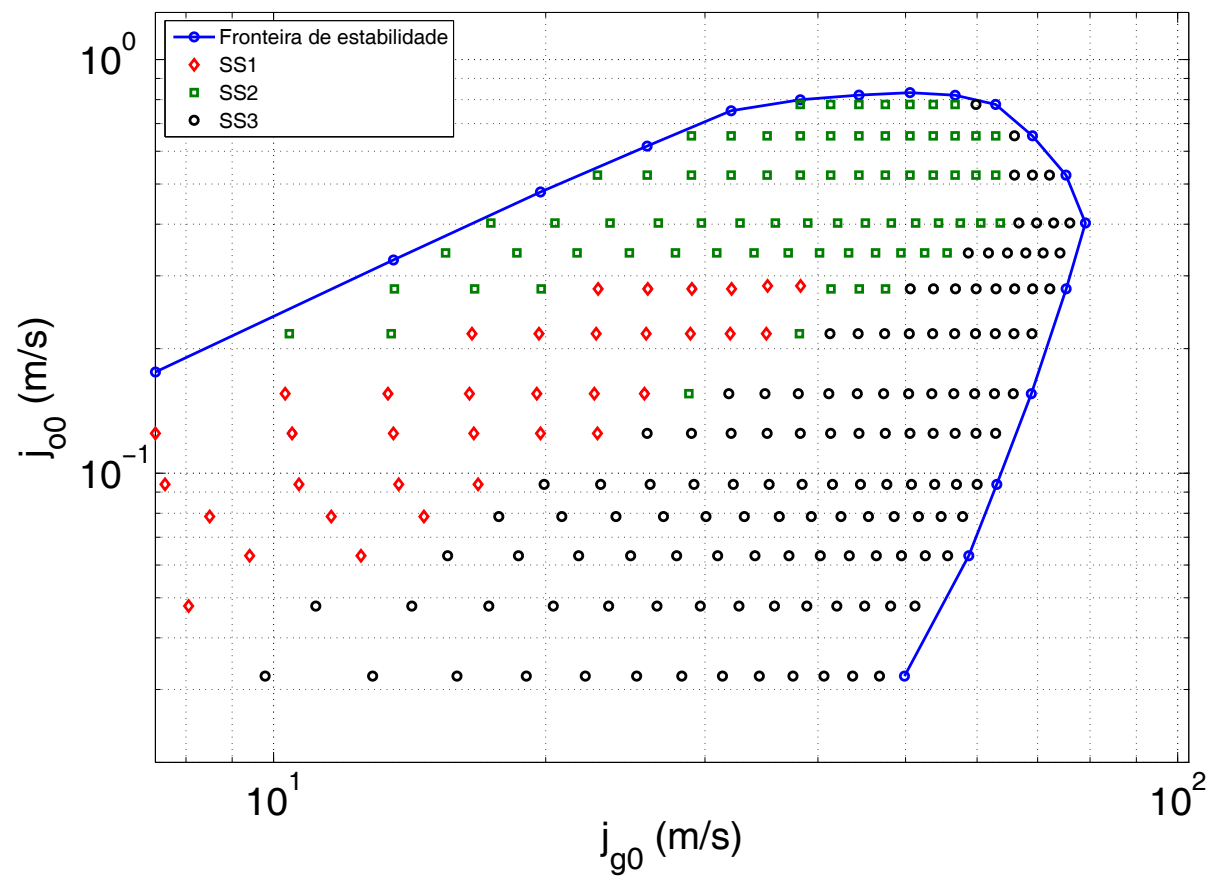

Figura 5.20: Mapa de tipos de instabilidade.

bilidade à direta, como acontece para sistemas água-ar (ver Fig. 2.4). Isso reflete o fato de a intermitência severa do tipo 3 para sistemas com transferência de massa ainda possuir o mesmo critério de classificação originalmente apresentado para sistemas água-ar; que afirma que para ser constatada a SS3, deve-se observar penetração contínua de gás no riser.

A região no mapa de estabilidade em que se localiza a intermitência severa do tipo 1 para sistemas com transferência de massa é menor que a região que caracteriza a SS1 para sistemas água-ar. Nos sistemas com transferência de massa foi observada a quase constante existência de gás no subsistema riser devido à vaporização, impedindo o cálculo do comprimento da golfada de líquido. Esse parâmetro é fundamental na classificação proposta por Tin e Sarshar (1993) e Wordsworth et al. (1998) para sistemas água-ar.

De acordo com a nova classificação, a SS1, intermitência severa com maiores amplitudes de pressão e períodos de ciclo mais longos, ocorre quando o riser torna-se completamente cheio de líquido, o que é observado nos sistemas com transferência de massa apenas no instante em que o nível de líquido no riser atinge o topo.

A vaporização aumenta o volume de gás livre no riser, aliviando o peso da coluna de líquido e fazendo com que as variações de pressão no ciclo sejam menores. Como consequência, parte da região que originalmente correspondia à intermitência severa do tipo 1 em sistemas água-ar passa a caracterizar a intermitência severa do tipo 2 em sistemas com transferência de 
massa.

\subsection{Mapas de estabilidade utilizando o critério de Pots}

O critério definido por Pots, Bromilow e Konijn (1987) para determinar a ocorrência da intermitência severa (ver Seção 2.4), por simplificação chamado de critério de Pots, apresenta o parâmetro $\Pi_{S S}$. Esse parâmetro será utilizado em estudos paramétricos e, portanto, é reapresentado abaixo:

$$
\Pi_{S S}=\frac{\Lambda Z_{c} T}{\alpha_{p} L \gamma_{g} M_{a} g} \frac{\dot{m}_{g}}{\dot{m}_{l}}
$$

onde $\gamma_{g}=M_{g} / M_{a}$ é a densidade relativa do gás, $M_{g}$ e $M_{a}=28,966 \mathrm{~g} / \mathrm{mol}$ são respectivamente as massas molares do gás e do ar, $Z_{c}$ é o fator de compressibilidade do gás, $\Lambda=$ $8314 \mathrm{~J} / \mathrm{K} \mathrm{kmol} \mathrm{é} \mathrm{a} \mathrm{constante} \mathrm{universal} \mathrm{dos} \mathrm{gases,} T$ é a temperatura, $\alpha_{p}$ é a fração de vazio no pipeline, $L$ é o comprimento do pipeline, $\dot{m}_{g}$ é a vazão mássica de gás e $\dot{m}_{l}$ é a vazão mássica de líquido.

O parâmetro é definido pela razão entre a taxa de aumento de pressão no pipeline e a taxa de aumento de pressão na base do riser, após haver a obstrução da passagem de gás do pipeline para o riser. Caso a condição $\Pi_{S S}<1$ seja observada, a taxa de aumento de pressão na base do riser (devido ao aumento na altura do nível de líquido) torna-se maior que a taxa de aumento de pressão no pipeline (devido ao gás que adentra o sistema). Sob tais condições, o riser preenche-se completamente de líquido antes que a pressão do gás seja capaz de expulsar a frente de acúmulo de líquido no pipeline. Essa condição indica, portanto, que a intermitência severa do tipo 1 ocorrerá no sistema.

As hipóteses simplificadoras assumidas pelo critério de Pots são: ausência de transferência de massa entre as fases; massa específica do gás desprezível frente à massa específica do líquido; riser vertical; e negligencia-se a queda de líquido no riser (estágio do ciclo de intermitência severa determinado por Taitel (1986) e apresentando na Seção 2.3).

De acordo com o critério, maiores temperaturas $T$, vazões mássicas de gás $\dot{m}_{g}$ e fatores de compressibilidade do gás $Z_{c}$, estabilizam o sistema. Já para maiores frações de vazio no pipeline $\alpha_{p}$, comprimentos do pipeline $L$, densidades relativas do gás $\gamma_{g}$ e vazões mássicas de líquido $\dot{m}_{l}$, o sistema tende a desestabilizar-se. Apesar das relações listadas serem facilmente evidenciadas pela Eq. (5.1), elas devem ser analisadas com cautela, pois várias variáveis podem mudar simultaneamente quando é modificada uma variável independente, sendo necessário 


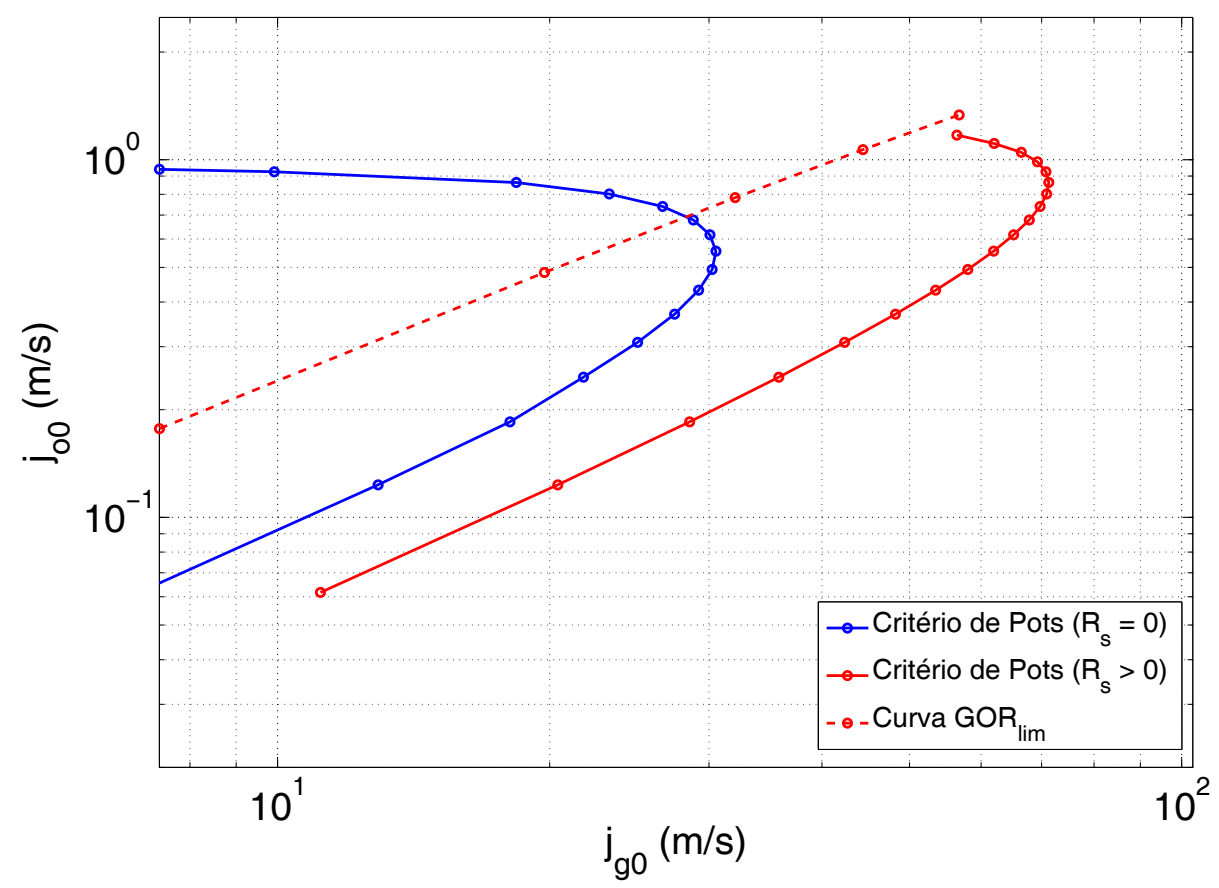

Figura 5.21: Mapa de estabilidade, segundo o critério de Pots, considerando razão de solubilidade nula $\left(R_{s}=0\right)$ e razão de solubilidade calculada segundo a aproximação de black-oil $\left(R_{s}>0\right)$.

avaliar o resultado global para o sistema.

Como visto, o critério desconsidera a transferência de massa entre as fases que ocorre durante a dinâmica do escoamento. No entanto, as vazões de gás e líquido de entrada e outras propriedades termodinâmicas nas condições de pressão e temperatura locais podem ser calculadas de maneira aproximada utilizando o modelo de estado estacionário (ver Seção 3.4), que usa para isso a aproximação de black-oil.

A Fig. 5.21 apresenta mapas de estabilidade construídos com base no critério de Pots e nos dados apresentados na Tabela 5.1. O mapa na cor azul $\left(R_{s}=0\right)$ considera a razão de solubilidade de gás em óleo nula e o mapa na cor vermelha $\left(R_{s}>0\right)$ considera que a razão de solubilidade de gás em óleo é calculada segundo a aproximação de black-oil. Ao fazer $R_{s}=0$, independentemente das condições de pressão e temperatura, impede-se que o gás inserido no sistema dissolva-se no óleo.

A linha vermelha contínua na Fig. 5.21 representa a fronteira de estabilidade obtida utilizando o critério de Pots. A curva foi determinada por meio do método da bissecção e de simulações em estado estacionário, em que são calculados os parâmetros $Z_{c}, \alpha_{p}, \dot{m}_{g}$ e $\dot{m}_{l}$. Define-se uma velocidade superficial de óleo na condição padrão $j_{o 0}$ e o método da bissecção é utilizado para estimar a velocidade superficial de gás na condição padrão $j_{g 0}$ que faz com que a 
Eq. (5.1) resulte em $\Pi_{S S}=1$.

É evidente que a ausência de gás livre no pipeline faz com que a intermitência severa não ocorra. A linha vermelha tracejada determina a curva limite para a existência de gás no pipeline. Seu cálculo também foi baseado no método da bissecção e em simulações em estado estacionário para calcular o parâmetro $\alpha_{p}$. Entretanto, para a determinação dessa linha foi utilizado um critério que estima, para certo valor de velocidade superficial de gás na condição padrão $j_{g 0}$, qual o mínimo valor de velocidade superficial de óleo na condição padrão $j_{o 0}$ que permite a existência de gás no pipeline. A obtenção de um reta revela a existência de um valor de razão gás-óleo limite $G O R_{\text {lim }}$, que divide a região no plano em que há gás livre no pipeline ou não.

De fato, a Eq. (E.45) mostra que a pressão de ponto de bolha $P_{\text {bolha }}$ depende da razão de solubilidade no ponto de bolha $R_{\text {sbolha }}$, ou razão gás-óleo $G O R$, da densidade relativa do gás $\gamma_{g}$, da temperatura $T$ e da densidade API $\gamma_{A P I}$. Dado que, para a construção do mapa de estabilidade, todas as demais variáveis são constantes exceto a razão gás-óleo, resulta que essa variável é a única que controla a pressão de ponto de bolha.

A linha vermelha tracejada determina a reta representante da razão gás-óleo limite $G O R_{\text {lim }}=42,8$. Esse valor de razão gás-óleo faz com que a pressão na base do riser seja aproximadamente igual à pressão de ponto de bolha, levando o gás livre a solubilizar-se no óleo.

Para valores de razão gás-óleo menores que $G O R_{\text {lim }}$ (região acima da linha tracejada), o estado estacionário calculado revela que a pressão na base do riser é superior à pressão de ponto de bolha e portanto não há gás livre no pipeline $\left(\alpha_{p}=0\right)$. Já para valores de razão gás-óleo maiores que $G O R_{\text {lim }}$ (região abaixo da linha tracejada), a pressão na base do riser é inferior à pressão de ponto de bolha, fazendo com que ocorra gás livre no pipeline $\left(\alpha_{p}>0\right)$. Observe que a razão gás-óleo limite calculada por meio de simulações em estado transiente e apresentada na Fig. 5.20 é semelhante à linha vermelha tracejada, possuindo valor de $G O R_{\text {lim }}=41,9$.

As linhas vermelhas contínua e tracejada não se cruzam. Isso ocorre pois conforme a linha contínua (determinada pelo critério de Pots) se aproxima da linha tracejada (determinada por $\left.G O R_{l i m}\right)$ a fração de vazio e a vazão mássica efetiva no pipeline tendem a zero $\left(\alpha_{p} \rightarrow 0 \mathrm{e}\right.$ $\dot{m}_{g} \rightarrow 0$ ), fazendo com que a razão $\dot{m}_{g} / \alpha_{p}$, e portanto o parâmetro $\Pi_{S S}$, resulte indeterminado.

A linha azul apresenta a fronteira de estabilidade, segundo o critério de Pots, considerando a razão de solubilidade de gás em óleo nula $\left(R_{s}=0\right)$. A curva também foi determinada 


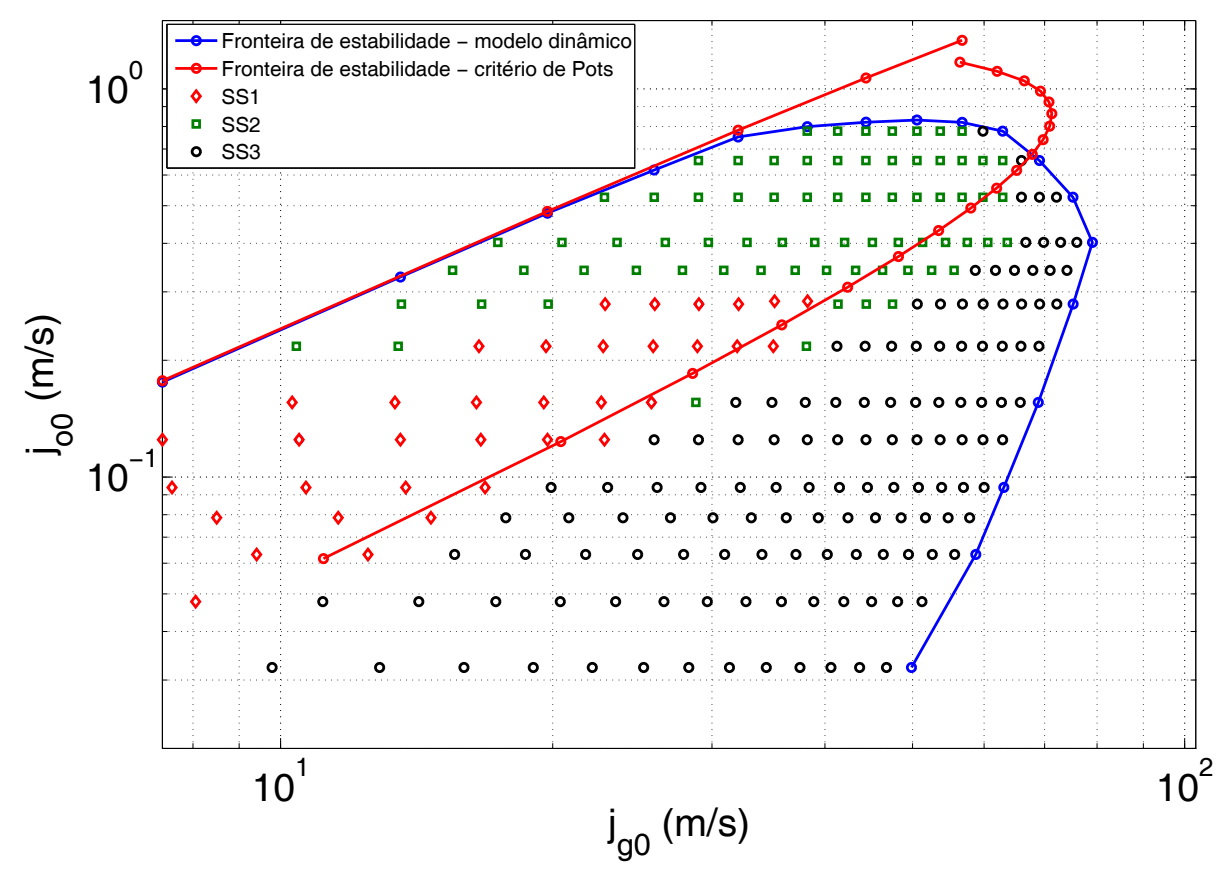

Figura 5.22: Mapa de tipos de instabilidade e fronteira de estabilidade segundo o critério de Pots.

por meio do método da bissecção e de simulações em estado estacionário, sendo definida pelos pontos $\left(j_{g 0}, j_{o 0}\right)$ em que se obtêm $\Pi_{S S}=1$. Ao forçar $R_{s}=0$, o gás livre é impedido de dissolver-se no óleo (entrar em solução) independentemente da pressão no pipeline. Sendo assim, a ausência de gás no pipeline $\left(\alpha_{p}=0\right)$ é impossibilitada e a fronteira de estabilidade é traçada de maneira contínua. Observe que a fronteira de estabilidade calculada desse modo assemelha-se à fronteira de estabilidade do tipo 1 para sistemas água-ar (ver Fig. 2.4), nos quais a dissolução de gás no líquido também não ocorre.

Observe também que a região instável torna-se maior quando é permitida a solubilização de gás em óleo. Esse comportamento ocorre pois, dada a condição local de temperatura e pressão, uma parte do gás que era forçosamente mantido na forma livre entra em solução, fazendo com que a vazão mássica de gás efetiva $\dot{m}_{g}$ diminua. Esse efeito, segundo o critério de Pots, desestabiliza o sistema.

A Fig. 5.22 apresenta a fronteira de estabilidade, obtida por meio do critério de Pots, sobreposta ao mapa de tipos de instabilidade, definido por simulações em estado transiente utilizando o modelo dinâmico. Observe que a fronteira de estabilidade determinada pelo critério de Pots prevê de maneira aproximada a região em que se localiza a intermitência severa do tipo 1 predita pelo modelo dinâmico. A curva de Pots ainda engloba grande parte da região de intermitência severa do tipo 2. Isso ocorre pois o critério de Pots prevê a formação e manutenção 
da frente de acúmulo de líquido no pipeline, impedindo a penetração de gás no riser; como é característico da SS1 e SS2. Entretanto, não considera os efeitos de vaporização dinâmicos, devido ao gradiente $D_{l} P / D t<0$ a que ocasionalmente são submetidas as partículas de óleo ao evoluírem no riser. A vaporização é responsável pela transição dos casos observados como SS1 em sistemas sem transferência de massa para casos classificados como SS2 em sistemas com transferência de massa (ver Seção 5.6). Portanto, o critério não é capaz de diferenciar a intermitência severa do tipo 1 da intermitência severa do tipo 2.

Dado que o mapa de estabilidade segundo o critério de Pots é calculado utilizando simulações em estado estacionário, seu cálculo exige baixo custo computacional e pode ser realizado de maneira ágil. Sendo assim, o critério mostra-se útil para a rápida verificação da região no espaço de parâmetros, definido pela dupla $\left(j_{g 0}, j_{o 0}\right)$, em que ocorrerá a intermitência severa do tipo 1 e 2, que representam os tipos mais perigosos para a operação do sistema de produção e separação dos fluidos.

\subsection{Estudo paramétrico}

Com o intuito de avaliar os efeitos sobre a fronteira de estabilidade devido à variação de diferentes parâmetros usados na caracterização geométrica do sistema pipeline-riser e na caracterização dos fluidos produzidos, um estudo paramétrico foi realizado.

Os parâmetros considerados no estudo são variáveis independentes ou de entrada no modelo, dadas por: densidade API $\gamma_{A P I}$; densidade relativa do gás $\gamma_{g}$; razão água-óleo $W O R$; temperatura dos fluidos $T$; diâmetro da tubulação $D$; coordenada horizontal do topo do riser $W_{r}$; altura do riser $Z_{r}$; pressão no separador $P_{\text {sep }}$; comprimento do pipeline $L$; e inclinação do pipeline $\beta$.

Os dados apresentados na Tabela 5.1 foram usados nas simulações, sendo que, para cada estudo paramétrico, determinado parâmetro teve seu valor modificado. Na maioria dos casos os parâmetros foram modificados em um valor acima e outro abaixo do apresentado na Tabela 5.1.

Para a análise dos resultados que seguem, serão consideradas três regiões do mapa de estabilidade. De acordo com a Fig. 5.23, a região de GOR baixo refere-se à região da fronteira de estabilidade ascendente em que ocorrem baixas velocidades superficiais de gás; a região de $G O R$ elevado refere-se à região de retração da fronteira de estabilidade para os valores mais altos de velocidades superficiais de gás; e a região de $G O R$ intermediário está relacionado à região do mapa que se encontra entre os limites de $G O R$ baixo e elevado. 


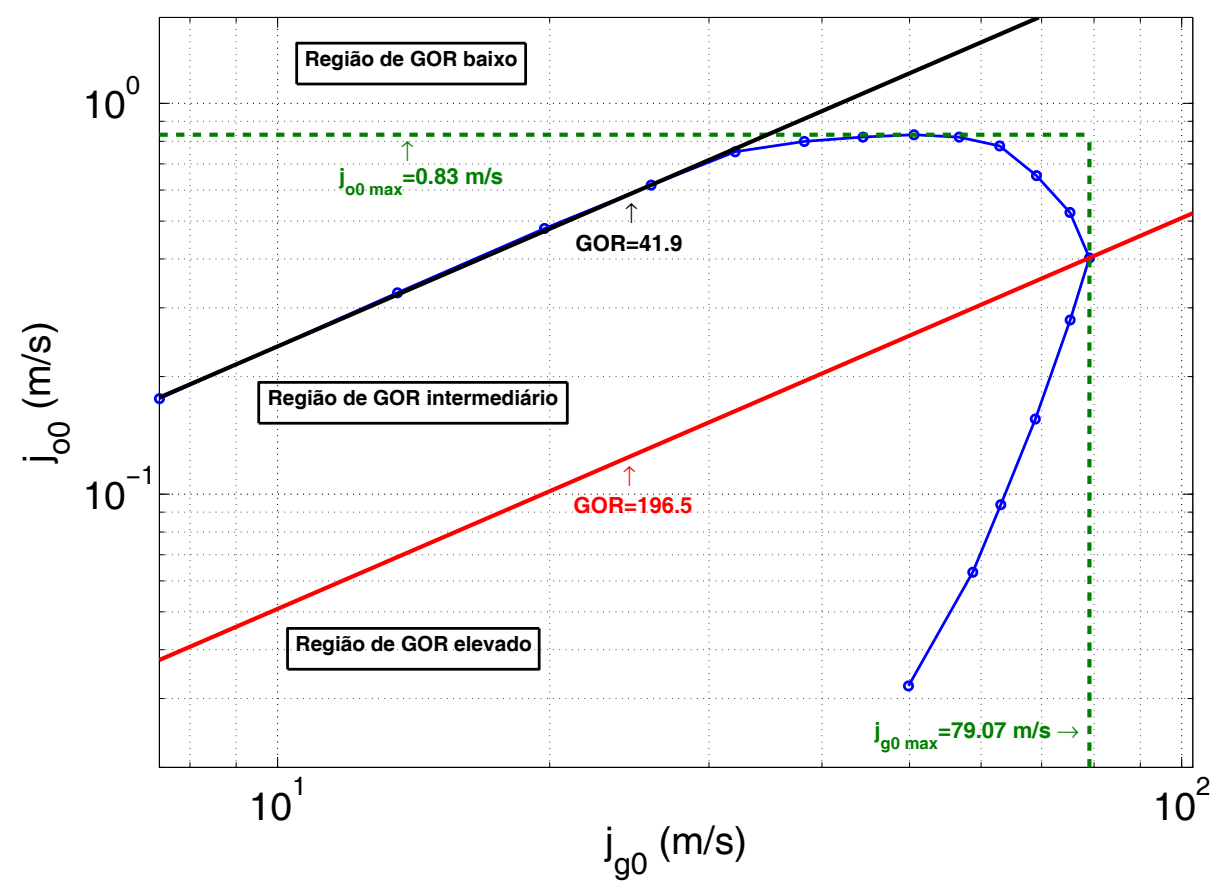

Figura 5.23: Regiões de $G O R$ baixo, intermediário e elevado.

A Fig. 5.24 apresenta mapas de estabilidade em que o parâmetro de estudo é a densidade API. Pode-se depreender que para a região de $G O R$ baixo e elevado não há grande influência da densidade API sobre as fronteiras de estabilidade; no entanto, para GOR intermediário a região instável se expande para maiores valores do parâmetro. O mesmo estudo paramétrico foi realizado com o uso do critério de Pots (ver Fig. 5.25) e as fronteiras de estabilidade apresentam comportamento semelhante.

A Fig. 5.26 apresenta o comportamento da fronteira de estabilidade com relação à densidade relativa do gás. Observe que, na região de $G O R$ baixo, para densidades relativas de gás maiores a fronteira de estabilidade desloca-se para baixo, resultando que o escoamento estabiliza-se com o aumento do parâmetro. Na região de $G O R$ intermediário e elevado, para densidades relativas de gás maiores, a fronteira de estabilidade desloca-se para a direita, revelando que o aumento do parâmetro leva o escoamento à instabilidade. A Fig. 5.27 mostra que as curvas obtidas com o critério de Pots apresentam comportamento semelhante.

A Fig. 5.28 apresenta as fronteiras de estabilidade segundo diferentes valores de razão água-óleo. Aumentando-se a razão água-óleo, a fronteira de estabilidade na região de $G O R$ intermediário desloca-se para baixo, diminuindo a região instável. Não é observada influência do WOR nas fronteiras de estabilidade para as regiões de GOR baixo e intermediário. O critério de Pots aplicado a diferentes valores de razão água-óleo apresenta o mesmo comportamento para a região de $G O R$ intermediário; no entanto, para a região de $G O R$ elevado, as curvas 
deslocam-se ligeiramente para a direita, aumentando a região instável para maiores $W O R$ (ver Fig. 5.29). Vale ressaltar que o critério de Pots engloba a região no mapa de estabilidade em que se localiza a intermitência severa do tipo 1 e parte da intermitência severa do tipo 2 . Já o mapa de estabilidade obtido com o modelo dinâmico leva em consideração os três tipos de intermitência, SS1, SS2 e SS3. Sendo assim, é possível abstrair que maiores valores de razão água-óleo faz com que uma maior região para a SS1 seja observada (pelo critério de Pots) e que maiores valores de razão água-óleo não tem influência sobre a fronteira de estabilidade que delimita a SS3 na região de GOR elevado (pela curva obtida com o modelo dinâmico).

A Fig. 5.30 apresenta mapas de estabilidade para diferentes temperaturas da mistura. Observa-se que na região de $G O R$ baixo a fronteira de estabilidade desloca-se para cima para maiores temperaturas, ampliando a região instável; já na região de $G O R$ elevado o efeito contrário ocorre, ou seja, para maiores temperaturas a fronteira de estabilidade desloca-se para a esquerda, fazendo com que a região instável diminua. A Fig. 5.31 mostra que as curvas obtidas com o critério de Pots apresentam o mesmo comportamento.

A Fig. 5.32 apresenta a influência do diâmetro interno da tubulação sobre os mapas de estabilidade. A variação no diâmetro não tem influência sobre a região de baixo $G O R$; entretanto, para a região de $G O R$ intermediário e elevado, observa-se que conforme o diâmetro aumenta obtêm-se uma maior região instável no mapa. A Fig. 5.33, que apresenta as fronteiras de estabilidade obtidas segundo o critério de Pots, apresentam o mesmo comportamento.

A Fig. 5.34 apresenta o comportamento das fronteiras de estabilidade para diferentes valores de pressão no separador. Observe que o aumento da pressão no separador faz com que a fronteira de estabilidade recue nas regiões de $G O R$ baixo, intermediário e elevado, tornando menor a região instável. As fronteiras de estabilidade resultantes do critério de Pots (ver Fig. 5.35) mostram que a região referente à intermitência severa do tipo 1 apresenta um leve aumento para maiores valores de pressão no separador.

A Fig. 5.36 apresenta mapas de estabilidade para diferentes alturas do riser. Observase que na região de $G O R$ baixo, alturas maiores fazem com que a região instável diminua, enquanto para a região de $G O R$ intermediário e elevado, alturas maiores fazem com que a região instável aumente. A Fig. 5.37 indica que as fronteiras de estabilidade obtidas segundo o critério de Pots apresentam o mesmo comportamento.

A Fig. 5.38 apresenta mapas de estabilidade para diferentes valores da coordenada horizontal do topo do riser, parâmetro que pode ser visualizada na Fig. 3.1. Na região de GOR elevado, observa-se que para maiores comprimentos da coordenada horizontal a fronteira de estabilidade desloca-se para a esquerda, resultando em uma menor região instável. A Fig. 5.39, 
Tabela 5.4: Modificações nos parâmetros para eliminação da intermitência severa: ( $\uparrow)$ indica aumento do parâmetro, $(\downarrow)$ indica diminuição do parâmetro e (-) indica pouca influência ou região de transição.

\begin{tabular}{|c|c|c|c|c|c|c|c|c|c|c|}
\hline & $\gamma_{A P I}$ & $\gamma_{g}$ & $W O R$ & $T$ & $D$ & $W_{r}$ & $P_{s e p}$ & $Z_{r}$ & $L$ & $\beta$ \\
\hline GOR baixo & - & $\uparrow$ & $\downarrow$ & $\downarrow$ & - & - & $\uparrow$ & $\uparrow$ & - & - \\
\hline GOR intermediário & $\downarrow$ & $\downarrow$ & - & - & $\downarrow$ & $\uparrow$ & $\uparrow$ & $\downarrow$ & $\downarrow$ & $\downarrow$ \\
\hline GOR elevado & - & $\downarrow$ & $\uparrow$ & $\uparrow$ & $\downarrow$ & $\uparrow$ & $\uparrow$ & $\downarrow$ & $\downarrow$ & - \\
\hline
\end{tabular}

mostra que as fronteiras de estabilidade obtidas com o critério de Pots não tem influência da coordenada horizontal do topo do riser.

A Fig. 5.40 apresenta os mapas de estabilidade em função do comprimento do pipeline. Maiores comprimentos do pipeline fazem com que a fronteira de estabilidade desloquem-se para a direita nas regiões de $G O R$ intermediário e elevado, aumentando a região instável do mapa. As fronteiras de estabilidade obtidas com o critério de Pots apresentam comportamento semelhante (ver Fig. 5.41).

A Fig. 5.42 apresenta mapas de estabilidade para diferentes valores de inclinação do pipeline. Para maiores inclinações do pipeline observa-se a expansão da fronteira de estabilidade na região de GOR intermediário. A Fig. 5.43 evidencia que as fronteiras de estabilidade obtidas com o critério de Pots apresentam o mesmo comportamento.

A Tabela 5.4 apresenta a compilação dos resultados para a região de $G O R$ baixo, intermediário e elevado. Considera-se que para diminuir a possibilidade de escoamento instável deve-se aumentar o parâmetro $(\uparrow)$, diminuir o parâmetro $(\downarrow)$, ou que o parâmetro não tem grande influência ou trata-se de uma região de transição entre diferentes comportamentos (-).

Observe que os parâmetros $\gamma_{A P I}, D, L$ e $\beta$ devem ser minimizados de modo a prevenir a intermitência severa. Já os parâmetros $W_{r}$ e $P_{s e p}$ devem ser maximizados. Outros parâmetros como $\gamma_{g}, W O R, T$ e $Z_{r}$ dependem da razão gás-óleo da mistura de hidrocarbonetos para determinação da influência sobre o escoamento. Vale ressaltar que, para um dado reservatório de petróleo, os parâmetros $\gamma_{A P I}, \gamma_{g}, W O R, G O R$ e $T$ não variam, ou variam pouco e ao longo de meses de exploração. Portanto, o projetista de sistemas de transporte submarino e elevação de óleo pode intervir sobre a geometria e disposição dos tubos, sendo as propriedades dos fluidos produzidos apenas um indicativo de tendência à ocorrência de intermitência severa. 


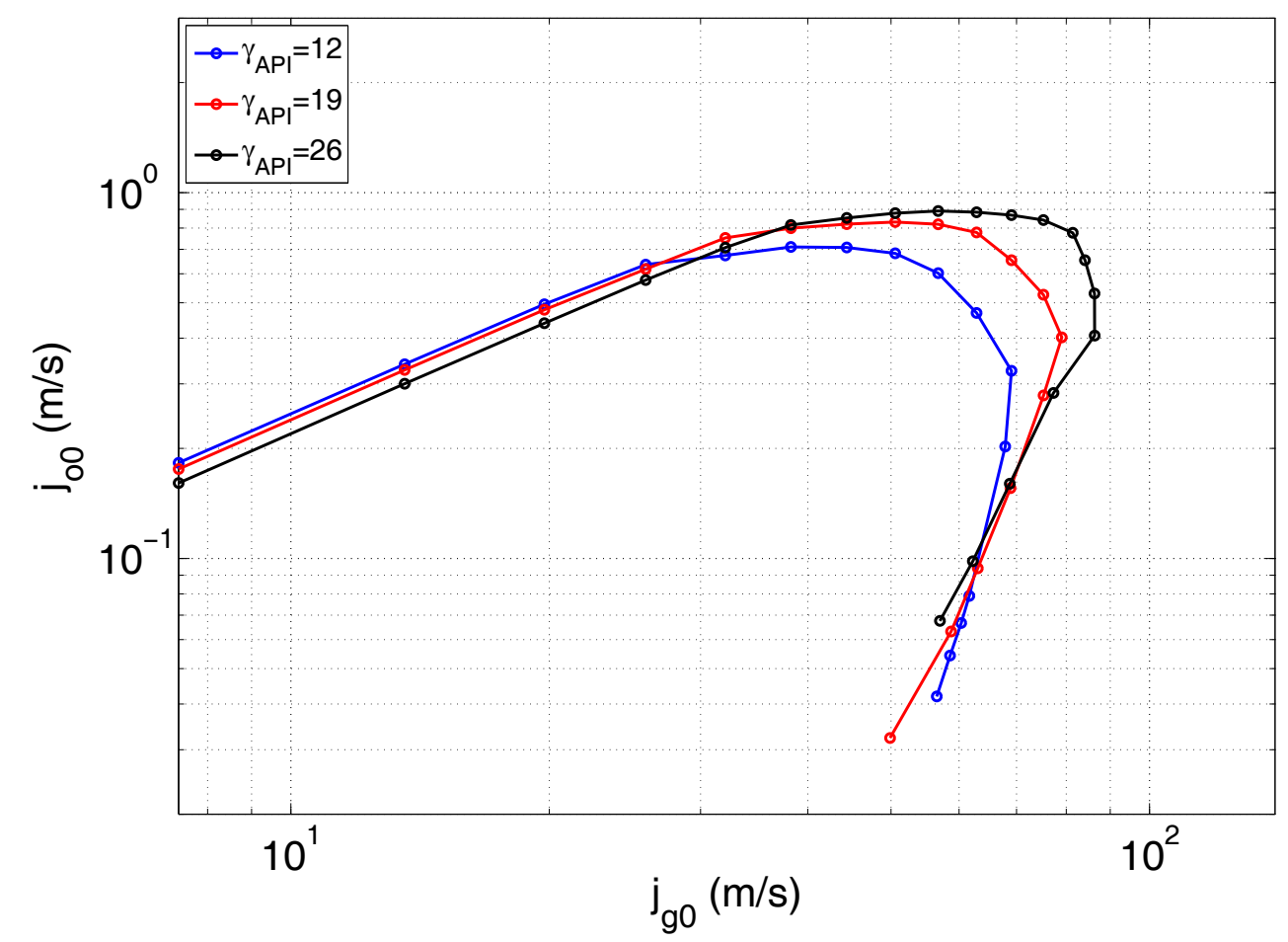

Figura 5.24: Estudo paramétrico para a densidade API $\gamma_{A P I}$ utilizando o modelo proposto.

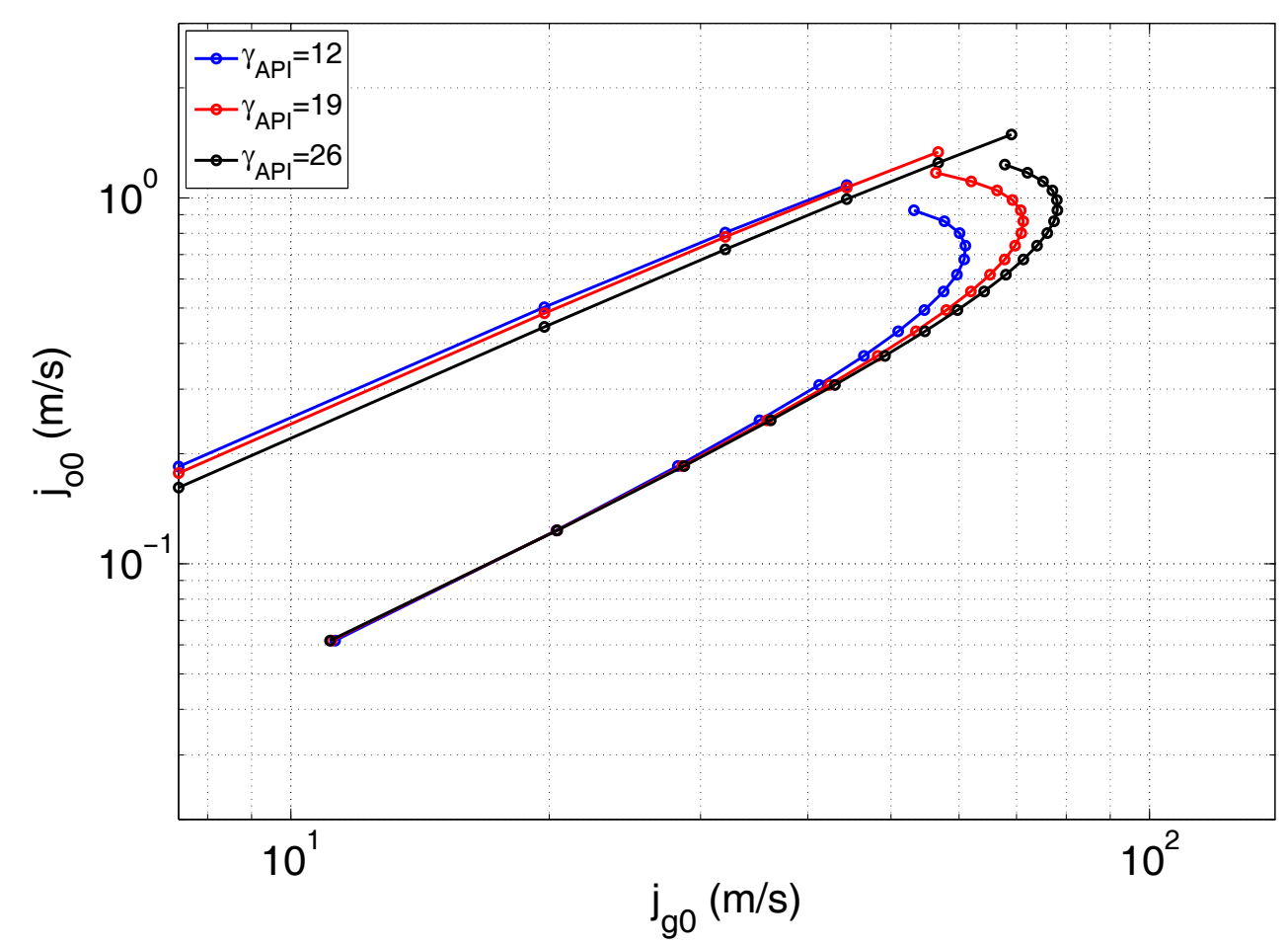

Figura 5.25: Estudo paramétrico para a densidade API $\gamma_{A P I}$ utilizando o critério de Pots. 


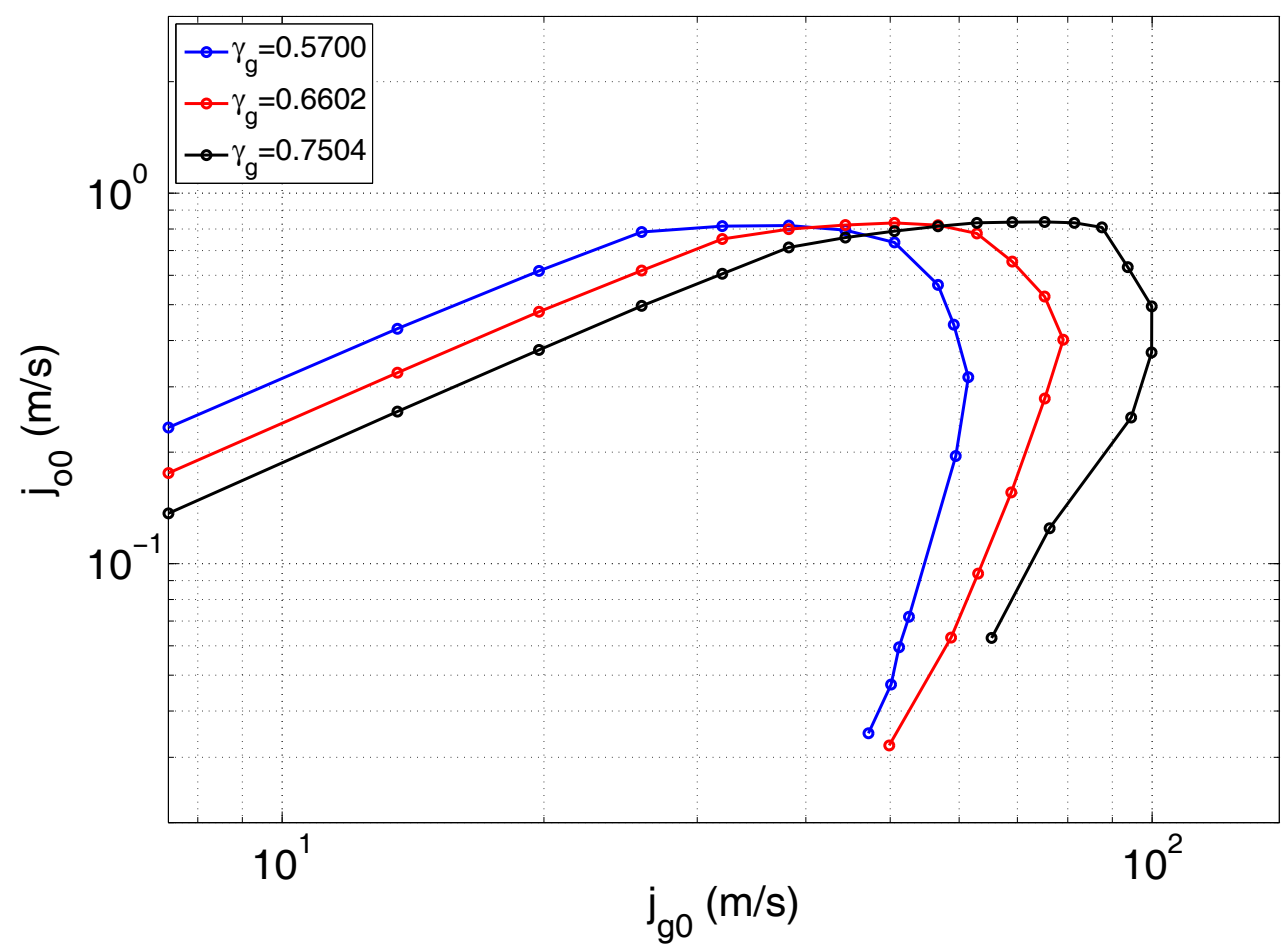

Figura 5.26: Estudo paramétrico para a densidade relativa do gás $\gamma_{g}$ utilizando o modelo proposto.

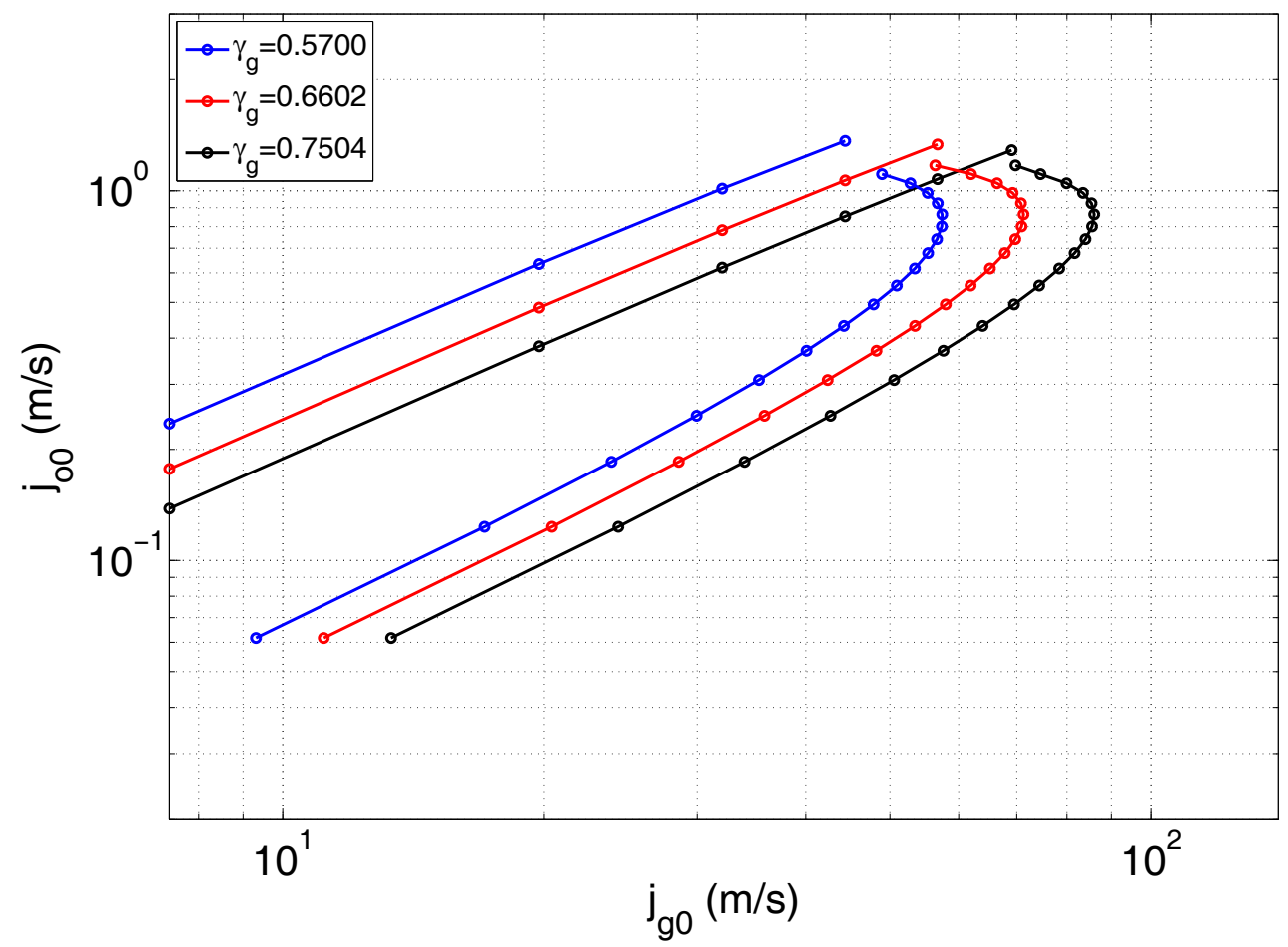

Figura 5.27: Estudo paramétrico para a densidade relativa do gás $\gamma_{g}$ utilizando o critério de Pots. 


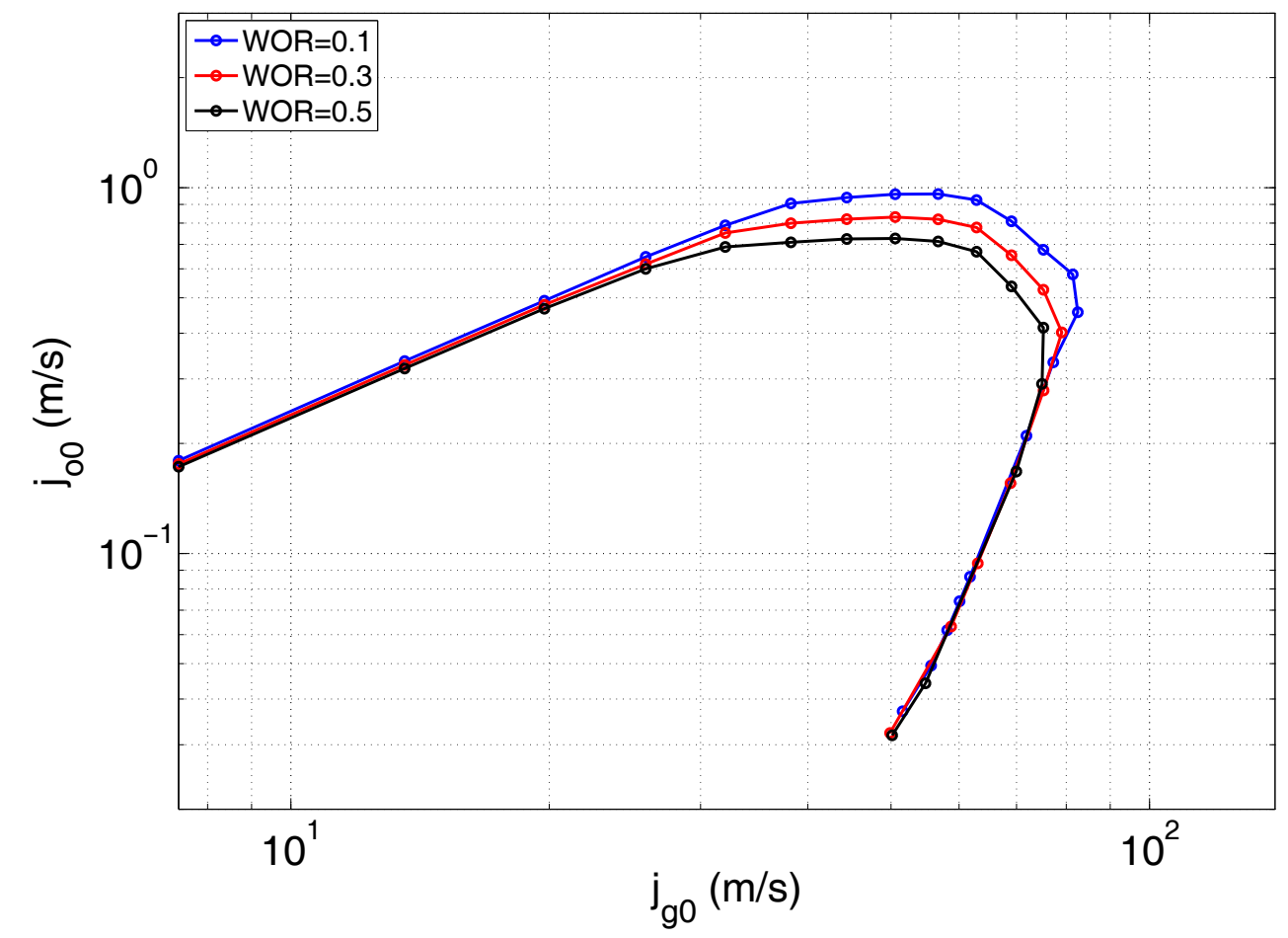

Figura 5.28: Estudo paramétrico para a razão água-óleo $W O R$ utilizando o modelo proposto.

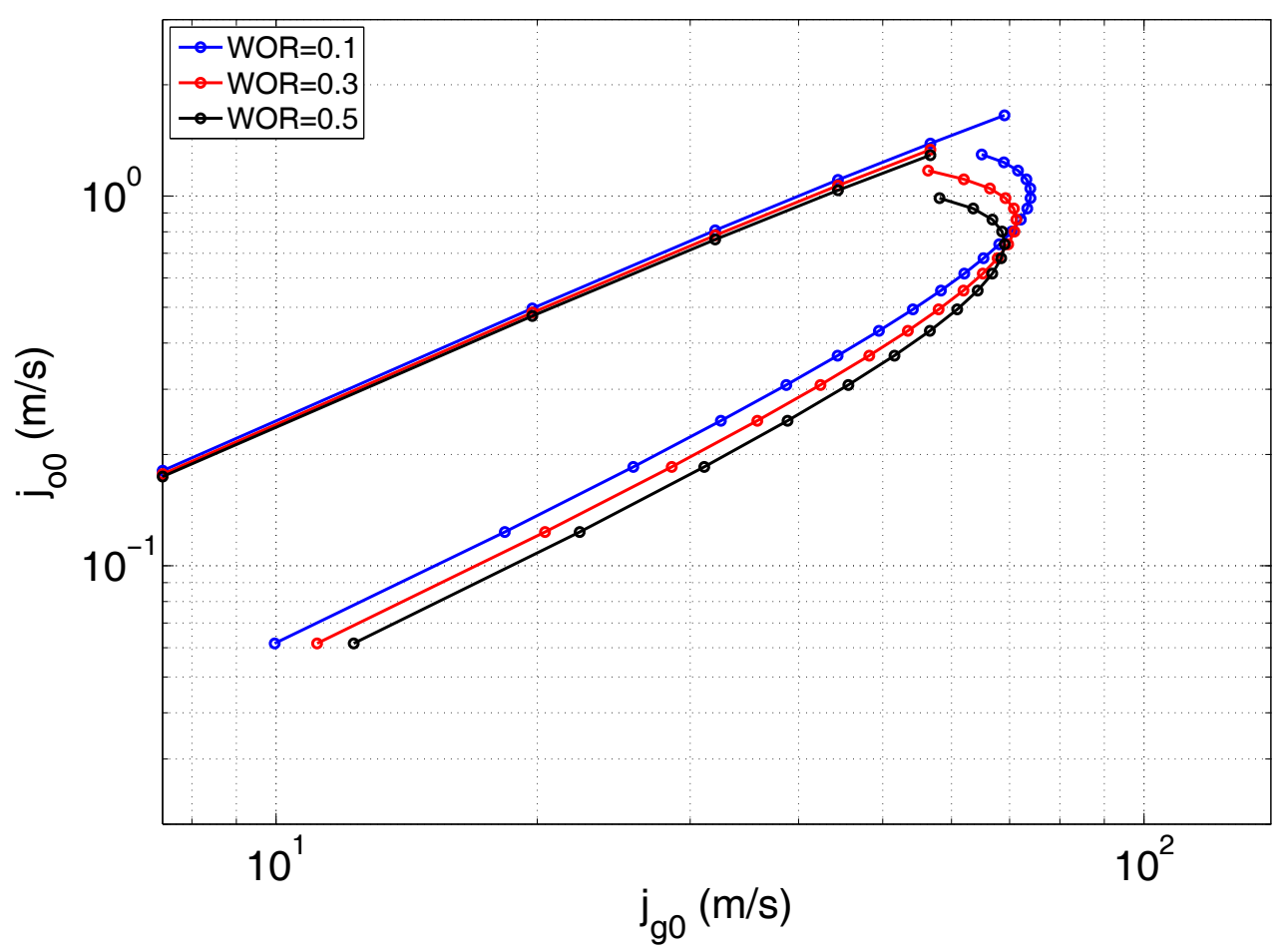

Figura 5.29: Estudo paramétrico para a razão água-óleo $W O R$ utilizando o critério de Pots. 


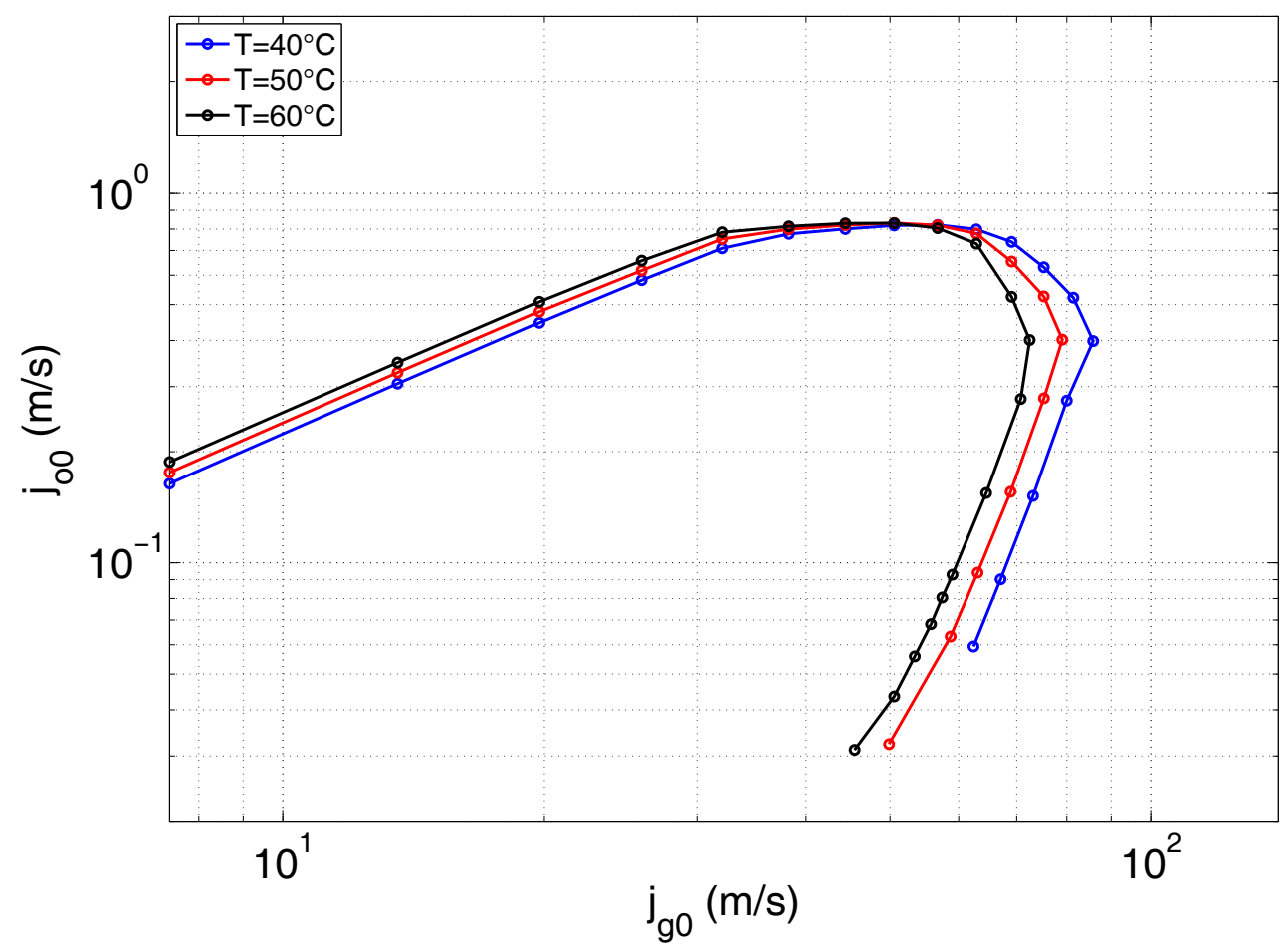

Figura 5.30: Estudo paramétrico para a temperatura $T$ utilizando o modelo proposto.

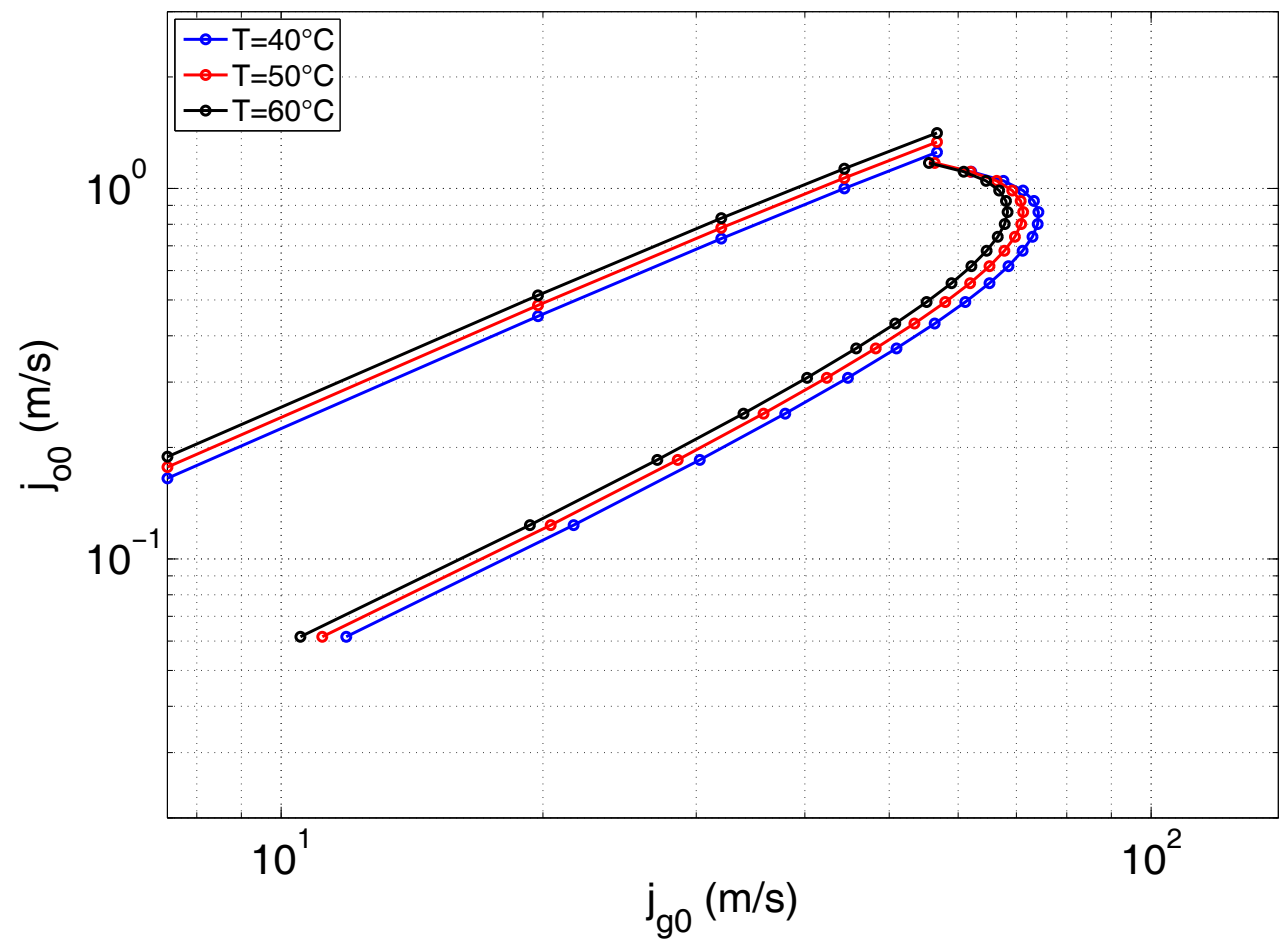

Figura 5.31: Estudo paramétrico para a temperatura $T$ utilizando o critério de Pots. 


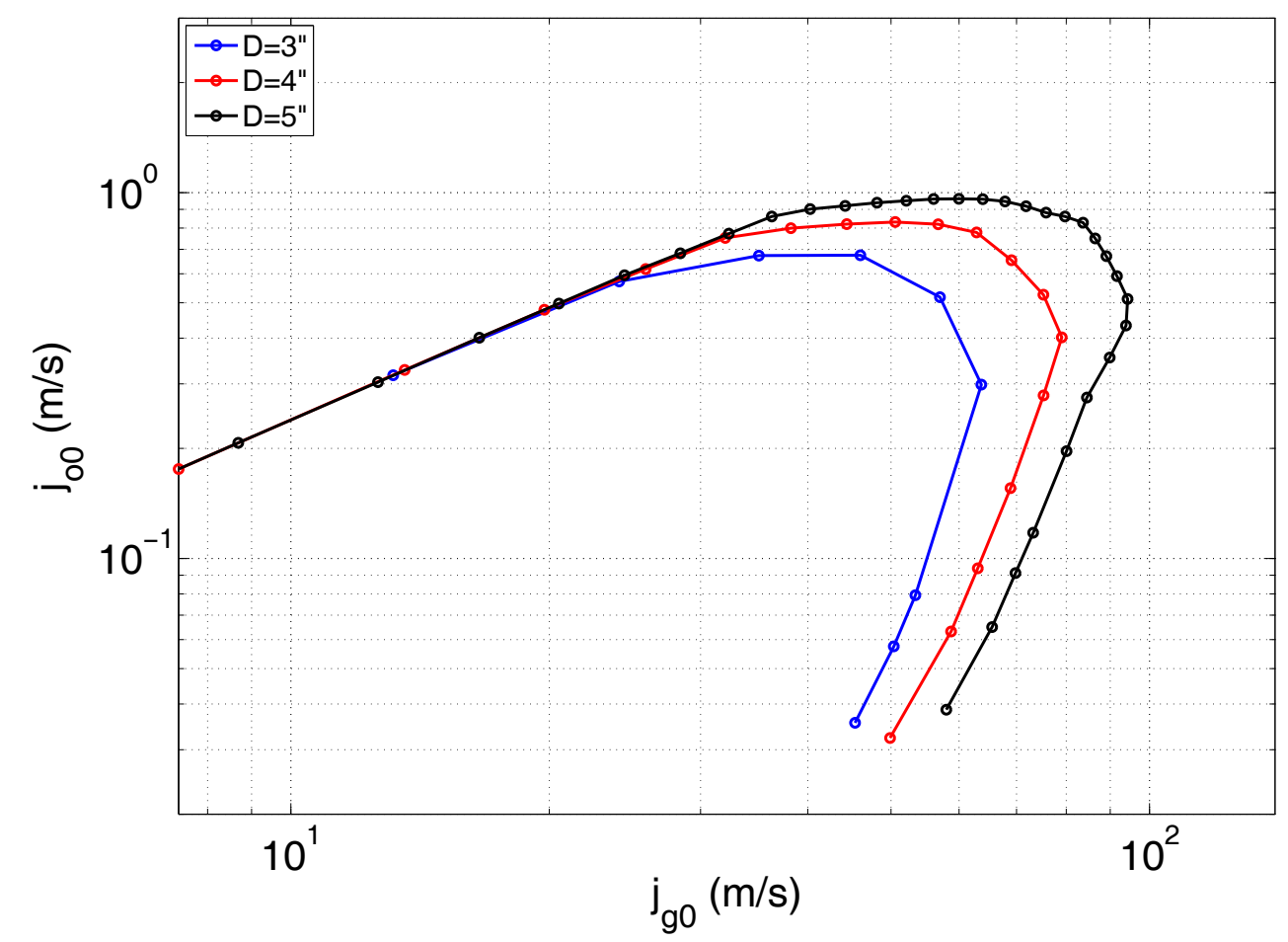

Figura 5.32: Estudo paramétrico para o diâmetro interno $D$ utilizando o modelo proposto.

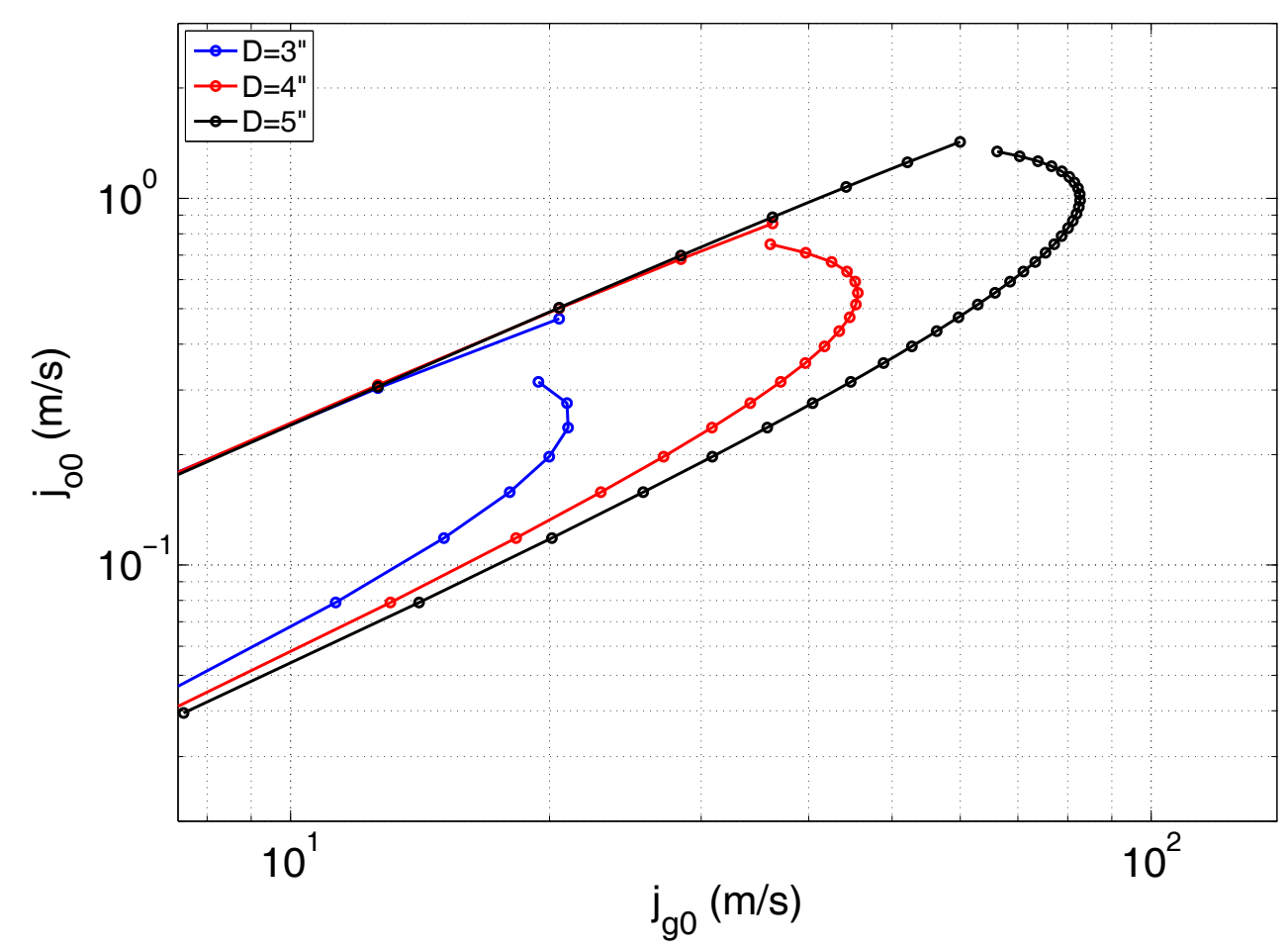

Figura 5.33: Estudo paramétrico para o diâmetro interno $D$ utilizando o critério de Pots. 


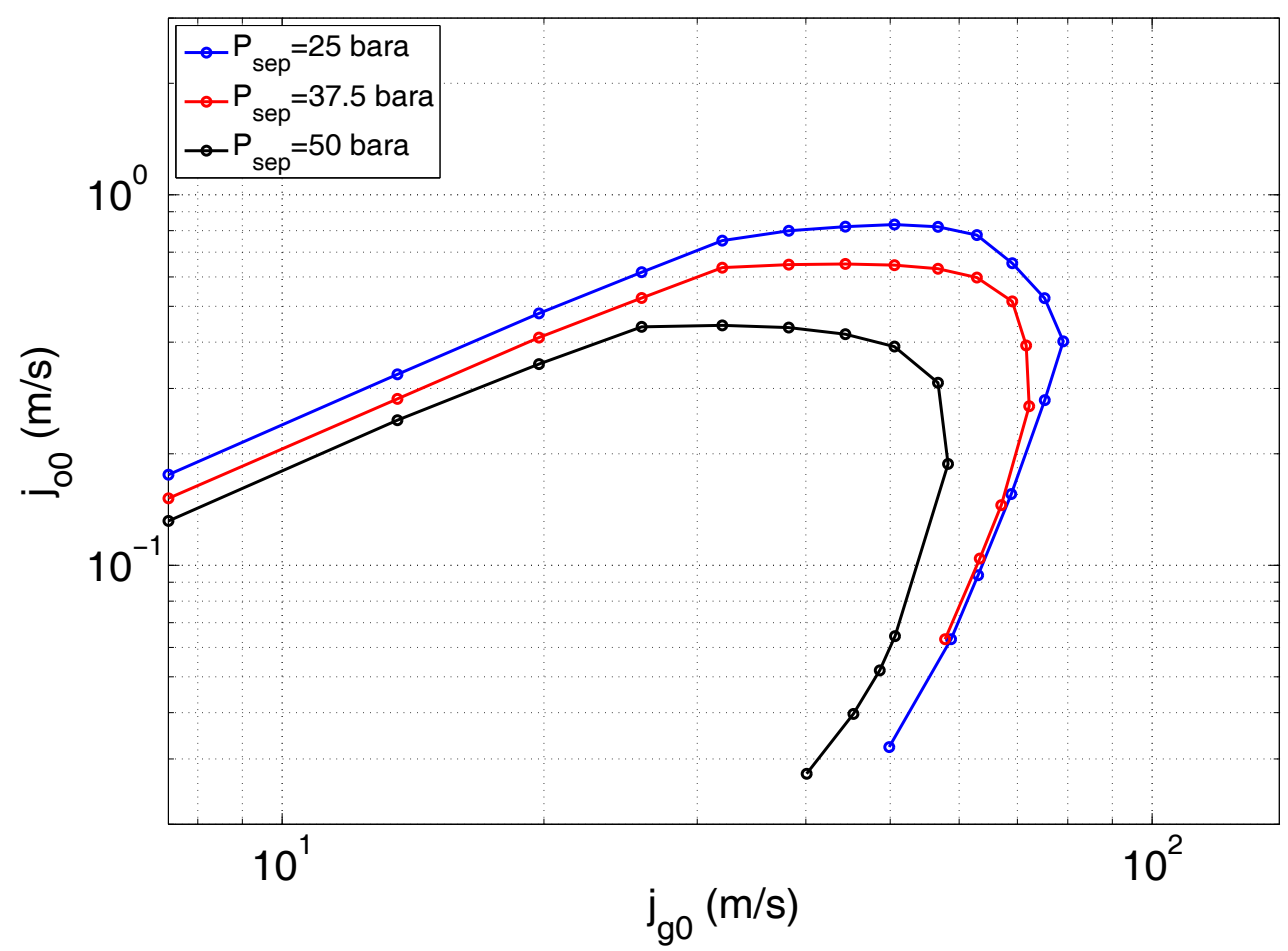

Figura 5.34: Estudo paramétrico para a pressão no separador $P_{\text {sep }}$ utilizando o modelo proposto.

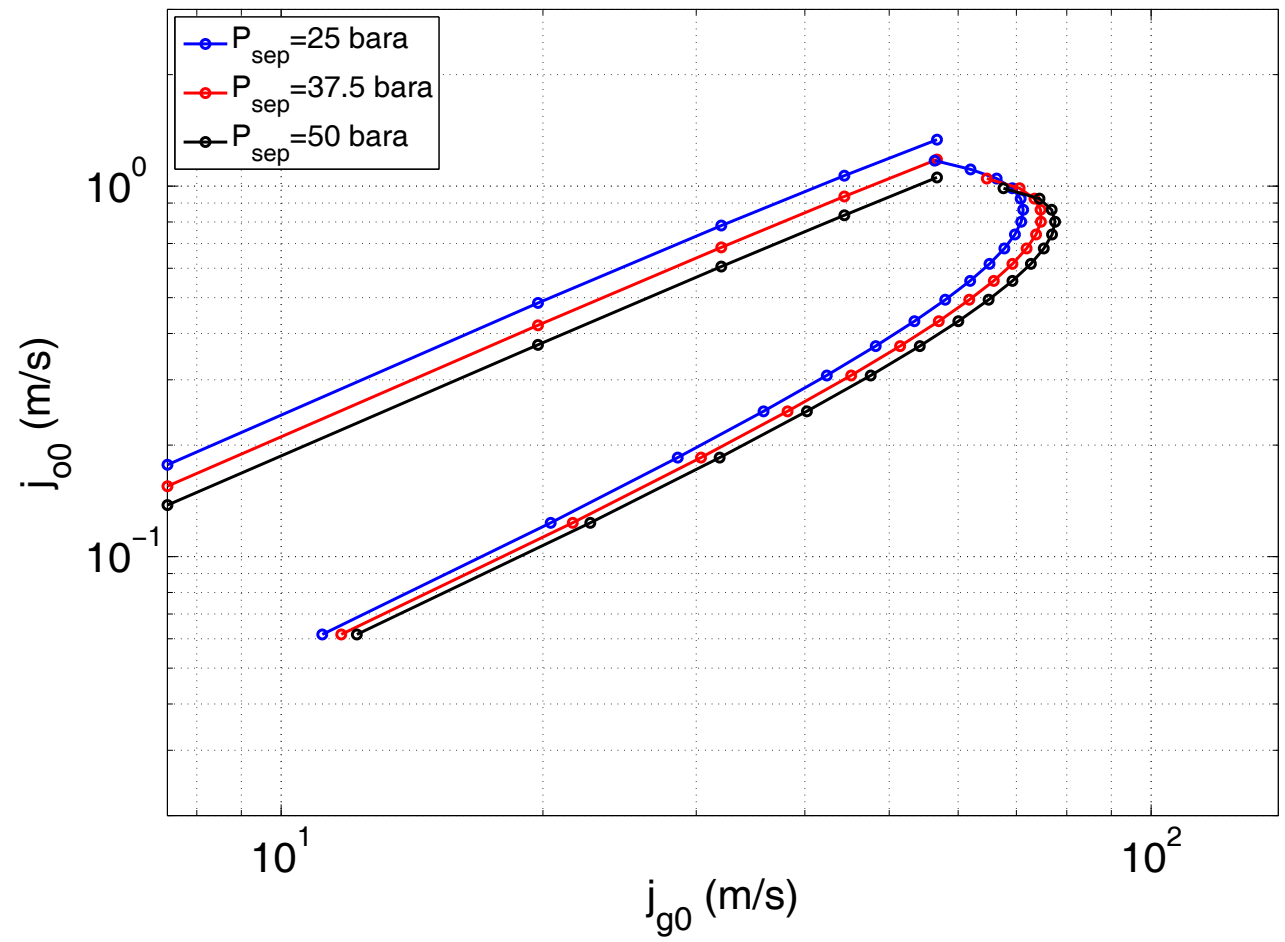

Figura 5.35: Estudo paramétrico para a pressão no separador $P_{\text {sep }}$ utilizando o critério de Pots. 


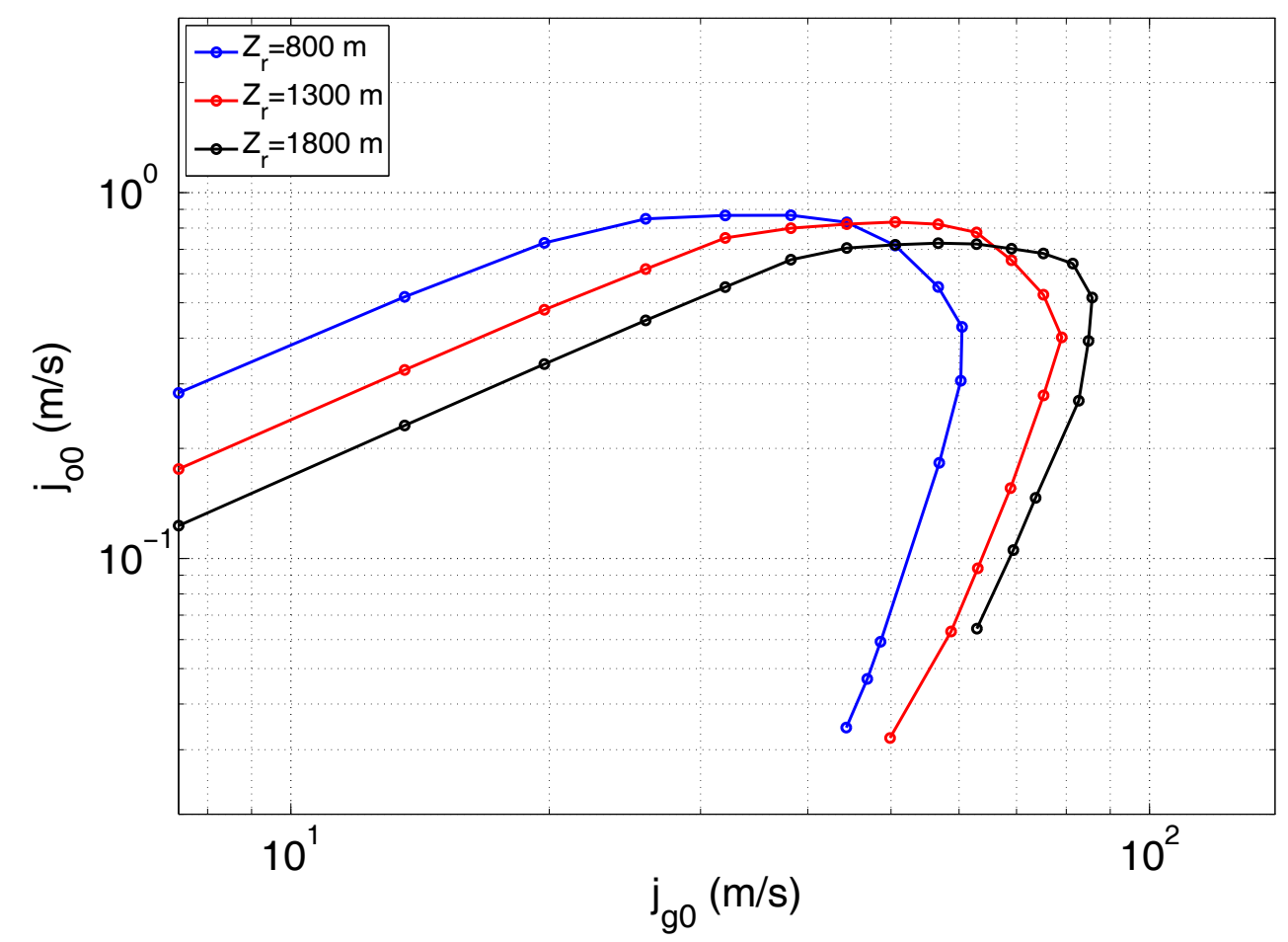

Figura 5.36: Estudo paramétrico para a altura do topo do riser $Z_{r}$ utilizando o modelo proposto.

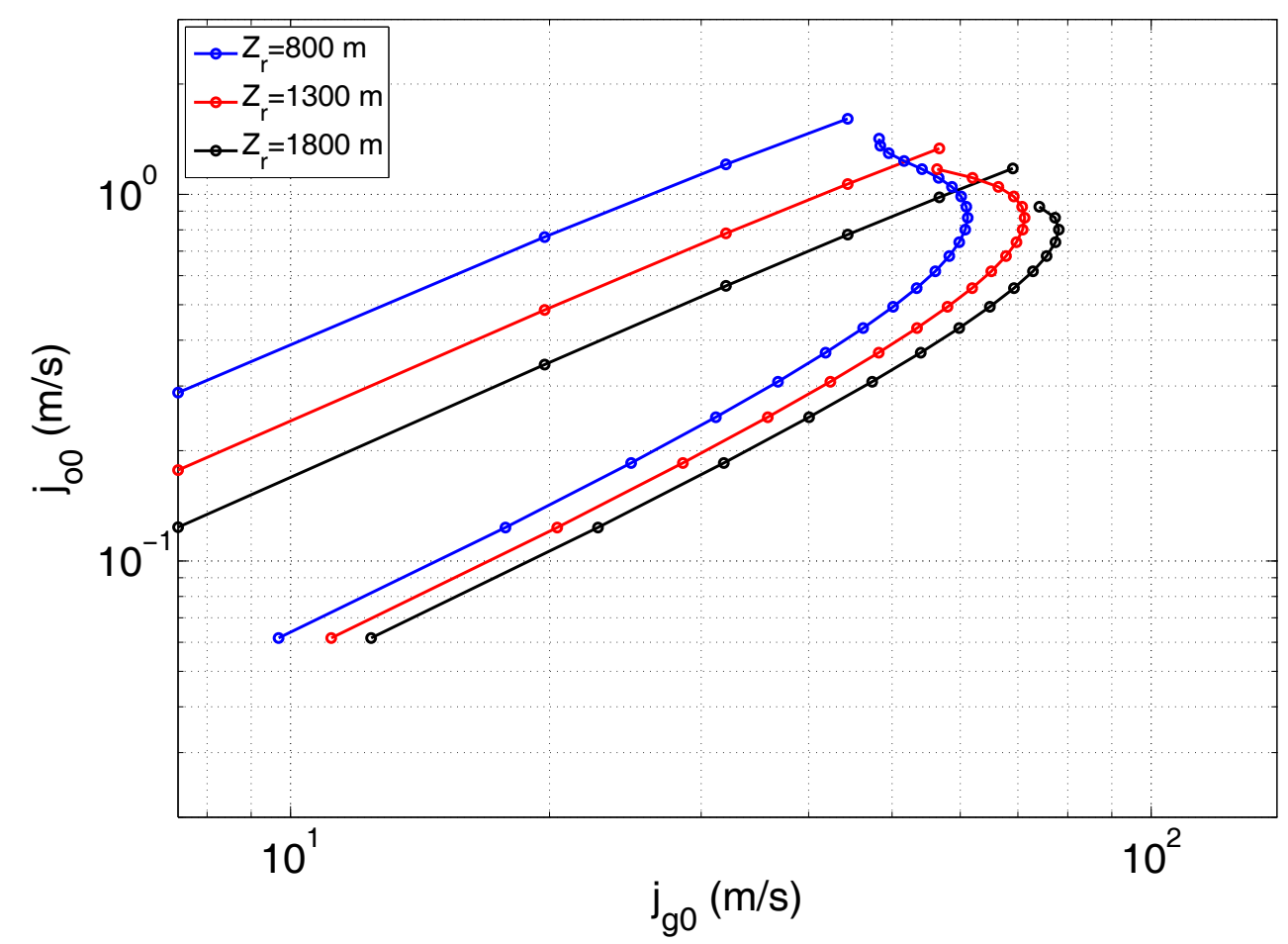

Figura 5.37: Estudo paramétrico para a altura do topo do riser $Z_{r}$ utilizando o critério de Pots. 


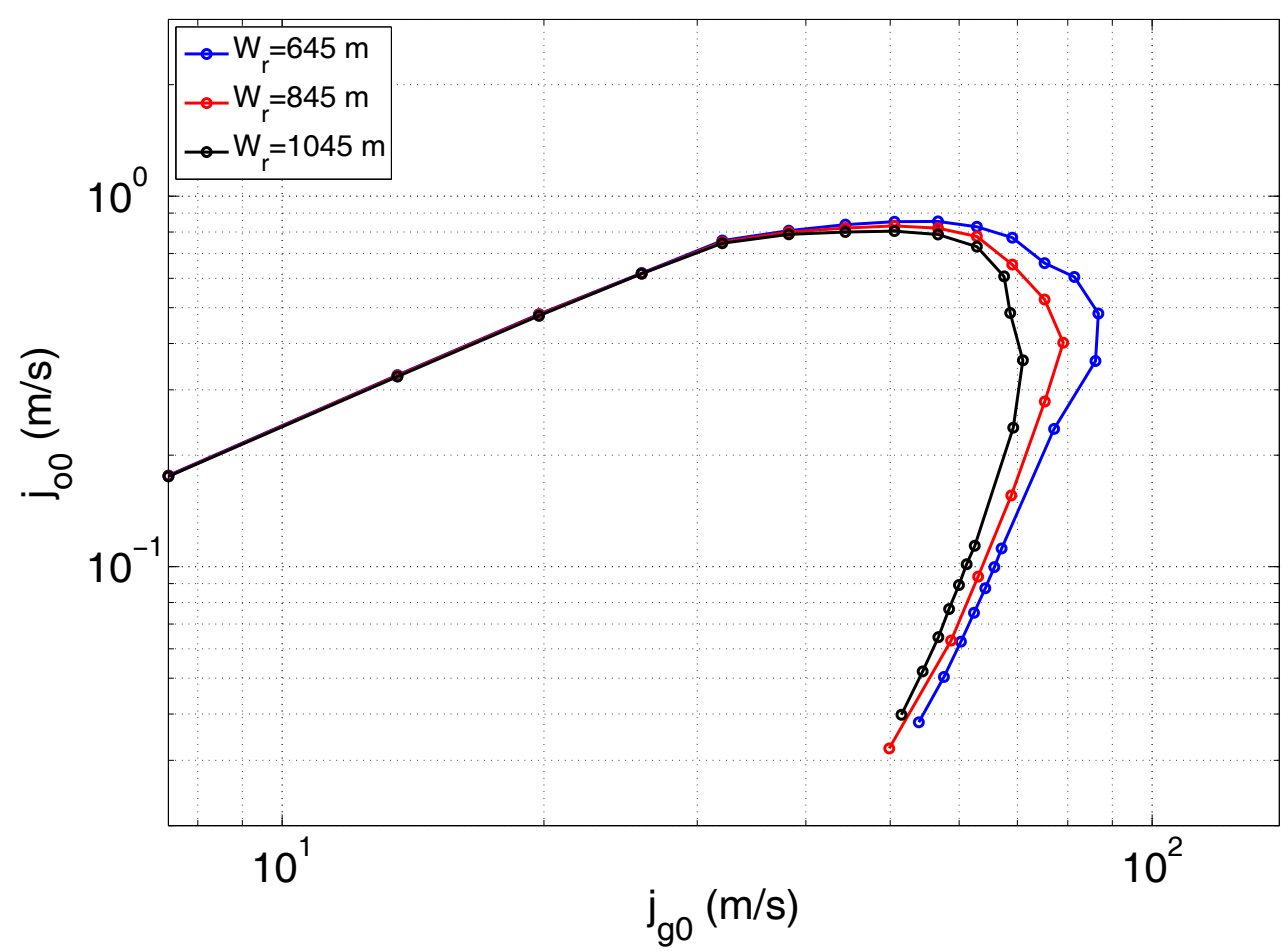

Figura 5.38: Estudo paramétrico para a coordenada horizontal do topo do riser $W_{r}$ utilizando o modelo proposto.

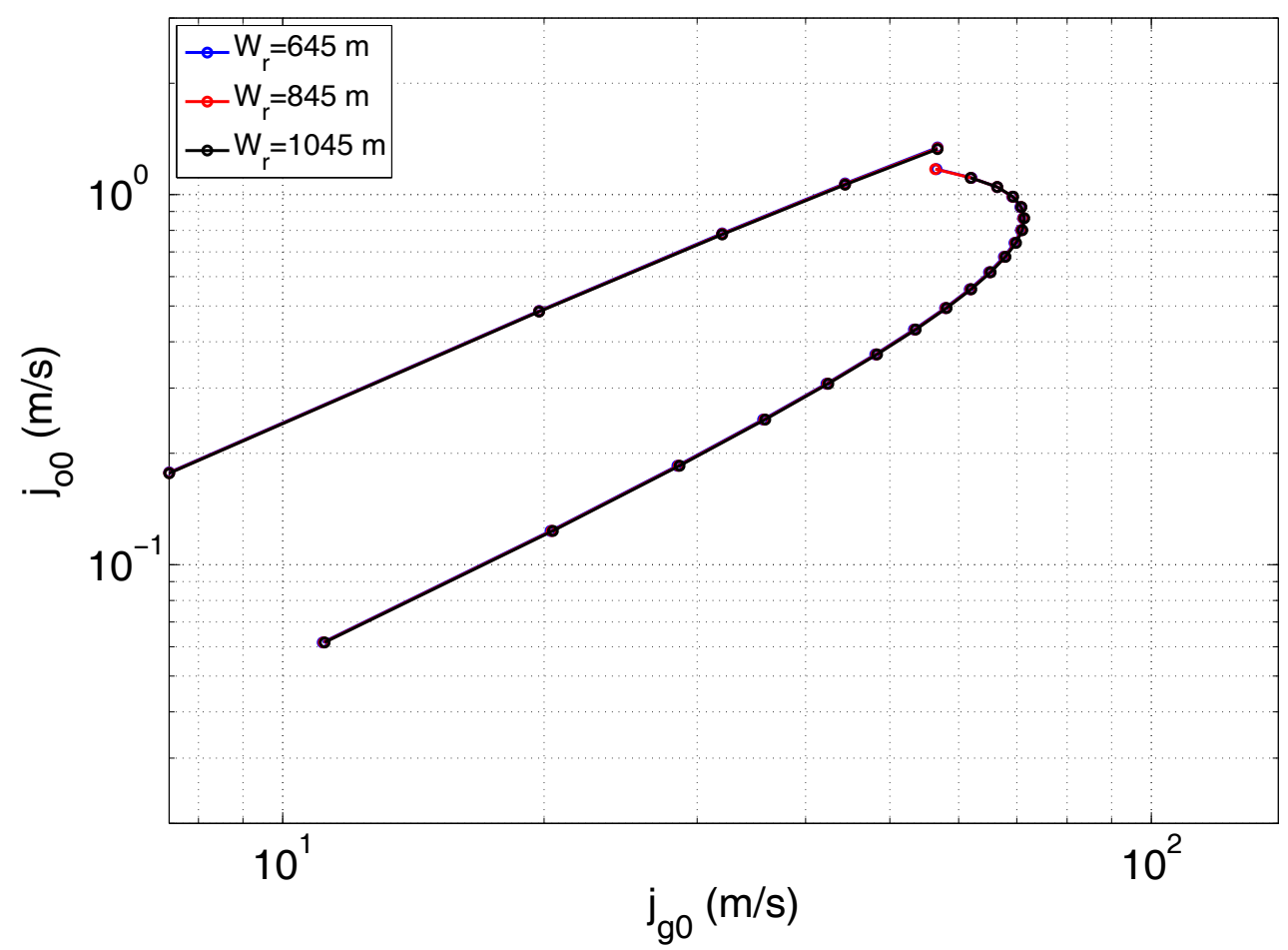

Figura 5.39: Estudo paramétrico para a coordenada horizontal do topo do riser $W_{r}$ utilizando o critério de Pots. 


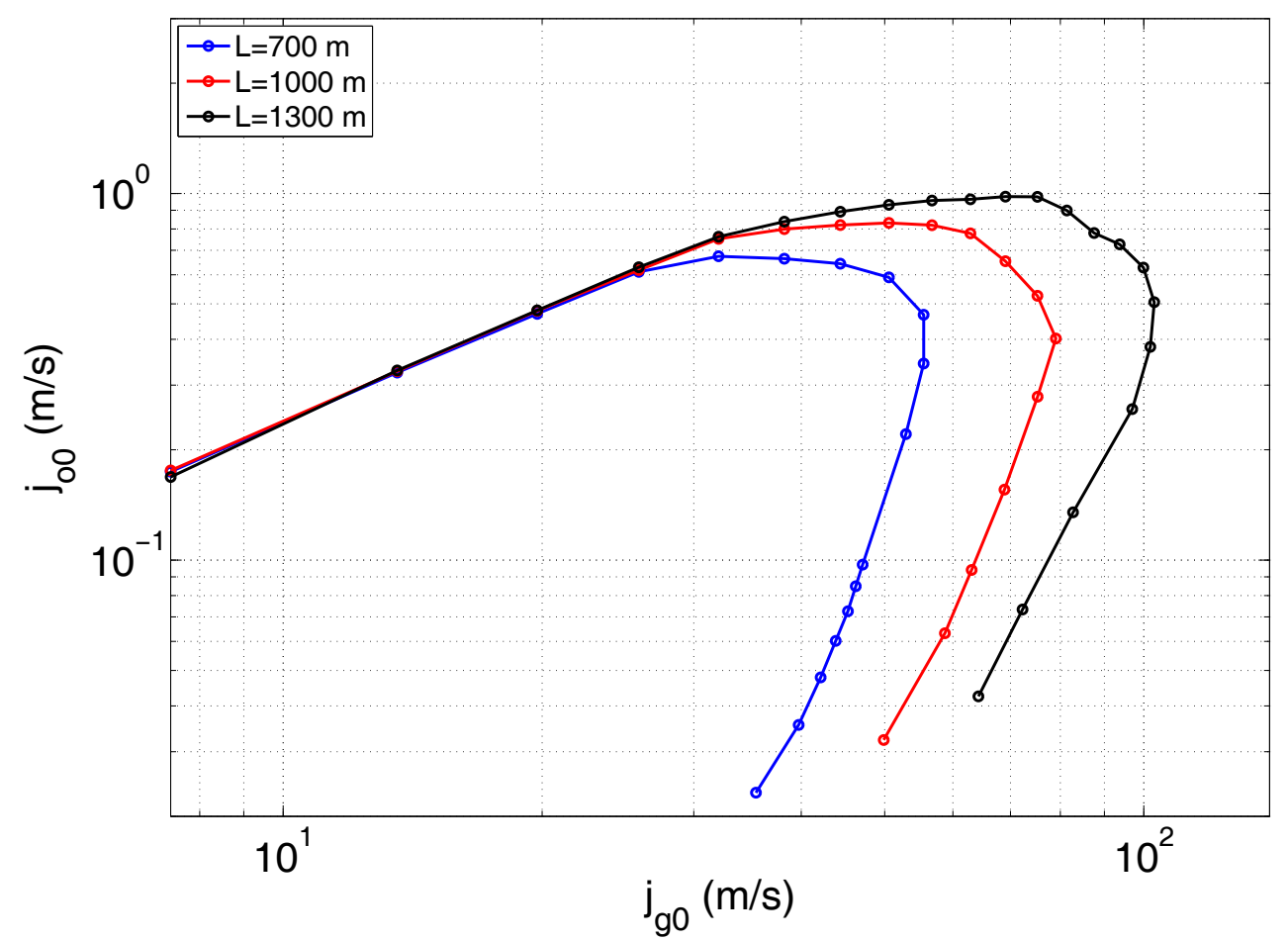

Figura 5.40: Estudo paramétrico para o comprimento do pipeline $L$ utilizando o modelo proposto.

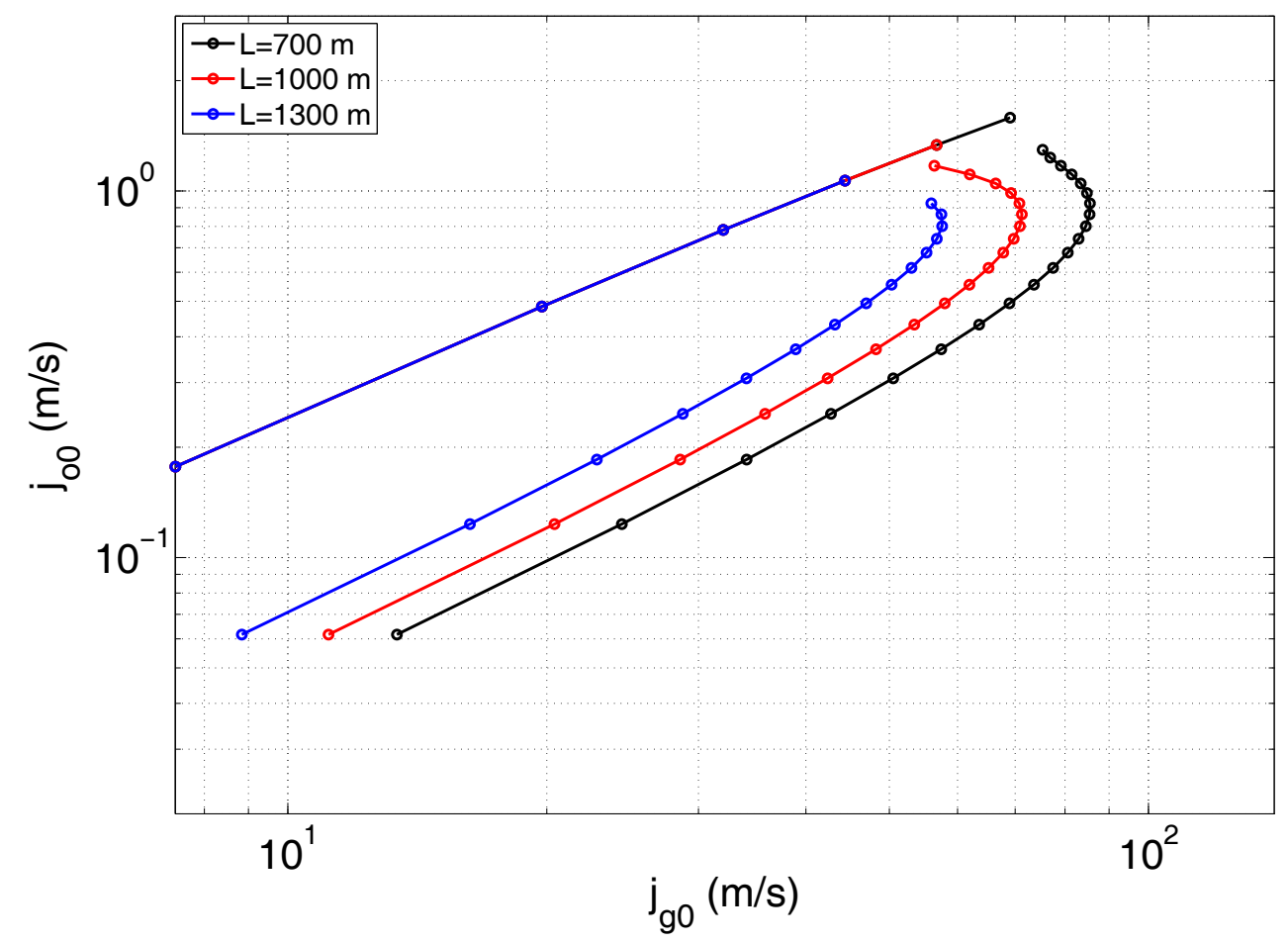

Figura 5.41: Estudo paramétrico para o comprimento do pipeline L utilizando o critério de Pots. 


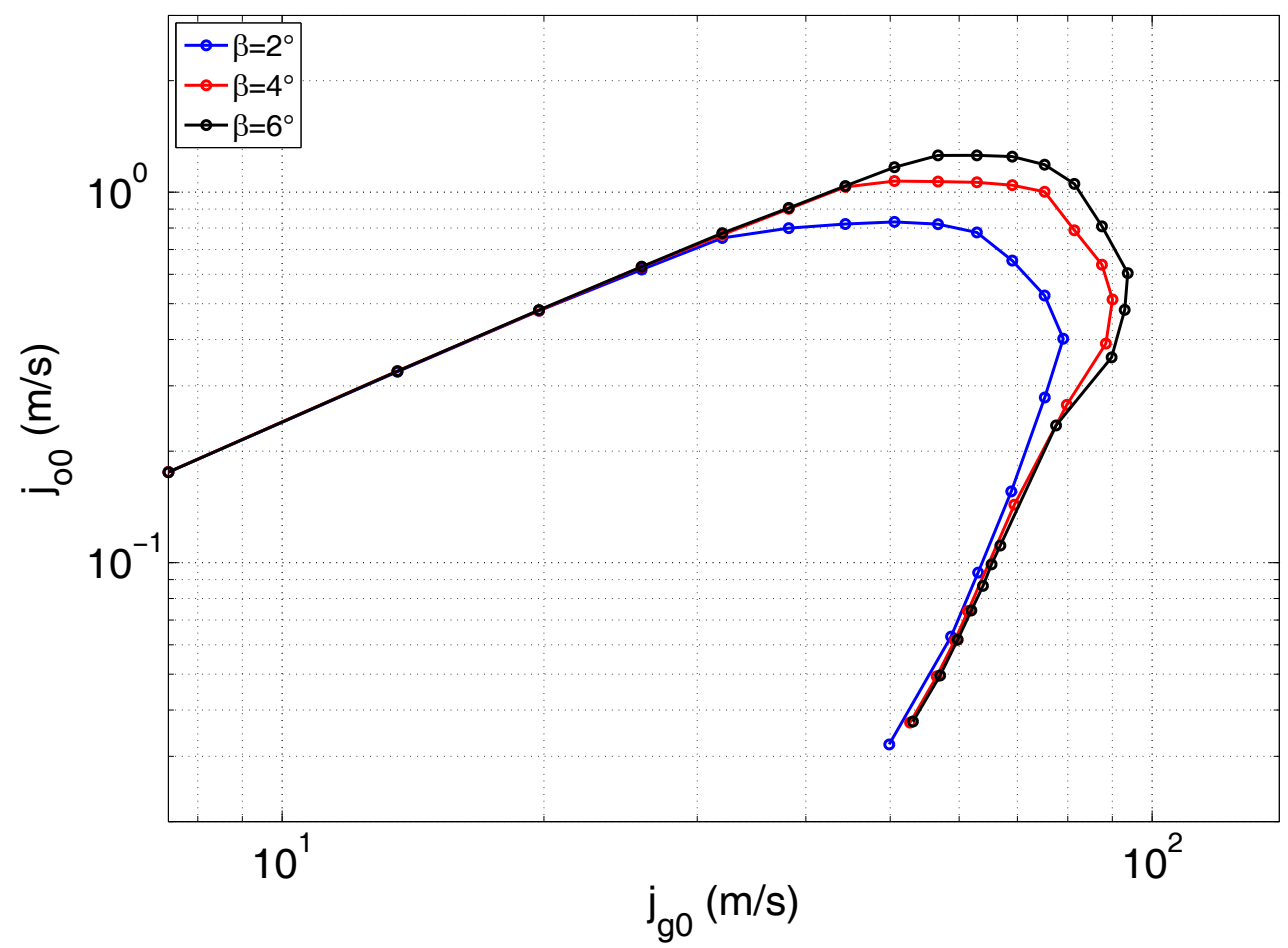

Figura 5.42: Estudo paramétrico para o ângulo de inclinação do pipeline $\beta$ utilizando o modelo proposto.

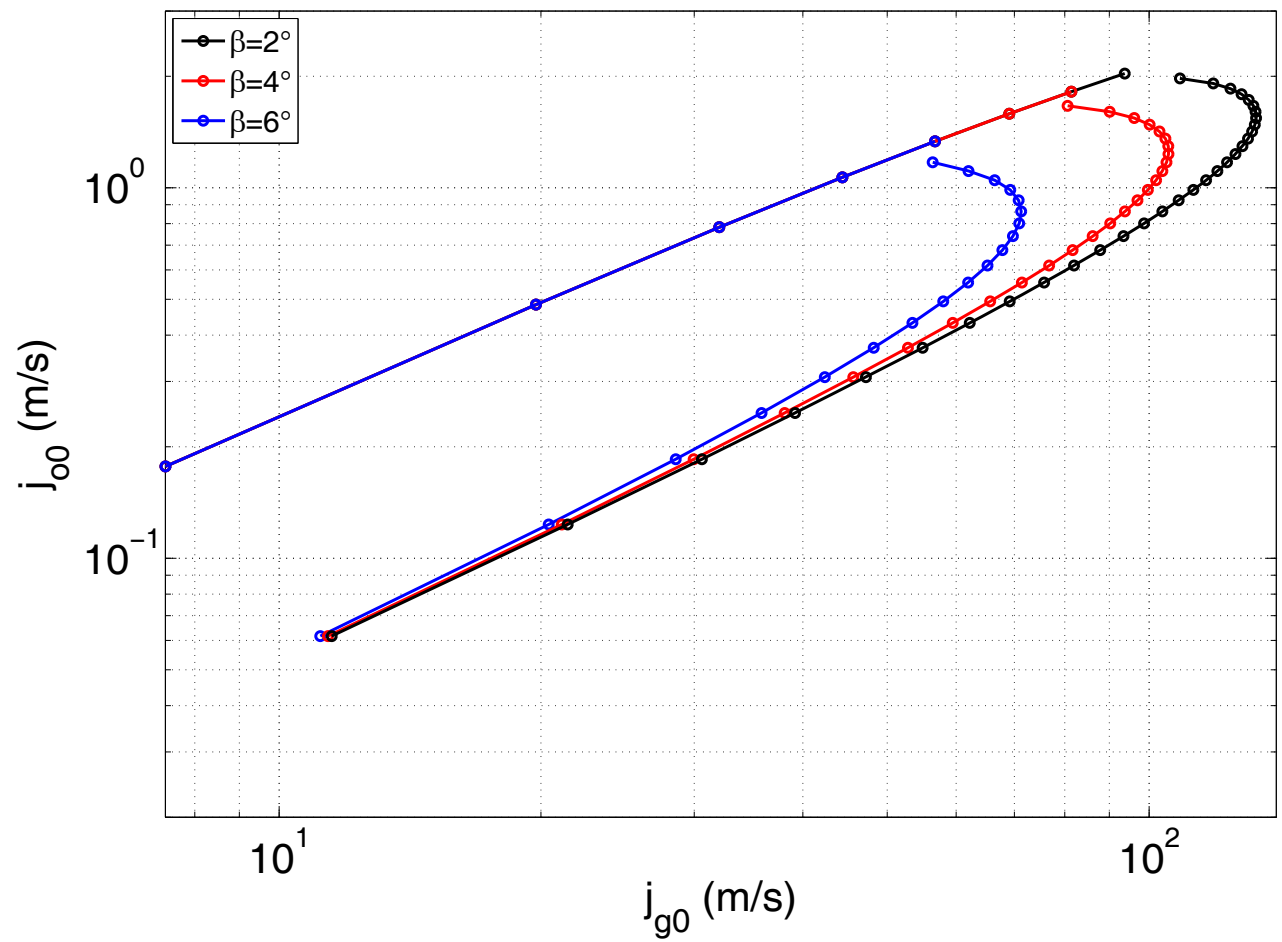

Figura 5.43: Estudo paramétrico para o ângulo de inclinação do pipeline $\beta$ utilizando o critério de Pots. 


\section{CONCLUSÕES}

Propôs-se construir um modelo matemático a fim de investigar o fenômeno da intermitência severa em sistemas pipeline-riser. $\mathrm{O}$ estado da arte contempla um cenário dominado por modelos cujo intuito é replicar o comportamento da intermitência severa em condições de laboratório, considerando sistemas pipeline-riser em que os fluidos são água e ar. A evolução dos trabalhos desenvolvidos por diferentes autores levou à obtenção de modelos capazes de prever a ocorrência da intermitência severa com uma boa concordância com resultados experimentais.

Apesar dos importantes avanços, os modelos mostravam-se limitados ao tentar extrapolálos para uso na predição de instabilidades em sistemas reais de produção de petróleo. Alguns pontos-chave que impossibilitavam o seu uso nessas circunstâncias são as grandes razões de pressão entre a base e o topo do riser em condições reais, levando a importantes efeitos de expansão, e os efeitos de transferência de massa devido à presença majoritária de hidrocarbonetos no escoamento.

Com o intuito de aproximar os modelos aos sistemas reais de produção de petróleo, as seguintes características foram incorporadas:

- Modelagem do escoamento trifásico de gás, óleo e água em um sistema pipeline-riser com geometria vertical ou catenária.

- Consideração da transferência de massa entre as fases gás e óleo (vaporização e condensação).

- Modelagem do comportamento do gás natural como um gás real.

- Consideração dos termos de compressibilidade das fases gasosa e líquida.

- Cálculo das propriedades termodinâmicas locais para os fluidos utilizando a aproximação de black-oil.

O resultados obtidos com o modelo foram comparados com os resultados obtidos por 
meio de simulações usando o código computacional OLGA, apresentando resultados e tendências bastante próximos.

A partir de simulações usando um caso de estudo, foi possível apresentar e discutir os diferentes estágios pelos quais o sistema passa durante o ciclo de intermitência severa. Foi constatado que, em sistemas onde há transferência de massa, sempre há alguma quantia de gás deixando o topo do riser, impedindo o cálculo de um comprimento de golfada de líquido (liquid slug length).

Uma nova classificação para a intermitência severa em sistemas com transferência de massa foi apresentada, em que o comprimento da golfada de líquido não é mais utilizado. A nova classificação considera como intermitência severa do tipo 1 o escoamento em que ocorre a interrupção do fluxo de gás na base do riser e constata-se momentaneamente o riser completamente cheio de líquido. A intermitência severa do tipo 2 também considera a interrupção do fluxo de gás na base do riser, porém o riser não chega a ficar completamente cheio de líquido. Já no caso da intermitência severa do tipo 3, o fluxo de gás do pipeline para o riser não é interrompido.

Vale ressaltar que o modelo captura importantes efeitos físicos em um sistema altamente não-linear, tais como o nível de líquido móvel no riser e a frente de penetração de líquido no pipeline. Isso tornou possível classificar os casos de estudo entre intermitência severa dos tipos SS1, SS2 e SS3.

Outra importante constatação é que durante o estágio de produção da golfada, diferentemente do que ocorre em sistemas água-ar, em que a pressão máxima mantém-se constante durante todo esse estágio, a vaporização faz com que a fração de vazio ao longo do riser assuma valores não nulos, aliviando a pressão da coluna de líquido na base do riser. Portanto, a pressão máxima na base do riser é atingida, porém seu patamar não é mantido, apresentando queda durante todo o estágio de produção da golfada.

Mapas de estabilidade foram construídos utilizando o novo modelo e importantes diferenças entre os mapas de estabilidade para sistemas água-ar e sistemas óleo-água-gás foram observadas. Primeiramente, em um sistema água-ar, as vazões da fase gasosa e da fase líquida podem variar independentemente, o que não ocorre em um sistema óleo-água-gás, no qual as vazões locais de gás e óleo dependem das condições de pressão e temperatura locais. Outra importante constatação é que, dado que o mapa de estabilidade é calculado variando-se as vazões volumétricas de gás e óleo na condição padrão, e consequentemente a razão gás-óleo $G O R$, conclui-se que diferentes óleos ou misturas de hidrocarbonetos são levadas em conta nos mapas de estabilidade ora construídos. Observa-se também que a linha de estabilidade decresce para 
vazões volumétricas de gás menores na condição padrão, o que não ocorre em sistemas água-ar. O motivo para este comportamento provém do fato de a região em que são observadas baixas vazões de gás estar relacionada a misturas com baixos $G O R$; nessas condições a quantia de gás que condensa é significativa em comparação ao gás livre, gerando um efeito estabilizante.

Também foi apresentado um mapa de tipos de instabilidade, em que se pôde observar que a região referente à intermitência severa do tipo 1 torna-se menor para sistemas com transferência de massa em relação aos sistemas água-ar. A vaporização aumenta o volume de gás livre no sistema, aliviando a pressão da coluna hidrostática e fazendo com que casos que eram antes classificados como SS1 passem a ser classificados como SS2.

Por meio de um estudo paramétrico verificou-se a influência de diferentes variáveis relacionadas à geometria e caracterização dos fluidos sobre o formato dos mapas de estabilidade. O estudo permite avaliar sistemas de produção de petróleo compostos por um pipeline e riser com relação à tendência de ocorrência da intermitência severa.

Mapas de estabilidade também foram construídos utilizando o critério apresentado por Pots, Bromilow e Konijn (1987). Avaliando a razão da taxa de aumento de pressão no pipeline e na base do riser, os autores determinaram um parâmetro que identifica a região no mapa de estabilidade em que ocorre a intermitência severa do tipo 1.

Dado que o critério de Pots permite obter mapas de estabilidade com baixo custo computacional comparado aos mapas construídos com base no modelo dinâmico, o uso do critério pode ser uma solução rápida para verificar a influência dos diferentes parâmetros sobre a fronteira de estabilidade.

Como sugestão para melhorias futuras no modelo dinâmico proposto, os seguintes pontos podem ser abordados:

- Queda de pressão no pipeline: As simulações realizadas utilizando o código OLGA sugeriram que quedas de pressão significativas ocorrem ao longo do pipeline; sendo assim, sua consideração representaria um avanço.

- Termos de inércia nas equações de conservação da quantidade de movimento: julga-se ser possível a utilização de uma equação de conservação da quantidade de movimento completa para o cálculo da pressão nos subsistemas; entretanto, para o cálculo das características, o modelo NPW (no-pressure-wave) ainda seria utilizado, de maneira a negligenciar as ondas de pressão. Sendo assim um modelo com pseudo-inércia seria desenvolvido.

- Inclusão de gas lift: o gas lift ocorre em sistemas reais como meio de aliviar o peso da 
coluna de líquido, levando eventualmente à melhoria da produtividade dos poços. Outro motivador para o uso do gas lift é a possibilidade de influenciar no espaço de parâmetros em que opera determinado sistema, retirando-o de uma possível região de instabilidade.

- Fração de vazio variável no pipeline: Devido à grande extensão do pipeline, especula-se que alterações, mesmo que pequenas, na fração de vazio teriam importantes efeitos no comportamento desse subsistema.

- Inclusão da modelagem de válvula reguladora (choke valve): a válvula reguladora está presente em muitos sistemas de produção de petróleo, representando um meio de controle do fluxo de produção.

- Estudo da interação entre o escoamento interno e externo aos tubos de transporte dos fluidos: o escoamento interno, por meio das golfadas de líquido, pode fazer com que os tubos movimentem-se; o mesmo ocorre da interação dos tubos com o escoamento externo, o que pode gerar vibrações induzidas por vórtice. A dinâmica do escoamento interno é influenciada pelo escoamento externo e vice-versa; tais influências devem ser investigadas futuramente.

- Extensão do modelo para geometria lazy-wave: o atual modelo contempla geometria catenária ou vertical. No entanto, outras geometrias observadas em sistemas de produção de petróleo, como a lazy-wave, podem ser levadas em conta utilizando uma modelagem semelhante à apresentada.

Recentemente os efeitos detalhados nos itens anteriores (exceto os dois últimos) foram implementados na modelagem de intermitência severa em sistemas água-ar, mostrando a viabilidade da extensão a sistemas com transferência de massa (BALIÑO, 2012). 


\section{REFERÊNCIAS}

AMES, W. F. Numerical methods for partial diferential equations. Rio de Janeiro: Academic Press, 1992. $451 \mathrm{p}$.

BALIÑO, J. L. Modeling and simulation of severe slugging in air-water systems including inertial effects. In: Proceeding of the 6th International Conference on Integrated Modeling and Analysis in Applied Control and Automation. Viena, Austria: IMAACA, 2012.

BALIÑO, J. L.; BURR, K. P.; NEMOTO, R. H. Modeling and simulation of severe slugging in air-water pipeline-riser systems. International Journal of Multiphase Flow, v. 36, n. 8, p. 643-660, 2010.

BEAL, C. The viscosity of air, water, natural gas, crude oils and its associated gases at oil field temperatures and pressures. Trans. AIME, v. 165, p. 94-112, 1946.

BEGGS, H. D.; ROBINSON, J. R. Estimating the viscosity of crude oil systems. Journal of Petroleum Technology, v. 27, n. 9, p. 1140-1141, 1975.

BENDIKSEN, K. H. An experimental investigation of the motion of long bubbles in inclined tubes. International Journal of Multiphase Flow, v. 10, n. 4, p. 467-483, 1984.

BØE, A. Severe slugging characteristics. Part I: Flow regime for severe slugging. Part II: Point model simulation study. Trondheim, Norway: [s.n.], 1981.

BRENNEN, C. E. Fundamentals of multiphase flow. Cambridge: Cambridge University Press, 2005. 345 p.

BROWN, G. G.; KATZ, D. L.; OBERFELL, G. G.; ALDEN, R. C. Natural gasoline and the volatile hydrocarbons. Tulsa: NGAA, 1948.

CHEN, N. H. An explicit equation for friction factor in pipe. Industrial \& engineering chemistry fundamentals, v. 18, n. 3, p. 296-297, 1979.

CHEW, J.; Connaly Jr, C. A. A viscosity correlation for gas-saturated crude oils. Trans. AIME, v. 216, p. 23-25, 1959.

CHEXAL, B.; LELLOUCHE, G.; HOROWITZ, J.; HEALZER, J. A void fraction correlation for generalized applications. Progress in Nuclear Energy, v. 27, n. 4, p. 255-295, 1992.

COLLADO, F. J. Reynolds transport theorem for a two-phase flow. Applied physics letters, v. 90, n. 2, p. 1-3, 2007.

COLLINS, A. G. Petroleum engineering handbook. In: BRADLEY, H. B. (Ed.). Dallas: SPE, 1987. cap. Properties of produced waters.

DRANCHUK, P. M.; ABOU-KASSEM, J. H. Calculation of z-factors for natural gases using equations of state. Journal of Canadian Petroleum Technology, v. 14, n. 3, p. 34-36, 1975. 
DREW, D. A.; PASSMAN, S. L. Theory of multicomponent fluids. New York: Springer-Verlag, 1999. $308 \mathrm{p}$.

EGBOGAH, E. O.; NG, J. T. An improved temperature-viscosity correlation for crude oil systems. Journal of Petroleum Science and Engineering, v. 4, n. 3, p. 197-200, 1990.

FABRE, J.; PERESSON, L. L.; CORTEVILLE, J.; ODELLO, R.; BOURGEOIS, T. Severe slugging in pipeline/riser systems. SPE Production Engineering, v. 5, n. 3, p. 299-305, 1990.

JANSEN, F. E. Elimination of severe slugging in a pipeline-riser system. Tese (MS Thesis) The University of Tulsa, Tulsa, 1990.

JANSEN, F. E.; SHOHAN, O.; TAITEL, Y. The elimination of severe slugging - experiments and modeling. International Journal of Multiphase Flow, v. 22, n. 6, p. 1055-1072, 1996.

KOKAL, S. L.; STANISLAV, J. F. An experimental study of two-phase flow in slightly inclined pipes - ii. liquid holdup and pressure drop. Chemical Engineering Science, v. 44, n. 3, p. 681-693, 1989.

LEE, A. L.; GONZALEZ, M. H.; EAKIN, B. E. The viscosity of natural gases. Journal of Petroleum Technology, v. 18, n. 8, p. 997-1000, 1966.

LORIMER, S. E.; ELLISON, B. T. Design guideline for subsea oil systems. In: Proceeding of the Facilities 2000: Facilities engineering into the next millenium. [S.1.: s.n.], 2000.

MANDHANE, J. M.; GREGORY, G. A.; AZIZ, K. A. A flow pattern map for gas-liquid flow in horizontal pipes. International Journal of Multiphase Flow, v. 1, n. 4, p. 537-553, 1974.

MASELLA, J. M.; TRAN, Q. H.; FERRE, D.; PAUCHON, C. Transient simulation of two-phase flows in pipes. International Journal of Multiphase Flow, v. 24, n. 5, p. 739-755, 1998.

MCCAIN, W. D. The properties of petroleum fluids. Tulsa: PennWell Books, 1990. 548 p.

MOKHATAB, S. Severe slugging in offshore production systems. New York: Nova Science Publishers, Inc., 2010. 105 p.

NEMOTO, R. H.; BALIÑO, J. L.; BURR, K. P. Characteristic values and compatibility conditions for the no-pressure-wave model applied to petroleum systems. In: Proceeding of the 20th international congress of mechanical engineering. Gramado-RS, Brazil: ABCM, 2009.

OLIVEIRA, R. R. A. Implementação numérica e análises paramétricas em estado estacionário para estudos de intermitência severa em sistemas de produção de petróleo. Modelo NPW com efeitos de vaporização. 66 p. Tese (Trabalho de conclusão de curso) - Escola Politécnica da Universidade de São Paulo, São Paulo, 2009.

POTS, B. F. M.; BROMILOW, I. G.; KONIJN, M. J. W. F. Severe slug flow in offshore flowline/riser systems. SPE Production Engineering, p. 319-324, 1987.

SARICA, C.; SHOHAM, O. A simplified transient model for pipeline-riser systems. Chemical Engineering Science, v. 46, n. 9, p. 2167-2179, 1991.

SCHMIDT, Z.; BRILL, J.; BEGGS, H. D. Choking can eliminate severe pipeline slugging. Oil \& Gas J, v. 12, p. 230-238, 1979. 
SCHMIDT, Z.; BRILL, J. P.; BEGGS, H. D. Experimental study of severe slugging in a two-phase-flow pipeline-riser system. SPE Journal, v. 20, n. 5, p. 407-414, 1980.

SCHMIDT, Z.; DOTY, D. R.; DUTTA-ROY, K. Severe slugging in offshore pipeline riser-pipe systems. SPE Journal, v. 25, n. 1, p. 27-38, 1985.

SINTEF. SINTEF Projects. 2012. http://www.sintef.no/home/

SINTEF-Petroleum-Research/Wellstream-Technology/Projects/.

SPT Group. OLGA - Multiphase flow simulator. 2012. http: / /www . sptgroup. com/ Products/olga.

STANDING, M. B. Volumetric and phase behavior of oil field hydrocarbon systems. Dallas: SPE, 1981.

STANDING, M. B.; KATZ, D. L. Density of natural gases. Trans. AIME, v. 146, p. 140-149, 1942.

TAITEL, Y. Stability of severe slugging. International Journal of Multiphase Flow, v. 12, n. 2, p. 203-217, 1986.

TAITEL, Y.; DUKLER, A. E. A model for predicting flow regime transitions in horizontal and near horizontal gas-liquid flow. AIChE Journal, v. 22, n. 1, p. 47-55, 1976.

TAITEL, Y.; VIERKANDT, S.; SHOHAM, O.; BRILL, J. P. Severe slugging in a riser system: experiments and modeling. International Journal of Multiphase Flow, v. 16, n. 1, p. 57-68, 1990.

TANNEHILL, J. C.; ANDERSON, D. A.; PLETCHER, R. H. Computational fluid mechanics and heat transfer. New York: Taylor \& Francis, 1997. 792 p.

TIN, V.; SARSHAR, M. An investigation of severe slugging characteristics in flexible risers. In: Proc. The 6th. international conference on multiphase production. Cannes, France: [s.n.], 1993.

VASQUEZ, M.; BEGGS, H. D. Correlations for fluid physical properties prediction. Journal of Petroleum Technology, v. 32, n. 6, p. 968-970, 1980.

VELARDE, J.; BLASINGAME, T. A.; MCCAIN, W. D. Correlation of black oil properties at pressures below bubblepoint pressure - a new approach. Journal of canadian petroleum technology, v. 38, n. 13, p. Paper 97-93, 1999.

VIERKANDT, S. Severe slugging in pipeline-riser system, experiments and modelling. Tese (MS Thesis) - The University of Tulsa, Tulsa, 1988.

WALLIS, G. B. One-dimensional two-pahse flow. United States: McGraw-Hill Book Company, 1969. 408 p.

WEISMAN, J. Two-phase flow patterns. Chapter 15 in Handbook of Fluids in Motion (eds: N.P. Cheremisinoff and R. Gupta). -: Ann Arbor Science Publ., 1983. 409-425 p.

WORDSWORTH, C.; DAS, I.; LOH, W. L.; MCNULTY, G.; LIMA, P. C.; BARBUTO, F. Multiphase flow behavior in a catenary shaped riser. California: CALtec Report No.: CR 6820, 1998. $157 \mathrm{p}$. 
YOCUM, B. T. Offshore riser slug flow avoidance: mathematical model for design and optimization. In: SPE European Meeting. London: paper SPE4312, 1973.

ZUBER, N.; FINDLAY, J. Average volumetric concentration in two-phase flow system. Journal of Heat Transfer, ASME Trans, v. 10, p. 951-965, 1965. 


\section{APÊNDICE A - INTRODUÇÃO AO ESCOAMENTO MULTIFÁSICO GÁS-LÍQUIDO}

Neste apêndice será fornecida uma breve introdução ao escoamento multifásico gás-líquido, com informações relevantes para o entendimento da tese. Serão apresentadas as variáveis envolvidas na modelagem da intermitência severa, assim como os possíveis padrões de escoamento que ocorrem em tubos horizontais e verticais. Também será apresentada a dedução da equação de conservação de massa para as fases gás, óleo e água.

\section{A.1 Definição das variáveis de interesse}

Será considerada a existência de apenas duas fases: a fase gasosa, representada pelo subscrito $g$ e a fase líquida, representada pelo subscrito $l$. Também será assumido escoamento unidimensional. A revisão que segue foi baseada no livro de Wallis (1969).

A vazão mássica total $(\mathrm{kg} / \mathrm{s})$, dada por $\dot{m}$, é a soma da vazão mássica de cada fase:

$$
\dot{m}=\dot{m}_{g}+\dot{m}_{l}
$$

A vazão volumétrica total $\left(\mathrm{m}^{3} / \mathrm{s}\right)$ é representada pelo símbolo $Q$ e as seguintes relações são diretas:

$$
\begin{gathered}
Q=Q_{g}+Q_{l} \\
Q_{g}=\frac{\dot{m}_{g}}{\rho_{g}} \\
Q_{l}=\frac{\dot{m}_{l}}{\rho_{l}}
\end{gathered}
$$

onde $\rho_{g}$ é a massa específica do gás e $\rho_{l}$ é a massa específica do líquido. 
A variável $\alpha$ representa a fração de vazio. Existem diferentes definições geométricas para essa variável, sendo as mais comuns a fração de vazio volumétrica $\alpha_{v}$ e a fração de vazio de seção transversal $\alpha$.

A fração de vazio volumétrica $\alpha_{v}$ é calculada como a fração volumétrica média de gás sobre toda a seção transversal do tubo e um comprimento de duto suficiente para eliminar flutuações locais. O comprimento do tubo deve ser muito maior que as dimensões de partículas discretas, como bolhas e gotas. Se um tubo de comprimento $L$ e seção transversal $A$ é isolado repentinamente por meio do fechamento de válvulas nas extremidades, pode-se avaliar o volume total da fase gasosa no tubo $\forall_{g}$ e o valor médio de $\alpha$ é dado por:

$$
\left\langle\alpha_{v}\right\rangle=\frac{\forall_{g}}{A L}
$$

Em termos da vazão volumétrica dos fluidos, a fração de vazio volumétrica pode ser expressa segundo a expressão que segue:

$$
\alpha_{v}=\frac{Q_{g}}{Q_{g}+Q_{l}}
$$

Frequentemente não é possível medir $\left\langle\alpha_{v}\right\rangle$ ao longo de um grande comprimento de tubo, pois o escoamento não é uniforme. Neste caso, várias medições instantâneas ao longo de um comprimento $\delta L$ será capaz de fornecer a média no tempo de $\alpha_{v}$ em determinada posição. $\mathrm{O}$ valor médio de $\alpha_{v}$ no espaço e tempo é dado por:

$$
\left\langle\alpha_{v}\right\rangle=\frac{\iint \alpha(\mathbf{r}, t) \mathbf{d r} d t}{\iint \mathbf{d r} d t}
$$

onde $\mathbf{r}$ é a coordenada radial do tubo em que se mede a variável.

Segundo Taitel (1986), médias são utilizadas devido ao fato de escoamentos multifásicos raramente serem verdadeiramente permanentes e valores médios são usados sobre um período de tempo característico do padrão de escoamento em questão. Um exemplo típico é o padrão de escoamento em golfadas, para o qual valores médios são calculados durante a passagem de uma ou duas golfadas.

A fração de vazio de seção transversal $\alpha$ é calculada como a razão da área de seção transversal ocupada pelo gás $A_{g}$ pela área de seção transversal total $A$ :

$$
\alpha=\frac{A_{g}}{A}
$$


Vale ressaltar que a relação entre a fração de vazio e a fração volumétrica de líquido é:

$$
\alpha+\alpha_{l}=1
$$

A velocidade das fases são apresentadas abaixo:

$$
\begin{aligned}
& u_{g}=\frac{Q_{g}}{A_{g}} \\
& u_{l}=\frac{Q_{l}}{A_{l}}
\end{aligned}
$$

Utilizando a definição de fração de vazio de seção transversal, apresentada na Eq. (A.8), as Eqs. (A.10) e (A.11) resultam nas seguintes expressões:

$$
\begin{gathered}
u_{g}=\frac{Q_{g}}{A \alpha} \\
u_{l}=\frac{Q_{l}}{A(1-\alpha)}
\end{gathered}
$$

Assim, as vazões volumétricas podem ser expressas como:

$$
\begin{gathered}
Q_{g}=u_{g} A \alpha \\
Q_{l}=u_{l} A(1-\alpha)
\end{gathered}
$$

Substituindo as Eqs. (A.14) e (A.15) na Eq. (A.6), obtemos a seguinte relação:

$$
\alpha_{v}=\frac{\alpha}{\frac{1}{S}(1-\alpha)+\alpha}
$$

onde $S$ é a razão de escorregamento, dada por $S=u_{g} / u_{l}$.

Logo, conclui-se que a fração de vazio volumétrica $\alpha_{v}$ vale o mesmo que a fração de vazio de seção transversal $\alpha$ para o caso em que se considera escoamento homogêneo, ou seja, $u_{g}=u_{l}$ ou $S=1$. Para outros casos, deve-se conhecer a razão de escorregamento $S$ de maneira a converter a fração de vazio volumétrica para a fração de vazio de seção transversal.

O símbolo $j$ é usado para representar o fluxo volumétrico $(\mathrm{m} / \mathrm{s})$, ou vazão volumétrica por unidade de área, ou velocidade superficial. Essa grandeza tem natureza vetorial. No entanto, como o escoamento é por hipótese unidimensional, $j$ será usado exclusivamente para representar seu valor escalar no sentido do movimento do fluido e direção determinada pelo tubo. 
A velocidade superficial para o gás e líquido é calculada da maneira que segue:

$$
\begin{aligned}
& j_{g}=\frac{Q_{g}}{A} \\
& j_{l}=\frac{Q_{l}}{A}
\end{aligned}
$$

A velocidade superficial total é dada por:

$$
j=\frac{Q_{g}+Q_{l}}{A}
$$

A velocidade superficial está relacionada com a fração volumétrica e velocidade das fases da maneira que segue:

$$
\begin{gathered}
j_{g}=\frac{A_{g} u_{g}}{A}=\alpha u_{g} \\
j_{l}=\frac{A_{l} u_{l}}{A}=\alpha_{l} u_{l}=(1-\alpha) u_{l}
\end{gathered}
$$

onde $u_{g}$ e $u_{l}$ são, respectivamente, a velocidade do gás e do líquido.

Como medida para o movimento relativo entre as fases, defini-se a velocidade de drift. A velocidade de drift de uma fase é definida como a velocidade dessa fase com relação a uma referência que se move com uma velocidade igual à velocidade superficial total, ou seja:

$$
\begin{aligned}
& u_{g j}=u_{g}-j \\
& u_{l j}=u_{l}-j
\end{aligned}
$$

\section{A.2 Padrões de escoamento}

Uma das maiores dificuldades em se trabalhar com escoamentos multifásicos é que as taxas de transferência de massa, quantidade de movimento e energia são bastante sensíveis à distribuição geométrica ou topologia das fases no escoamento. Torna-se importante, portanto, uma descrição fenomenológica das distribuições geométricas, padrões de escoamento (flow patterns), ou regimes de escoamento (flow regimes) que são observados em escoamentos multifásicos (BRENNEN, 2005).

A Fig. A.1 mostra a distribuição geométrica das fases para o escoamento de uma mistura água-ar em um tubo horizontal de diâmetro $5,1 \mathrm{~cm}$. Na figura, $\mathrm{G}$ indica a presença da fase 


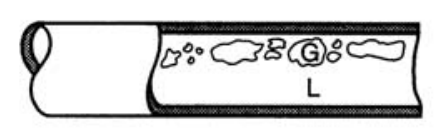

Bubble

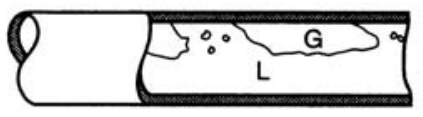

Plug

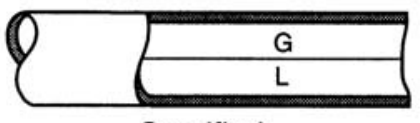

Stratified

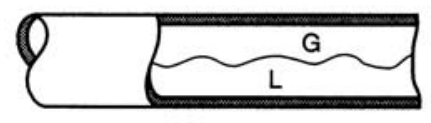

Wavy

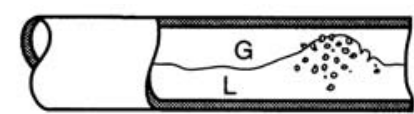

Slug

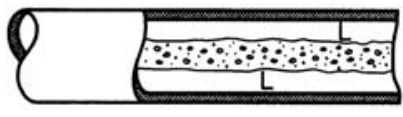

Annular

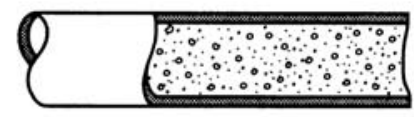

Disperse

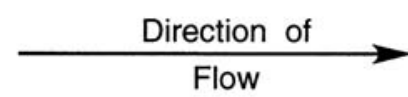

Figura A.1: Esboços dos padrões de escoamento para misturas água-ar em um tubo horizontal de diâmetro 5,1 cm. Adaptado de Weisman (1983).

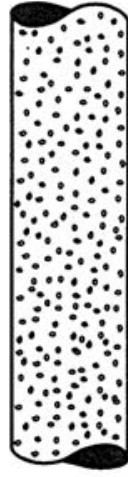

Bubbly

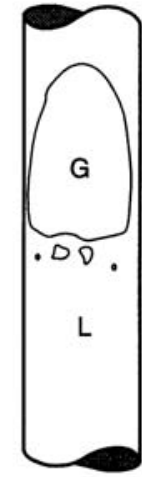

Slug

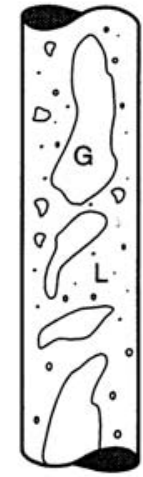

Churn

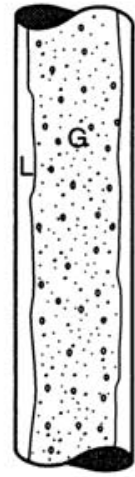

Annular

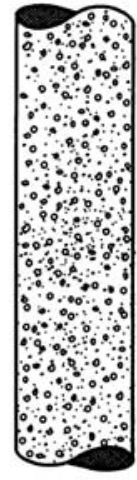

Disperse

Figura A.2: Esboços dos padrões de escoamento para escoamento bifásico em um tubo vertical. Adaptado de Weisman (1983).

gasosa e L da fase líquida. Os padrões de escoamento apresentados são: escoamento em bolhas (bubble flow), escoamento em golfadas (slug flow), escoamento em bolhas alongadas (plug flow), escoamento anular (annular flow), escoamento estratificado (stratified flow), escoamento disperso (disperse flow) e escoamento estratificado ondulado (wavy flow).

Já a Fig. A.2 mostra a disposição das fases para o escoamento de uma mistura água-ar em um tubo vertical. Os padrões de escoamento são: escoamento em bolhas (bubbly flow), escoamento em golfadas (slug flow), escoamento em transição ou caótico (churn flow), escoamento anular (annular flow) e escoamento disperso (disperse flow).

Numerosas investigações foram feitas para determinar a dependência dos padrões de 


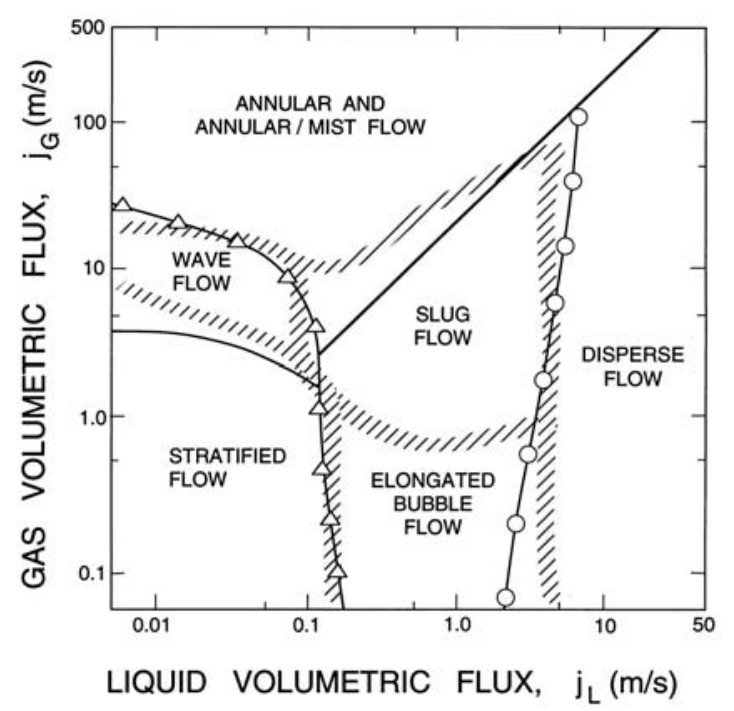

Figura A.3: Mapa de padrão de escoamento para o escoamento de misturas água-ar em um tubo horizontal de $2,5 \mathrm{~cm}$ à temperatura de $25^{\circ} \mathrm{C}$ e pressão de 1 bar. Reproduzido de Mandhane, Gregory e Aziz (1974).

escoamento com relação à velocidade superficial das fases, fração de vazio e outras propriedades dos fluidos, como massa específica, viscosidade e tensão superficial. Os resultados são frequentemente apresentados na forma de um mapa de padrão de escoamento, o qual identifica o padrão de escoamento que ocorre em função de um espaço de parâmetros definido pela velocidade superficial das fases.

A Fig. A.3 mostra a ocorrência de diferentes padrões de escoamento para o escoamento de uma mistura água-ar em um tubo horizontal de diâmetro $2,5 \mathrm{~cm}$; os padrões de escoamento na horizontal são apresentados na Fig. A.1. As regiões de transição observadas experimentalmente são mostradas pelas áreas tracejadas e as linhas sólidas representam predições teóricas.

Já a Fig. A.4 mostra os padrões de escoamento encontrados para o escoamento de misturas água-ar em um tubo vertical de diâmetro $2,5 \mathrm{~cm}$; os padrões de escoamento na vertical são apresentados na Fig. A.2.

\section{A.3 Dedução da equação da continuidade}

Partindo da equação de transporte de Reynolds, a equação da continuidade para uma fase $k$, é apresentada abaixo (COLLADO, 2007): 


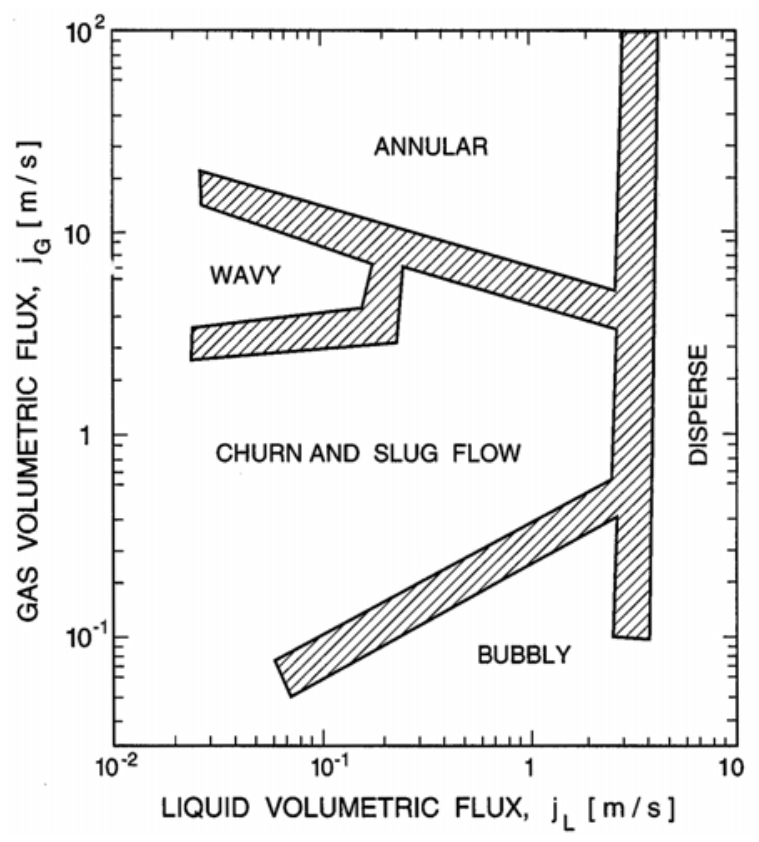

Figura A.4: Mapa de padrão de escoamento para o escoamento de misturas água-ar em um tubo vertical de diâmetro 2,5 cm. Adaptado de Weisman (1983).

$$
\frac{d m_{k}}{d t}=\int_{v_{k}} \frac{\partial \rho_{k}}{\partial t} d v_{k}+\int_{S_{k}} \rho_{k} \mathbf{u}_{\mathbf{k}} \cdot \hat{\mathbf{n}} d S_{k}=G_{k}
$$

sendo $m_{k}$ a massa da fase $k$ no volume de controle, $\rho_{k}$ a massa específica da fase $k$ no volume de controle, $\mathbf{u}_{\mathbf{k}}$ a velocidade da fase $k$ na superfície de controle com relação ao sistema de coordenadas estático, $\hat{\mathbf{n}}$ o vetor normal às superfícies de controle e $G_{k}$ a taxa de produção de massa da fase $k$ no volume de controle.

Aplicando o teorema de Gauss à última integral, obtêm-se:

$$
\int_{S_{k}} \rho_{k} \mathbf{u}_{\mathbf{k}} \cdot \hat{\mathbf{n}} d S_{k}=\int_{v_{k}} \frac{\partial}{\partial s}\left(\rho_{k} \mathbf{u}_{\mathbf{k}}\right) d v_{k}
$$

Substituindo o resultado na equação inicial, chega-se à seguinte expressão:

$$
\int_{v_{k}} \frac{\partial \rho_{k}}{\partial t} d v_{k}+\int_{v_{k}} \frac{\partial}{\partial s}\left(\rho_{k} \mathbf{u}_{\mathbf{k}}\right) d v_{k}=\int_{v} \Gamma_{k} d v
$$

onde $\Gamma_{k}$ é a taxa de produção de massa da fase $k$ por unidade de volume da mistura de fases.

Considerando escoamento unidimensional e com área transversal constante, o volume de controle infinitesimal pode ser expresso por $d v_{k}=A_{k} d s$. E a equação de conservação de 
massa assume a forma:

$$
\int \frac{\partial}{\partial t}\left(\rho_{k} A_{k}\right) d s+\int \frac{\partial}{\partial s}\left(\rho_{k} u_{k} A_{k}\right) d s=\int \Gamma_{k} A d s
$$

Com base nas Eqs. (A.8) e (A.20), a equação de conservação da massa pode ser expressa como segue:

$$
\int\left[\frac{\partial}{\partial t}\left(\rho_{k} \alpha_{k}\right)+\frac{\partial}{\partial s}\left(\rho_{k} j_{k}\right)-\Gamma_{k}\right] d s=0
$$

Finalmente, a equação da continuidade em sua forma conservativa para uma fase $k$, considerando área transversal constante e escoamento unidimensional, é dada por:

$$
\frac{\partial}{\partial t}\left(\rho_{k} \alpha_{k}\right)+\frac{\partial}{\partial t}\left(\rho_{k} j_{k}\right)=\Gamma_{k}
$$




\section{APÊNDICE B - DEDUÇÃO DAS EQUAÇÕES DE ESTADO PARA O MODELO DO RISER UTILIZANDO O MÉTODO DAS CARACTERÍSTICAS}

Neste apêndice é apresentada a dedução das equações de estado para o modelo do riser utilizando o método das características, de modo a explicitar os procedimentos matemáticos ocultados na Seção 3.1.4.

Segundo Ames (1992), a aplicação do método das características ao sistema misto hiperbólico-parabólico referente ao conjunto de equações de conservação fará com que as equações diferenciais parciais sejam referenciadas segundo suas coordenadas características. Com isso, um novo sistema de equações diferenciais direcionais equivalente ao sistema inicial será obtido, facilitando assim a resolução do mesmo.

\section{B.1 Manipulação algébrica das equações de conservação}

O objetivo da manipulação algébrica que segue é fazer com que todas as derivadas parciais das equações de conservação sejam aplicadas às variáveis de estado, a saber $\alpha, \alpha_{o}, P$ e $j$. As equações de conservação (ver Seção 3.1.2), dadas pela equação da continuidade para o gás, para o óleo e para a água, junto à equação de conservação da quantidade de movimento para a mistura, leva ao seguinte sistema misto hiperbólico-parabólico quase-linear:

$$
\frac{\partial}{\partial t}\left(\rho_{g} \alpha\right)+\frac{\partial}{\partial s}\left(\rho_{g} j_{g}\right)=\Gamma
$$




$$
\begin{gathered}
\frac{\partial}{\partial t}\left(\rho_{o} \alpha_{o}\right)+\frac{\partial}{\partial s}\left(\rho_{o} j_{o}\right)=-\Gamma \\
\frac{\partial}{\partial t}\left(\rho_{w} \alpha_{w}\right)+\frac{\partial}{\partial s}\left(\rho_{w} j_{w}\right)=0 \\
\frac{\partial P}{\partial s}=-\frac{4 \tau_{w}}{D}+\rho_{m} g_{s}
\end{gathered}
$$

O cálculo das derivadas parciais para as equações da continuidade leva ao seguinte sistema:

$$
\begin{gathered}
\alpha \frac{\partial \rho_{g}}{\partial t}+\rho_{g} \frac{\partial \alpha}{\partial t}+j_{g} \frac{\partial \rho_{g}}{\partial s}+\rho_{g} \frac{\partial j_{g}}{\partial s}=\Gamma \\
\alpha_{o} \frac{\partial \rho_{o}}{\partial t}+\rho_{o} \frac{\partial \alpha_{o}}{\partial t}+j_{o} \frac{\partial \rho_{o}}{\partial s}+\rho_{o} \frac{\partial j_{o}}{\partial s}=-\Gamma \\
\alpha_{w} \frac{\partial \rho_{w}}{\partial t}+\rho_{w} \frac{\partial \alpha_{w}}{\partial t}+j_{w} \frac{\partial \rho_{w}}{\partial s}+\rho_{w} \frac{\partial j_{w}}{\partial s}=0
\end{gathered}
$$

Dado que o escoamento é considerado isotérmico e que os fluidos não apresentam variação na composição, a massa específica do gás depende apenas da pressão (ver Seção 3.1.3.3); sendo assim, é possível expressar suas derivadas parciais como segue:

$$
\begin{gathered}
\frac{\partial \rho_{g}}{\partial s}=\frac{\partial \rho_{g}}{\partial P} \frac{\partial P}{\partial s} \\
\frac{\partial \rho_{g}}{\partial t}=\frac{\partial \rho_{g}}{\partial P} \frac{\partial P}{\partial t}
\end{gathered}
$$

De modo análogo, é possível expressar as derivadas parciais da massa específica do óleo como segue:

$$
\begin{aligned}
& \frac{\partial \rho_{o}}{\partial s}=\frac{\partial \rho_{o}}{\partial P} \frac{\partial P}{\partial s} \\
& \frac{\partial \rho_{o}}{\partial t}=\frac{\partial \rho_{o}}{\partial P} \frac{\partial P}{\partial t}
\end{aligned}
$$

As derivadas parciais da massa específica da água são dadas por:

$$
\frac{\partial \rho_{w}}{\partial s}=\frac{\partial \rho_{w}}{\partial P} \frac{\partial P}{\partial s}
$$




$$
\frac{\partial \rho_{w}}{\partial t}=\frac{\partial \rho_{w}}{\partial P} \frac{\partial P}{\partial t}
$$

Sendo assim, o conjunto de equações da continuidade pode ser apresentado da seguinte maneira:

$$
\begin{gathered}
\alpha \frac{\partial \rho_{g}}{\partial P} \frac{\partial P}{\partial t}+\rho_{g} \frac{\partial \alpha}{\partial t}+j_{g} \frac{\partial \rho_{g}}{\partial P} \frac{\partial P}{\partial s}+\rho_{g} \frac{\partial j_{g}}{\partial s}=\Gamma \\
\alpha_{o} \frac{\partial \rho_{o}}{\partial P} \frac{\partial P}{\partial t}+\rho_{o} \frac{\partial \alpha_{o}}{\partial t}+j_{o} \frac{\partial \rho_{o}}{\partial P} \frac{\partial P}{\partial s}+\rho_{o} \frac{\partial j_{o}}{\partial s}=-\Gamma \\
\alpha_{w} \frac{\partial \rho_{w}}{\partial P} \frac{\partial P}{\partial t}+\rho_{w} \frac{\partial \alpha_{w}}{\partial t}+j_{w} \frac{\partial \rho_{w}}{\partial P} \frac{\partial P}{\partial s}+\rho_{w} \frac{\partial j_{w}}{\partial s}=0
\end{gathered}
$$

O termo $\Gamma$, dado pela taxa temporal de massa de gás que deixa a solução e é adicionada ao gás livre por unidade de volume da mistura (ver Seção 3.1.3.6), envolve derivadas parciais de $R_{s}$, o fator de solubilidade de gás em óleo. Esta variável depende apenas da pressão (considerando escoamento isotérmico), de modo que é possível expressar suas derivadas da maneira que segue:

$$
\begin{gathered}
\frac{\partial R_{s}}{\partial t}=\frac{\partial R_{s}}{\partial P} \frac{\partial P}{\partial t} \\
\frac{\partial R_{s}}{\partial s}=\frac{\partial R_{s}}{\partial P} \frac{\partial P}{\partial s}
\end{gathered}
$$

Sendo assim, $\Gamma$ é dado por:

$$
\Gamma=-\frac{\rho_{d g 0} \alpha_{o}}{B_{o}} \frac{\partial R_{s}}{\partial P}\left(\frac{\partial P}{\partial t}+\frac{j_{o}}{\alpha_{o}} \frac{\partial P}{\partial s}\right)
$$

A substituição da nova expressão de $\Gamma$ nas equações da continuidade leva ao seguinte conjunto de equações:

$$
\begin{gathered}
\left(\alpha \frac{\partial \rho_{g}}{\partial P}+\frac{\rho_{d g 0} \alpha_{o}}{B_{o}} \frac{\partial R_{s}}{\partial P}\right) \frac{\partial P}{\partial t} \\
+\rho_{g} \frac{\partial \alpha}{\partial t}+\left(j_{g} \frac{\partial \rho_{g}}{\partial P}+\frac{\rho_{d g 0} j_{o}}{B_{o}} \frac{\partial R_{s}}{\partial P}\right) \frac{\partial P}{\partial s}+\rho_{g} \frac{\partial j_{g}}{\partial s}=0
\end{gathered}
$$




$$
\begin{gathered}
\left(\alpha_{o} \frac{\partial \rho_{o}}{\partial P}-\frac{\rho_{d g 0} \alpha_{o}}{B_{o}} \frac{\partial R_{s}}{\partial P}\right) \frac{\partial P}{\partial t} \\
+\rho_{o} \frac{\partial \alpha_{o}}{\partial t}+\left(j_{o} \frac{\partial \rho_{o}}{\partial P}-\frac{\rho_{d g 0} j_{o}}{B_{o}} \frac{\partial R_{s}}{\partial P}\right) \frac{\partial P}{\partial s}+\rho_{o} \frac{\partial j_{o}}{\partial s}=0 \\
\alpha_{w} \frac{\partial \rho_{w}}{\partial P} \frac{\partial P}{\partial t}+\rho_{w} \frac{\partial \alpha_{w}}{\partial t}+j_{w} \frac{\partial \rho_{w}}{\partial P} \frac{\partial P}{\partial s}+\rho_{w} \frac{\partial j_{w}}{\partial s}=0
\end{gathered}
$$

Sabe-se que $j_{g}=j_{g}(\alpha, P, j, \theta)$ e $\theta=\theta(s)$, sendo assim a derivada parcial espacial de $j_{g}$ pode ser extendida como apresentado abaixo:

$$
\frac{\partial j_{g}}{\partial s}=\frac{\partial j_{g}}{\partial \alpha} \frac{\partial \alpha}{\partial s}+\frac{\partial j_{g}}{\partial P} \frac{\partial P}{\partial s}+\frac{\partial j_{g}}{\partial j} \frac{\partial j}{\partial s}+\frac{\partial j_{g}}{\partial \theta} \frac{d \theta}{d s}
$$

Substituindo (B.23) em (B.20), obtêm-se a equação da continuidade para o gás com as derivadas parciais sendo aplicadas às variáveis de estado:

$$
\begin{gathered}
\rho_{g} \frac{\partial \alpha}{\partial t}+\left(\alpha \frac{\partial \rho_{g}}{\partial P}+\frac{\rho_{d g 0} \alpha_{o}}{B_{o}} \frac{\partial R_{s}}{\partial P}\right) \frac{\partial P}{\partial t}+\rho_{g} \frac{\partial j_{g}}{\partial \alpha} \frac{\partial \alpha}{\partial s} \\
+\left(j_{g} \frac{\partial \rho_{g}}{\partial P}+\rho_{g} \frac{\partial j_{g}}{\partial P}+\frac{\rho_{d g 0} j_{o}}{B_{o}} \frac{\partial R_{s}}{\partial P}\right) \frac{\partial P}{\partial s} \\
+\rho_{g} \frac{\partial j_{g}}{\partial j} \frac{\partial j}{\partial s}+\rho_{g} \frac{\partial j_{g}}{\partial \theta} \frac{d \theta}{d s}=0
\end{gathered}
$$

A Eq. (3.19) revela que a velocidade superficial total é a soma das velocidades superficiais do óleo, água e gás:

$$
j=j_{o}+j_{w}+j_{g}
$$

A derivada parcial espacial dessa última expressão é dada por:

$$
\frac{\partial j}{\partial s}=\frac{\partial j_{o}}{\partial s}+\frac{\partial j_{w}}{\partial s}+\frac{\partial j_{g}}{\partial s}
$$

Partindo das Eqs. (3.12) e (3.13), obtemos a relação abaixo:

$$
j_{w}=j_{o} \frac{\alpha_{w}}{\alpha_{o}}
$$

Se derivarmos essa expressão em relação à variável espacial $s$, obtemos:

$$
\frac{\partial j_{w}}{\partial s}=\frac{\alpha_{w}}{\alpha_{o}} \frac{\partial j_{o}}{\partial s}+\frac{j_{o}}{\alpha_{o}} \frac{\partial \alpha_{w}}{\partial s}-\frac{j_{o} \alpha_{w}}{\alpha_{o}^{2}} \frac{\partial \alpha_{o}}{\partial s}
$$


É possível substituir essa última expressão na Eq. (B.26) e resolvê-la para a derivada parcial espacial de $j_{o}$, resultando então na seguinte equação:

$$
\frac{\partial j_{o}}{\partial s}=\frac{\alpha_{o}}{\alpha_{w}+\alpha_{o}}\left(\frac{\partial j}{\partial s}-\frac{j_{o}}{\alpha_{o}} \frac{\partial \alpha_{w}}{\partial s}+\frac{j_{o} \alpha_{w}}{\alpha_{o}^{2}} \frac{\partial \alpha_{o}}{\partial s}-\frac{\partial j_{g}}{\partial s}\right)
$$

A partir da Eq. (3.11) podemos representar $\alpha_{w}$ em função das variáveis de estado $\alpha_{o}$ e $\alpha:$

$$
\alpha_{w}=1-\alpha_{o}-\alpha
$$

A derivada parcial espacial dessa expressão leva a:

$$
\frac{\partial \alpha_{w}}{\partial s}=\frac{\partial}{\partial s}\left(1-\alpha_{o}-\alpha\right)=-\frac{\partial \alpha_{o}}{\partial s}-\frac{\partial \alpha}{\partial s}
$$

Substituem-se, então, as Eqs. (B.23) e (B.31) na Eq. (B.29) e esta última na Eq. (B.21), o que resulta na equação da continuidade para o óleo com as derivadas parciais sendo aplicadas às variáveis de estado:

$$
\begin{gathered}
\rho_{o} \frac{\partial \alpha_{o}}{\partial t}+\left(\alpha_{o} \frac{\partial \rho_{o}}{\partial P}-\frac{\rho_{d g 0} \alpha_{o}}{B_{o}} \frac{\partial R_{s}}{\partial P}\right) \frac{\partial P}{\partial t}+\frac{\rho_{o}}{\alpha_{o}+\alpha_{w}}\left(j_{o}-\alpha_{o} \frac{\partial j_{g}}{\partial \alpha}\right) \frac{\partial \alpha}{\partial s} \\
+\frac{\rho_{o} j_{o}}{\alpha_{o}} \frac{\partial \alpha_{o}}{\partial s}+\left(j_{o} \frac{\partial \rho_{o}}{\partial P}-\frac{\alpha_{o} \rho_{o}}{\alpha_{o}+\alpha_{w}} \frac{\partial j_{g}}{\partial P}-\frac{\rho_{d g 0} j_{o}}{B_{o}} \frac{\partial R_{s}}{\partial P}\right) \frac{\partial P}{\partial s} \\
+\frac{\alpha_{o} \rho_{o}}{\alpha_{w}+\alpha_{o}}\left(1-\frac{\partial j_{g}}{\partial j}\right) \frac{\partial j}{\partial s}-\frac{\alpha_{o} \rho_{o}}{\alpha_{w}+\alpha_{o}} \frac{\partial j_{g}}{\partial \theta} \frac{d \theta}{d s}=0
\end{gathered}
$$

Partindo da Eq. (B.30), a derivada parcial temporal da fração volumétrica de água é dada por:

$$
\frac{\partial \alpha_{w}}{\partial t}=\frac{\partial}{\partial t}\left(1-\alpha_{o}-\alpha\right)=-\frac{\partial \alpha_{o}}{\partial t}-\frac{\partial \alpha}{\partial t}
$$

Resolvendo a Eq. (B.28) para a derivada parcial espacial de $j_{o}$ e substituindo essa nova expressão na Eq. (B.26) é possível obter a seguinte equação:

$$
\frac{\partial j_{w}}{\partial s}=\frac{\alpha_{w}}{\alpha_{w}+\alpha_{o}}\left(\frac{\partial j}{\partial s}-\frac{j_{w}}{\alpha_{w}} \frac{\partial \alpha_{o}}{\partial s}+\frac{j_{w} \alpha_{o}}{\alpha_{w}^{2}} \frac{\partial \alpha_{w}}{\partial s}-\frac{\partial j_{g}}{\partial s}\right)
$$

Devem-se substituir as Eqs. (B.31) e (B.23) na equação apresentada acima e, em seguida, substituir a expressão resultante na Eq. (B.22), o que resulta na equação da continuidade para água com as derivadas parciais sendo aplicadas às variáveis de estado: 


$$
\begin{gathered}
\rho_{w} \frac{\partial \alpha}{\partial t}+\rho_{w} \frac{\partial \alpha_{o}}{\partial t}-\alpha_{w} \frac{\partial \rho_{w}}{\partial P} \frac{\partial P}{\partial t}+\frac{\rho_{w}}{\alpha_{o}+\alpha_{w}}\left(j_{o}+\alpha_{w} \frac{\partial j_{g}}{\partial \alpha}\right) \frac{\partial \alpha}{\partial s}+\frac{\rho_{w} j_{w}}{\alpha_{w}} \frac{\partial \alpha_{o}}{\partial s} \\
+\left(-j_{w} \frac{\partial \rho_{w}}{\partial P}+\frac{\alpha_{w} \rho_{w}}{\alpha_{o}+\alpha_{w}} \frac{\partial j_{g}}{\partial P}\right) \frac{\partial P}{\partial s}+\frac{\alpha_{w} \rho_{w}}{\alpha_{o}+\alpha_{w}}\left(\frac{\partial j_{g}}{\partial j}-1\right) \frac{\partial j}{\partial s} \\
+\frac{\alpha_{w} \rho_{w}}{\alpha_{o}+\alpha_{w}} \frac{\partial j_{g}}{\partial \theta} \frac{d \theta}{d s}=0
\end{gathered}
$$

Como resultado da manipulação algébrica das equações, o sistema misto hiperbólicoparabólico quase-linear dado pelas equações de conservação é representado pelas Eqs. (B.24), (B.32), (B.35) e (B.4) em que as derivadas parciais são aplicadas às variáveis de estado e à variável $\theta$, a qual será considerada conhecida a partir da definição da geometria do riser (ver Seção 3.1.1).

\section{B.2 Procedimento para a obtenção do sistema de equações na forma normal}

O sistema de equações expresso na forma normal é dado pelo sistema expresso em relação às coordenadas características. A apresentação do procedimento algébrico para a obtenção do sistema na forma normal é o objetivo desta seção.

Considere o vetor de variáveis de estado definido por:

$$
\mathbf{u}=\left[\begin{array}{llll}
\alpha & \alpha_{o} & P & j
\end{array}\right]^{T}
$$

A derivada parcial temporal do vetor $\mathbf{u}$ é dada por:

$$
\frac{\partial \mathbf{u}}{\partial t}=\mathbf{u}_{t}=\left[\begin{array}{llll}
\frac{\partial \alpha}{\partial t} & \frac{\partial \alpha_{o}}{\partial t} & \frac{\partial P}{\partial t} & \frac{\partial j}{\partial t}
\end{array}\right]^{T}
$$

Analogamente, a derivada parcial espacial do vetor $\mathbf{u}$ é dada por:

$$
\frac{\partial \mathbf{u}}{\partial s}=\mathbf{u}_{s}=\left[\begin{array}{llll}
\frac{\partial \alpha}{\partial s} & \frac{\partial \alpha_{o}}{\partial s} & \frac{\partial P}{\partial s} & \frac{\partial j}{\partial s}
\end{array}\right]^{T}
$$

Considere também o seguinte sistema misto hiperbólico-parabólico quase-linear de quatro equações em quatro incógnitas:

$$
\sum_{i=1}^{4}\left(a_{j i} u_{s}^{i}+b_{j i} u_{t}^{i}\right)+d_{j}=0, \quad j=1,2,3,4
$$


Adota-se, então, a notação matricial:

$$
\mathbf{A}=\left[a_{j i}\right], \quad \mathbf{B}=\left[b_{j i}\right], \mathbf{d}=\left[d_{j}\right]
$$

Sendo assim, pode-se definir o sistema de equações na forma matricial como segue:

$$
\mathbf{A} \mathbf{u}_{s}+\mathbf{B} \mathbf{u}_{t}+\mathbf{d}=0
$$

Define-se então a matriz T, matriz que determina uma transformação linear. Ao aplicar essa transformação linear ao sistema (B.40), obtemos:

$$
\mathbf{T A} \mathbf{u}_{s}+\mathbf{T B} \mathbf{u}_{t}+\mathbf{T d}=0
$$

O novo sistema é equivalente ao sistema original, pois toda solução do novo sistema também é solução do sistema original. A aplicação da transformação linear ao sistema de equações original tem como objetivo o desenvolvimento de uma forma canônica. Uma forma conveniente é tal que se possa definir:

$$
\mathbf{T A}=\mathbf{E T B},
$$

onde $\mathbf{E}$ é a matriz diagonal definida por:

$$
\mathbf{E}=\left(\begin{array}{cccc}
e_{1} & 0 & 0 & 0 \\
0 & e_{2} & 0 & 0 \\
0 & 0 & e_{3} & 0 \\
0 & 0 & 0 & e_{4}
\end{array}\right)
$$

Assumindo a Eq. (B.42) como verdadeira, pode-se representar o sistema (B.41) como:

$$
\mathbf{E T B} \mathbf{u}_{s}+\mathbf{T B} \mathbf{u}_{t}+\mathbf{T d}=0
$$

Para a determinação dos elementos da matriz T, deve-se antes determinar os elementos $e_{j}$ da matriz E. Para isso é necessário referir-se à Eq. (B.42) novamente, mas agora de uma maneira mais detalhada, como segue:

$$
\sum_{k=1}^{4} t_{j k} a_{k i}=\sum_{k=1}^{4} e_{j} t_{j k} b_{k i}, \quad i=1,2,3,4
$$

Nesta expressão, para cada valor de $i$, faz-se $j$ assumir os valores 1, 2, 3, 4. Essa 
expressão pode ser modificada para:

$$
\sum_{k=1}^{4}\left(a_{k i}-e_{j} b_{k i}\right) t_{j k}=0
$$

que consiste em um sistema de 4 equações homogêneas para $t_{j k}$, com $k=1,2,3,4$. Para que haja uma solução não-trivial, a condição necessária e suficiente é:

$$
\operatorname{det}\left(\mathbf{A}-e_{j} \mathbf{B}\right)=0
$$

As raízes definidas por (B.47), definirão os $e_{j}$, com $j=1,2,3,4$, que são na verdade os autovalores generalizados relacionados com as matrizes A e B. Considerando um sistema de referência cartesiano, em que o versor i representa a posição $s$ e o versor $\mathbf{j}$ representa o tempo $t$, tem-se que a direção $d s_{k} \mathbf{i}+d t_{k} \mathbf{j}$, para a qual $d s_{k} / d t_{k}=e_{k}$, é tida como a $k$-ésima direção característica. E os valores $e_{k}$ são chamados de características do sistema.

Conhecida a matriz $\mathbf{E}$, pode-se determinar os elementos da matriz $\mathbf{T}$ por meio da Eq. (B.45). O sistema quase-linear na forma normal é calculado de acordo com a Eq. (B.44).

Considere que ETB $=\mathbf{A}^{*}, \mathbf{T B}=\mathbf{B}^{*}$ e que $\mathbf{T d}=\mathbf{d}^{*}$. Sendo assim, o sistema de equações na forma normal dado pela expressão (B.44) pode ser representado por:

$$
\mathbf{A}^{*} \mathbf{u}_{s}+\mathbf{B}^{*} \mathbf{u}_{t}+\mathbf{d}^{*}=0
$$

que também pode assumir o seguinte formato:

$$
\sum_{i=1}^{4} b_{j i}^{*}\left(e_{j} u_{s}^{i}+u_{t}^{i}\right)+d_{j}^{*}=0,
$$

em que a somatória deve ser calculada para dado valor de $j, \operatorname{com} j=1,2,3,4$.

Por inspeção da Eq. (B.49), conclui-se que, pelo fato de $e_{j}$ possuir unidade de velocidade, pode-se definir a derivada direcional da componente $u^{i}$ do vetor $\mathbf{u}$, como segue:

$$
\frac{D_{e_{j}} u^{i}}{D t}=e_{j} \frac{\partial u^{i}}{\partial s}+\frac{\partial u^{i}}{\partial t}
$$

em que o índice $e_{j}$ da derivada direcional, refere-se à direção característica definida pela característica $e_{j}$.

Finalmente, tem-se que, ao calcular o sistema de equações na forma normal, as deriva- 
das parciais nas direções $s$ e $t$ são substituídas por derivadas direcionais, tomadas nas direções características. E daí provém a grande simplificação para a solução do sistema de equações, pois as equações podem ser integradas obedecendo as direções características definidas.

\section{B.3 Cálculo das características}

Para o cálculo das características do sistema de equações, deve-se recorrer à Eq. (B.47). Antes, no entanto, é necessário definir os elementos das matrizes A e $\mathbf{B}$ com base no sistema de equações de conservação dado pelas Eqs. (B.24), (B.32), (B.35) e (B.4):

$$
\begin{gathered}
\mathbf{A}=\left(\begin{array}{cccc}
a_{11} & 0 & a_{13} & a_{14} \\
a_{21} & a_{22} & a_{23} & a_{24} \\
a_{31} & a_{32} & a_{33} & a_{34} \\
0 & 0 & a_{43} & 0
\end{array}\right) \\
a_{13}=j_{g} \frac{\partial \rho_{g}}{\partial P}+\rho_{g} \frac{\partial j_{g}}{\partial P}+\frac{\rho_{d g} j_{o}}{B_{o}} \frac{\partial R_{s}}{\partial P} \\
a_{31}=\rho_{g} \frac{\partial j_{g}}{\partial \alpha} \\
a_{23}=j_{o} \frac{\partial \rho_{o}}{\partial P}-\frac{\alpha_{o} \rho_{o}}{\alpha_{o}+\alpha_{w}} \frac{\partial j_{g}}{\partial P}-\frac{\rho_{d g 0} j_{o}}{\beta_{o}} \frac{\partial R_{s}}{\partial P} \\
a_{24}=\frac{\alpha_{o} \rho_{o}}{\alpha_{w}+\alpha_{o}}\left(1-\frac{\partial j_{g}}{\partial j}\right) \\
\rho_{o}+\alpha_{w}
\end{gathered}
$$




$$
\begin{aligned}
& a_{32}=\frac{\rho_{w} j_{w}}{\alpha_{w}} \\
& a_{33}=-j_{w} \frac{\partial \rho_{w}}{\partial P}+\frac{\alpha_{w} \rho_{w}}{\alpha_{o}+\alpha_{w}} \frac{\partial j_{g}}{\partial P} \\
& a_{34}=\frac{\alpha_{w} \rho_{w}}{\alpha_{w}+\alpha_{o}}\left(\frac{\partial j_{g}}{\partial j}-1\right) \\
& a_{43}=1 \\
& \mathbf{B}=\left(\begin{array}{cccc}
b_{11} & 0 & b_{13} & 0 \\
0 & b_{22} & b_{23} & 0 \\
b_{31} & b_{32} & b_{33} & 0 \\
0 & 0 & 0 & 0
\end{array}\right) \\
& b_{11}=\rho_{g} \\
& b_{13}=\alpha \frac{\partial \rho_{g}}{\partial P}+\frac{\rho_{d g 0} \alpha_{o}}{B_{o}} \frac{\partial R_{s}}{\partial P} \\
& b_{22}=\rho_{o} \\
& b_{23}=\alpha_{o} \frac{\partial \rho_{o}}{\partial P}-\frac{\rho_{d g 0} \alpha_{o}}{B_{o}} \frac{\partial R_{s}}{\partial P} \\
& b_{31}=\rho_{w} \\
& b_{32}=\rho_{w} \\
& b_{33}=-\alpha_{w} \frac{\partial \rho_{w}}{\partial P}
\end{aligned}
$$




$$
\begin{aligned}
& \mathbf{d}=\left(\begin{array}{llll}
d_{1} & d_{2} & d_{3} & d_{4}
\end{array}\right)^{T} \\
& d_{1}=\rho_{g} \frac{\partial j_{g}}{\partial \theta} \frac{d \theta}{d s} \\
& d_{2}=-\frac{\alpha_{o} \rho_{o}}{\alpha_{w}+\alpha_{o}} \frac{\partial j_{g}}{\partial \theta} \frac{d \theta}{d s} \\
& d_{3}=\frac{\alpha_{w} \rho_{w}}{\alpha_{o}+\alpha_{w}} \frac{\partial j_{g}}{\partial \theta} \frac{d \theta}{d s} \\
& d_{4}=\frac{4 \tau_{w}}{D}-\rho_{m} g_{s}
\end{aligned}
$$

A partir da Eq. (B.47) resulta que os autovalores, ou valores característicos, são dados por:

$$
e_{1}=\frac{\partial j_{g}}{\partial \alpha} ; e_{2}=\frac{j_{o}}{\alpha_{o}}=u_{l} ; e_{3}=\infty ; e_{4}=\infty
$$

\section{B.4 Determinação do sistema de equações na forma normal}

O sistema de equações na forma normal também é chamado de sistema de equações nas coordenadas características, ou ainda de equações de compatibilidade.

No caso de utilizarmos a correlação de Bendiksen (1984) para calcular os parâmetros $C_{d}$ e $U_{d}$, estes parâmetros dependem apenas da inclinação $\theta$, além de possuir uma descontinuidade em $j$, ou seja $C_{d}=C_{d}(j, \theta)$ e $U_{d}=U_{d}(j, \theta)$. Sendo assim as seguintes relações são estabelecidas:

$$
\begin{gathered}
\frac{\partial j_{g}}{\partial P}=0 \\
\frac{\partial j_{g}}{\partial j}=\alpha C_{d} \\
\frac{\partial j_{g}}{\partial \theta}=\alpha\left(j \frac{\partial C_{d}}{\partial \theta}+\frac{\partial U_{d}}{\partial \theta}\right)
\end{gathered}
$$




$$
\frac{\partial j_{g}}{\partial \alpha}=C_{d} j+U_{d}=u_{g}
$$

A partir desses resultados, é possível reescrever as Eqs. (B.24), (B.32) e (B.35):

$$
\begin{gathered}
\rho_{g} \frac{\partial \alpha}{\partial t}+\left(\alpha \frac{\partial \rho_{g}}{\partial P}+\frac{\rho_{d g 0} \alpha_{o}}{B_{o}} \frac{\partial R_{s}}{\partial P}\right) \frac{\partial P}{\partial t}+\rho_{g} u_{g} \frac{\partial \alpha}{\partial s}+\left(j g \frac{\partial \rho_{g}}{\partial P}+\frac{\rho_{d g} j_{o}}{B_{o}} \frac{\partial R_{s}}{\partial P}\right) \frac{\partial P}{\partial s} \\
+\rho_{g} \alpha C_{d} \frac{\partial j}{\partial s}+\rho_{g} \alpha\left(j \frac{\partial C_{d}}{\partial s}+\frac{\partial U_{d}}{\partial s}\right)=0 \\
\rho_{o} \frac{\partial \alpha_{o}}{\partial t}+\left(\alpha_{o} \frac{\partial \rho_{o}}{\partial P}-\frac{\rho_{d g 0} \alpha_{o}}{B_{o}} \frac{\partial R_{s}}{\partial P}\right) \frac{\partial P}{\partial t}+\frac{\rho_{o}}{\alpha_{o}+\alpha_{w}}\left(j_{o}-\alpha_{o} u_{g}\right) \frac{\partial \alpha}{\partial s} \\
+\rho_{o} u_{l} \frac{\partial \alpha_{o}}{\partial s}+\left(j \rho_{o} \frac{\partial \rho_{o}}{\partial P}-\frac{\rho_{d g} 0}{B_{o}} \frac{\partial R_{s}}{\partial P}\right) \frac{\partial P}{\partial s}+\frac{\alpha_{o} \rho_{o}}{\alpha_{w}+\alpha_{o}}\left(1-\alpha C_{d}\right) \frac{\partial j}{\partial s} \\
-\frac{\alpha \alpha_{o} \rho_{o}}{\alpha_{w}+\alpha_{o}}\left(j \frac{\partial C_{d}}{\partial s}+\frac{\partial U_{d}}{\partial s}\right)=0 \\
\rho_{w} \frac{\partial \alpha}{\partial t}+\rho_{w} \frac{\partial \alpha_{o}}{\partial t}-\alpha_{w} \frac{\partial \rho_{w}}{\partial P} \frac{\partial P}{\partial t}+\frac{\rho_{w}}{\alpha_{o}+\alpha_{w}}\left(j_{o}+\alpha_{w} u_{g}\right) \frac{\partial \alpha}{\partial s}+\rho_{w} u_{l} \frac{\partial \alpha_{o}}{\partial s} \\
-j \rho_{w} \frac{\partial P}{\partial P}+\frac{\alpha_{w} \rho_{w}}{\alpha_{o}+\alpha_{w}}\left(\alpha C_{d}-1\right) \frac{\partial j}{\partial s}+\frac{\alpha \alpha_{w} \rho_{w}}{\alpha_{o}+\alpha_{w}}\left(j \frac{\partial C_{d}}{\partial s}+\frac{\partial U_{d}}{\partial s}\right)=0
\end{gathered}
$$

Partindo desse conjunto de equações da continuidade, junto à equação de conservação da quantidade de movimento para a mistura (Eq. (B.4)), pode-se determinar as matrizes A, B e o vetor d. Os autovalores foram apresentados nas Eqs. (B.77) e a partir da Eq. (B.81) obtemos:

$$
e_{1}=u_{g} ; e_{2}=u_{l} ; e_{3}=\infty ; e_{4}=\infty
$$

Conhecida a matriz $\mathbf{E}$, é possível calcular a matriz $\mathbf{T}$ por meio da Eq. (B.45). Sendo assim, com base na Eq. (B.48), os elementos não-nulos da matriz $\mathbf{B}^{*}$ são dados por:

$$
\begin{gathered}
b_{11}^{*}=1 \\
b_{13}^{*}=\frac{\left(1-\alpha C_{d}\right)}{\rho_{g}}\left(\alpha \frac{\partial \rho_{g}}{\partial P}+\frac{\rho_{d g 0} \alpha_{o}}{B_{o}} \frac{\partial R_{s}}{\partial P}\right)-\frac{\alpha_{o}}{\rho_{o}} \frac{\partial \rho_{o}}{\partial P} \alpha C_{d} \\
+\frac{\rho_{d g} \alpha_{o}}{\rho_{o} B_{o}} \frac{\partial R_{s}}{\partial P} \alpha C_{d}-\frac{\alpha_{w}}{\rho_{w}} \frac{\partial \rho_{w}}{\partial P} \alpha C_{d}
\end{gathered}
$$




$$
\begin{gathered}
b_{21}^{*}=\alpha_{o} \\
b_{22}^{*}=\alpha_{o}+\alpha_{w} \\
b_{23}^{*}=\alpha_{o} \alpha_{w}\left(\frac{1}{\rho_{o}} \frac{\partial \rho_{o}}{\partial P}-\frac{\rho_{d g} 0}{\rho_{o} B_{o}} \frac{\partial R_{s}}{\partial P}-\frac{1}{\rho_{w}} \frac{\partial \rho_{w}}{\partial P}\right)
\end{gathered}
$$

Os elementos não-nulos da matriz $\mathbf{A}^{*}$ são dados por:

$$
\begin{gathered}
a_{11}^{*}=u_{g} \\
a_{13}^{*}=u_{g}\left[\frac{\left(1-\alpha C_{d}\right)}{\rho_{g}}\left(\alpha \frac{\partial \rho_{g}}{\partial P}+\frac{\rho_{d g 0} \alpha_{o}}{B_{o}} \frac{\partial R_{s}}{\partial P}\right)-\frac{\alpha_{o}}{\rho_{o}} \frac{\partial \rho_{o}}{\partial P} \alpha C_{d}\right. \\
\left.+\frac{\rho_{d g 0} \alpha_{o}}{\rho_{o} B_{o}} \frac{\partial R_{s}}{\partial P} \alpha C_{d}-\frac{\alpha_{w}}{\rho_{w}} \frac{\partial \rho_{w}}{\partial P} \alpha C_{d}\right] \\
a_{22}^{*}=u_{l}\left(\alpha_{o}+\alpha_{w}\right) \\
a_{23}^{*}=u_{l} \alpha_{o} \alpha_{w}\left(\frac{1}{\rho_{o}} \frac{\partial \rho_{o}}{\partial P}-\frac{\rho_{d g} 0}{\rho_{o} B_{o}} \frac{\partial R_{s}}{\partial P}-\frac{1}{\rho_{w}} \frac{\partial \rho_{w}}{\partial P}\right)
\end{gathered}
$$

Por sua vez, a componente não-nula do vetor $\mathbf{d}^{*}$ é:

$$
\begin{gathered}
d_{1}^{*}=\alpha\left(j \frac{\partial C_{d}}{\partial s}+\frac{\partial U_{d}}{\partial s}\right)+\left(u_{l}-u_{g}\right)\left(\frac{4 \tau_{w}}{D}-\rho_{m} g_{s}\right) \\
\times\left\{\frac{-\rho_{d g 0} \alpha_{o}}{\rho_{o} B_{o}} \frac{\partial R_{s}}{\partial P}\left[\frac{\rho_{o}}{\rho_{g}}\left(1-\alpha C_{d}\right)+\alpha C_{d}\right]+\frac{\alpha_{o}}{\rho_{o}} \frac{\partial \rho_{o}}{\partial P} \alpha C_{d}\right. \\
\left.+\frac{\alpha_{w}}{\rho_{w}} \frac{\partial \rho_{w}}{\partial P} \alpha C_{d}\right\}
\end{gathered}
$$

Com base na Eq. (B.50), pode-se exprimir as equações na forma normal da seguinte maneira:

$$
b_{11}^{*} \frac{D_{g} \alpha}{D t}+b_{13}^{*} \frac{D_{g} P}{D t}+d_{1}^{*}=0
$$


164

$$
b_{21}^{*} \frac{D_{l} \alpha}{D t}+b_{22}^{*} \frac{D_{l} \alpha_{o}}{D t}+b_{23}^{*} \frac{D_{l} P}{D t}=0
$$




\section{APÊNDICE C - DEDUÇÃO DA EQUAÇÃO DE ESTADO COMPLEMENTAR PARA O MODELO DO RISER}

Neste apêndice é apresentada a dedução da equação de estado complementar para o modelo do riser, com o objetivo de evidenciar os cálculos omitidos na Seção 3.1.4.

A dedução inicia-se reescrevendo as equações de continuidade para o gás, óleo e água, dadas respectivamente pelas Eqs. (B.82), (B.83) e (B.84), segundo as derivadas direcionais definidas pelas Eqs. (3.40) e (3.41):

$$
\begin{gathered}
\rho_{g} \frac{D_{g} \alpha}{D t}+\alpha \frac{\partial \rho_{g}}{\partial P} \frac{D_{g} P}{D t}+\frac{\rho_{d g} \alpha_{o}}{B_{o}} \frac{\partial R_{s}}{\partial P} \frac{D_{l} P}{D t}+\rho_{g} \alpha \frac{\partial u_{g}}{\partial s}=0 \\
\rho_{o} \frac{D_{l} \alpha_{o}}{D t}+\alpha_{o} \frac{\partial \rho_{o}}{\partial P} \frac{D_{l} P}{D t}-\frac{\rho_{d g} \alpha_{o}}{B_{o}} \frac{\partial R_{s}}{\partial P} \frac{D_{l} P}{D t} \\
+\frac{\rho_{o} \alpha_{o}}{1-\alpha}\left(u_{l}-u_{g}\right) \frac{\partial \alpha}{\partial s}+\frac{\rho_{o} \alpha_{o}}{1-\alpha} \frac{\partial j}{\partial s}-\frac{\alpha \alpha_{o} \rho_{o}}{1-\alpha} \frac{\partial u_{g}}{\partial s}=0 \\
\rho_{w} \frac{D_{g} \alpha}{D t}+\rho_{w} \frac{D_{l} \alpha_{o}}{D t}-\alpha_{w} \frac{\partial \rho_{w}}{\partial P} \frac{D_{l} P}{D t}+\frac{\rho_{w} \alpha_{o}}{1-\alpha}\left(u_{l}-u_{g}\right) \frac{\partial \alpha}{\partial s} \\
-\frac{\alpha_{w} \rho_{w}}{1-\alpha} \frac{\partial j}{\partial s}+\frac{\alpha \alpha_{w} \rho_{w}}{1-\alpha} \frac{\partial u_{g}}{\partial s}=0
\end{gathered}
$$

Isolando a derivada direcional na direção do líquido da fração volumétrica de óleo $D_{l} \alpha_{o} / D t$ na Eq. (C.2) e substituindo na Eq. (C.3), obtemos:

$$
\frac{D_{g} \alpha}{D t}+\frac{D_{l} P}{D t}\left(\frac{\rho_{d g} \alpha_{o}}{B_{o} \rho_{o}} \frac{\partial R_{s}}{\partial P}-\frac{\alpha_{o}}{\rho_{o}} \frac{\partial \rho_{o}}{\partial P}-\frac{\alpha_{w}}{\rho_{w}} \frac{\partial \rho_{w}}{\partial P}\right)-\frac{\partial j}{\partial s}+\alpha \frac{\partial u_{g}}{\partial s}=0
$$


Dividindo a Eq. (C.1) pela massa específica do gás $\rho_{g}$ e subtraindo a equação resultante da Eq. (C.4), obtemos:

$$
\frac{\partial j}{\partial s}=-\frac{\alpha}{\rho_{g}} \frac{\partial \rho_{g}}{\partial P} \frac{D_{u g} P}{D t}+\frac{D_{u l} P}{D t}\left[\frac{\rho_{d g 0 \alpha_{o}}}{B_{o}} \frac{\partial R_{s}}{\partial P}\left(\frac{1}{\rho_{o}}-\frac{1}{\rho_{g}}\right)-\frac{\alpha_{o}}{\rho_{o}} \frac{\partial \rho_{o}}{\partial P}-\frac{\alpha_{w}}{\rho_{w}} \frac{\partial \rho_{w}}{\partial P}\right]
$$

A expressão acima refere-se à equação de estado que, ao ser discretizada e resolvida numericamente, fornecerá o valor da velocidade superficial total $j$ ao longo do riser. 


\section{APÊNDICE D - DEDUÇÃO DAS EQUAÇÕES DE ESTADO PARA O MODELO DO PIPELINE}

Neste apêndice será apresentada a dedução das equações de estado para o modelo do pipeline, evidenciando a manipulação algébrica das equações de conservação que foi ocultada na Seção 3.2 .

Com base nas hipóteses estabelecidas na Seção 3.2, o modelo do pipeline contempla dois volumes de controle. Dependendo do estado em que se encontra o pipeline, sem penetração de líquido $(x=0)$ ou com penetração de líquido $(x>0)$, é possível que apenas um volume de controle exista ou ambos volumes de controle sejam levados em conta.

Nas equações que seguem, as variáveis que exibem o índice $b$ estão relacionadas à condição de pressão verificada na base do riser. Do mesmo modo, as variáveis que exibem o índice $s$ estão relacionadas à condição de pressão na interface entre os volume de controle $\forall_{1}$ e $\forall_{2}$ (localizada na posição $x$ ) e, finalmente, as variáveis que possuem o índice $m$ estão relacionadas à condição de pressão média no volume de controle $\forall_{2}$. O índice $\forall_{1}$ relaciona a variável ao volume de controle $\forall_{1}$ e, analogamente, o índice $\forall_{2}$ relaciona a variável ao volume de controle $\forall_{2}$. Por sua vez, o índice in refere-se à entrada do pipeline.

Dado que o escoamento é isotérmico e a composição dos fluidos não varia com o tempo, as propriedades dos fluidos variam apenas com a pressão. Sendo assim, as seguintes relações são válidas:

$$
\begin{aligned}
& \frac{\partial \rho_{g}}{\partial t}=\frac{\partial \rho_{g}}{\partial P} \frac{\partial P}{\partial t} \\
& \frac{\partial \rho_{o}}{\partial t}=\frac{\partial \rho_{o}}{\partial P} \frac{\partial P}{\partial t} \\
& \frac{\partial \rho_{w}}{\partial t}=\frac{\partial \rho_{w}}{\partial P} \frac{\partial P}{\partial t}
\end{aligned}
$$




$$
\begin{gathered}
\frac{\partial R_{s}}{\partial t}=\frac{\partial R_{s}}{\partial P} \frac{\partial P}{\partial t} \\
\frac{\partial R_{s}}{\partial s}=\frac{\partial R_{s}}{\partial P} \frac{\partial P}{\partial s}
\end{gathered}
$$

O modelo do pipeline é baseado em um sistema de parâmetros concentrados, de tal maneira que pressões representativas para os volumes de controle $\forall_{1}$ e $\forall_{2}$ são consideradas. Sendo assim, as propriedades dependentes da pressão não variam no espaço. Logo, a derivada espacial da solubilidade de gás em óleo $R_{s}$, dada pela Eq. (D.5), resulta:

$$
\frac{\partial R_{s}}{\partial s}=0
$$

Com isso o termo de vaporização, dado pela Eq. (3.35), pode ser reduzido a:

$$
\Gamma=-\frac{\rho_{d g 0} \alpha_{o}}{B_{o}} \frac{\partial R_{s}}{\partial P} \frac{\partial P}{\partial t}
$$

\section{D.1 Equacionamento para comprimento de penetração de líquido nulo (estado $x=0$ )}

Para o estado $x=0$ existe apenas o volume de controle $\forall_{1}$. Portanto, as equações de conservação que seguem serão aplicadas exclusivamente nesse volume de controle.

\section{D.1.1 Equação da continuidade para o gás}

Aplicando a equação da continuidade para o gás no volume de controle $\forall_{1}$, obtemos:

$$
\frac{\partial}{\partial t}\left(\rho_{g} \alpha_{\forall_{1}}\right)+\frac{\partial}{\partial s}\left(\rho_{g} j_{g}\right)=\Gamma
$$

Integrando a expressão acima com relação à variável espacial $s$, considerando como limites de integração as posições $s_{i}=0$ e $s_{f}=L$, e sabendo que a pressão na região estratificada possui um valor constante, dada pela pressão na base do riser $P_{b}$, obtemos a seguinte equação:

$$
\frac{\partial}{\partial t}\left(\rho_{g b} \alpha_{\forall_{1}}\right) L+\rho_{g b} j_{g b}-\rho_{g b} j_{g i n}=\Gamma L
$$

Expandindo a derivada temporal usando a regra da cadeia na Eq. (D.9) e usando as 
Eqs. (D.1) e (D.7), chegamos à expressão que segue:

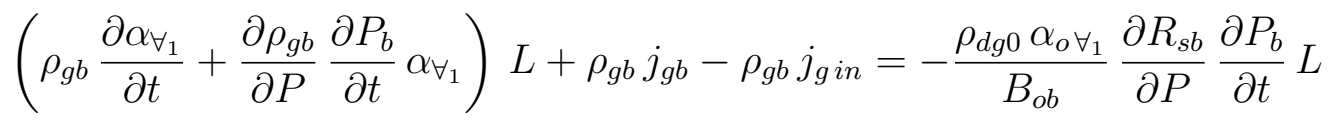

Resolvendo a expressão acima para a velocidade superficial de gás na base do riser $j_{g b}$, descartando variações da fração de vazio, obtemos a seguinte equação de estado:

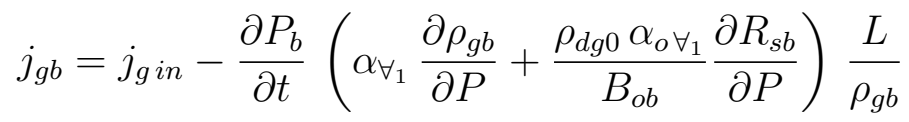

\section{D.1.2 Equação da continuidade para o óleo}

Aplicando a equação da continuidade para o óleo no volume de controle $\forall_{1}$, obtemos:

$$
\frac{\partial}{\partial t}\left(\rho_{o} \alpha_{o \forall}\right)+\frac{\partial}{\partial s}\left(\rho_{o} j_{o}\right)=-\Gamma
$$

Com base em procedimento análogo ao utilizado na seção anterior, é possível desenvolver a Eq. (D.12) para o seguinte formato:

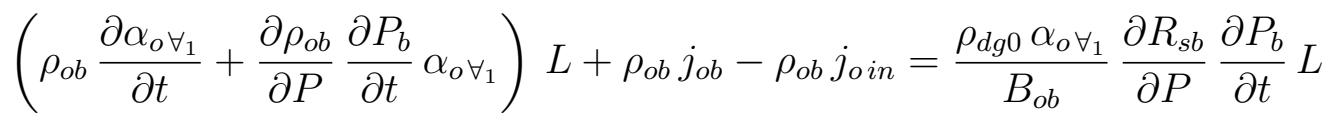

Resolvendo a expressão acima para a velocidade superficial de óleo na base no riser $j_{o b}$, considerando que a fração volumétrica de óleo não varia com o tempo, chegamos à equação de estado que segue:

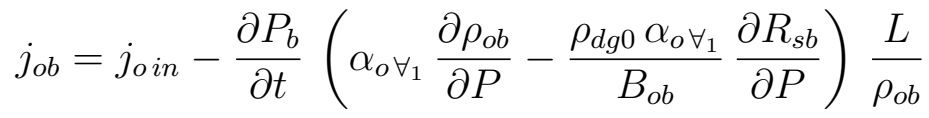

\section{D.1.3 Equação da continuidade para a água}

Aplicando a equação da continuidade para a água no volume de controle $\forall_{1}$, obtemos:

$$
\frac{\partial}{\partial t}\left(\rho_{w} \alpha_{w} \forall_{1}\right)+\frac{\partial}{\partial s}\left(\rho_{w} j_{w}\right)=0
$$

Utilizando procedimento análogo ao utilizado nas seções anteriores, chegamos à seguinte equação:

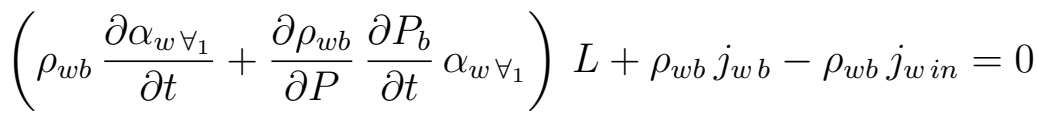

Resolvendo a expressão acima para a velocidade superficial de água na base do riser 
$j_{w b}$, considerando que a fração volumétrica de água não varia com o tempo, chegamos à seguinte equação de estado:

$$
j_{w b}=j_{w i n}-\alpha_{w \forall_{1}} \frac{\partial \rho_{w b}}{\partial P} \frac{\partial P_{b}}{\partial t} \frac{L}{\rho_{w b}}
$$

\section{D.2 Equacionamento para comprimento de penetração de líquido positivo (estado $x>0$ )}

A condição $x>0$ é observada quando o líquido penetra no pipeline, impedindo que o gás adentre o riser. Neste caso coexistem os volumes de controle $\forall_{1}$ e $\forall_{2}$. A pressão na região estratificada do volume de controle $\forall_{1}$ possui o mesmo valor da pressão observada na interface entre os volumes de controle, dada por $P_{s}$. A pressão no volume de controle $\forall_{2}$ depende da posição e de maneira a avaliar as propriedades dos fluidos e suas derivadas, uma pressão representativa para $\forall_{2}$, dada por $P_{m}$, é utilizada:

$$
\begin{gathered}
P_{s}=P_{b}-\rho_{l} g x \sin \beta \\
P_{m}=\frac{P_{b}+P_{s}}{2} \\
\rho_{l}=\alpha_{o \forall} \rho_{o m}+\alpha_{w \forall} \rho_{w m}
\end{gathered}
$$

\section{D.2.1 Volume de controle $\forall_{1}$}

\section{D.2.1.1 Equação da continuidade para o gás}

Aplicando a equação da continuidade para o gás no volume de controle $\forall_{1}$, obtemos:

$$
\frac{\partial}{\partial t}\left(\rho_{g} \alpha_{\forall_{1}}\right)+\frac{\partial}{\partial s}\left(\rho_{g} j_{g}\right)=\Gamma
$$

Integrando a expressão acima com relação à variável espacial $s$, considerando como limites de integração as posições $s_{i}=0$ e $s_{f}=(L-x)$, e sabendo que a pressão na região estratificada possui um valor constante, dada pela pressão na interface entre os volumes de controle $P_{s}$, obtemos a seguinte equação:

$$
\frac{\partial}{\partial t}\left(\rho_{g s} \alpha_{\forall_{1}}\right)(L-x)+\rho_{g s} j_{g s}-\rho_{g s} j_{g i n}=\Gamma(L-x)
$$

Expandindo a derivada temporal usando a regra da cadeia na Eq. (D.22) e usando as 
Eqs. (D.1) e (D.7), chegamos à expressão que segue:

$$
\begin{aligned}
\left(\rho_{g s} \frac{\partial \alpha_{\forall_{1}}}{\partial t}+\right. & \left.\frac{\partial \rho_{g s}}{\partial P} \frac{\partial P_{s}}{\partial t} \alpha_{\forall_{1}}\right)(L-x)+\rho_{g s} j_{g s}-\rho_{g s} j_{g i n}= \\
& -\frac{\rho_{d g 0} \alpha_{o \forall_{1}}}{B_{o s}}\left(\frac{\partial R_{s s}}{\partial P} \frac{\partial P_{s}}{\partial t}\right)(L-x)
\end{aligned}
$$

A velocidade do gás na fronteira entre os volume de controle é dada pela velocidade da frente de acúmulo de líquido $d x / d t$, sendo assim, a velocidade superficial do gás na fronteira $j_{g s}$ é calculada como segue:

$$
j_{g s}=-\alpha_{\forall_{1}} \frac{d x}{d t}
$$

Substituindo a Eq. (D.24) na Eq. (D.23) e rearranjando os termos, chegamos a:

$$
\frac{\partial \alpha_{\forall_{1}}}{\partial t} \rho_{g s}+\frac{\partial P_{s}}{\partial t}\left(\alpha_{\forall_{1}} \frac{\partial \rho_{g s}}{\partial P}+\frac{\rho_{d g 0} \alpha_{o \forall_{1}}}{B_{o s}} \frac{\partial R_{s s}}{\partial P}\right)-\frac{\rho_{g s}}{L-x}\left(\alpha_{\forall_{1}} \frac{d x}{d t}+j_{g i n}\right)=0
$$

Considera-se que não haja variação na fração de vazio $\alpha_{\forall_{1}}$. E resolvendo a equação acima para a velocidade da frente de acúmulo de líquido $d x / d t$, chegamos à seguinte equação de estado:

$$
\frac{d x}{d t}=-\frac{j_{g i n}}{\alpha_{\forall_{1}}}+\frac{\partial P_{s}}{\partial t}\left(\alpha_{\forall_{1}} \frac{\partial \rho_{g s}}{\partial P}+\frac{\rho_{d g 0} \alpha_{o \forall_{1}}}{B_{o s}} \frac{\partial R_{s s}}{\partial P}\right) \frac{(L-x)}{\rho_{g s} \alpha_{\forall_{1}}}
$$

\section{D.2.1.2 Equação da continuidade para o óleo}

Aplicando o princípio da conservação de massa para o óleo no volume de controle $\forall_{1}$, obtemos:

$$
\frac{\partial}{\partial t}\left(\rho_{o} \alpha_{o \forall_{1}}\right)+\frac{\partial}{\partial s}\left(\rho_{o} j_{o}\right)=-\Gamma
$$

Integrando a expressão acima com relação à variável espacial $s$, considerando como limites de integração as posições $s_{i}=0$ e $s_{f}=(L-x)$, e sabendo que a pressão na região estratificada possui um valor constante, dada pela pressão na interface entre os volumes de controle $P_{s}$, obtemos a seguinte equação:

$$
\frac{\partial}{\partial t}\left(\rho_{o s} \alpha_{o \forall}\right)(L-x)+\rho_{o s}\left(j_{o s}+\alpha_{o \forall} \frac{d x}{d t}\right)-\rho_{o s} j_{o i n}=-\Gamma(L-x)
$$

A interface entre os volumes de controle (ou a frente de acúmulo de líquido) pode mover-se, sendo sua velocidade dada por $d x / d t$. Sendo assim, o termo somado à velocidade su- 
perficial de óleo na interface $j_{\text {os }}$ refere-se à velocidade superficial com que se move a interface.

Utilizando procedimento análogo ao apresentado na seção anterior, chegamos à equação:

$$
\begin{gathered}
\frac{\partial \alpha_{o \forall_{1}}}{\partial t} \rho_{o s}+\frac{\partial P_{s}}{\partial t}\left(\alpha_{o \forall_{1}} \frac{\partial \rho_{o s}}{\partial P}-\frac{\rho_{d g 0} \alpha_{o \forall_{1}}}{B_{o s}} \frac{\partial R_{s s}}{\partial P}\right) \\
+\frac{\rho_{o s}}{(L-x)}\left(j_{o s}+\frac{d x}{d t} \alpha_{o \forall_{1}}\right)-\frac{\rho_{o s} j_{o i n}}{(L-x)}=0
\end{gathered}
$$

Isolando a velocidade superficial de óleo na interface entre os volumes de controle $j_{o s}$, descartando variações na fração volumétrica de óleo, chegamos à seguinte equação de estado:

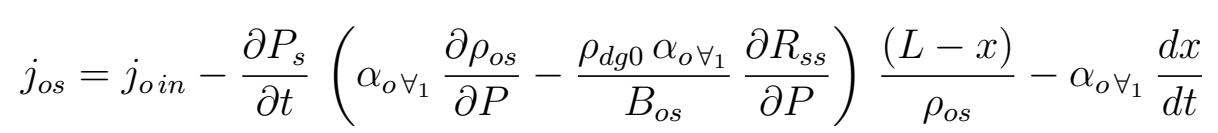

\section{D.2.1.3 Equação da continuidade para a água}

Aplicando a equação da continuidade para a água no volume de controle $\forall_{1}$, obtemos:

$$
\frac{\partial}{\partial t}\left(\rho_{w} \alpha_{w \forall_{1}}\right)+\frac{\partial}{\partial s}\left(\rho_{w} j_{w}\right)=0
$$

Realizando procedimento análogo ao apresentado nas seções anteriores, obtemos a seguinte expressão:

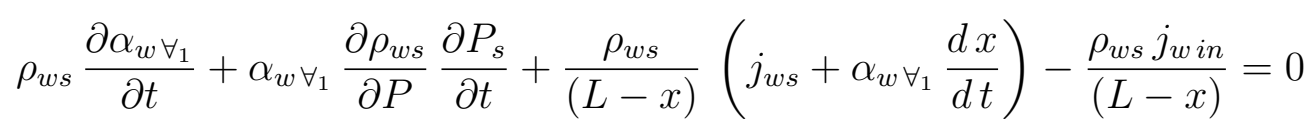

Isolando a velocidade superficial de água na interface $j_{w s}$, descartando variações de fração volumétrica de água, obtemos a seguinte equação de estado:

$$
j_{w s}=j_{w i n}-\alpha_{w \forall} \frac{\partial \rho_{w s}}{\partial P} \frac{\partial P_{s}}{\partial t} \frac{(L-x)}{\rho_{w s}}-\alpha_{w \forall_{1}} \frac{d x}{d t}
$$




\section{D.2.2 Volume de controle $\forall_{2}$}

\section{D.2.2.1 Equação da continuidade para o óleo}

Aplicando a equação da continuidade para o óleo no volume de controle $\forall_{2}$ considerando que não existe transferência de massa, obtemos:

$$
\frac{\partial}{\partial t}\left(\rho_{o} \alpha_{o \forall_{2}}\right)+\frac{\partial}{\partial s}\left(\rho_{o} j_{o}\right)=0
$$

Integrando a expressão acima com relação à variável espacial $s$, considerando como limites de integração as posições $s_{i}=(L-x)$ e $s_{f}=L$, e sabendo que a pressão no volume de controle $\forall_{2}$ possui o valor médio $P_{m}$, obtemos a seguinte equação:

$$
\frac{\partial}{\partial t}\left(\rho_{o m} \alpha_{o \forall_{2}}\right) x+\rho_{o b} j_{o b}-\rho_{o s}\left(j_{o s}+\alpha_{o \forall} \frac{d x}{d t}\right)=0
$$

onde o termo somado à velocidade superficial de óleo na interface $j_{\text {os }}$ refere-se à velocidade superficial com que se move a interface.

Expandindo a derivada temporal na Eq. (D.35) e utilizando a Eq. (D.2), obtemos:

$$
\left(\rho_{o m} \frac{\partial \alpha_{o \forall}}{\partial t}+\alpha_{o \forall_{2}} \frac{\partial \rho_{o m}}{\partial P} \frac{\partial P_{m}}{\partial t}\right) x+\rho_{o b} j_{o b}-\rho_{o s}\left(j_{o s}+\alpha_{o \forall_{1}} \frac{d x}{d t}\right)=0
$$

Isolando a velocidade superficial do óleo na base do riser $j_{o b}$, descartando variações de fração volumétrica de óleo, chegamos à expressão:

$$
j_{o b}=\frac{1}{\rho_{o b}}\left(\rho_{o s} j_{o s}+\rho_{o s} \alpha_{o \forall} \frac{d x}{d t}-x \alpha_{o \forall 2} \frac{\partial \rho_{o m}}{\partial P} \frac{\partial P_{m}}{\partial t}\right)
$$

\section{D.2.2.2 Equação da continuidade para água}

Aplicando a equação da continuidade para a água no volume de controle $\forall_{2}$, obtemos:

$$
\frac{\partial}{\partial t}\left(\rho_{w} \alpha_{w \forall_{2}}\right)+\frac{\partial}{\partial s}\left(\rho_{w} j_{w}\right)=0
$$

Realizando procedimento análogo ao apresentado na seção anterior, obtemos:

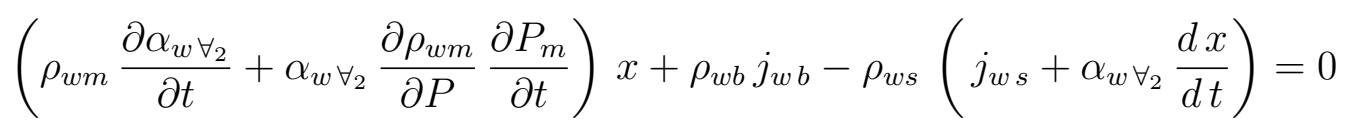

Isolando a velocidade superficial da água na base do riser $j_{w b}$, descartando variações 
na fração volumétrica de água, chegamos à expressão:

$$
j_{w b}=\frac{1}{\rho_{w b}}\left(\rho_{w s} j_{w s}+\rho_{w s} \alpha_{w \forall} \frac{d x}{d t}-x \alpha_{w \forall 2} \frac{\partial \rho_{w m}}{\partial P} \frac{\partial P_{m}}{\partial t}\right)
$$

\section{D.2.2.3 Equação da continuidade para a fase líquida}

Aplicando a equação da continuidade para a fase líquida (óleo e água) no volume de controle $\forall_{2}$, obtemos:

$$
\frac{\partial}{\partial t}\left(\rho_{l} \alpha_{l \forall_{2}}\right)+\frac{\partial}{\partial s}\left(\rho_{l} j_{l}\right)=0
$$

Realizando procedimento análogo ao apresentado nas seções anteriores, obtemos:

$$
\left(\rho_{l m} \frac{\partial \alpha_{l \forall_{2}}}{\partial t}+\alpha_{l \forall_{2}} \frac{\partial \rho_{l m}}{\partial P} \frac{\partial P_{m}}{\partial t}\right) x+\rho_{l b} j_{l b}-\rho_{l s}\left(j_{o s}+j_{w s}+\alpha_{l \forall_{1}} \frac{d x}{d t}\right)=0
$$

A fração de vazio de líquido é constante e vale $\alpha_{l \forall_{2}}=1$, sendo assim, obtemos a seguinte expressão para a velocidade do líquido na base do riser $u_{l b}$ :

$$
u_{l b}=\frac{1}{\rho_{l b}}\left[\rho_{l s}\left(j_{o s}+j_{w s}+\alpha_{l \forall} \frac{d x}{d t}\right)-x \frac{\partial \rho_{l m}}{\partial P} \frac{\partial P_{m}}{\partial t}\right]
$$

Dado que as fases líquidas estão homogeneizadas e possuem mesma velocidade, a fração de vazio de óleo no volume de controle $\forall_{2}$ é dada por:

$$
\alpha_{o \forall}=\frac{j_{o b}}{u_{l b}}
$$

A fração de vazio de água no volume de controle $\forall_{2}$ é calculada como segue:

$$
\alpha_{w \forall 2}=1-\alpha_{o \forall}
$$




\section{APÊNDICE E - CORRELAÇÕES PARA AS PROPRIEDADES DOS FLUIDOS}

Neste apêndice serão apresentadas as definições das propriedades termodinâmicas, assim como as fórmulas analíticas utilizadas para calculá-las. O apêndice é um complemento à Seção 3.3.

\section{E.1 Variáveis independentes}

As variáveis independentes são os dados de entrada para a utilização das correlações. Além da pressão $P$ e temperatura $T$, esta seção reúne as outras variáveis independentes que serão utilizadas no cálculo das propriedades termodinâmicas.

Para as definições que seguem, de acordo com o American Petroleum Institute, a condição padrão é definida como $P_{0}=1 \mathrm{~atm}$ e $T_{0}=60^{\circ} \mathrm{F}$.

\section{E.1.1 Densidade relativa do óleo na condição padrão e densidade API}

A densidade API $\gamma_{A P I}$, ou grau API, é definida como segue:

$$
\gamma_{A P I}=\frac{141,5}{\gamma_{o 0}}-131,5
$$

A densidade relativa do óleo na condição padrão $\gamma_{o 0}$ (adimensional), é dada por:

$$
\gamma_{o 0}=\frac{\rho_{o 0}}{\rho_{w r e f 0}}
$$

onde $\rho_{\text {wref } 0}=62,37 \mathrm{lbm} / \mathrm{ft}^{3}=999,014 \mathrm{~kg} / \mathrm{m}^{3}$ é a massa específica da água de referência na condição padrão. 


\section{E.1.2 Razão gás-óleo}

A razão gás-óleo GOR (adimensional), também chamada de razão de solubilidade no ponto de bolha $R_{\text {sbolha }}$, é definida por:

$$
G O R=\frac{Q_{g 0}}{Q_{o 0}}
$$

onde $Q_{g 0}$ e $Q_{o 0}$ são correspondentemente as vazões volumétricas de gás e de óleo, ambos na condição padrão.

\section{E.1.3 Razão água-óleo ou razão de água mais sedimentos a líquido mais sedimentos}

A razão água-óleo WOR (adimensional) é dada como:

$$
W O R=\frac{Q_{w 0}}{Q_{o 0}}
$$

onde $Q_{w 0}$ é a vazão volumétrica da água na condição padrão.

A razão de água mais sedimentos a líquido mais sedimentos $B S W$ (adimensional) é definida como:

$$
B S W=\frac{Q_{w 0}}{Q_{w 0}+Q_{o 0}}
$$

A relação entre as duas variáveis é dada pela expressão:

$$
W O R=\frac{B S W}{1-B S W}
$$

\section{E.1.4 Salinidade da água}

A salinidade da água $Y$ (em porcentagem) é calculada como a razão da massa de sólidos dissolvidos em água pela massa total da amostra de água.

\section{E.1.5 Densidade relativa do gás livre na condição padrão}

A densidade relativa do gás livre na condição padrão $\gamma_{g 0}$ (adimensional) é definida como: 


$$
\begin{gathered}
\gamma_{g 0}=\frac{M_{g 0}}{M_{a}} \\
M_{g 0}=\sum_{i} y_{i 0} M_{i}
\end{gathered}
$$

onde $M_{g 0}$ é a massa molar aparente da mistura de gás livre na condição padrão, $M_{a}=28,966$ é a massa molecular aparente da mistura de gases correspondente ao ar, $y_{i 0}$ é a fração molar do componente livre $i$ da mistura na condição padrão e $M_{i}$ a correspondente massa molecular.

Considerando que o fator de compressibilidade na condição padrão é igual à unidade, ou seja, que os gases se comportam como gases ideais, resulta:

$$
\gamma_{g 0}=\frac{M_{g 0}}{M_{a}}=\frac{\rho_{g 0}}{\rho_{\text {aref } 0}}
$$

onde $\rho_{\text {aref } 0}=0,076362 \mathrm{lbm} / \mathrm{ft}^{3}$ é a massa específica do ar de referência na condição padrão.

\section{E.2 Fator volume de formação de gás}

O fator volume de formação de gás (adimensional) é calculado pela razão:

$$
B_{g}=\frac{Q_{g}}{Q_{g 0}}
$$

onde $Q_{g}$ e $Q_{g 0}$ são respectivamente as vazões volumétricas do gás livre na condição de medição e na condição padrão (considerando a mesma massa de gás).

Partindo da relação constitutiva para o gás real (apresentada na Seção 3.1.3.3) e supondo a passagem de uma massa fixa de gás livre entre a condição padrão e a local, obtemos:

$$
\frac{P_{o}}{\rho_{g 0} Z_{c 0} T_{0}}=\frac{P}{\rho_{g} Z_{c} T}
$$

onde $Z_{c}$ é o fator de compressibilidade e as temperaturas são absolutas. Como $Z_{c 0}=1$, o fator volume de formação de gás resulta:

$$
B_{g}=\frac{\rho_{g 0}}{\rho_{g}}=\frac{P_{0}}{T_{0}} \frac{Z_{c} T}{P}
$$


Finalmente, escrevendo as variáveis na condição padrão $\left(P_{0}=14,7\right.$ psia, $\left.T_{0}=520^{\circ} R\right)$, obtemos:

$$
B_{g}=0,02827 \frac{Z_{c} T}{P}
$$

onde a temperatura está em graus Rankine e a pressão em psia.

\section{E.2.1 Fator de compressibilidade}

Segundo a correlação de Dranchuk e Abou-Kassem (1975), que correlaciona os resultados do gráfico de Standing e Katz (1942), o fator de compressibilidade (adimensional) é dado por:

$$
Z_{c}=1+C_{1} \rho_{p r}+C_{2} \rho_{p r}^{2}-A_{9} C_{3} \rho_{p r}^{5}+A_{10}\left(1+A_{11} \rho_{p r}^{2}\right)\left(\frac{\rho_{p r}^{2}}{T_{p r}^{3}}\right) \exp \left(-A_{11} \rho_{p r}^{2}\right)
$$

onde:

$$
\begin{gathered}
C_{1}=A_{1}+\frac{A_{2}}{T_{p r}}+\frac{A_{3}}{T_{p r}^{3}}+\frac{A_{4}}{T_{p r}^{4}}+\frac{A_{5}}{T_{p r}^{5}} \\
C_{2}=A_{6}+\frac{A_{7}}{T_{p r}}+\frac{A_{8}}{T_{p r}^{2}} \\
C_{3}=\frac{A_{7}}{T_{p r}}+\frac{A_{8}}{T_{p r}^{2}} \\
\rho_{p r}=\frac{0,27 P_{p r}}{Z_{c} T_{p r}} \\
P_{p r}=\frac{P}{P_{p c}} \\
T_{p r}=\frac{T}{T_{p c}}
\end{gathered}
$$

Nas relações anteriores $\rho_{p r}, P_{p r}$ e $T_{p r}$ são respectivamente a massa específica, pressão e temperatura pseudo-reduzida da mistura de gás, enquanto $P_{p c}($ psia $)$ e $T_{p c}\left({ }^{o} R\right)$ são, respectivamente, a pressão e temperatura pseudo-críticas (dependentes da composição molar) da mistura. 
Tabela E.1: Parâmetros para uso na correlação de Dranchuk e Abou-Kassem (1975) (ver Seções E.2.1 e E.13.3).

\begin{tabular}{|c|c|c|c|c|c|c|}
\hline Parâmetro & $A_{1}$ & $A_{2}$ & $A_{3}$ & $A_{4}$ & $A_{5}$ & $A_{6}$ \\
\hline Valor & 0,3265 & $-1,0700$ & $-0,5339$ & 0,01569 & $-0,05165$ & 0,5475 \\
\hline Parâmetro & $A_{7}$ & $A_{8}$ & $A_{9}$ & $A_{10}$ & $A_{11}$ & \\
\hline Valor & $-0,7361$ & 0,1844 & 0,1056 & 0,6134 & 0,7210 & \\
\hline
\end{tabular}

Os parâmetros presentes na correlação estão relacionados na Tabela E.1.

Como a massa específica pseudo-reduzida da mistura depende do fator de compressibilidade, deve ser utilizado um método iterativo para resolver a Eq. (E.14). A correlação de Dranchuk \& Abbou-Kassem é confiável na seguinte faixa de variáveis: $0,2 \leq P_{p r}<30$ para $1,0<T_{p r} \leq 3,0$ e $P_{p r}<1,0$ para $0,7<T_{p r}<1,0$.

\section{E.2.2 Pressão e temperatura pseudo-críticas}

Para sistemas de gás natural, Standing (1981) correlacionou os dados apresentados na carta de Brown et al. (1948) em função da densidade relativa do gás, resultando:

$$
\begin{gathered}
P_{p c}=677+15,0 \gamma_{g}-37,5 \gamma_{g}^{2} \\
T_{p c}=168+325 \gamma_{g}-12,5 \gamma_{g}^{2} \\
\gamma_{g}=\frac{M_{g}}{M_{a}}
\end{gathered}
$$

onde $\gamma_{g}\left(0,57 \leq \gamma_{g} \leq 1,68\right)$ é a densidade relativa do gás e a temperatura está em graus Rankine.

\section{E.3 Massa específica do gás}

De acordo com a aproximação de black-oil (ver Seção 3.1.3.5), a densidade relativa do gás não muda com variações de pressão e temperatura. Portanto, a partir das Eqs. (3.29) e (E.10), 
obtemos a seguinte expressão para a massa específica do gás:

$$
\rho_{g} \cong \frac{\rho_{g 0}}{B_{g}}
$$

\section{E.4 Fator volume de formação de óleo}

O fator volume de formação de óleo (adimensional) é dado por:

$$
B_{o}=\frac{Q_{o}}{Q_{o 0}}
$$

onde $Q_{o}$ é a vazão volumétrica de óleo na condição de medição (considerando diferentes massas em relação a $Q_{o 0}$, já que o gás dissolvido aparece como gás livre na condição padrão).

McCain (1990) mostrou que, por meio de um balanço material, vale a seguinte relação:

$$
B_{o}=\frac{\rho_{o 0}+\frac{P_{0} M_{a}}{\Lambda T_{0}} R_{s} \gamma_{d g}}{\rho_{o}}
$$

Assume-se como válida a aproximação de black-oil e a partir da substituição da Eq. (3.30) na equação apresentada acima, fazendo referência à relação constitutiva de gás real dada pela Eq. (3.1.3.3), obtemos a seguinte expressão:

$$
B_{o} \cong \frac{\rho_{o 0}+\rho_{g 0} R_{s}}{\rho_{o}}
$$

\section{E.5 Massa específica do óleo}

Para o cálculo da massa específica do óleo foi usada a correlação apresentada por Velarde, Blasingame e McCain (1999):

$$
\begin{gathered}
\rho_{o}=\rho_{b s}-\left(0,00302+1,505 \rho_{b s}^{-0,951}\right)(T-60)^{0,938}+ \\
{\left[0,0216-0,0233\left(10^{-0,0161 \rho_{b s}}\right)\right](T-60)^{0,475}}
\end{gathered}
$$




$$
\begin{gathered}
\rho_{b s}=\rho_{p o}+\left[0,167+16,181\left(10^{-0,0425 \rho_{p o}}\right)\right]\left(\frac{P}{1000}\right) \\
-0,01\left[0,299+263\left(10^{-0,0603 \rho_{p o}}\right)\right]\left(\frac{P}{1000}\right)^{2} \\
\rho_{p o}=\frac{R_{s} \gamma_{g s}+4600 \gamma_{o 0}}{73,71+R_{s} \gamma_{g s} \rho_{a}^{-1}}
\end{gathered}
$$

onde $\gamma_{g s}$ é a densidade relativa do gás medida nas condições do separador e $\gamma_{o 0}$ é a densidade relativa do óleo na condição padrão.

$$
\begin{aligned}
& \rho_{a}=-49,8930+85,0149 \gamma_{g s}-3,70373 \gamma_{g s} \rho_{p o} \\
& +0,047982 \gamma_{g s} \rho_{p o}^{2}+2,98914 \rho_{p o}-0,035689 \rho_{p o}^{2}
\end{aligned}
$$

Para resolver as Eqs. (E.30) e (E.31), é necessário fazer substituições sucessivas a partir do valor inicial dado pela Eq. (E.32).

$$
\rho_{p o}=52,8-0,01 R_{\text {sbolha }}
$$

onde $R_{\text {sbolha }}$ é a razão de solubilidade no ponto de bolha, ou razão gás-óleo $G O R$, dada em $s f c / S T B$. A pressão e a temperatura são dadas, respectivamente, em psia e ${ }^{\circ} \mathrm{F}$. A massa específica do óleo $\rho_{o}$ é obtida em $l b m / f t^{3}$.

\section{E.6 Fator volume de formação de água}

O fator volume de formação de água (adimensional) é dado por:

$$
B_{w}=\frac{Q_{w}}{Q_{w 0}}
$$

onde $Q_{w}$ é a vazão volumétrica de água na condição de medição (considerando a mesma massa de água, desde que desprezamos a solubilidade do gás em água e a vaporização de água).

A correlação para o fator volume de formação de água $B_{w}$, retirado de McCain (1990), 
182

é dada por:

$$
\begin{gathered}
B_{w}=\left(1+\Delta V_{w P}\right)\left(1+\Delta V_{w T}\right) \\
\Delta V_{w T}=-1,0001\left(10^{-2}\right)+1,33391\left(10^{-4}\right) T+5.50654\left(10^{-7}\right) T^{2} \\
\Delta V_{w P}=-1,95301\left(10^{-9}\right) P T-1,72834\left(10^{-13}\right) P^{2} T \\
-3,58922\left(10^{-7}\right) P-2,25341\left(10^{-10}\right) P^{2}
\end{gathered}
$$

A correlação é válida para temperaturas na faixa $90^{\circ} \mathrm{F}<T<255^{\circ} \mathrm{F}$ e pressões na faixa 1 kpsia $<P<5$ kpsia.

\section{E.7 Massa específica da água}

A massa específica da água na condição local de temperatura e pressão é determinada por meio da seguinte expressão:

$$
\rho_{w}=\frac{\rho_{w 0}}{B_{w}}
$$

onde $\rho_{w 0}$ é massa específica da água na condição padrão.

\section{E.8 Razão de solubilidade gás-óleo}

A razão de solubilidade gás-óleo é dada por:

$$
R_{s}=\frac{Q_{d g 0}}{Q_{o 0}}
$$

onde $Q_{d g 0}$ é a vazão volumétrica (na condição padrão) do gás dissolvido na condição de medição.

A correlação para o cálculo da razão de solubilidade foi retirada do trabalho de Velarde, Blasingame e McCain (1999). Definem-se, inicialmente, a pressão reduzida e a razão de solubilidade gás-óleo reduzida: 


$$
\begin{gathered}
P_{r}=\frac{P}{P_{b o l h a}} \\
R_{s r}=\frac{R_{s}}{R_{\text {sbolha }}}
\end{gathered}
$$

onde $P_{b o l h a}$ é a pressão no ponto de bolha em psig e $R_{s b o l h a}$ é a razão de solubilidade no ponto de bolha $(G O R)$ em $s c f / S T B$.

A razão de solubilidade reduzida é calculada como segue:

$$
R_{s r}=a_{1} P_{r}^{a_{2}}+\left(1-a_{1}\right) P_{r}^{a_{3}}
$$

Os coeficientes na equação acima são dados por:

$$
\begin{gathered}
a_{1}=9,7310^{-7} \gamma_{g}^{1,672608} \gamma_{A P I}^{0,929870} T^{0,247235} P_{\text {bolha }}^{1,056052} \\
a_{2}=0,022339 \gamma_{g}^{-1,004750} \gamma_{A P I}^{0,337711} T^{0,132795} P_{\text {bolha }}^{0,302065} \\
a_{3}=0,725167 \gamma_{g}^{-1,485480} \gamma_{A P I}^{-0,164741} T^{-0,091330} P_{\text {bolha }}^{0,047094}
\end{gathered}
$$

onde $\gamma_{g}$ (adimensional) é a densidade relativa do gás, T é a temperatura em ${ }^{\circ} F$ e $P_{b o l h a}$ deve estar em psig. A correlação é válida para os seguintes intervalos das variáveis: $70^{\circ} \mathrm{F} \leq T \leq 307^{\circ} \mathrm{F}$, $102 \mathrm{scf} / \mathrm{STB} \leq R_{\text {sbolha }} \leq 1808 \mathrm{scf} / \mathrm{STB}, 11,6 \leq \gamma_{A P I} \leq 53,4,0,561 \leq \gamma_{g} \leq 1,101 \mathrm{e}$ 106 psia $\leq P_{\text {bolha }} \leq 5312$ psia.

\section{E.9 Pressão no ponto de bolha}

Para calcular a pressão no ponto de bolha utiliza-se a correlação proposta por Velarde, Blasingame e McCain (1999):

$$
\begin{gathered}
P_{\text {bolha }}=1091,47\left[R_{\text {sbolha }}^{0,081465} \gamma_{g s}^{-0,161488} 10^{X}-0,740152\right]^{5,354891} \\
X=0,013098 T^{0,282372}-8,2\left(10^{-6}\right) \gamma_{A P I}^{2,176124}
\end{gathered}
$$

O valor de $P_{b o l h a}$ é dado em psia. $R_{\text {sbolha }}$ é a razão de solubilidade no ponto de bolha $(G O R)$ em $s c f / S T B$. A correlação é válida para os seguintes intervalos das variáveis: $74^{\circ} \mathrm{F} \leq \mathrm{T} \leq 327^{\circ} \mathrm{F}, 10 \mathrm{scf} / \mathrm{STB} \leq R_{\text {sbolha }} \leq 1870 \mathrm{scf} / \mathrm{STB}, 12 \leq \gamma_{A P I} \leq 55,0,556 \leq$ 
$\gamma_{g s} \leq 1,367$ e 70 psia $\leq P_{\text {bolha }} \leq 6700$ psia

\section{E.10 Viscosidade do gás}

Para o cálculo da viscosidade do gás na condição de medição utiliza-se a correlação de Lee, Gonzalez e Eakin (1966), válida para pressões pseudo-reduzidas $P_{p r}<10$ e temperaturas pseudo-reduzidas segundo a densidade relativa do gás, dadas na Tabela E.2.

$$
\begin{gathered}
\mu_{g}=F_{1} 10^{-4} \exp \left(F_{2} \rho_{g}^{F_{3}}\right) \\
F_{1}=\frac{\left(9,379+0,01607 M_{g}\right) T^{1,5}}{209,2+19,26 M_{g}+T} \\
F_{2}=3,448+\frac{986,4}{T}+0,01009 M_{g} \\
F_{3}=2,447-0,2224 F_{2}
\end{gathered}
$$

A viscosidade $\mu_{g}$ é dada em $c P, \rho_{g}$ é a massa específica em $g / \mathrm{cm}^{3}, M_{g}$ é a massa molar aparente do gás dada em $\mathrm{g} / \mathrm{mol}$ e $T$ é a temperatura em ${ }^{\circ} \mathrm{R}$.

Tabela E.2: Faixas de validade da correlação de Lee, Gonzalez e Eakin (1966).

\begin{tabular}{|c|c|}
\hline Densidade relativa do gás & Temperatura pseudo-reduzida \\
\hline $0,56<\gamma_{g}<0,9$ & $1,3<T_{p r}<2,5$ \\
\hline $0,9<\gamma_{g}<1,2$ & $1,1<T_{p r}<2,0$ \\
\hline $1,2<\gamma_{g}<1,5$ & $1,1<T_{p r}<1,7$ \\
\hline $1,5<\gamma_{g}<1,7$ & $1,1<T_{p r}<1,6$ \\
\hline
\end{tabular}

\section{E.11 Viscosidade do óleo}

\section{E.11.1 Viscosidade do óleo morto}

A viscosidade do óleo morto de Beal (1946), em centiPoise, na pressão padrão, foi correlacionada por Egbogah e Ng (1990) na forma:

$$
\log _{10} \log _{10}\left(\mu_{o d}+1\right)=1,8653-0,025086 \gamma_{A P I}-0,5644 \log _{10} T
$$


onde $T$ está em ${ }^{\circ} \mathrm{F}$. As faixas de validade para a correlação são: $60^{\circ} \mathrm{F} \leq T \leq 175^{\circ} \mathrm{F}$ e $5 \leq \gamma_{A P I} \leq 58$.

\section{E.11.2 Viscosidade do óleo saturado}

As curvas de viscosidade do óleo saturado $\mu_{o}$ (em centiPoise) em função da viscosidade do óleo morto $\mu_{o d}$, propostas por Chew e Connaly Jr (1959), foram correlacionadas por Beggs e Robinson (1975) da seguinte maneira:

$$
\begin{gathered}
\mu_{o}=G_{1}\left(\mu_{o d}\right)^{G_{2}} \\
G_{1}=10,715\left(R_{s}+100\right)^{-0,515} \\
G_{2}=5,44\left(R_{s}+150\right)^{-0,338}
\end{gathered}
$$

onde $R_{s}$ está em $S C F / S T B$. As faixas de validade para a correlação são: temperatura até $295^{\circ} \mathrm{F}$ e pressão até 5250 psig.

\section{E.11.3 Viscosidade do óleo subsaturado}

A viscosidade do óleo subsaturado foi correlacionada por Vasquez e Beggs (1980) da seguinte forma:

$$
\begin{gathered}
\mu_{o}=\mu_{o b}\left(\frac{P}{P_{\text {bolha }}}\right)^{H} \\
H=2,6 P^{1,187} \exp \left(-11.513-8.9810^{-5} P\right)
\end{gathered}
$$

onde $\mu_{o b}$ é a viscosidade no ponto de bolha (avaliada das correlações anteriores para $R_{s} \equiv$ $G O R$ ) e as pressões estão em psia. A correlação é válida para pressões de até 9500 psig. 


\section{E.12 Viscosidade da água}

\section{E.12.1 Viscosidade da água na pressão padrão}

Segundo Collins (1987), a viscosidade da água, em centiPoise, na pressão padrão, pode ser expressa como:

$$
\begin{gathered}
\mu_{w 0}=I_{1} T^{I_{2}} \\
I_{1}=109,574-8,40564 Y+0,313314 Y^{2}+8,7221310^{-3} Y^{3} \\
I_{2}=-1,12166+2,6395110^{-2} Y-6,7946110^{-4} Y^{2} \\
-5,4711910^{-5} Y^{3}+1,5558610^{-6} Y^{4}
\end{gathered}
$$

onde $T$ está em ${ }^{\circ} F$ e a salinidade $Y$ está em porcentagem de peso de sólidos. As faixas de valores das variáveis para a correlação são: $100^{\circ} \mathrm{F} \leq T \leq 400^{\circ} \mathrm{F}$ e salinidades de até $26 \%$.

\section{E.12.2 Viscosidade da água na condição de medição}

Segundo Collins (1987), a viscosidade da água à condição de medição pode ser expressa como:

$$
\mu_{w}=\mu_{w 0}\left(0,9994+4,029510^{-5} P+3,106210^{-9} P^{2}\right)
$$

onde $P$ está em psia. As faixas de valores das variáveis para a correlação são: $86,5^{\circ} \mathrm{F} \leq T \leq 167^{\circ} \mathrm{F}$ e pressão até 14000 psia.

\section{E.13 Derivadas das propriedades termodinâmicas}

Nesta seção serão apresentadas as expressões das derivadas das correlações da razão de solubilidade gás-óleo e das massas específicas do gás, óleo e água. 


\section{E.13.1 Razão de solubilidade gás-óleo}

A partir da Eq. (E.39), obtemos:

$$
\frac{\partial P_{r}}{\partial P}=\frac{1}{P_{b o l h a}}
$$

A partir da Eq. (E.40), obtemos:

$$
\frac{\partial R_{s}}{\partial P}=R_{s b o l h a} \frac{\partial R_{s r}}{\partial P}
$$

Partindo da Eq. (E.41), chegamos a:

$$
\frac{\partial R_{s r}}{\partial P}=\frac{1}{P_{b o l h a}}\left[a_{1} a_{2} P_{r}^{\left(a_{2}-1\right)}+\left(1-a_{1}\right) a_{3} P_{r}^{\left(a_{3}-1\right)}\right]
$$

Substituindo a Eq. (E.63) na Eq. (E.62), obtemos a expressão da derivada da razão de solubilidade gás-óleo com relação à pressão:

$$
\frac{\partial R_{s}}{\partial P}=\frac{R_{\text {sbolha }}}{P_{\text {bolha }}}\left[a_{1} a_{2} P_{r}^{\left(a_{2}-1\right)}+\left(1-a_{1}\right) a_{3} P_{r}^{\left(a_{3}-1\right)}\right]
$$

\section{E.13.2 Massa específica do óleo}

A partir da Eq. (E.28), a derivada da massa específica do óleo é dada por:

$$
\begin{gathered}
\frac{\partial \rho_{o}}{\partial P}=\frac{\partial \rho_{b s}}{\partial P}-(T-60)^{0,938}\left[-1,4313 \rho_{b s}^{-1,951} \frac{\partial \rho_{b s}}{\partial P}\right] \\
+(T-60)^{0,475}\left[8,637710^{-4} 10^{-0,0161 \rho_{b s}} \frac{\partial \rho_{b s}}{\partial P}\right]
\end{gathered}
$$

A partir da Eq. (E.29), obtemos:

$$
\begin{aligned}
& \frac{\partial \rho_{b s}}{\partial P}=\frac{\partial \rho_{p o}}{\partial P}+\frac{P}{1000}\left(-1,583510^{-0,0425} \frac{\partial \rho_{p o}}{\partial P}\right)+\frac{1}{1000}\left(0,167+16,18110^{-0,0425 \rho_{p o}}\right) \\
& -0,01\left(\frac{P}{1000}\right)^{2}\left(-36,516510^{-0,0603 \rho_{p o}} \frac{\partial \rho_{p o}}{\partial P}\right)-\frac{0,02 P}{1000^{2}}\left(0,299+26310^{-0,0603 \rho_{p o}}\right)
\end{aligned}
$$


Baseando-se na Eq. (E.30), obtemos:

$$
\frac{\partial \rho_{p o}}{\partial P}=\frac{\frac{\partial R_{s}}{\partial P} \gamma_{g s}}{73,71+\frac{R_{s} \gamma_{g s}}{\rho_{a}}}-\frac{R_{s} \gamma_{g}+4600 \gamma_{o 0}}{\left(73,71+\frac{R_{s} \gamma_{g s}}{\rho_{a}}\right)^{2}}\left(\frac{\frac{\partial R_{s}}{\partial P} \gamma_{g s}}{\rho_{a}}-\frac{R_{s} \gamma_{g s}}{\rho_{a}^{2}} \frac{\partial \rho_{a}}{\partial P}\right)
$$

Partindo da Eq. (E.31), chegamos a:

$$
\frac{\partial \rho_{a}}{\partial P}=\frac{\partial \rho_{p o}}{\partial P}\left(-3,70373 \gamma_{g s}+0,095964 \gamma_{g s} \rho_{p o}+2,98914-0,071378 \rho_{p o}\right)
$$

\section{E.13.3 Massa específica do gás}

O cálculo da derivada da massa específica do gás com relação à pressão é realizado a partir da Eq. (3.64):

$$
\frac{\partial \rho_{g}}{\partial P}=-\frac{\rho_{g 0}}{B_{g}^{2}} \frac{\partial B_{g}}{\partial P}
$$

Considerando a Eq. (E.12), chegamos a:

$$
\frac{\partial B_{g}}{\partial P}=0,2827\left(\frac{\partial Z_{c}}{\partial P} \frac{T}{P}-\frac{Z_{c} T}{P^{2}}\right)
$$

A derivada do fator de compressibilidade com relação à pressão, a partir da Eq. (E.14), é dada por:

$$
\begin{aligned}
& \frac{\partial Z_{c}}{\partial P}=C_{1} \frac{\partial \rho_{p r}}{\partial P}+2 C_{2} \rho_{p r} \frac{\partial \rho_{p r}}{\partial P}-5 A_{9} C 3 \rho_{p r}^{4} \frac{\partial \rho_{p r}}{\partial P}+2 A_{10} A_{11} \frac{\rho_{p r}^{3}}{T_{p r}^{3}} \exp \left(-A_{11} \rho_{p r}^{2}\right) \frac{\partial \rho_{p r}}{\partial P} \\
& +A_{10}\left(1+A_{11} \rho_{p r}^{2}\right)\left[2 \frac{\rho_{p r}}{T_{p r}^{3}} \exp \left(-A_{11} \rho_{p r}^{2}\right) \frac{\partial \rho_{p r}}{\partial P}-2 A_{11} \frac{\rho_{p r}^{3}}{T_{p r}^{3}} \exp \left(-A_{11} \rho_{p r}^{2}\right) \frac{\partial \rho_{p r}}{\partial P}\right]
\end{aligned}
$$

onde os parâmetros presentes na expressão estão relacionados na Tabela (E.1).

Com base nas Eqs. (E.18) e (E.19), obtemos:

$$
\begin{gathered}
\frac{\partial P_{p r}}{\partial P}=\frac{1}{P_{p c}} \\
\frac{\partial \rho_{p r}}{\partial P}=0,27\left(\frac{1}{Z_{c} T_{p r} P_{p r}}-\frac{P_{p r}}{T_{p r} Z_{c}^{2}} \frac{\partial Z_{c}}{\partial P}\right)
\end{gathered}
$$




\section{E.13.4 Massa específica da água}

O cálculo da derivada da massa específica da água com relação à pressão é realizado a partir da Eq. (E.37):

$$
\frac{\partial \rho_{w}}{\partial P}=-\frac{\rho_{w 0}}{B_{w}^{2}} \frac{\partial B_{w}}{\partial P}
$$

Com base nas Eqs. (E.34) e (E.36), obtemos:

$$
\frac{\partial B_{w}}{\partial P}=\left(1+\Delta V_{w T}\right) \frac{\partial \Delta V_{w P}}{\partial P}
$$

$\frac{\partial \Delta V_{w P}}{\partial P}=-1,9530110^{-9} T-3,4566810^{-13} P T-3,5892210^{-7}-4,5068210^{-10} P$ (E.76) 


\section{APÊNDICE F - DEDUÇÃO DAS EQUAÇÕES PARA O ESTADO ESTACIONÁRIO}

O estado estacionário é utilizado como condição inicial para as simulações transientes. Nesta seção serão deduzidas as equações utilizadas para o seu cálculo (ver Seção 3.4). As condições para ocorrência do estado estacionário são penetração contínua de gás $(x=0)$ e riser cheio.

O subsistema riser é discretizado segundo o número de nós $N$. Cada nó é denominado por um número $i$, sendo que o primeiro nó $(i=1)$ localiza-se na base do riser e sua posição é definida por $s(1)=0$. O último nó $(i=N)$ localiza-se no nível de líquido, com sua posição dada por $s(N)=s_{u}$. No caso do estado estacionário, o nível de líquido sempre estará localizado no topo do riser, cuja posição é dada por $s_{t}$. Logo, para o estado estacionário $s(N)=s_{u}=s_{t}$.

Considera-se que os nós sejam equidistantes no estado estacionário. Sendo assim, para encontrar a posição de cada nó $s(i)$, é necessário calcular a posição do topo do riser a partir da Eq. (3.3) e da abscissa do topo $X$ :

$$
s_{t}=\varphi \sinh \left(\frac{X}{\varphi}\right)
$$

A posição de cada nó é dada por:

$$
\begin{gathered}
s(i)=(i-1) \Delta s \quad \text { para } \mathrm{i}=1, \ldots, \mathrm{N} \\
\Delta s=\frac{s_{t}}{N-1}
\end{gathered}
$$

Calcular o estado estacionário para o riser significa calcular os valores das variáveis de estado em cada nó: $\alpha(i), \alpha_{o}(i), j(i)$ e $P(i)$.

Tornando as derivadas temporais nulas nas Eqs. (3.6), (3.7) e (3.8), obtemos respectivamente: 


$$
\begin{gathered}
\frac{\partial}{\partial s}\left(\rho_{g} j_{g}\right)=-\rho_{d g 0} j_{o 0} \frac{\partial R_{s}}{\partial s} \\
\frac{\partial}{\partial s}\left(\rho_{o} j_{o}\right)=\rho_{d g 0} j_{o 0} \frac{\partial R_{s}}{\partial s} \\
\frac{\partial}{\partial s}\left(\rho_{w} j_{w}\right)=0
\end{gathered}
$$

Integrando a Eq. (F.4) com relação à variável espacial $s$, obtemos:

$$
\rho_{g} j_{g}-\rho_{g 0} j_{g 0}=-\rho_{d g 0} j_{o 0} R_{s}
$$

Isolando a velocidade superficial do gás $j_{g}$, obtemos:

$$
j_{g}=\frac{\rho_{g 0} j_{g 0}-\rho_{d g 0} j_{o 0} R_{s}}{\rho_{g}}
$$

A partir da Eq. (3.64) e da definição de razão gás-óleo $G O R$, obtemos:

$$
j_{g}=j_{o 0} B_{g}\left(G O R-R_{s}\right)
$$

Integrando a Eq. (F.5) com relação à variável espacial $s$, obtemos:

$$
\rho_{o} j_{o}-\rho_{o 0} j_{o 0}=\rho_{d g 0} j_{o 0} R_{s}
$$

Isolando a velocidade superficial de óleo $j_{o}$, obtemos:

$$
j_{o}=j_{o 0} \frac{\rho_{d g 0} R_{s}+\rho_{o 0}}{\rho_{o}}
$$

A partir da Eq. (E.27), chegamos a:

$$
j_{o}=j_{o 0} B_{o}
$$

Integrando a Eq. (F.6) com relação à variável espacial $s$, obtemos:

$$
\rho_{w} j_{w}-\rho_{w 0} j_{w 0}=0
$$


Isolando a velocidade superficial da água $j_{w}$, obtemos:

$$
j_{w}=\frac{\rho_{w 0} j_{w 0}}{\rho_{w}}
$$

A partir da Eq. (E.37) e da definição de razão água-óleo $W O R$, chegamos a:

$$
j_{w}=j_{o 0} W O R B_{w}
$$

A fração de vazio é calculada utilizando o modelo de drift-flux, dada pela Eq. (3.22). A fração volumétrica para a fase óleo é calculada por meio de uma relação entre as Eqs. (3.11), (3.12) e (3.13), dada por:

$$
\alpha_{o}=\frac{1-\alpha}{\frac{j_{w}}{j_{o}}+1}
$$

Para a fase água, a fração volumétrica é calculada por:

$$
\alpha_{w}=1-\alpha-\alpha_{o}
$$

A velocidade superficial total $j$ é calculada segundo a Eq. (3.19), reapresentada aqui:

$$
j=j_{o}+j_{w}+j_{g}
$$

A pressão ao longo do riser é calcula por meio da discretização da Eq. (3.9), dada pela Eq. (4.3). O procedimento numérico completo para o cálculo do estado estacionário é apresentado na Seção 4.4. 